ting $x$

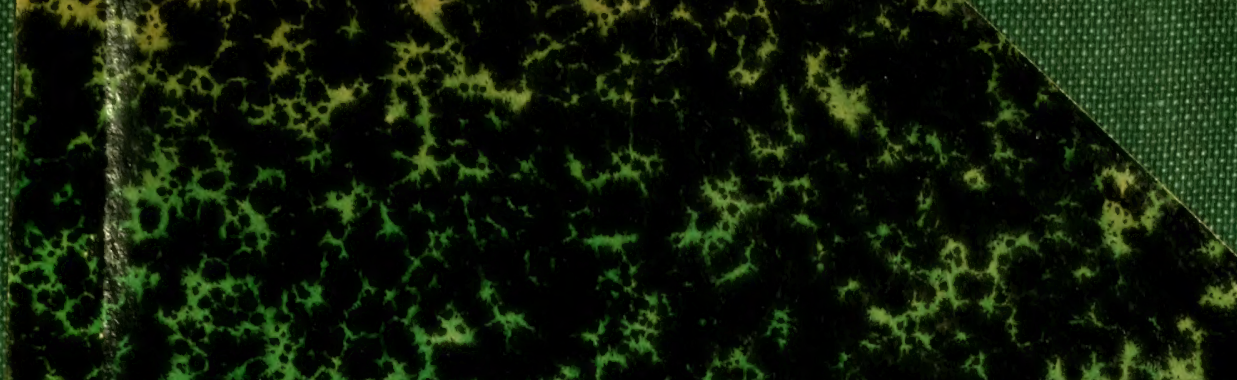

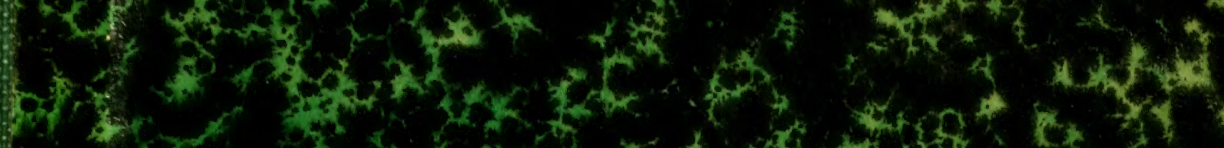

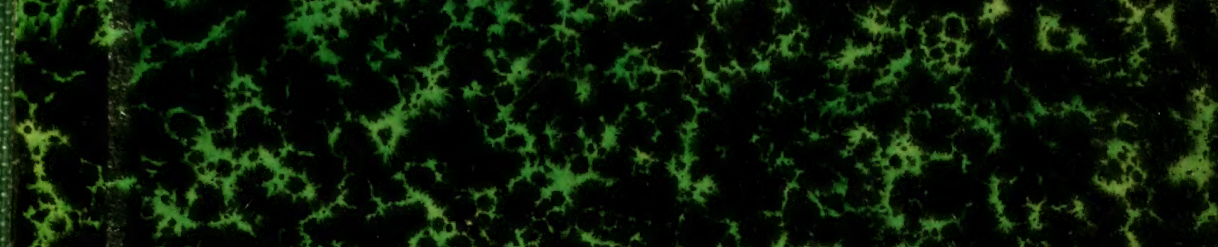

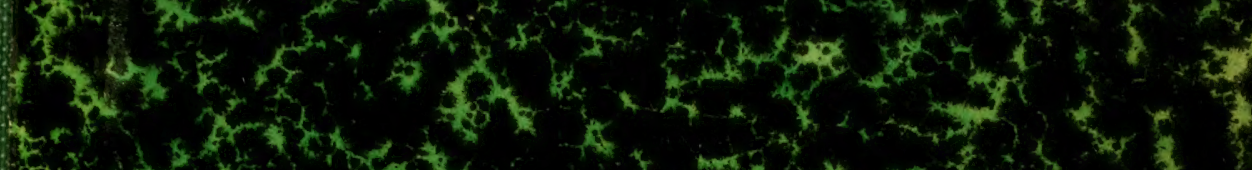

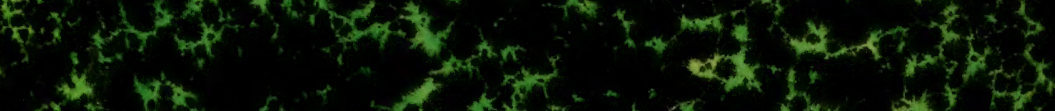

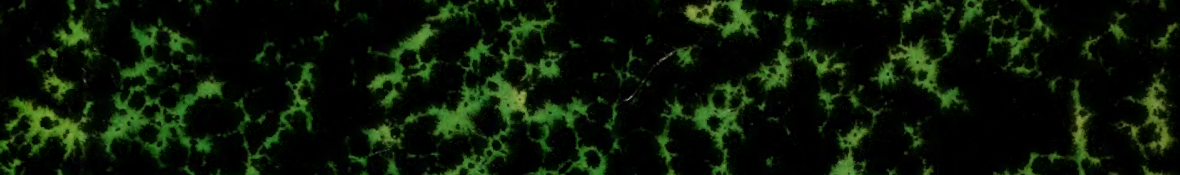

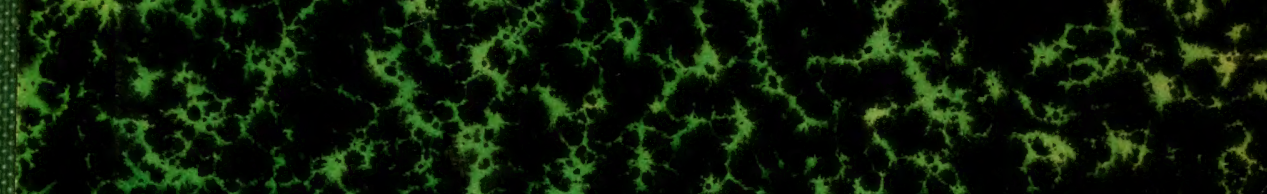

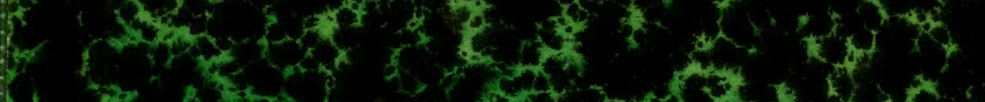

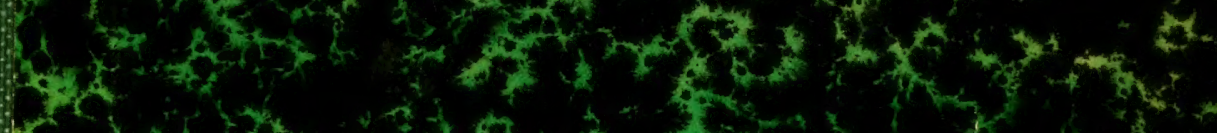

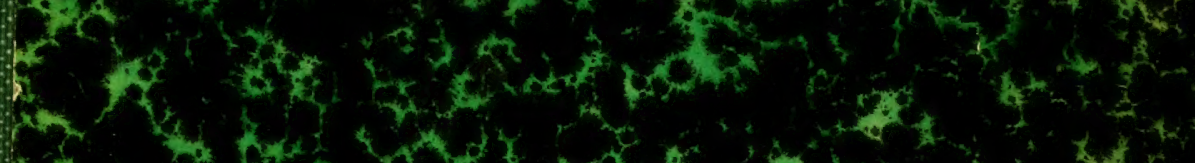

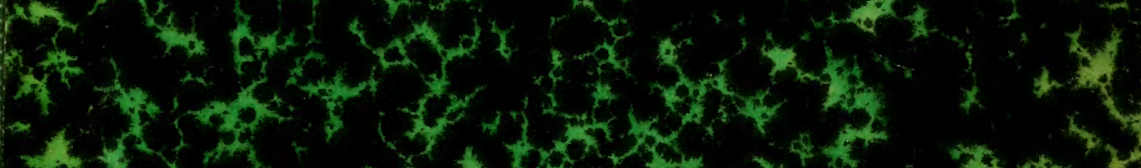

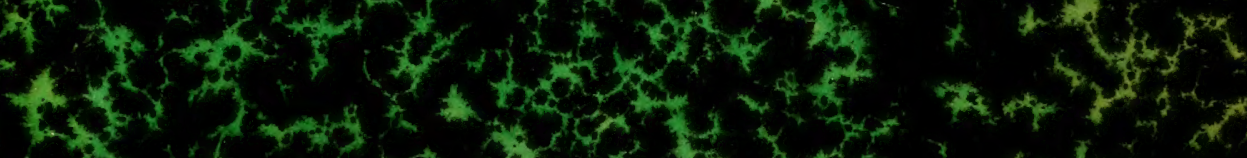

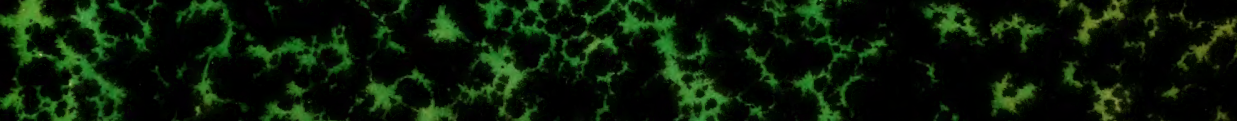

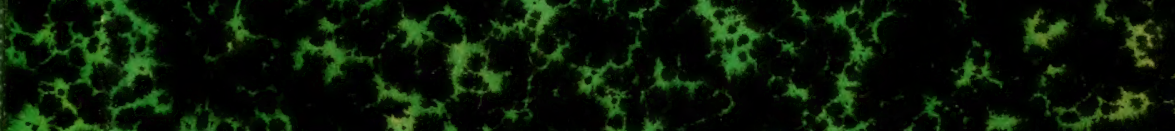

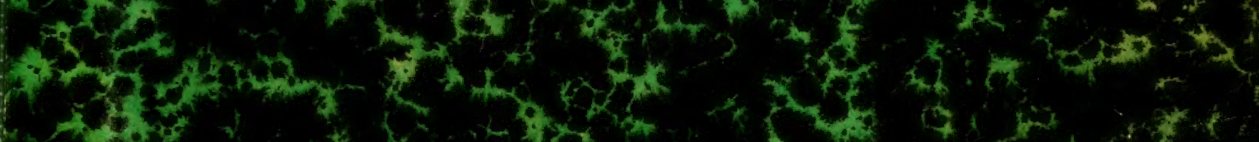
thet

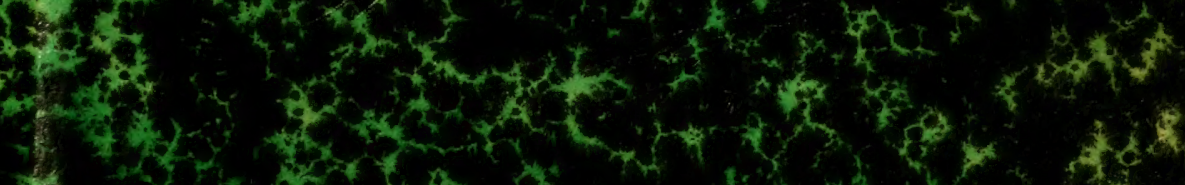
4.

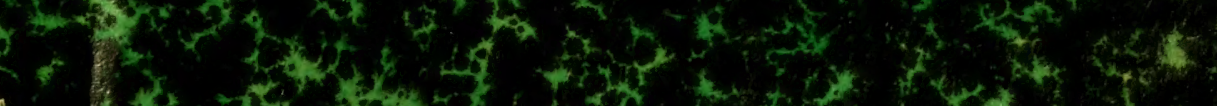




\section{HARVARD UNIVERSITY.}

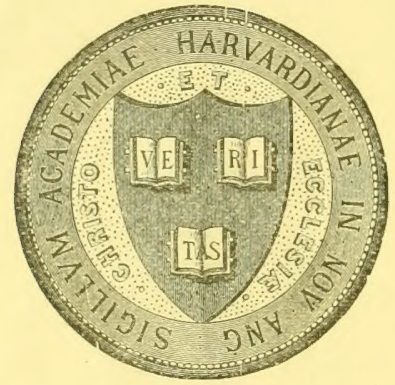

LIBRARY

OF THE

MUSEUM OF COMPARATIVE ZOÖLOGY.

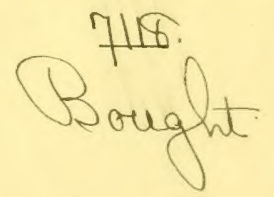

Sivember 21,1878. 




\section{SINÓPSIS}

DE LAS

\section{ESPEGIES FÓSILES}

QUE SE haN ENCONTRADO EN ESPAÑA,

POR

L. MALLADA.

Cuaderno 1."

MADRID.

IMPRENTA Y FUNDICION DE M. TELLO,

IMPRESOR DE CÁMARA DE $\mathrm{S}$. M.

Isabel la Católica, 23.

sing 1878. 




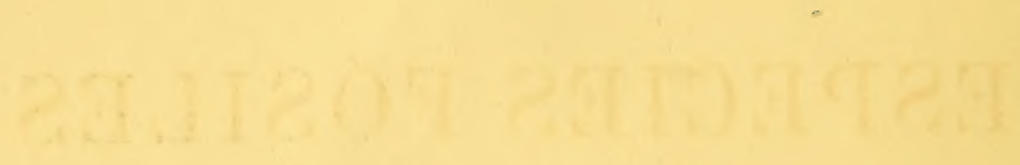




\section{SINÓPSIS}

DE LAS

\section{ESPECIES FÓSILES}

QUE SE HAN ENCONTRADO EN ESPAÑA,

por

L. MALLADA.

Guaderno 1.

MADRID.

IMPRENTA Y FUNDICION DE M. TELLO,

IMPRESOR DE CÁMARA DE S. M.

Isabel la Católica, 23.

1878. 



\section{SINOPSIS}

DE: L.AS

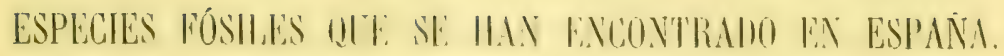

\section{INTRODUGGION,}

Llamado el Cuerpo de lnewenieros de minas á contribuir a la formacion del Mapa geológico de muestro territorio, suministrando a la Comision especial encargada de llevarlo á cabo, cuantos datos y noLicias pueda recoger cada individuo, es seguro que una de las priucipales dificultades con que la mayor parte de los mismos habráu de: tropezar, es la carencia de un cuerpo de doctrina donde se hallen reunidos los diversos materiales hasta ahora conocidos de la Paleontologia espanola. Por desgracia, los antecedentes no muy numerosos, relativos á la Fanna y á la Flora fósiles de nuestro suelo, se hallan diseminados en varios escritos, una qran parte extranjeros. En ellos, vemos unas especies descritas y figuradas con detalle; otras, de un modo sucinto; otras, en que se describen, más no se figuran; y están en mayoria aruellas de las que sólo se mencionan la localidad y edad geologica en que aparecen, y para cuyo conocimiento tenemos que acudir a las obras clásicas de utras naciones. Por otra parte, entre estos libros de consulta, por regla general muy costosos, y los elementales de los cursos académicos, que sólo nos enseñan í conocer los caracléres genéricos, echamos de mónos ın Manual, yue como la Conchiologiu mineralógica de Sowerby para los fósiles de la Gran Bretaña, la Sinopsis des echinides fossiles de Desor y la Introduction a l'eude des polypiers fossiles, de Mr. Fromentel, nos conduzea desde los primeros trabajos de la determinacion de la especie, à su perfecto y delallado conocimiento.

Reunir eu un solo volimen los esparcidos datos oblenidos hasta el dia, y presentar los rasgos más notables de cala especie, nos parece de interés para los principiantes, que por falta de los libros de Paleontologia necesarios, se ven detenidos en la precisa clasificacion 
pecies jurásicas y carboniferas, la mayor parte de las cuales han sido comprobadas posteriormente.

En el mismo año se publicó en el Bulletin de la Société géologique de France $\left(2^{\mathrm{e}}\right.$ série, 1. 2. ${ }^{\circ}$, p. 459) el arlículo de A. Paillete, titulado Recherches sur quelques mes des roches qui constituent la province des Asturies, en el que se mencionan algumos fúsiles carboniferos. A su continuacion se halla la interesante Note sur les fossiles du terrain paleozoïque des Asturies, en la cual sus ilustres autores De Verseuil y D'Arcmac describen 15 especies nuevas, y ademas citan otras 16 ya conocidas. Este trabajo es de la mayor importancia para el estudio de los fósiles devonianos de Leon y Astúrias, y le señalamos en primer lugar entre los que en su dia habrán de formar la base de la Paleontología española.

En el tomo 4. ${ }^{\circ}$ de los Anales de Minas (1846), vemos un artículo de Maestre titulado Ojeala geognóstica y minera solire el litoral del Mediterrineo, desde el cabo de Palos hasta el estrecho de Gibraltar, que contiene indicaciones de fósiles.

Mr. D'Archice, en la sesion del 3 de Mayo de 1848 de la Société gíologique de France (t. 5. ${ }^{\circ}$, p. 298), participó el descubrimiento de una capa de numulites en la provincia de Córdoba por el geólogo Mr. Prat.

En el mismo año se publicó el Reconocimiento geológico del señorio de Vižcaya, por Colletre, en el cual se citan 15 especies jurásicas y cretáceas.

La misma fecha tiene la Descripcion de los terrenos de Valdesabero y sus cercanias en las montañas de Leon, por Prano, que dos años despues reprodujo el Bulletin de lu Sociélé géologique de France $\left(2^{\mathrm{e}}\right.$ série, 1. $70^{\circ}$, p. 157), sirviéndola de complemento una preciosa Nole sur les fossiles devoniens dia district de Salhero, por De Verveun, en la que su ilustre autor presenta una lista de 77 especies, 20 de las cuales son poliperos determinados por J. HaIME. Del total, 28 constaban ya en la lista de 1845, y son muevas 19 que se figuran y describen y 9 poliperos de que se dio cuenta en la obra clásica Mlonographie des polypiers fossiles des terrains palenzoiques, de la cual, asociado à MiLne Enwaros, es tambien autor el cilado J. Hime. Bien puede asegurarse que la Nota de que nos ocupamos hubiera bastado por si sola para formar una brillante reputacion, si su autor, antes de aquel año, no gozara de esclarecito nombre por sus notables trabajos.

En el primer tomo de la Revista Minera $(1850)$, encontramos los 
signientes escritos de interis bara muestro objeto: ma nota de Mr. De Venseut, en yu' se mencionan algumas especies paleozóicas (pig. 9.); una lista de lósiles jurisicos recogidos en Ablanque, por Ezugenu (pág. 298), y uma noti del St. (i. de Salazar (pág. 402), en yne se participa el descubrimiento de restos de un mastodonte. en Castrofuerte, à orillas del lisla (Leon).

Hablando de los fósiles mumuliticos de Astmrias (Bull. Soc. géol. de France, 2e série, 1. (i, p. 52zi, De Verveur cila tres especies de aquella formacion.

El tomo 2. 'de la Revistu Minera, correspondiente à 1351 , contiene, entre otros, los signientes trabajos: Ia Descripcion geológica del antiguo corregimiento de Albarracin, por el ingeniero de Minas D. S. Ronriguez, en la cual se halla inscrito un buen múmero de especies jurásicas y algunas creláceas; un articulo sobre Reslos de yrandes paquidermos, por Ezouenu (pás. 55), y la Iraduccion del trabajo de D. Sunrre, Solve el distrito secumdario de Portugul, al N. del Tajo, a propósito de la cual advierte Cu la existencia de algunas especies cretáceas en Congostrina y Tamajon (Guadalajara).

En el tomo 5. ${ }^{0}$ de la misma publicarion (pás. 559), el eminente De Verseut publicó la importante Memoria tilulada Del terreno creticeo de España, donde se consignan copiosos datos, y se hace relacion de numerosas especies recogidas por el mismo, por los señores Prado, Naranjo, Maestre y otros geólogos.

En la sesion del 6 de Diciembre del mismo año, celebrada por la Société géologique de France, expuso DE Verneur los principales r'esultados de un viaje que acababa de hacel en compañia de M. Ed. Collomb, por la region Sud-Este de nuestra Peninsula. Con el luminoso y detallado escrito de ambos señores, Coup d'eil sur la constilution géologrique de quelques provinces de l'Espagne (Bull. Soc. geol. de France; 2e série, 1. 10, p. 61), se enriquece grandemente nuestro Catálogo, dándonos con él á conocer sobre umas doscientas especies, entre ellas tres nuevas. Forma el complemento á tan precioso trabajo la Description des ossements fossiles de mumiféres, por M. P. Gervas, en que se hace un estudio detenido de los restos recogidos por los Sres. De Verneuil, De Collomb, De Loriere, Ezyuerxa, Botella y Visniouski.

Algunas indicaciones de fósiles se encuentran ademas en la Nota sobre geologria de Cataluña, de S. P. Pratt, publicadạ en el Quaterly Journal (t. 8, p. 2(i8); en el Exhracto de una Memoria geolo- 
gica sobre el distrito minero de Sicrra Almagrera y Murcia, de D. R. Peluico; en la Memoria geognéstico-agricola sobre la provincia de Astivias, por I. P. Pastor, publicada por la Academia de Ciencias, y en la Memoria que comprende el resimen de los trabajos verificados en el año de 1852 por las diferentes secciones de la Comision encargada de formar el Mapa yeológico de Madrid y el general del Reino.

En 1854 comunicó Prado á la Sociedad geológica de Francia la Note sur la constiution geologique de la province de Segovie (Bull. $2^{\mathrm{e}}$ série, t. 11, p. 555), en la cual se citan doce especies cretáceas. En la misma publicacion (pág. 661) hallamos otro articulo de VerneuIL y De Lonúre, titulado Apercu de un voyage géologique el tableau des altitudes prises en Espagne pendant l'été de 1855, donde se mencionan diversas especies. La antes citada Academia de Ciencias publicó en el primer tomo de sus Memorias el Ensayo de una descripcion general de la cxtructura geológica del terreno de España en la Peninsula, por Ezoverna. En su seccion tercera, el infatigable académico estampa un catilogo general de las cuatrocientas cincuenta especies fósiles recogidas hasta arquella fecha, la mayor parte por el ilusire DE VerNeUiL.

En el tomo 5. de la Revista Hinera, ademas de la reproduccion de la Nola sobre la constitucion geológica de la provincia de Segovia, por Prado, encontramos (pág. 562) la Ojeada sobre la geologia del reino de Valencia, en que su autor, D. F. de Botella, nos cita algunas especies numuliticas y restos de vertebrados.

De magnificos resultados fué el siguiente año de 1855. J. Hane comunicó a la Sociedad geológica de Francia su notable Notice sur lu géologie de l'ile de Najorque (Bull. 1. 12, p. 754), con la cual su autor enriquece nuestra lista con un buen número de especies, de ellas cinco nuevas; y deshace algunos errores paleontológicos en que habia incurrido su predecesor Bouvy. En el mismo volúmen (pág. 182) se encuentra la excelente memoria de Pravo Sur la géologie d'Almaden, dine partie de la Sierra Horena, el des montagnes de Toledo, importante bajo muchos conceptos; y más adelante (pág. 964), formando su complemento, se halla la Description des fossiles, por MII. DE VERseur et Barrande. Con esta preciosa Memoria y las dos citadas sobre lósiles devonianos de Asturias y de Sabero, tenemos las tres principales para el estudio paleontológico de los sistemas siluriano y devoniano de nuestro pais. Describen en arquella 16 especies nuevas siluriamas y 8 devonianas; sigue una lista de 56 de las primeras y 62 
de las segumdas, y terminan los antores con interesantes consideraciones sobre los sistemas paleozóicos.

En la Descripcion geológica industrial de la cucnca carbonifera de Sum Juan de las Ihudesas, cila Minstre algunas especies siluriamas y hulleras de dicha localidad.

Las Observations yeuloyinues el haromilriques failes en Espagne en 1855, por Verseull el Comboun, que se dieron í conocer el signiente

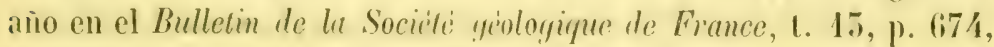
contribuyen al sucesivo anmento de nuestra lista general.

El ingeniero de montes Sr. Olazabar. nos da escasas indicaciones de lósiles en su Memoria premiada por la Real Academia de Ciencias, litulada Suclo, clima, cullivo agrario y forestal de la provincin de Vizcaya.

En el tomo 14 de la 2." série del Bulletin de la Société génloginue de. Firance, encontramos las Observations sur le terrain mumulitique de la province de Barcelone, por A. V $\mathrm{EzIx}$, que nos suministra 74 especies, de las cuales 8 son muevas. Este articulo apareció luegro traducilo en la Revistu Minera, t. 9, pás. 169; y formando lollelos aparte, el ilustrado profesor se ocupó de la misma materia, describiendo varias especies numuliticas, miocenas y pliocenas de la indicada provincia.

En el tomo $8 .^{\circ}$ de la Revista Miner vas a la cuenca luullera de Villanueva del Rio. Tanto en la referente al Sr. Pellico como en la suscrita por el Sr. Kítu, se hallan consignadas algunas especies vegetales.

La Descripcion geolóyica de la provincia de Oviedto, por D. Guillermo Scurzz (1858), contiene la relacion de numerosas especies devonianas, carhoniferas, jurásicas, cretáceas y numuliticas, é interesantes apuntes de los parajes donde las exploraciones paleontológicas podrian practicarse con buen éxito.

El distinguido profesor D. Juan Vilavova y Piera nos presenta mua buena porcion de fósiles jurásicos y creláceos, algunos nuevos, en su Memoria georgnostico-agricola sobre la provincia de Castellon, premiada y publicada en 1859 por la Real Academia de Ciencias.

Otro año brillante para la Ilistoria de la Paleontolosia espanola fué el 1860. Este dió principio con mua Nole sur une partie du pais Basque espungol, por De Verneur, Colloub, el Trigur (Bull. Soc. géol. de France, 2e série, 1. 17, pritz. 5ej), a la que sigue una descripcion por M. G. Cotteau de 10 equinodermos, tres de ellos tal vez nue- 
vos. En ella se da cuenta del hallazgo de un buen número de especies jurísicas, cretáceas y terciarias, y le acompaña un bosquejo de las tres provincias hermanas y parte de Navarra.

En la pág. 516 de la misma publicacion, se encuentra el importante articulo de Prado Sur l'existence de la faune primordiale dans le chaine cantalrique, en el cual se participa tal descubrimiento, y de paso se mencionan varias especies carboniferas y devonianas. Formando su complemento, empieza en la pág. 526 la Description des fossiles, por De Verneut y Barranie, en la cual estos dos sábios nos dan á conocer 17 especies, de ellas 8 nuevas.

En el tomo 11 de la Revista Minera, encontramos $n$ artículo Sobre la geologia de Málaga y parte meridional de Andalucia, por T. Axsted, en que se citan numerosas especies terciarias, sobre todo foraminiferos. Más adelante (pág. 597 ), se da razon del hallazgo, por' D. J. M. Aríxzazu de una cabeza de Rhinoceros encontrada en la cuesta de Parapa cerca de Briviesca.

En el siguiente año (1861) apareció en el Bulletin de la Sociélé géologiune de France (t. 18, pág. 541) la interesante memoria titulada Coupes du versant meridional des Pyrénees, en la cual sus autores iII. Verneula y De Kevserding, citan varias especies cretáceas y terciarias de las provincias de Lérida y Huesca.

En la pág. 622 del tomo 12 de la Revisli Minera, hace referencia el Sr. D. E. Sancuez á varios fósiles del siluriano superior, encontrados por De Verneuil en Ogasa y Camprodon.

En la Memoria solre las minas de Almaden y Almadenejos, escrita por los ingenieros Sres. Bennaldez y Rua Figueroa, se insertan olsservaciones geológricas de Prabo, en que se mencionan varias especies.

En 1862 se dió á la estampa la Memoria sobre los depósitos carboniferos de Utrillas y Gargallo, por el ingeniero Jefe del Cuerpo de Minas, el Sr. D. Lucas de Aldina, y en ella se citan bastantes especies cretáceas y jurásicas. Este trabajo se reprodujo más tarde en la Revista Minera, t. 14, pág. 261.

En un suelto de la misma publicacion (t. 15, pág. 479), se participa el descubrimiento de la fauna primordial en los términos de Hanchones y Murero, cerca de Daroca, por el infatigable De VeliNEUII.

Mr. E. Deslongchamps, en sus Etudes critiques sur les brachiopodes nouveaux ou peu conmus (pág. 64), describe 14 especies, de ellas 5 nuevas, recogidas por De Vernful en el lias medio de España. 
Halagüeño fué tambien el año 1865. A él referimos en primer Iugar, la interesante obra Notes on the Geology and Mineralogy of the spanish provinces of santander and Madrid, por los Sres. W. R. Suuduax y J. P'. O'Reilcy, libro en que aparece bien representada la parte relativa á fósiles, y en que se da noticia de gran numero de especies, la mayor parte eretíceas y algunas jurásicas, encontradas en el distrito de Comillas.

Los Sres. Vennevil y Lantet presentaron á la Sociedad geológica de Francia la Nole sur le calcaire de Lychus de Segura (Aragon) (Bull. Soc. géol. de France, 1. 20, piag. (684), en la cual se cilan diferentes de la provincia de Teruel, tres de ellas nuevas.

Ipareció despues el Ensayo de descripcion geoynóstica de la provincia de Teruel, en sus relaciones con lu Agricullura de la misma, por el ilustrado y celoso profesor Sr. D. Juan Vilanova. En eilas vemos dos listas, una de 186 especies jurásicas y otra de 181 cretaceas, y agregando á estas las terciarias, se suma el prodigioso número de $\mathbf{4 0 0 ,}$ de las cuales más de 60 figuran como nuevas. Estas y otras ya conocidas, se hallan representadas en láminas que al texto acompanaan. Es un resultado de los más notables que podemos estampar en esta reseña histórica.

La Descripcion del terreno numulitico de Mallorca, por D. P. Bouvx, en que se mencionan numerosas especies y se amplian y rectifican datos estampados anteriormente, se publicó en el tomo 14 de la Revisla Minera.

En el año 1864 salió á luz la Descripcion física y geológica de la provincin de Madrid, en la cual D. C. de Prado acabó de afirmar su nombre ya bien acreditado. En esa Memoria, que bien puede servir de modelo para todas las de su clase, á pesar de referirse á un territorio ingrato para la Paleontologia, se consignan 28 especies, de las cuales 8 son nuevas, y de ellas hace nuestro honorable maestro su descripcion correspondiente.

En la Descripcion fisica y geológica de la provincia de Santander, por D. A. Maestre, se hallan tambien citadas diversas especies jurảsicas, cretáceas y numuliticas.

En 1865 señalamos una verdadera preciosidad para el estudio paleontológico de nuestro suelo, la Monographie paleontologique de l'étage aptien de l'Espagne, con que M. II. Coquano nos dotó del más interesante libro sobre fósiles cretáceos de España. Cuenta hasta 251 especies, de las cuales 120 son nuevas, eifra á la que ninguno 
ha llegado hasta el dia. La descripcion é ilustraciones relativas í cada una de aquellas, son muy á propósito para atraer á su estudio.

El ingeniero de Minas, Sr. Fensandez Soba, participa el hallazgo de huesos fósiles en Quintana (Leon), en la Revista Minera (t. 16, påg. 609.)

Curioso se nos ofrece el siguiente año 1867. En el Bulletin de la Socièté géologique, registramos los siguientes articulos de interés para nuestro objeto: Sur l'existence des elayes corallien, Kimmeridgien el porlandien dans la province de Castellon de la Plana, et notamment dans les Atalayas de A lcala de Chisvert, ainsi que dans les montagnes comprises entre Morella el la mer, por H. H. Cogundi una Nola sobre los lignitos del N. de Bergu, por Verneull, y otra del Sr. Vildinova, sobre la geologia de la provincia de Valencia.

En el Bosquejo geológico de la serrania de Cinenca, por M. E. JAc@uot, traducido por mi querido maestro el Sr. Egozcue y Cia en Ia Revista Minera, 1. 18, pág. 489, se mencionan diferentes especies devonianas, jurásicas y cretáceas.

No ménos brillante que el anterior fué el año 1368. Registramos en èl un hermoso cuaderno destinado í asentar las bases de la Paleontología española. Nos referimos á la Description des fossiles du neocomien superieur de Vtrillas et ses environs, londe sus eminentes autores De Verveull, et G. De Loriere, describen 54 especies, de ellas 26 nuevas.

La Descripcion geológica minera de las provincias de Murcia y Albacete, por D. F. de BotelLa, hace mencion de varias especies recogidas por el mismo y por De Verneuil, y contiene una lámina de 6 especies de peces fósiles de la serrata de Lorca, 5 de ellas nuevas.

El afamado geólogo M. A. LeYmerie, que tantos trabajos ha hecho acerca de los Pirineos franceses, se decidió á visitar nuestro pais, y en 1869 comunicó á la Sociedad geológica de Francia los resultados de sus exploraciones por el valle del Segre Recit l'une exploration geologique de la vallée de la Serpre (Bulletin, 2e série, 1. 26, pig. 604). En su interesante escrito, que se publicó tambien en el tomo 27 de la Revista Mlinera, nos ofrece al wunas especies jurásicas y cretaceas.

Mr. Coeuno hace referencia de varias especies cretáceas de la frontera espanola entre Gabís y Sallent, en su Apercu geologique sur la vallée d'Osseau (Bull. soc. géol. de France, 2e série, 1. 27, pág. 45).

La provincia de Teruel habia gozado el privilegio de llamar la 
alencion de varios geólogos; y alemas de la Memoria yar cilarla, los

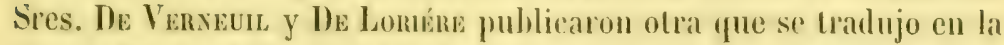
Revista Minera, 1. 25, pity. 11. A continuarion de ella presentio el senor Egozene y Cia la traduccion de la Hescripeion geológica de la provincia de Teruel, por II. II. Couvasn. En ella se menciona ma gran parte de las especies delalladis en su Monografia, de que anteriormente dimos cuenta.

En 1871 apareció la interesante Memoria titulada Escursion yeoLógica por el $N$. de Berga (Revista Mineru, 1. 22, paig. 528). Su aulor, D. L. M. Vmat nuestro ilustrado amigo y condiscipulo, contribuye. a aumentar nuestro catílogro con un buen numero de especies no reconocidas en España hasta aquella fecha.

En 1872 se publicó la Monografía paleontológica del piso aptico de Torlosa, Chert y Benifuxi, por D. J. J. LAvoeren, en la cual se deseriben 67 especies, de ellas 51 mevas, numero que, como dice muy hien el autor, merece el nombre de respetable, si se atlende á lo circunscrito de las tres localidailes.

El Sr. J. Mic-Puerson, en su Bosquejo yeológico de la provincia de Cidiz, menciona alımas especies secundarias y terciarias recogidas por el mismo y por De Verneuil.

La Reseña geológica de la provincia de Guadalajara, por D. Salvador C.stonerox, recientemente publicada, señala otro buen número de aquellas, sobre toilo jurásicas y cretíceas, recogidas por Prado, Ezquerra, De Verneuil y el autor.

Para terminar, haremos mérito de dos trabajos notables que, ofreciendo grran interés para el estudio de nuestros fósiles, csta Comision acaba de publicar. Nos referimos al Bosquejo de una descripcion fisica y gealüyica de la provincia de Zarayoza, por D. F. Il. Dosirre, en el que consigna mis de 150 especies; y los Datos para el conocimiento del terreno yurumense de Calahuñ, por D. L. M. VIDAL, donde se describen y figuran 51 , de las cuales 28 son nuevas.

Escrita ya la primera parte de este Catilogo, llega á muestras manos el villimo número de los Anales de la Sociedud española de IIistorin Valural (1. 5. , cuad. 2. ${ }^{\circ}$, , pue contiene la Énumeracion de planlas fósiles españolıs, por D. A. de Aneitro. Nosolros, que hemos sido testigos del entusiasmo por la ciencia y lahoriosidad del autor, no podemos ménos de concerler á atpuella la importancia que merece; y (2I su vista, prescindiriamos de los vorgetales fósiles, si no atendiéra- 
mos á que el objeto principal de este Catálogo es dar un ligero conocimiento de nuestros restos orgánicos, por su aplicarion á los trabajos geológicos.

De estos escritos hemos tomado las principales indicaciones de localidad respecto á las especies que inscribimos; pero sin un exámen de todas ellas, nuestra lista no of receria garantia alguna de seguridad respecto á la existencia real de carla una en nuestro suélo. Muchos son los autores mencionados que merecen entero crédito en sus referencias, pero de otros no podemos tener completa confianza. Hemos basado nuestro trabajo en la inspeccion de los ejemplares que existen en las colecciones de la Comision del Mapa geológico y la Escuela de Minas. Las especies que no llevan ningun signo delante de sı número de órden, no han podido ser comprobadas. Aquellas que van precedidas del signo * son raras; más frecuentes las que llevan delante ${ }^{*}$ y abundan las marcadas con $* *$, cuyo estudio y adquisicion recomendamos en primer lérmino á nuestros lectores.

La necesidad de hacer el Calálogo lo ménos voluminoso, á la par que lo más completo que nos ha sido posible, nos ha inducido á emplear un gran número de abreviaturas, que el lector comprenderá fácilmente. En las sinonimias hemos sido muy parcos, y sólo apuntamos las usadas en lugar de los verdaderos nombres, en los escritos referentes á España. Tampoco hemos podido extendernos gran cosa en la descripcion de las especies, permitiéndonos únicamente algun detalle en aquellas que, por su abundancia ú otro motivo especial, ofrezcan mayor interés para la determinacion de las formaciones geológicas correspondientes.

7 de Febrero de 1875

Lucas Mallada. 


\title{
TERRENO PALEOZOICO.
}

\author{
SISTEMA SILURIANO.
}

Una ojeada sobre el Bosquejo geolígico de España y Portugal, de los Sres. De Verneuil y Collomb, hasta para observar que, á excepcion de la terciaria lacustre, no se ve formacion más desarrollada que la siluriana. Interrumpida por varios macizos graniticos, ocupa ésta casi todil la region occidental de nuestro territorio, é invade el vecino reino, de cuya superficie ocupa una tercera parte próximamente. El triángulo cuyos vértices fueran Alcaraz, Luarca y el cabo de San Vicente, nos limitaria una dilatada extension, perteneciente en mucho más de su mitad al sistema siluriano de la Península. Ademas de esta gran parte, contamos con otras pertenecientes á la misma época de dimensiones más reducidas, pero que entre todas suman un total considerable. Tenemos un manchon siluriano de unas 100 leguas cuadradas entre Torrelaguna (Madrid) y Atienza (Guadalajara); otro, próxinamente de igual superficie, entre Búrgos, Logroño y Soria, cogiendo una porcion de las tres provincias; dos fajas extensas en la de Zaragoza, una desde Moncayo á Montalvan, y otra que cruza por Calatayud y Daroca; un pequeño islote al $\mathrm{N}$. 0 . de Segovia; otro al N. de Molina de Aragon; otros dos mayores al x. de la Sierra de Albarracin; varios hicia las costas de Cataluña, y una zona que desde Camprodon, cruzando el valle de Andorra, sigue por los Pirineos, terminando por la parte de Espana hácia Benasque.

Dejando a un lado consideraciones petrologicas y estratigráticas que nos llevarian muy lejos, apuntaremos algunas ideas que creemos de interés para nuestro objeto.

Por más que la inmensa mayoria de las áreas que acabamos de 
señalar, se compone, como roca dominante, de pizarras arcillosas casi siempre satinadas ó relucientes y con frecuencia sin fósiles, no era extraño se descubrieran en tantos kilómetros cuadrados diferentes parajes del mayor interés paleontológico, y que correspondieran á distintas edades de la gran formacion de que nos ocupamos.

La fauna primordial está marcada en cinco puntos diversos: el primero (por su importancia paleontológica) fué descubierto por Prado, y forma en la cordillera cantábrica, al N. de Sabero, una zona de caliza roja arcillo-ferruginosa; el segundo, encontrado por los Sres. De Verneuil y Donayre y explorado por este último, se extiende en Murero, junto á Daroca, formado de pizarras arcillosas cenicientas ó ligeramente rojizas; el tercero, dado á conocer por De Verneuil, se halla en los cortijos de Malagon (montes de Toledo), compuesto de una arenisca algo micáfera, deleznable, de color amarillento; el cuarto, junto í Belmonte (Astúrias), con poca importancia hasta la fecha, se halla constituido por una pizarrilla arcillosa grís verdosa, muy pobre en restos orgánicos; el quinto, señalado por los Sres. De Verneuil y Collomb, entre Calatayud y el Mloncayo, no ha podido ser comprobado todavia de un modo resuelto.

La fauna segunda se nos ofrece más rica y en muchas localidades (1), sobre todo al N. de Sierra Morena, en el territorio de Almaden y Almadenejos, lan minuciosamente estudiado por los señores Prado, De Verneuil y D. Eusehio Sanchez. Se compone, por regla general, de pizarras arcillosas más ó ménos foliảceas, ya algo satinadas ya micáceas (como las del Puente de las Ovejas), casi siempre algo ferruginosas y de colores gris parduzco ó gris amarillento.

A la fauna tercera pertenecen las calizas negruzcas de Ogasa, Camprodon y otros términos de los Pirineos catalanes; las pizarras de graptolites, muy arcillosas, suaves al tacto, de colores gris rosáceo ó heces del vino, del arroyo del Lapiz (Ciudad-Real), y las pizarras ampeliticas de varios silios de esta última provincia y de las de Salamanca, Segovia, Orense, Leon, Cáceres y otras.

Por las provincias citadas, forman crestones salientes, sobre los depósitos de pizarras arcillosas, varias sierrecillas compuestas de cuarcitas que con frecuencia contienen cruzianas y otros restos que constituyen nuestra flora siluriana.

(1) A esta fauna corresponden las especies silurianas, cuyo horizonte geológico no expresamos en el Catálogo.

14 


\section{PARADOXIDES.}

* 1. P. Pradoanus, Vern. el Barr. (Bulletin de lit Societé ycolonique de France; 2e série, 1. 17, p. 526, 1. (i).-Cabeza con cuatro pares de sureos laterales ademas del surco occipital; los dos posteriores unidos en el eje forman ranuras trasversas; los dos anteriores aislados; 17 segmentos en el torax; coccix plano, exi\$no, relativamente muy alargado y triangular. Longitud $50 \mathrm{~mm}$; lat. 54. Fauma primordial. Adrados, Corniero, Crémenes, el Soberon, la Velilla, Primajos, Valdoré, Vozmediano, Vornuevo y otros términos al N. de Sabero (Leon).

2. P. spinossus, Boek. (Rarrande; systime silurien du centre de la Bohime; 1. 1, p. 570, 1. 11, 12 y 15).-De forma oval, glabela bombeada con cuatro pares de surcos; puntas genales inmediatas al torax; 18 segmentos torácicos; la penúltima punta de sus pleuras más larga que las demas. Coceix en dos segmentos; el segundo triple de largo que el primero. Fauna primordial. Al N. de Sabero? Murero (Zaragoza).

5. P. rotundatus, Barr. (Ibid.; p. 571, 1. 14).-Difiere del anterior por la isualdad de sus últimas puntas pleurales, y sus puntas genales más apartadas del torax. Fauna primordial. Murero.

4. P. Bohemicus, Boek (Ibid.; p. 567, 1. 10, fig. 22-25).Las dos últimas puntas pleurales muy alargadas; 20 segmentos en el torax. Fauna primordial. Sabero.

\section{ARIONELLUS.}

** 5. A. ceticephalus, Barr. (Ibid.; p. 405, 1. 10, f. 1-21). - Presenta dos perioilos de desarrollo: cuando llega a $10^{\mathrm{mm}}$ de longitud tiene 16 segmentos en el torax y dos á tres en el eje del coccix, que es muy hombeado. Glabela casi al nivel del resto de la calseza; ojos muy perqueños; eje del torax saliente en semi-circulo, la mitad de ancho que una loba lateral. Fauna primordial de la cordillera Cantábrica. 


\section{CONOCEPHALITES.}

**6. C. Sulzeri, Schlott. sp. (Ibid.; p. 119, 1. 15, 14 y 26).-Especie sin ojos. Glabela con tres pares de surcos algo encorvados; 14 segmentos en el torax, cryo eje tiene un ancho próximamente la mitad del de cada una de las lobas laterales. Las pleuras se doblan bruscamente hácia atrás casi en ángulo recto. Coccix con einco segmentos. Lo que más suele abundar en los yacimientos son las cabezas; en general son muy granulosas, à veces con un tubérculo saliente en el vértice del anillo occipital. En la caliza roja arcillosa de la fauna primordial al N. de Sabero, se presenta una variedad notable por la falta casi completa de granulacion. Los ejemplares de Hurero (Zaragoza), se ofrecen defornados como si su yacimiento hubiera sufpido una compresion lateral.

* 7. C. Coronatus, Barr. (Ibid.; p. 424, 1. 15).-Difiere del anterior, con el cual suele hallarse asociado, por su menor talla, y por una protuberancia aislada y redondeada en el vértice anterior de la glabela. Un tubérculo espiniforme se destaca en el anillo occipital.

* 8. C. Ribeiro, Barr. et Vern. (Bull. de la Societé géol. de France; $2^{\mathrm{e}}$ série, 1. 17, p. 528, 1. 6, f. 7 à 12).-Especie más pequeña que la anterior con la cual se ofrece, aunque ménos abundante, en la zona de caliza roja al N. de Sahero y en Murero. Ojos relativamente muy pequeños, granos espiniformes salientes en el eje del torax y en la zona anterior de los pleuras. La parte plana i interna de estas es á veces granulada, otras lisa; 14 segmentos dificiles de comprobar, porque los mejores ejemplares se presentan arrollados de modo que su extremidad posterior se oculta bajo la cabeza.

\section{ELLIPSOCEPHALUS.}

* 9. E. Pradoanus, Barr. et Vern. (Bull. Soc. gcol. Frence; $2^{e}$ série, 1. 12, p. 968, 1. 25, 1. 5)?-Glabela figurando un cuadrilítero alargado; ojos colocados atrás y prolongados por un filete delicado hasta la grlabela; ésta, tres veces más larga que ancha; borde 


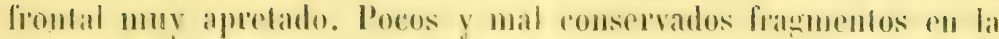
arenisca cuarzosil, algo micilera, gris amarillenta de los cortijos de Ilalagon (montes de Toledo).

\section{DALMANITES.}

* 10. D. socialis, Barr. (Systéme silurien du centre de la Bohime: 1. 552, 1. 21, 22, 26 y 27).-Cabeza hombeada, de contormo exterior parabólico; limbo pronumciado á lo largo de los carrillos: nulo ó rudimentario al rededor de la loba frontal de la glaliela; ésta, con tres pares de surcos profundos; anillo occipital bien destacado. La loba frontal que ocupa los \% de la longimul de la glabela, lleva m hoyuelo alargalo hácia el centro de ligura: 25 a 54 filas de Tá 9 lentes rada ma en cada ojo. Eje toricico bien limitado por Jos surcos dorsales, de anillos adelgazarlos en el medio, y alcanzando su mayor altura en el $5 .^{0}$ segmento. Las plemras se doblan hícia atris poco anles de la milad de su longitud, y se hallan divididas en dos lajas desiguales por un surco oblicuo: 9 a 15 articulaciones en el eje del coccix, que termina en un apéndice caudal y ocupa algo ménos del tercio de la anchura tolal. En cada loba lateral del coccix hay de 6 a 8 costillas. Gruesos mranos en la glabela y en las extremidades de ios anillos del eje torícico. - Fuenlabrada, La Balleslera, cercanias de Almaden y Almadenejos. En el puente de las Ovejas se ha encontrado una variedad distinta del lipo, por un hocico que remata la glabela formando un saliente de $5^{\mathrm{mm}}$.

* 11. D. Phillipsi, Barr. (Ilind.; p. 557, 1. 22, 26).-Giabela aplastada por encima, con surcos dorsales profumdos casi rectilineos; 5 pares de surcos laterales, el posterior muy marcado. El surco occipital hace en el medio m fuerte seno hicia adelante. Los ojos no llegan al nivel de la glabela, y carla mo tiene mas 150 lentecillas. Anillos del torax separados por anchas y profundas ranuras: li a 8 articulaciones en el eje del coccix, que es semicircular, con limbo estrecho y 5 a a costillas en cada loba lateral. Luarca (Asturias). Navalpino, Porzuna, Peralejo, La Ballestera, entre Palacios y Guadalmez; Huerta del Llano, Almaden.

12. D. Dujardini, liou. (Bull. Soc. geol. de France: 2) 
série, t. 4, p. 528, I. 5, f. 5).-Tal vez no sea más que ma variedad del anterior, con el cual viene asociado, y del que se distingue por su coccix triangular, la ausencia del limbo al rededor de este, y un tubérculo saliente colocado en medio del borde frontal.

* 15. D. Vetillarti, Rou. (Bull. Sic. geool. France; פe série 1. 8, p. 559).-Los surcos laterales del medio de la glahela se reducen á dos hoyuelos que no llegan al surco dorsal. Los ángulos genales y la extremidad del coccix son redondeados. La Ballestera.

* 14. D. Torrubiæ, Barr. et Vern. (Bull. Soc. yéol. de France; $2^{\mathrm{e}}$ série, 1. 12, p. $976,1.26$, f. 5).-Glabela aplastada y deprimida bajo el nivel de los ojos, que se elevan sobre la parte central de la cabeza: 8 articulaciones en el eje del coccix, cuyas pleuras se pliegan hácia atrís paralelamente al eje. La Ballestera, Puente de las 0vejas.

15. D. Downingiæ, Murch.=Phacops Downingire, Murch (Sihuria 1. 18, f. 2 a 5).-Los ejemplares de La Ballestera, Fontanosas, Brazatortas y Almadenejos son un tercio mayores que los de Inglaterra, en donde se presenta en el siluriano superior.

16. D. Hausmani, Brong, (sp).=A saphus Hausmanni, Brony. (Barrande: Systême silur. du centre de la Bohème; p. 558, 1. 25, f. 20, I. 24, f. 1 á 12). - Glabela con tres hoyuelos; ojos con 420 á 600 lentecillas cada uno. El eje del torax apenas llega á los dos tercios de la anchura de una loba lateral; un sureo ancho divide las pleuras en dos zonas: coccix muy bombeado á través, con apéndice caudal exiguo y rodeado por un limbo estrecho; el eje, con 18 a 19 articulaciones, y 15 á 14 costillas á cada lado. Gruesos granos en la loba frontal, y otros menores en la terminacion de los anillos del cje. Silur. sup. (Edad G. de Barrande). Caliza de Santa Cruz de Mudela.

\section{CALYMENE.}

* * 17. C. Tristani, Brong. (Bull. soc. géol. de France; $2^{\mathrm{e}}$ série, t. 12, p. 972, 1. 25, 1. 5).-Fácilmente distinguible por su borde frontal prolongado y arremangado: lobas laterales muy ple- 


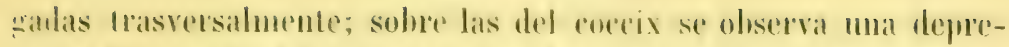
sion oblicua al eje fue pasa por los punlos domble romienza ol sureo sulural de bis plemats. Ihumban los ejemplares arrollados en hola. La Ballestera, Fonlinosas, Brazatorsas, La Cánacollera, Solama del Romeral y otres pumlos de las ceremias de Almadenejos; Iluerla del Lhano, detris del llospilal, y obros silios de las immediaciones de Mmaden; cerro de Hirallores, Porzma, á poes libomelros de Meariz: Santa Cruz de Mudrla, l'uente de las Ovejas y Paulete, proximo a Ciudad-Real, entre la Lasa de la Vexat y Santa Eufenia; 12 libimetros al $\mathrm{N}$. de Villaharta, camino de Mmaden a Córboba: Horcajo de los Montes y Fuenlabrada de los Monles de Toledo, Herrera del Duque (Badajoz), Nava Entresierra, entre la Sierra de finadalupe y el Tajo (Cáceres); Pardos, al N. de Molina de Aragon (Gruadalajara); Luarea (Astúrias).

** 18. C. Arago, Rou. (Ibid.; 1. 975, 1. 25, f. 4).-Se dislingue de la anterior por el borde frontal rudincutario, encorvado verticalmente bajo la cabeza en arco ojival, redondeado en el vérlice, mirando hiria arriba su convexidad; y por su coccix desprovisto de segmentacion en las lobas lalcrales, subdivididas cada una en dos partes: la interna triangular, lisa y saliente; la exterior segmentada. Pizarıas de Almadenejos, La Ballestera, Valdemorillo, P'uente de las Orejas, Horcajo de los Montes de Tolede, y Pardos, al N. de Molina de Iragon; Calizas de Herrera del Durue (Badajoz).

19. C. transiens, Vern. el Barr. (Ibid.; p. 974, 1. 25, f. 5).-Con gxanulaciones finas en la superficie de su cuerpo como la $C$. Tristani, Brong.; ; liene una cabeza muy parecida a la de la $C$. Arayo, Rou., de la que difiere por tener tres plemras en los triảngulos laterales del coccix. Fontanosis, La Ballestera, Puente de las Orejas, Retamosi, Hnerta del Llano, Mlmaden, Solana del Romeral. Almadenejos.

20. C. pulchra, Barr. Siystrime silur. An centre de la Bohrime, p. 77, 1. 19, 1. I a !),-Cabeza de contorno exterior semicircular; borde frontal redondeado, espeso, arremangarlo, separado de la glabela por una ranura ancha; adornalo inferiormente por una sirie de espinas; ghabela bombeada, de surcos dorsales profundos, muleriores poco marcalos y posteriores bilurrarlos: ojos salientes 
con 150 lentecillas en carla uno, dispuestas en tresholillo; 15 segmentos en el torax, cuyo eje es algo más ancho que las lobas laterales; las pleuras se encorvan bruscamente en lit mitad de su extension, y están divididas por un surco en dos partes muy desiguales, la posterior mucho más ancha que la otra; coccix semi-eliptico, con 8 anillos en el eje y 6 costillas á cada lado, separadas por surcos profundos. La Ballestera, Valdemorillo, Almadenejos, Horcajo de los Montes de Toledo, Cerca de Pardos, al N. de Molina de Aragon.

\section{HOMALONOTUS.}

21. H. rarus, Corda (sp). (Ibil.; p. 581, 1. 29, โ. 21 y 22.)Cabeza tan regularmente bombeada que parece un cuarto de esfera; glabela trapezoidal, determinada por surcos dorsales estrechos y profundos; ojos muy pequeños, colocados muy arlelante: el eje del coccix ocupa el tercio de la anchura total, y apenas se notan senales de segmentacion en toda la superficie. Almaden y Almadenejos.

* 22. H. Brongniarti, Desl. (sp).=Asaphus Brongniardii, Desl. (Memoires de la Societé Limnéenne du Calvalos; année 1825 p. 501, 1. 19.)-Un ancho borde rodea la grlabela, que es de forma prolongada, y presenta jumto á su base dos pequenas protuberancias oculiformes. Los fragmentos recogidos en las pizarras arcillosis de La Ballestera y las areniscas amarillentas deleznables del valle de Juan Gil (Almaden), corresponden á parte del torax y al coccix, que es bombeado de eje terminado en una especie de pezon, de lobas laterales fuertemente encorvadas y débilmente segmentadas.

\section{LICHAS.}

* 25. L. Hispanica, Barr. el Vern. (Bulletin de la Socielé géol. de F'rance, $2^{\mathrm{e}}$ série, 1. 12, p. 977, 1. 24, 1. 1.)-Borde frontal ancho; cuerpo central de la glabela como un hemisferio, terminarlo atrás por una parte baja y estrecha que ocupa la cuarta parte de la longitud total; surcos, anterior y medio, paralelos entre si y reunidos en el interior, de donde parte una depresion que atraviesa la parte baja de la loba central, dejando tras si un borde tras- 
rersal que simula un segumlo anillo occipital. Surco posterior de la - Liblela encorvato en sus extremidates. La loba anterior figura un cralo alarwado; la central es doble en superficie; la posterior punteaguda en sus extremos y muy perpueña: anillo occipital con un ligero lubereulo en el centro; ranapacho con muchos granos desiguales rematados en punta. De este hermoso y grande trilobite no se han hallado más que fragmentos en las rereamias de Almaden y en el Puente de las Ovejas.

\section{TRINUCLEUS.}

* 24. T. Goldfussi, Barr. (Systeme silurien du centre de la Boheme, p. 628, 1. 50, f. 29 á 40.)-La cabeza ocupa la mitad y el coccix la quinta parte de la longitud tolal: limbo semicircular prolongado paralelamente al eje hasta la mitad del torax, y adornado con seis á ocho filas concéntrieas de perforaciones redondas; grlabela muy saliente, ovoide, adelgazada hácia la nuca; de cuatro á seis segmentos en el torax, cuyo eje, muy saliente, ocupa algo mís de la mitad del ancho de una loba lateral; plemras apenas dobladas hícia atrás; coccix casi triangular, muy saliente, con seis it ocho anillos. Fragmentos (de cabezas, sobre todo) en la arenisca amarillenta terrosa de Valdeazognes, y la psamita agrisada de Peralejo, rocas probablemente posteriores i las pizarras arcillosas de las especies anteriores.

\section{ASAPHUS.}

* 25. A. nobilis, Barr. (Ibil.; p. 657, 1. 51 y 52).-De forma oval; cabeza parabólica, cuya punta genal llega al sexto segmento; glabela oval, poro saliente, dividida en dos partes casi iguales por un surco que une las extremidades anteriores de los ojos. Estos últimos, en semicirculo, poco salientes, con unas 12,000 lentecillas cada uno; 8 segmentos en el torax, cuyo eje ocupa el cuarto de la anchura total, y cuya latitul no varia en toda su extension. Las pleuras, ligeramente bombeadas, terminan en una punta corta, ancha y plana, aryueada hácia abajo; un ancho surco las divide en sus dos tercios interiores. El coccix ocupa algo más del tercio de la longitud del cuepo; es de figura paraboblica, y su eje 
saliente disminuye progresiramente en anchura, desapareciendo bruscamente. En él se cuentan de 10 á 18 articulaciones, cada una adornada con dos curvas concéntricas, cuyo vértice agudo mira hicia abajo, en los individuos adultos; en los jóvenes no existe este adorno. Las lobas laterales tienen en general 9 costillas separadas por surcos intercostales, estrechos y profundos. El carapacho suele estar provisto de diversos adornos: estrias concéntricas al contorno exterior de la cabeza, nervios $\dot{o}$ filetes irregulares y ramificados en las pleuras; estrias trasversas é irregulares en el eje; surcos parabolicos en el coccix, etc. Puente de las Ovejas, Brazatortas, Fontanosa, La Ballestera, Solana del Romeral, Huerta del Llano, Las Navas, junto á Herrera del Duque.

* 26. A. Cianus, Barr. el Vern. (Bulletin de la Soc. géol. de France; $2^{\mathrm{e}}$ série, t. 12, p. 979, 1. 25, f. 5).-Grande especie, de wabela cilindroide, ligeramente aplastada atrás, bombeada y saliente en la frente; ojos alargados, colocados hácia el medio de la lonsitud á cada lado de la glabela y compuesto de gran numero de lentecillas, tal vez diez mil en cada uno; 8 anilios en ef torax, separados por anchas y profundas ranuras: surcos dorsales profundos limitan el eje que ocupa el tercio de la anchura total, y se eleva en arco rebajado sobre el nivel de las lobas laterales. IItuerta del Llano.

27. A. Glabratus, Sharpe (sp). (Ibid.; p. 980, 1. 25, f. 1.) $=$ Ogygiu ylabrala, Sharpe. (Qual. Jour. géol. Soc., t. 9, p. 160, 1. 7, f: 4).-Cabeza semicircular; glabela muy ensanchada de atrás adelante; ojos grandes, con unas 2,000 facetas microscópicas; 8 anillos en el torax: coccix de contorno semicircular, de eje saliente, ocupando ménos del tercio de la anchura total, y con 5 á 7 articulaciones, de las cuales sólo la primera estí bien marcada; en cada loba lateral 4 a $\ddot{b}$ costillas sin surco sutural, pero bien separadas por ranuras intercostales: carapacho con estrias finas, salientes, algo sinnosas, trasversas sobre el eje y oblicuas á los lados. Huerta del Llano, Brazatortas, Retamosa, La Ballestera, Puente de las Ovejas Ciudad lieal), Luarca (Asturias.)

28. A. contractus, Barr. el Vern. Bull. Soc. gíoloyique de France; $2^{\mathrm{e}}$ série, 1. 12, p. 981, 1. 21, f. 5 y 5a).-Solo se conocen le esta especie shabelas aisladas que son bombeadas, en forma de 
fria, cuya punta, corontula de un tubereulo, Hega al surco occipiLal, y cuya base se apoya sobre ol horde frontal aplastado, de dos a it $5^{\mathrm{mm}}$ de anchura: este horde rodea la wlabela, ensanchándose gradualmente á los lados: el anillo occipital está bien marcado. El carrillo fijo parece hastante bombeato. Tal vez algun coccix atribuido al A. glabratus, Sharpe, pertenczea i esta especie.-Solana del Romeral y Puente de las Ovejas.

\section{ILLAENUS.}

29. 29. Hispanicus, Barr. el Vern. (Ibid.; I. 25, f. 6. ) - Cabeza algo más desarrollada que el coccix; 10 segmentos r'n el torax, cuyo eje ocupa un tercio de la anchura total, y se estrecha ligeramente en su longitud: parte interna y horizontal de las pleuras más corta que su parte externa; en el origen de cada una de ellas hay un agugerito en forma de embudo; carapacho con mias estrias trasversales onduladas, desigualmente espaciadas, que resultan de unas séries de puntos huecos, y son muy distintas de los plieguecitos que se observan en el I. Crassicauda. Los mayores ejemplares alcanzan $9 \mathrm{em}$ de longitud por 6 de anchura. La Ballestera, Horcajo de los Montes, Saceruela, Huerta del Llano, Almaden, Solana del Romeral, Almadenejos.

50. I. Sanchezi, Barr. et Vern. (Ilidid.; p. 982, I. 25, f. 7.-Pequeña especie, de ojos muy desarrollados, que ocupan alg̣o ménos del tercio de la longitud de la cabeza y tienen lentecillas relativamente grandes; ocho segmentos en el torax, cuyo eje осира un tercio de la anchura total, y de pleuras muy encorvadas al tercio de su longitud; cabeza y coccix casi iquales, muy bombeados y casi sin señales de lobacion. La Ballestera y el Madroñal de la Caracollera.

\section{CHEIRURUS.}

51. C. Marianus, Barr. et Vern. (Ibid.; p. 970, 1. 25, f. 4). - Glabela sumamente convexa; borde frontal aplastado y mucho mis ancho que el del Ch. chiviger; ojos it harte externa del surco lateral medio. Solo se conocen frammentos del Puente de las Ovejas. 


\section{PLACOPARIA.}

* 52. P. Tourneminei, Rou. (sp)._-Calymene Tourneminei, Rou. (Ibid.; p. 968, 1. 25, f. 6).-Loba frontal más estrechia que la mayor anchmra de la glabela; la gran sutura es marginal en la region frontal, y despues cada rama atraviesa el borde, cae en el surco genal que sigue aflorando el talud del carrillo, para terminar en el ámgulo maxilar, en una depresion muy marcada: en el contorno lateral de los carrillos hay a cada lado seis á siete dentelladuras poco salientes, que se ocultan bajo el coccix, en los ejemplares bien conservados. Sin ojos. Once segmentos en el torax; coccix con cuatro pleuras á cada lado, y en el eje cinco arliculaciones, de las cuales la última es rudimentaria. La P. Zippei, Corda, de Bohemia, muy parecida á esta especie, sobre todo por su coccix, se distingue por su glabela ensanchada gradualmente de atrís adelanle; por su torax que tiene doce segmentos, y por ser de doble lalla. Los ejemplares de nụestra especie alcanzan por término medio $51^{\mathrm{mm}}$ de longitud por 16 de anchura. Pardos, al $\mathrm{N}$. de Moliua de Aragon; La Ballestera, Almadenejos, Huerta del Llano, Fontanosas, Porzuna, Puente de las Ovejas, El Viso, junto a la Venta de Cárdenas.

\section{ORTHOCERATITES.}

* 55. O. duplex, Wahl. (Murchison, de Ternenil el de Keyserling; Geologie de la Russie, l'Europe el des montagnes de l'Oural: vol. 2, p. 551, 1. 24, f. 7 y 1. 25, 1. 2).-Concha lisa; alcanza á veces grandes dimensiones; sifon lateral, estrechado dehajo de cada tabique, y envuelto de varias liminas que nacen una bajo de otra, siendo las más delgadas las más interiores. A un individuo de $55 \mathrm{~mm}$ de diámetro le corresponde una longitud de 660, un espesor del sifon de 22 y una distancia de tabique i tabique $=16$. Solana del Romeral, Huerta del Llano, Navalpino.

54. O. annulatum, Sow. (sp). Mac Coy. (A systematic Descrip)tion of the brit. paloroz. fossils in the geol. Museum of the univ. of Cambridge; p. 519).- - Seccion oval; sifon ancho y excéntrico; anillos sa- 
lientes algूo oblicuos, tress en media pulgata it un diamedro de ? lineas, y 4 en el mismo espacio a un diamel'o de 6. Bspacios interamulares concavos, profundos, con seis it siete estrias transversas, Iorcidas hícia abajo en mumerosas ondas, a veres cruzadas por estrias longitudimales. Silur. sup. Ogasa.

5i. O. giganteum, Sow. (Ihid : P. 57I). - Liso o con ligeras lineas transversas de crecimiento; silon ancho, poco excentrico; secrion casi circular; tabinues numerosos, ligeramente excentricos. Silur. sup. Ogasa, Cabo de Creus.

56. O. striatum, Sow. (Ilid.; p. 405).-Ligeramente comprimido; sifon ancho, excéntrico; estrias linas, irregulares, mas catorce en el espacio de una línea. Asociado al anterior.

57. O. laterale, Phill. (Ibid.; p. 572).-_eccion oval; tabiques oblicuos, numerosos; sifon algo excéntrico; estrias finas, irregulares. Asociado al anterior.

58. O. tenuis, Wahl.-Asociado al anterior. (?)

59. O. bohemicum, Barr. (Systéme silur. tu centre de la Boheme; 1. 2, 1. 214, f. 11 a 15).-De seccion circular; silon central; inillos convexos deprimidos hácia los tabiques, espaceados un centimetro próximamente. Silur. sup. Ogasa.

40. O. timidum, Barr. (Ibic.; 1. 217, f. 6 y 7).-Pequeño; de seccion circular; estrias de erecimiento apretadas. Asociado al anterior.

41. O. placidum, Barr.-Asociado al anterior.

42. O. originale, Barr.-Asociado al anterior.

45. O. nummularium, Sow. (Hurchison: Siluria; 1. 26, [. 5). De unos 10 a $15 \mathrm{~cm}$ de diimetro; tabiques espaceados á ménos de un rentimetro; sifon casi marwinal. Silur. sup. Camprodon.

44. O. ammonum, Barr.-Asociado al anterior. 


\section{LITUITES.}

45. L. intermedius, Vern. el Barr. (Bulletin de la Soc. géol. de France, $2^{\mathrm{e}}$ série, 1. 12, p. 985, 1. 27, f. 5).-Estrias muy finas, muy encorvadas en la region externa; le diferencian del $L$. convolvans, cuya concha es lisa, y del $L$. cornuarielis, que tiene estrias lamelosas desiguales. Almadenejos, Huerta del Llano.

\section{EUOMPHALUS.}

46. E. subuloideus, Portl.-Silur. sup. Ogasa.

\section{PLEUROTOMARIA.}

47. P. Bussacensis, Sharpe. (Quart. Jounnal yeological $S_{0-}$ ciety; เ. 9, p. 986, 1. 9, f. 8).-Concha lisa, compuesta de 6 vueltas redondeadas, separadas por una sutura profunda; la viltima algo anzulosa en el medio, por donde se extiende un seno profundo. Pizarras arcillosas de la Puebla de Don Rodrigo; Huerta del Llano, Almaden.

\section{RIBEIRA.}

* 48. R. pholadiformis, Sharpe. (Ilid.; p. 158, I. 9, f. 17). -Univalva no arrollada en espiral, comparable á una Calyptrea lateralmente comprimida, hasta que los bordes viniesen á encontrarse dejando una hendidura para el pié del animal. Redondeada anteriormente, adelgazada en la otra extremidad; lineas concéntricas, ạ̣das, desiguales. Cercanías de Almaden.

\section{CAPULUS.}

* 49. C. cantabricus, Barr. et. Vern. (Bull. de la Societé ycol. de France, $2^{\mathrm{e}}$ série, 1. 17, p. 5.51, 1. 8, f. 4).-Casi cónico; pun- 


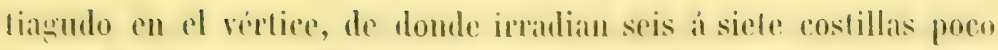
mareadas, que terminan en la base, que es redondeada. Callizat ancillosa roja de la fauna primordial al N. de Sabero.

50. C. robustus, Barr.-Silur. sup. Ogasa?

\section{BELLEROPHON.}

** i1. B. bilobatus, Sow. (Mac Coy: Asystematic Descr. of the Irit. palaros. fos. in the geol. Huseum of the T'niv. of Cambr.; p. 508). - Concha globulosa; abertura ancha, bilobada por un profundo seno; ombligo muy pequeño en los moldes, cubierto en la concha; superficie con estrias finas, irregulares, algo flexuosas, aryueadas. Abundan, sobre todo, los moldes, que son lisos. Los ejemplares del Puente de las Orejas, suelen presentar un carácter que no es general, i saber: un surco detrís del borde, que parece ser la huella de una boca antigua. Inerta del Llano; Solana del Romeral; Loma del Herradero, Valdeazogues; La Ballestera; Cerro de Miraflores, al N. de Porzuna. Herrera del Duque. Luarca.

* 52. B. acutus, Sow.=B. carinalus, Sow. (llid.; p. 509).De pequena talla, comprimido; su mayor espesor está en el ombli„o, que es muy perpueño: dorso agudo, á veces cortante; abertura triangular un tercio más larga que ancha. Huerta del Llano, Mlmaden; Solani del Romeral, Almadenejos. Hall considera esta especie como una var. de la anterior.

\section{THECA.}

* 55. T. triangularis, Port. (sp).-De forma piramidal; puntiaguda; seccion triangular, con estrias transversas muy finas.Los ejemplares del Puente de las Ovejas aparecen aplastados en las pizarras arcillosas y arcillas pizarrosas ģrises y rosíceas, asociados á la Cardiola interrupla. Silur. sup.

\section{TENTACULITES.}

*\% 54. T. scalaris, Schlot. (Ihil.; 1. 997, 1. 27, f. 10)-Plerípodo rompuesto de ronos truncados, escalonados unos sobre otros 
como las divisiones de un anteojo de larga vista. Tal vez sean moldes del T. anmullatus. La naturaleza de este fósil ha sido ohjelo de varias controversias, considerándose por algunos paleontologistas como $\mathrm{Or}$ thoceras jóven, aislándole otros entre los cuerpos incerter sedis, $\dot{o}$ clasificindole entre los crinoides. Esta última opinion no podia prevalecer, pues ni se compone de piezas articuladas ni presenta la fractura espática propia de aguellos. Murchison le coloca al lado del Dentalimm, y finalmente, Richter le reune à los pterópodos. Areniscas amarillentas del Entredicho, Valdeazogue.

\section{SANGINOLITES.}

* 55. S. Pellicoi, Vern. et Barr. (Bulletin de la Soc. géol. de France, $2^{\mathrm{e}}$ série, 1. 12, p. 991, 1. 27, 1. 4).-Equivalva, inequilátera, delgada y lisa, cerrada en sus dos extremidades, de bordes delgados y cortantes; doble larga que ancha; un diente delgado en cada valva por debajo del nates; impresiones musculares dohles; la anterior, colocada cerca del borde bajo el nates, es redondeada; la posterior, mayor y eliptica, se halla junto al borde superior. Otra impresion correspondiente al músculo retractor se ve bajo el nates, y ademas otras cuatro pequeñitas entre las de los músculos anterior y posterior. Abundan los moldes en la Caracollera, Huerta del Llano, Solana del Romeral, La Ballestera, Fuenlabrada, Cerro de Miraflores, al N. de Porzuna, Sevilleja. Herrera del Duque.

\section{CYPRICARDIA.}

56. C ? Beirensis, Sharpe. (Muar. Journ. yeol. Society; 1. 9, p. 152, 1. 9, f. 16).-Trapezoidal, ligeramente deprimida en su parte media; region anterior redondeada y más ancha que la posterior. Un diente largo al lado posterior de la charnela. Nimadenejos.

\section{CARDIOLA.}

* 57. C. interrupta, Brod. (Mlac Coy: A sylem. Descrip. of the brit. paltens. foss. in the geol. Misemm of the Inive. of. Cambridge; 


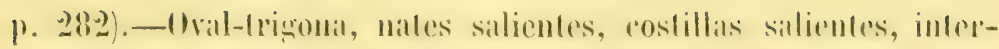

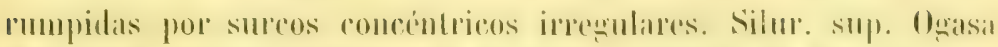
(lirineos eatalanes. Calizas del Mlamillo y Castillo de Asmaron.

58. C. fibrosa, Sow. (lhil.; [1. 232).-Ditiere de la anterior por sus costillas salientes mis linas, los sureos concénlricos más pequeños y su forma más oblicua. Ogasa.

\section{ARCA.}

* 59. A. Naranjoana, Verı. et Barr. (Bull. de la Soc. géol. de France, 2c s'irie, 1. 12, 1. 989, 1. 26, 1. 12).-Concha transversa, muy inequivalva, terminada ('u pumta obtusa posteriomente. Lna quilla oblicua redondeada se dirige deste el nales ál li extremidad posterior. Una depresion oblicua, poco pronunciada, ocupa la region central de la concha. Nates poco proeminentes; área poco profunda; charnela igual á la milad de la longitud de la concha, con dientes pequeños, de 10 á 12 en la regrion posterior. La Ballestera, La Cerrata y Solana del Romeral, Almadenejos.

\section{CUCULL开A.}

* 60. C. Caravantesi, Ver'n. el Barl. (Ibid.; p. 990, 1. 27, 1. j).-Equivalva globulosa; estrechada hácia arlelante, ensanchada atrás; contorno casi trapezoidal; superficie regularmente bombeada; nates poco separados, colocados en el tercio anterior; impresion muscular anterior redondeada. Las IJeras de la Pueblat de Don Rodrigo; Solana del Romeral.

\section{NUCULA.}

(i). N. Hopensacki, Vern. et Barr. (Ihid.; p. 989, 1. 28, f. 8).-Conchat transversa más ancha que larga, de nacles terminal; impresiones musculares muy designales, la posterior apenas visible, la anterior muy jrofunda; tres a cuatro dientes delante del nates, mayores y mis oblicuos que los 11 de atris. En los moldes, 
la impresion anterior se presenta bajo la forma de un lubérculo aislado, parecido al de las Redonias. Las N. Beirensis, Sharpe y V. Bussancis, Sharpe son más triángulares y ménos trasversas. Cercanias de Almaden.

* 62. N. Ribeiro, Sharpe (Quurt. jour. geol. Society; t. 9, 1. 149, 1. 9, 1. 15).-Concha pequeña, giobulosa, nates proeminentes; 10 a 12 estrias fuertes de crecimiento; cinco dientes anteriores; unos 15 pequeñitos al rededor del umbo, y 10 posteriores de tamaìo intermedio. Músculo anterior, representado en los moldes por una proeminencia aislada y rodeada por' un surco profindo. Pizarras arcillosas de Fontanesas y Santa Cruz de Mudela.

5. N. Costæ, Sharpe, (Ihil.; 1. 9, I. 4).-0val triangular; impresiones musculares igualmente fuertes; unos 20 dientes cardinales; (i posteriores; los mayores en el centro de cada série. Moldes en Santa Cruz de Mudela.

64. N. Eschwegii, Sharpe (Thil.; I. 9, f. 10).-Oval; una depresion hácia el nates; dientes pequeños, numerosos en la regrion posterior, escasos en la anterior. Huerta del Llano.

\section{REDONIA.}

** 65. R. Deshayesiana, Rouault (Bull. Soc. géol. de France; $2^{\mathrm{e}}$ sirie, $\left.\mathrm{t}, 12, \mathrm{p} .986,1.26, \mathrm{f} .10\right)$.-Concha transversa, equivalva muy inequilateral, nates encorvados, ocupando la extremidad posterior; superficie casi lisa, con estrias desiguales de crecimiento. Abundan los moldes interiores, que son notables por uni especie de pilar en forma de cuna hajo el nates de cada valva en el sitio que ocupaba el músculo anterior, el cual estaba separado de la cavidad general de la concha, por una lámina vertical. Bajo los nates se ve en la charnela algunas canalitas yue recuerdan los dientes muiltiples de las Nuculas; pero que no pulieron servir de medio de articulacion, pues solo se ofrecen, á lo que parece, en una de las valvas. Pizarras arcillosas de la Caracollera, Fontanosas, La Ballestera, Solana del Romeral, Huerta del Llano, Santa Cruz de Mudela, Las Navas, entre Genave y Montiel; Luarea. 
* liti. R. Duvaliana, Rosı. (Ilid.; p. 9187, 1. 201, 1. 11). - Se distingue de la anterior por ser menos inepuilitera, ménos lrasversa, mis bombeada; de nates no ferminales, deshordablos por la laimula y el horde anterior. Los moldes interioges lienen jumbo al nareles la especie de pilar cumpilorme que representa la profunda catvidad donde se alojaha el moscolo anterior; el posterior se halla cerea de la cxteremidad de ha concha. Fontanosas, El Romeral, Inerta del Llano, Panlete, luente de las Orejas, Cerro de Miraflores, al N. de Porzuma, Ilerrera del Duque, Luarca.

\section{ORTHIS.}

* lit. O. primordialis, Vern. el Barr. (Bull. Soc. grol. de Frunce: ze série, 1. 17, p. 52, 1. 8, f. (i).-Concha transversa redondeada á los lados, más ancha que larna; la arista cardinal apenas alcanza los tres cuartos de la anchura lotal de la concha; las dos valvas son proximamente del mismo espesor; profundo seno en la ventral, que produce un pliegue muy saliente en la opuesta. Numerosas estrias dicotomas a los lados, casi simples en el seno. Eu m espacio de $5^{\mathrm{mm}}$ se cuentan siete, a $5^{\mathrm{mm}}$ del nates. Se distinque del 0 . lyns, que tambien tiene dos áreas igualmente desarrolladas, porque la viltima tiene pocos pliegues y no dicotomos. Calizá roja de la fauna primordial de Adrados, Cerecedo y Crémenes (Leon).

* 63. O. calligrama, Dalm. (Th. Davidson. A monograph of the british fossil brechiopoda. The silurian brach.; 1. 240, 1. 5., 1. I i 2.4. The palarontografieal Sociely. London, 1869).-Generalmente más ancha que laroa, teniendo su mayor anchura hicia el medio; redondeada á los lados: valva ventral, uniformemente convexa; nates pequeño retorcido; area de regular anchura; abertura triangular: valva dorsal, ménos profunda que la olra y más convexa en el umbo. Unos 28 pliegues en ambas, simples, radiantes, dejando espacios cóncavos intermedios, cruzados por finas estrias de crecimiento y más señalados hácia los bordes. En el interior de la valva dorsal se marea un proceso cardinal pequeño, deste el vertice hácia el centro, y un ancho pliegue longitudinal separa en dos partes las ricatrices izquierilas. Hucrlit del Llano, Almaden; Puente de las Ovejas á cuatro leguas de Ciudad-Real. 
li9. O. vespertilio, Sow. (Ilbid.; p. 256, I. 50, f. 11 i 21 ). -De corle cuadrado, redondeado á los lados y esruuinas, con freruencia prolongada en la region cardinal, donde se mide la mayor anchura: valva dorsal convexa y saliente, con un profundo seno que corresponde con un bocel angular saliente en la ventral. Una y otra con numerosas estrias radiantes, finas y dicotomas ó interpuestas, formando á modo de haces de 4 en 40 de 5 en 5 . Esta especie varia mucho en el espesor de la valva dorsal. Se encuentran moldes en las pizarras arcillosas de la Ballestera.

70. O. testudinaria, Dalm. (Ibid.; p. 226, I. 27, f. 15 à 24).-Casi orluicular, redondeada en la region frontal, más ancha que larga; charnela recta y algo menor que la mayor anchura: valva ventral algo elevada hícia el medio, de nates pequeño y retorcido y área estrecha: valva dorsal ligeramente convexa y deprimida hácia el medio: superficie de una y otra con 70 a 30 costillas bastante señaladas en los bordes, procedentes más de la mitad de la interpolacion de las más finas entre las principales que se marcan poco hácia los nates. En los moldes se marcan muy bien las impresiones musculares separadas por las láminas braquiales, y $\mathbf{1 1}$ punteado muy fino procedente de las granulaciones de la superficie interior de las valvas, carícter muy comun en las leptenas, pero raro en los orthis. De Verneuil y Barrande refieren á esta especie el 0 . Bussacensis, Sharpe del silur. inf. del vecino reino. Fontanosas, la Ballestera, cercanias de Almaden y Almadenejos, Herrera del Duque.

\section{ORTHISINA.}

" 71. O. vaticina, Salter. (Bulletin de la Soc. géol. de France, $2^{\mathrm{e}}$ série, 1.17, p. 555, 1. 8, f. 8.) - Concha casi cuadrangular, ligeramente escotada por bajo de las extremidades laterales: longitud tres cuartos de la anchura: valva ventral doble en espesor que la dorsal, con una área doble en altura: abertura interesando las dos valvas, y en parte cubierta por un deltidium: en la punta del nates existe un foramen finisimo, apenas visible: las valvas, regularmente bombeadas, no tienen seno mareado. Adornan la superficie estrias finas, dicotomas, con espinas tubiformes hasta de $2^{\mathrm{mm}}$ de longitud en la valva ventral. Longitud $18^{\mathrm{mm}}$, lat. 24, esp. 8. Fau- 
na primordial al N. de Sabero, en Mdrados: Corniero, la Velilla, Valdoré y Vozmediano.

72. O. Pellico, Vern. el Bar'. (Tbid.: p. 5.5., 1. 8, 1. 7.)-Bastante pequena, transwersa; un cuarto mis anchia que larga, de corte cuadrado en sus extremos: la arista cardinal alcanza la mayor anchura de la concha: valva ventral, dohle profumdia que la dorsal, con una área doble en altura que forma un ángulo recto con la arista cardinal: la abertura está cubierta en parte por un détidium rue haja de la punta del nates y que apenas lleca a tocar á la olra valva. No hay seno en ninguna, y la comisura no tiene contornos ondulados; 5 a 4 estrias principales a los lados y 2 a 5 intermedias más finas. La region central está limitada por 2 estrias pronunciadas, entre las que se distinguen 2 a 5 más finas. Asociada á la anterior.

\section{STROPHOINENA.}

75. S. antiquata, Sow. (sp). (Mac Coy: A systema descr. of the hrit. paleruz. fos in the geol. Huseum of the Univ. of Cambr.; p. 241. Orthis antiqualn, Sow.) - Charnela tan larga como la mayor anchura de la concha; 5 a 4 lineas de crecimiento, escamosas, muy pronunciadas, interrumpidas por costillas radiantes desiguales, más gruesas á los lados que en el centro. Calizas del silur. sup. del castillo de Asnaron.

\section{LEPTÆNA.}

74. L. sericea. Sow. (Ibid.; P. 257.)-0hlonga trasversalmente; charnela algo mís ancha que la mayor anchura de la concha: valva ventral convexa, con un nates retoreido muy perfueño: valva dorsal cóncava, siguiendo la curvatura de la opnesta, con área muy estrecha: superficie de ambas con finas estrias redondeadas; unas 50 principales y otras muchas interpuestas de 6 en 6 . Interior de la valva ventral con depresiones musculares divididas por un r'eston central en la parte posterior; interior de la valva dorsal con una inipresion muscular ancha, dividida a uno y otro lado en dos pares alargados. Almaden, el Viso de Círdenas. 


\section{CHONETES.}

75. C. striatella. Dalm. (sp). Orthis striatalla, Dalm. Th., Davidson: A monograph of the brit. fos. brach. The silur. Irach. p. 551, 1. 49, f. 25 á 26. (Paleontografical Sociely). - Más ancha que la longitud de la charnela; extremidades agudas; redondeado á los lados: valva ventral convexa regularmente, deprimida hácia las orejetas; nates pequeño; área estrecha; abertura pequenia con un pseudo-deltidium; valva dorsal cóncava; superficie de ambas valvas con numerosas estrias radiantes, hasta unas 80 en el borde, interponiéndose muchas pequenas entre las principales; 4 espinas tubulares a cada lado en la charnela de la valva ventral. Umbria de la Cerrata, Almadenejos.

\section{DISCINA.}

76. D. primæva. Vern. et Barr. (Bull. Soc. géol. de Fran$c e, 2$ e série, t. 17, p. 532, 1. 8, f. 2).-Concha muy delgada, córnea, traslucida, de color amarillento, ligeramente bombeada, orbicular, de contorno redondeado, con estrías concrintricas muy finas y 5 estrias radiantes del vértice hicia atras. Fauna primordial al N. de Sabero.

\section{OBOLUS.}

* 77. O. filosus. Hall (sp).=0rbicula? filosa, Hall. (PalreontoInyy of New-York; 1. 1, 1. 99, 1. 5. 1. 9.)-Casi orbicular, aplastada, reluciente, casi córnea, negruzca, esfoliacea: estrias radiantes, muy finas, regulares, entre las que se interponen otras más delgadas. Los individuos jóvenes son muy hombeados, y se hacen cada vez más deprimidos á medida que se desarrollan. Nuestros ejemplares son de doble tamaño que la especie tipo americana. l'izarras arcillosas de la Iluerta del Llano, Puente de las Ovejas, la Ballestera.

78. O. Bowlesi. Vern. at Barr. Bull. Soc. gíol, de France; $2^{\mathrm{c}}$ série, 1. 12, 1. 995, 1. 26, l. 9).-Estriada, esfoliacea y de 
una lextura casi córnea como la anterior, se distingue de ella por su forma más alargada: una valva parece más hombeada pue la otra, y ambas son mits resistentes hilcia el medio, donde se senala un saliente simétrico, en el pue se reconocen las liminas del aparato braquial. P'uchla de D. Rodrigo, la Ballestera, Fuenlabrada.

\section{ECHINOSPH闆ITES.}

* 79. E. Murchisoni. Vern. et Barr. (Ibil.; 1. 26, f. 7).-Cáliz ensanchado en la parte superior, y terminado en la inferior por una especie de tallo ó pediunculo algo encorvado. Su seccion trasversal es circular $\dot{o}$ casi eliptica, y se compone de un numero considerable de planuitas exicgonas, cubiertas de granulaciones salientes i) cohmmitas tendidas muas sobre otras. Destacadas estas plaquitas, yneda una superficie tranulosa, indicio de agujeritos ó puntos hundidos en el interior de aruellas. Solana del Romeral, Almadenejos. Luarca?

\section{TROCHOCISTITES.}

* 80. T. bohemicus? Barr. (Bull. Soc. géol. de France; $2^{\mathrm{c}}$ série, t. 17, p. $557,1.8,1.1)$-Contorno eliptico, formado por ma série de escudetes que recuerdan las llantas de una rueda de 7 a 9 en número; escudetes interiores, mucho menores y exagonales. Fauna primordial al N. de Sabero.

\section{SYNOCLADIA.}

81. S. hypnoides. Sharpe. (Ouart. Jour. giol. Sociely; 1. ?, 1. 147, 1. 7, f. 10j.-CRamas parecidas à muswo de un tejido de maIlas; cada rama lormada por dos filas de celdillas, separadas unas y otras por depresiones profumbas. Dehesa de Castilseras, Almaden; Cumbres de Santa Eufemia (Córdoba.)

\section{MONOGRAPSUS.}

* 82. II. Nilssoni, Barr. (sp).= Graptolites temuis, Portl. (II. B. Geinitz: Die Graptolithen, ein Honograplischer versuch zur. Bc- 
reurtheilung der Granuaclienformation in Sachsen; p. 55, I. 2, f. 17 a 20, 24, 25, 28 i 32). - Huy delgado; celdillas comparativamente anchas y muy separadas entre si; su márgen inferior larga, recta, formando un ángulo con el eje de 20 a $50^{\circ}$; su márgen superior la mitad de larga, ligeramente cóncava, casi horizontal. Por término medio hay de una a dos celdillas por milimetro. Silur. sup. (1) Corral de Caracuel, Arroyo del Lapiz, El Chorrillo, Almaden.

* 85. IVI. latus, Iac Coy (sp). (Ihil.; p. 59, I. 2, I. 57 y 58 ).Recto de 5 a $5^{\text {mm }}$ de anchura: celdillas muy pequeñas, triangulares, ligeramente encorvadas, no excediendo su longitud del ancho de su base, sin llegar cada ma a $1^{\mathrm{mm}}$ de extension. En muchos ejemplares se divisan las lineas inclinadas, que bajan desde cadla celdilla hasta el eje. Corral de Caracuel.

84. M. Halli, Barr. (sp). (Ibid.; p. 41, I. 5, l. 5 á 8).-De menor anchura que el anterior: celdillas apretadas, redondas y rematadas en punta, normales ó casi normiles al eje. Puente Horeno, sobre el Jabalon.

* 85. Mr. Becki, Barr. (sp) $=$ = Graptolites lobifernus, Nac Coy (Ibid.; p. 41, 1. 5, f. 12 a 19).-Recto, como los anteriores; de 2 á $5^{\mathrm{mm}}$ de anchura; de celdillas en lobas redondeadas, por término medio 2 en la extension de 5 milimetros. Arroyo del Lapiz, Corral de Caracuel (Ciudad-Real), Ciñera (Leon.)

* 86. MI. Priodon, Bromn $(\mathrm{sp}) \cdot=$ Graptolites ludensis, Murch. (Ibid.; p. 42, 1. 5, f. 20 a 27). -Celdillas más apretadas que en el anterior, más profundamente separadas, encorvadas y casi tubulosas en su remate. Gargantiel, Almaden.

* 87. III. convolutus, Hisinger. $(\mathrm{sp}) \cdot=$ Graplolites spiralis, (iein. (Ibid.; 1). 45, 1. 4, 1. 24, 26 a 28, 30 a 35).-En pequeños fragmentos retorcidos en espiral de pocas vueltas; celdillas próximamente normales al eje capilar, y doble de largas que la distancia que separa una de otra. Gargantiel.

(1) Esta especie y las siguientes son de un nivel superior á la fauna segunda. 


\section{DIPLOGRAPSUS.}

* 88. D. palmeus, Barr. (sp).= Graptolites palmeus, Barr. (Ilicil.; p. 21, 1. 1, f. 5 a 19).-Celdillas de corte rectangular en su remate, apretadas y dispmestas bajo un ángulo de tis a $45^{\circ}$ á umo y otro lado de un eje desmudo en su parte superior y muy delgado. Gargantiel.

* 89. D. pristis, Hisinger. (sp). (Ibid.; p. 22, 1. 1, f. 20

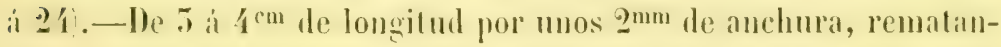
do en punta gradualmente: eje central capilar, á uno y otro lado del cual hay tuhos estrechos comprimidos, produciendo cinco dentelladuras en el espacio de $\mathbf{4}^{\mathrm{mm}}$. Corral de Caracuel.

\section{RUSOPHYCUS.}

90. R. bilobatus, Vanuxem. (sp'. (Hall. Puloentology of' $N$. York; p. 24, 1. 9, f. 1).-Vegetal compuesto de dos lobas separadas en una de sus extremidades, y divididas hácia la otra por un seno profundo: la seccion de cadla loba es oval ó casi cuadrangular; numerosas arrugas transversales, irregulares y algo simuosas por toda la superficie: en algunos ejemplares sale de entre ambas lobas un tallo lelgado, de alqunas pulgadas de longitud, de algo ménos de $I^{\mathrm{cm}}$ de diámetro y muy irregular en su grueso. Silur. sup. Guadalmez.

\section{BUTHOTREPHIS.}

91. B. gracilis, Hall. (Ilbid.; p. 18, 1. 5).-Planta delgalla y frácil, con numerosas ramas irregularmente divergentes, à veces reuratadas en punta de 1 a $4^{\mathrm{mm}}$ de anchura. Silur. sup. Almaden.

\section{CRUZIANA.}

92. C. Bronni, Ronault. (sp). Freme Bromni, Rou. Prullo.

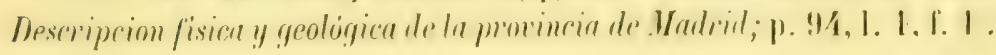


-Surco central profundo, con aristas poco regulares, tendiendo á bifurcarse, pero sin interrumpirse; la direccion de estas y de las estrias que las separan varia hasta llegar á ser paralela al eje en unos puntos, mientras que en otros es muy oblicua y en sentido inverso: su long̣itud debió ser considerable y su anchura llega hasta $10^{\mathrm{cm}}$. AI N. de la Puebla de la Mujer Muerta (Madrid), Santa Cruz de Atea (Zaragoza).

* 95. C. Prevosti, Rouault. (sp). Frena Prevosti, Rouault. (Ibid.; 1. 1, f. 2).-Bilobada por un surco más ancho que profundo, de apariencia anular, á causa de ensanches poco distantes entre si; con crestones salientes de direccion muy variable. El Atazar (Madrid). Santa Cruz de Atea (Zaragoza). .

* 94. C. Torrubiæ, Prado. (Ibid.; p. 95, 1. 4, f. 20).-Ciun tres junquillos paralelos, de los cuales salen á uno y otro lado otros oblícuos, paralelos y alternados, que figuran como tres ramas sin hojas, siendo la superior la más ancha. El Atazar.

* 95. C. Ximenezii, Prado. (Ibid.; 1. 1, f. 4).-Cuerpo algo achatado, separado en dos por un surco central, con estrias oblicuas que parten en sentido inverso de aquel: en el horde de la derecha tiene dos cordoncillos separados por un surco medio. El Atazar.

* 96. C. Carpetana, Prado. (Ibid.; 1. 1, 1. 5).-Trilobada por dos surcos longitudinales, lisa y sin estrias. Puebla de la Mlujer Muerta.

* 97. C. Murchisoni, Prado. (Ibid.; p. 26, 1. 1, f. 6).-Cilindroidea, unilobada y lisa, compuesta de dos partes, una interior y otra exterior á manera de corteza. Asociada á las anteriores.

* 98. C. Cordieri, Rouault, (sp).=FranaCordieri, Ron.(Bull.

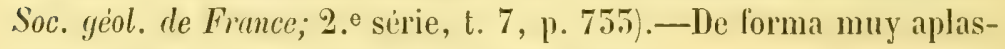
tada, dividida en cuatro partes, bien marcadas por tres surcos; las partes laterales extermas son redondeadas, y las estrias que la cubren muy finas y sin traza de bifurcacion. Santa Cruz de Atea. 


\section{SCOLITHUS.}

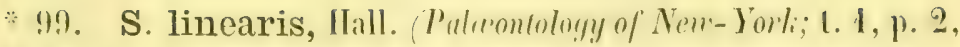
I. 1, f. 1).-Tallo cilindrico, rectilineo, liso o ligeramente estriado; de warn longitud relalivamente á sull dimetro, que por termino medio es a te imm. Se presenta enclavado á distancias uniformes en las cuarcitas de Used, Pnesto de Acered y Santa Cruz de Atea.

100. S. verticalis, IFall. (Ihil.; 1. 2, p. (i, 1. 2, 1. 5).-Wuy parecito al anterior, del cual no se distingue más que por su posicion perpendicular á los estratos. Asociado al anterior.

Reducido es el numero de las especies silurianas determinadas hasta el dia; pero á ellas se podrán ag̣regar, cuando se obtengan ejemplares hien conservados, otras varias, entre las cuales senaliremos las siguientes:

1. Dos ó tres especies de Agnostus, una parecida al $A$. inleger, Barr; Leperditiu, lal vez la $L$. salvensis, Jones; Capulus, con surcos concéntricos al vértice, el cual inclina hácia adelante; un braquiopodo, quizás constituyendo un género nnevo, distinto del Siphonotrefu, por su concha lisa y caliza, procediendo todos de la fauma primordial de la cordillera Cantábrica.

2. ${ }^{\circ}$ Varios (rithoceralites, entre ellos uno de sifon pequeño y central y de tabiques separados, parecido al 0 . regulturis, recogidos en las pizarras de Sierr'a-Morena.

7. Algunas Vuculas, que ademas de las citadas, se hallaron pu Bussaco (Porlunal) y fueron descrilas por sharpe en el (hutrtely dourmel yeol. Sirce, I. 9. Sospechamos la existencia de la X. Beirensis, N. Ezquerre y N. Maestri en las cercanias de Almaden.

4." Varias especies tal rez nuevas, alemas de las descritas, pertenecientes al género Comzina, y muy ahundantes en los crestones de arenisca y de cuarcita que constituyen las sierrecillas, bajo las cuales so extienden las pizarras de la segunda fauna, y que pueden encontrarse en la Puebla de la Mujer Mnerta (Madrid); Cerca de Tatmames, rli la Sierra de Francia (Salamanca); Iospital del Olbispo, en el rentro de la Sierma de Guadalupe, Sierras de San Pedro y Sin- 
tiago (Cíceres); Castuera (Badajoz); Castilseras, Sierra de la Cárcel, de la Vírgen del Castillo y otros puntos inmediatos á Almaden; Brazatortas, Puente el Fresno, etc. (Ciudad-Real): Puerto de San Pablo y otros puntos de los montes de Toledo; Murero, Villafeliche, Used, Santa Cruz de Atea (Zaragoza).

5. Ademas de las Cruzianas y Scolithus ya anotados, otros restos vegetales correspondientes à los géneros Foralites, Tigilites y Myrianites, descubiertos en la provincia de Zaragoza por mi querido Jefe y amigo D. Felipe M. Donayre.

6. ${ }^{\circ}$ Una lingula, varias bivalvas, entre ellas tal vez la Dolabra elliptica, Mac Coy, y otros cuerpos incerter serlis, encontrados por Prado en la provincia de Madrid. 


\section{SISTEMA DEVONIANO.}

El sistema devoniano es uno de los que más importancia paleontológica ofrecen en España, habiendo hasta la fecha suministrado mayor número de especies que el siluriano, en una extension total que apenas llega a li vigésima parte de la de este último, al cual, en superficies casi siempre muy reducidas, acompaña en las diversas regiones en que más atrás le dejamos señalado. Su depósito principal es el que á uno y otro lado de la cordillera cantábrica ocupa una parte de las provincias de Leon y Asturias, investigatas por los Sres. Prado, De Verneuil, Schulz, Paillette y otros geólogos. En la segunda provincia empieza al Oeste del concejo de Somiedo y del valle de Tuna; llega hasta cerca de 'Tineo, y pasa por Salas y Pravia, en cuyas cercanias termina su limite occidental, en contacto siempre con el siluriano. Desde la ria de Pravia sigue la costa por el caho de Peñas hasta cerca de Gijon, con frecuencia interrumpido por formaciones posteriores, que en el centro de la provincia y á cortas distancias de la Capital se intercalan, haciendo diversos entrantes y salientes. Continúa el limite oriental su marcha sinuosa al Sur de Tudela y Morcin, al Oeste de Riosa, Quirós y Peña Obiña, penetrando por el puerto de la Ventana y no lejos de Pajares en la provincia de Leon. En esta, el mismo manchon, de contornos muy irregulares por la parte del Este, continúa á derecha é izquierda de la carretera, que liga ambas provincias desde el puerto de Pajares hasta la Pola de Gordon, siendo muy rica en fósiles la reguion inmediata á Sabero, en contacto con la fauna primordial, y cubierli por el carbonifero y el cretáceo. Los términos de Aidrados, Mleje, Alejico, Colle, Crémenes, La Velilla, Las Peñotas, Peña Corarla, liobedo, Valcueva, Valdoré y Veneros, minuciosamente explorados por l'rado, suministran una gran parte de las especies que mencionaremos. 
Así como en el sistema siluriano son las pizarras arcillosas la roca dominante y escasean las calizas, en el devoniano sucede la inversa. La caliza es el principal elemento en el manchon que acabamos de reseñar, y en ella es donde se presentan los mejores fósiles, sobre todo en las localidades leonesas, y en Ferroñes y Arnao, donde es bastante arcillosa y pasa á una marga más ó ménos impregnada de hidróxidos de hierro. La arenisca roja es tambien muy frecuente, y en ambas provincias se halla tan cargada de la sustancia mineralógica que acabamos de citar, que constituye verdaderas menas beneficiables. La arenisca gris ó parda y las grauwackias abundan tambien; pero ambas rocas son muy pobres en restos ortsánicos, asi como las pizarrillas arcillosas con ellas alternantes.

A este depósito principal deben ligarse, por bajo de la caliza carbonifera, otros dos afloramientos, ya de mucha menor superficie, pero todavia ricos en fósiles (casi todos recogidos por el mismo Prado) al Norte de Cervera de Rio Pisuerga, en los confines de Palencia y Santander, y pronto tendremos que repetir muchas veces las localidades de Levanza, Mudá, Valdebreto y Vergano, donde las calizas siguen siendo la roca dominante.

Pasando á los confines de Extremadura, Córdoha y La Mancha, hallamos diferentes puntos, en los cuales Prado y De Verneuil nos señalan el sistema con abundantes especies. En Guadalperal, Chillon, Casa de la Vega y otros sitios de las cercanias de Almaden, existen representantes muy reducidos entre el siluriano, con el cual parece alternar el devoniano, á causa de los numerosos pliegues que se presentan. La roca dominante es la arenisca ferruginosa, en la yue se ofrecen tambien fajitas intercaladas de caliza impura. En idénticas condiciones se encuentran otros islotes devonianos, que en el Bosquejo geológico de la Península por De Verneuil y Colloml vemos dibujados entre Almaden y Santa Eufemia, al Norte de Cabeza del Buey y en los términos de Fuenlabrada y Ilerrera del Duque, donde dominan las calizas.

Añadiremos, por nuestra parte, que en la provincia de Cíceres deben corresponder al sistema varias capas de caliza y arcilla endurecida, que solorepuestas à unas pizarras más ó ménos melamorlosearlas que á su vez se hallan en contacto con el granito y relacionadas intimamente con criaderos de fosforita, se presentan en la capital, y sobre todo en la Aliseda, con diversos fósiles.

Segun las investigaciones de E. De Verneuil, Mr. Jacquot y otras 
lecientes pue pronto se harán publicas por esta Comision, en la provincia de Cuenca existen ofros manchoncilos de reducidas superfiries, a saber: $m$ inmediato i Ilinarejos, en el cerro del Ilierro, que ya por su nombre indica el mineral que le caracteriza; otro al Sur de Iligneruelas; ofro entre Talayuelas y Garaballa, al pie del pico Ranera; y otro, el mas importante en extension, en el térnino de Bonillas. Las rocas que componen el sistema son areniscas y calizas arcillosas fosiliferas, acompanadas de cuarcitas de colores claros y filadios cloríticos.

En su Mapa greológrico de la provincia de Teruel señala el señor Vilanova otro deposilo devoniano, entre la Hoz de la Vieja y ArmiIlas, cubriendo al N. E. al siluriano, y cubierlo a su vez al S. O. por el trias, bajo el cual debe extenderse para reaparecer, segun la misma alineacion, en los confines de arpuella provincia y la de Zaragroza, representado por la faja de Luesma, Fombuena y Nogueras, donde el Sr. Donayre consiguii reconer algunas especies bien conservadas.

Otro afloramiento de menor importancia se halla junto i Atienza (Guadalajara).

En los Pirineos, si bien en las provincias de Gerona y Lérida es donde el sistema devoniano ofrece su mayor desarrollo, apoyado directamente sobre el granito y cubierto por formaciones más recientes en varios puntos que, segun tenemos entendido, son en la actualidad objeto de interesantes estudios, no falta en otras, y desde lucgo merece citarse, una faja que apareciendo hácia Roncesvalles Navarra), penetra en Francia, y principalmente los depósitos ancilogos en la de Huesca, en la cual el Sr. Donayre y yo le hemos visto ocupando una extension mayor todavia que la señalada en el Bosquejo de los Sres. De Vernenil y Collomb. Aunque bien pohre en fósiles, hace tres anos le encontramos en la parte $\mathrm{N}$. del valle de Canfranc, en cuyas rertientes le cubren el cretáceo y el ummulitico, y recienles investigaciones me lo han hecho ver inmediatamente solsrepuesto al granito en el valle de Tena, entre Pueyo, Panticosa, Escarrilla y el Puerto de Sallent, y comprobar su desarrollo notable en los valles de Bielsa, Gistain y Benasque, donde le señalaron hace ílgum liempo los ilustres geólogros De Verneuil y de liaysserlingू. La rocia dominante signe siendlo la caliza, que alterna con pizarras mis i ménos metamorfoseadas.

Casi fodas las especies que vamos í describir, corresponden al 
devoniano inferior; algunas son comunes tambien al devoniano medio, pero el superior tiene poco desarrollo. Sin embargo, este último se encuentra en la Collada de Llama (Leon), formado por margas pizarrosas con rinones ferruginosos.

No indicando expresamente el horizonte, entiéndase que la especie corresponde á la parte inferior.

\section{PROETUS.}

* 101. P. Cuvieri, Steininger (Mém. Soc. géol, de France; I. 1, p. 555. Bronn: Lethaea geognostica; 1. IX², f. 7). -La cabeza ocnpa poco más de $1 /$ de la longitud total; borde frontal ancho, terminado en un ángulo genal redondeado; glabela deprimida, de forma casi rectangular, redondeada por delante; surcos anterior y medio muy cortos; surcos posteriores redondeados y pequeños; ojos salientes, pequeños y lisos. El torax ocupa próximamente la mitad de la longitud total; tiene $\mathbf{1 0}$ segmentos, y su eje es algo más ancho que las pleuras, que se hallan divididas en dos partes desiguales por un surco á ellas paralelo. El coccix ocnpa algo ménos de $1 / 4$ de la longitud total; tiene de 7 á 8 segmentos en el eje, que es saliente y redondearlo, y está rodeado de un limbo plano ó casi cóncavo. Caliza de Colle, arenisca parduzca de Valdoré (Leon). Arcillas amarillentas y color de heces de vino endurecidas por su proximidad á las dioritas y criaderos de fosforita de la Aliseda (Cáceres).

\section{PHACOPS.}

$* *$ 102. Ph. 1atifrons, Bronn (sp) $=$ Calymenelalifrons, Bronn。 (Bull. Soc. géol. de France; $2^{\text {e }}$ série, t. 7, p. 167, 1.5, f. 1 y 2).-Caheza con fuertes granulaciones; glabela muy grande, ocupando los dos tercios de la cabeza, y plegándose por debajo de tal modo que la sutura frontal, donde se adhiere el epistomo, se halla inferiormente it algunos milimetros de la extremidad anterior. Entre la glabela y el anillo occipital hay dos tubérculos pequeñitos lịados por un crestoncillo poco marcado: ojos muy desarrollados compuestos de 70 a 80 lentecillas salientes, encajadas en un marquito exigono. Torax con granulaciones más finas que las de la cabeza; de eje rom- 
puesto de 11 segmentos, enfre carla mo de los condes se percibe muy desarrollado el grion destinado a pasar bajo las articulaciones en los diversos movimientos del animal; plenras divididas en su mitad inferna por un surco on dos fajas, ma anterior estrecha y lisa, otra posterior elerada y tramulada. Coceix sramulado como el torax, redondeato y compuesto de 7 artirulariones en el eje y 5 á los lados; estits hltimas, soldadas entre si, desaparecen antes de llegar al márgen. Esta especie es comm al devoniano medio é inferior. Arnao (Asturias, Meje; Colle; Corniero; las Penotas; Sabero; Trespando; Valdore; Vozmediano; pizaras negras de la orilla izquierda del Esla, bajo la Pena del Cuervo (Leon). Herrera del Injue (Badajoz). Castillejo y Guadalperal, Amaden (Ciudad Real). Cerro del Hierro, Hinarejos (Cuenca); Valdebreto; Indá (Palencia). Camla el Gallo, Llerena (Badajoz).

\section{DALMANTTES.}

** 105. D. calliteles, fireen (sp).=Crypherus calliteles, Green. (Ibid; p. 164, 1. 5, 1. 5).--Cabeza redondeada, adelgazada en la regrion frontal, con granulaciones ó tubérculos pequeños; glabela ensanchada a partir de la base hasta los los tercios de la longitud, separarla del borde anterior por una márgen estrecha, y dividida por tres surcos laterales en cuatro lobas distiulas: la anterior casi trapezoidal, ocupando más de la milad; las otras tres decreciendo sucesivamente en anchura á medida que se acercan al anillo occipital, el cual está separado de la wlabela por un surco que alraviesa lodo el escudo cefálico. La sulura facial cruza el carrillo a la altura de la lase del ojo, por el cual pasa, y de alıi sigue el contorno de la glabela, termiuando en el borde frontal. Surcos entre la glabela y los carrillos muy pronunciados: ojos, sostenidos por tubéreulos granulados como el resto del carapacho, con umas 150 facetas: carrillos más estrechos que los ojos; puntas gremales prolongadas hasta el 5. ${ }^{0}$ segmento. 11 anillos en el torax, adornados en su parte media, asi como el occipital, de un tubéreulo puntiagudo; pleuras divididas por un surco profundo en 2 partes ignales. Coccix con 11 a 12 anillos en el eje, correspondiendo a cada uno de los a primeros otras i costillas a cada lado, las cuales, divididas por" un surco protumdo, terminan en Im limbo, de domde se destacan is aprondires esponiformes, ligera- 
mente encorvados: tambien el eje del coccix termina en un apéndice de igual longitud: toda la superficie del coccix está finamente granulada. Nuestros ejemplares difieren de los de América por su cabeza algo más puntiaguda, y su coccix más alargado con relacion al torax. Colle; Valcueva; Aleje; Sabero; Valdoré. Levanza. Cerro del Hierro, Hinarejos.

* 104. D. stellifer, Burm. (sp).= Phacops stellifer, Burm. (Ibid; 1. 12, p. 1000, 1. 28, f. 5).-Difiere del anterior por ser el apéndice espiniforme del eje más corto que los laterales, y todos $\mathbf{1 1}$ más delgados. Arenisca de Guadalperal.

* 105. D. laciniata, Roem. (sp).= Pleuracanthus lacinialus, Roem. (Ibid; p. 999, 1. 28, f. 1).-Terminan las pleuras del coccix en cinco puntas espiniformes á cada lado, pero no el eje, cuya exIremidad es lisa aunque saliente. Un limbo delante de la glabela. Chillon. Orbó.

106. D. sublaciniata, de Vern. et Barr. (Ibid; 1. 28, f. 2).No tiene limbo delante de la glabela, que casi alcanza el borde, y cuyos segundos surcos laterales no llegan al dorsal. Cinco puntas espiniformes á cada lado del coccix; las dos últimas más separadas entre si que en la especie anterior, porque el eje es más ancho. Viña de Aillon y Guadalperal.

\section{HOIMALONOTUS.}

** 107. H. Pradoanus, de Vern. (Ibid; 1. 12, p. 168, 1. 5, f. 4).-Cabeza desconocidla. Torax incompleto: los surcos laterales son tan profundos, que las tres lobas se destacan bien pronunciadas, carácter que no es frecuente en el género. El guion de las articulaciones no es del todo liso como en el Phacops latifrons. Las costillas intermedias continuan en las pleuras hasta el punto donde arranca una facela casi triangular, definida por una arista que divide oblicuamente las pleuras, y adornada de elegantes granulaciones que no se ven más que al lente. El eje y las pleuras están cubiertos de numerosos tuhérculos, tal vez restos de espinas, que tienen tendencias á alinearse en filas regulares. El coccix se compone de 10 á 12 
sowmentosen el eje, y 8 i 10 en las articulaciones lalerales, fue son mucho más anchas que el eje. Ia superlicie lleva tubéreulos de dislinto grueso, algumos muy zordos, perforados en su vírtice, donde se insertaban espinas pequenas. El gran tamaño de esta especie sirre para distinguirla de otras parecidas, entre ellas del II. armatus, Burm., especie espinosa del biliel, cuyo coccix es tres veces menor. Guadalperal, Amaden, Colle.

\section{BRONTEUS.}

* 108. B. Castroi, nov. sp.-Entre las varias especies de trilobites recogidas por Prado en la Cordillera Cantibrica (Colle, Aleje, Valdore, Arrados, Corniero, etc.), nos ha llamarlo la alencion por su l'recuencia y sus formas un Bronteus, que deste luego no podia referirse al $B$. Flahelifer, frold, especie del Eifel, cuyo coccix no liene bifurcada la costilla central. Las demas especies devonianas extranjeras no remen como la nuestra sranulaciones y estrias á la vez. En la que ramos a describir se notan estas illtimas bien senaladas, alģo sinnosas, interrumpidas y onduladas hácia el borde 0 limho del coccix, á donde no alcanzan las costillas radiantes. Son estas en número de siete á cada lado y una central, que, en el tercio inferior de su longitud, se bifurca en dos ramales tan anchos como arfuellas, y todas se hallan separadas por depresiones ó surcos, cuya anchura es un tercio de la de las costillas. Llevan esas costillas varias límeas de granos gruesos: una junto al remate del eje, dos a mos $8^{\mathrm{mm}}$ de este, y cu su terminacion parece agregarse otra tercera dispuesta con poca resularidad. El eje del coccix es rudimentario, formado por un tribugulo isósceles, cuya base es casi doble de su altura, de vértice opuesto á aquella redondeado, limitado por dos surcos laterales y otro anterior profundos, y haciendo un saliente central que corresponde a la prolongacion de la costilla del medio. En su relieve, el coccix es convexo en su primera milad, se aplana suavemente haciéndose algo cóncavo hácia al borde, volviendo á levantarse en este último deste el sitio en que se marcan las estrias onduladas. Del torax sólo hemos visto fragmentos de escaso valor. La cabeza, no tan bien conservada como el coccix, es granulosa, pero sin estrias; está limitada por surcos dorsales que delante del occipital llegan à estrecharse mucho divergiendo de alli ripidamente 
hácia afuera, de suerte que la loba frontal es muy dilatada, siendo su anchura triple, de la rue tiene la glabela en su base. Los surcos anteriores están indicados por dos depresiones cortas, anchas y poco profundas; los surcos medios se reducen á dos hoyuelos poco marcarlos, y los posteriores son poco más perceptibles; pero en cambio el surco occipital es más aucho y profundo que los dorsales. Cada ojo está determinado por un arco en semicirculo, en el que sobresalen de 9 á 10 granos, poco menores que los del resto del carapacho y muy salientes los extremos. No tenemos á la vista otra especie del género que presente este carácter. En el anillo occipital se ven otros tantos granos espiniformes, y en el resto de la cabeza hay otros 60 ó 70 tambien muy salientes. En un principio vacilamos en referir nuestra especie á la que, procedente de Nehon, atribuyer'on De Verneuil y d'Archiac al $B$. pabellifer, Gold, y que despues recibió el nombre de $B$. Gervillei, Barr.; pero careciendo esta última de las estrias del coccix, indicaba ya una diferencia notable con la nuestra. De todos modos, todavía nos quedan dudas acerca de sit relacion más ó ménos estrecha con la especie francesa, por otra parte no descrita ni figurada hasta la fecha que sepamos. La siluriana de Bohemia que mas parecida encontramos es el $B$. Haidinge$r i$, Barr., cuyo coccix es casi idéntico, pero cuya cabeza, aunque de. forma muy análoga, lleva adornos muy diferentes, predominando en ella las estrias y escaseando más los tubérculos, y en sus ojos sólo tiene dos puntas oblicuas terminales. Si se diese á los viltimos caractéres ménos importancia, tal vez hubiéramos referido nuestra especie á aquella, cuyo mayor coccix tiene, segun II. Barrande, $32 \mathrm{~mm}$ de longitud por $\mathbf{4 0}$ de anchura, mientras que nuestros ejemplares suelen ser de doble tamaño. Si, en definitiva, estos corresponden á una especie nueva, les proponemos el nombre de Bronteus Castroi como débil muestra de consideracion y respeto al digno Director de la Comision del Mapa geológico de España, D. Manuel Fernandez de Castro.

\section{SERPULA.}

109. S. omphalotes, Gold.(Petrefacta Fermanice; 1. 1, p. 210, 1. 67, f. 5.)-1luy pequeña, lisa, algo comprimida y planorbiforme; compuesta de 5 vueltas, la úllima muy ámplia, con una boca recta, oval. Diámetro 2 a $4^{\mathrm{mm}}$. Ferroñes. 


\section{ORTHOCERATITES.}

110. O. Jovellani, Vern. el di. Irel. liuil. Sure giol. de Frence; 2 e série, 1. 2, p. 4(i1, 1. 15.)-Concha muy grande, casi conoide

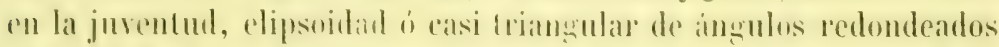

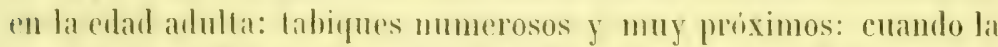
roncha liene 2em de diametro, hay 8 en lat alluma de $2 \mathrm{~cm}$, y cuando anpuel es de 9, solo bay 4 en la misma altura. Son ligeramente rincaros, de hordes algo sinuosos en el ángulo redondeado en pue se halla el sifon y hacia el medio del larlo mayor que le es opuesto. Sifon matreporiforme, siluado cerea del borle en el ingulo opuesto al lado mayor, ligeramente eliptico en su seccion, radiando de su eje numerosas laminitas estrechas y apretadas. En el sitio en que el sifon atraviesa cada tabique, la pared de este se tnerce, forma un canal que se estrecha hicia el medio de cada cimara, y produce una angostura rne da al sifon ma disposicion en rosario. Esta especie atcanzaria una longitud hasta de 2 metros, talla de otro Orthoceras 1) trintyuluris, Verti. el d'Areh, que se distingue del nuestro por su sifon simple y colocado hácia el lado mayor de la pirámide. Ferroìes.

111. O. vermicularis, Vern. (Jurchison, de Vemenil et de Leyserling: Criolonge de la Russie d'Europe de des montugnes de l'Oural: 1. 2, p. 555, 1. 25, f. 4).-Concha recta y cónica, tabiques numerosos, ligeramente cóncavos, ádistancias de $2 \mathrm{~mm}$ : sifon central, en forma de rosario, sin comunicacion con las cimaras, siendo su dianetro $=1 / 6$ del total de.Ia concha. Casa de la Vega, Chillon.

\section{CYRTHOCERAS.}

* 112. C. Lujani, Vern. et Barr. (Bull. Soc. yól. de France; 2r serie, 1. 12, p. 1001, 1. 27, f. 1). - Concha en forma de un tuloo liqeramente encorvado, de contorno un poco eliptico, no excediendo en un venteavo el liámetro mayor al menor: sifon pequeño, central. Los labiqnes tienen en profundidad alwo menos de ${ }^{1}$ : de su diámetro. Adermanla estrias longitudinales, filiformes. espaceadas 
$f^{\mathrm{mm}}$, entre las que se distingnen estrias transversas más finas y apretadas, un poco oblicuas y torcidas hícia la abertura al pasar por la region ventral (convexa) de la concha. Un tubérculo, casi imperceptible, se destaca en el cruce de las estrias, y ademas se observan algunos anillos anchos transversos, separados y medio borrados, que siguen la misma inflexion que las estrias. Calizas de Herrera del Duque.

\section{TURBO.}

* 115. T.? subcostatus, Gold. (sp). = Natica subcostala, de Verin et d' Arch. = Neritu subcostatt, Gold. (Transactions of the geologrical Sociely of London; $2^{\mathrm{e}}$ serie, 1. (i, p. 566 , 1. 54, f. 5 y 6).-Cilobular, de espira corta, compuesta de 5 á 6 vueltas; la villima compone la casi totalidad: sutura profunda, arrancando desde ella plie"vues oblicuos, que se bifurcan hácia el medio, intercalándose á véres otras simples. Boca ancha, semilunar, oblicua al eje, redondeada en sus extremos; borde columelar deprimido, cubierto por una caHlosidad en ángulo recto con el labio derecho que es muy dilatado. Guadalperal.

\section{PLEUROTOIMARIA.}

* 114. P. catenulata, de Vern. el d' Arch. (Ibid; p. 359, 1. 52, f. 17).-De espira corta, compuesta de 4 vueltas ligeramente convexas; adornadas con 6 a 7 estrias transversales, cruzadas por otras más finas de crecimiento; aquellas son de forma de cordoncillo. La base de la última vuelta es convexa, ancha, con numerosas estrias concéntricas. Ombligo muy pequeño; abertura transversa; labio ligeramente arqueado; columnilla saliente. La banda del seno se extiende entre los dos cordoncillos más gruesos situados en la parte inferior. Chillon.

\section{CAPULUS.}

11.). C. compressus, Gold. (sp).=Pileopsis compressu, Gold. Petrefactu Germaniox; 1.5, p. 9, 1. 167, 1. 18.)-Concha lisa y comprimida de modo que su dorso resulta agumlo á modo de quilla. Guadalperal. 
* 116. C. priscus, Gohel. (sp).=Pilropsis priscu, liold. (Ibid; 1. Llii, f. 1.)-llís pequeno y reloredib que el anterior, de superficie muy rugosa por las mumerosas astrias concentricas de crecimienlo casi lamelares; i veces con lubérulos y pecas crateriformes. Sabero.

117. C.? cassideus, d'Arch. et Verm. = Pileopsis cassidea, d'Arch. et Vern. (Trans: of the géol. Soc. of Lundon; $2^{\mathrm{e}}$ série, 1. 5, p. 566, I. 54, f. 10.)-Pequeño, de forma cinica muy oblicua, agudo en el centro de sus ruellas; vérlice relorcido y puntiagndo; aberlura casi eliptica, transversa; paralelis i ellat, estrias finas, entre las que se dihujan lineas de puntos. Guadalperal.

\section{GRAIMTMYSIA.}

* 118. G. Hamiltonensis, De Vern. (Bull. Soc. yéol. de France; 2 e série, 1. 4, p. 696).—El género Grammysia, referido por algunos antores al Corlinia y conservado por otros, está caraclerizado por De Vernenil del modo siguiente: Concha equivalva, inequilátera, no cutreabierta, con dos impresiones musculares muy desiguales; impresion paleal redondeada porteriormente, terminada en la impresion muscular mayor ; ligamento exterior bastante prolongado en la depresion del corselele; superficie atravesada por una costilla ohlicua, que desde el nates baja al centro del borde inferior, y por alounos pliegues concéntricos redondeados. La especie de que nos ocmpamos, encontrada en Chillon por el antor citado, es notible por la auchura de la costilla radiante oblicua, y que mide hasta cerca de $8^{\mathrm{mm}}$ en el borde. Entre las numerosas estrias concéntricas, se distinguen, sobre todo, de 18 á 20 muy marcadas y espaceadas con regularidad.

\section{DOLABRA.}

119. D. unilateralis, Sow $(\mathrm{sp}) .=$ Cucullude unilaterulis, Sow (Mac Coy: A systematic description of the hritish pal. Joss. in the yéol. Mus of Univ. of Cambridge; p. 595).-Rombal oblicua en la juventud, se hace más oval en los adultos; valvas muy bombeadas, la izquierda . mucho más que la derecha; nates muy anchos y proximos entre si; 
recron anal truncarla oblicuamente con un pliewne oblicuo, redondeabo; region bucal uniformemente arpueada, con lineas de crecimiento concéntricas, irregulares; dientes cardinales casi rectos v muy delgados. Puerto del Ciervo, Almaden.

120. D? Damnoniensis, Sow (sp) $=$ Avicula Dammoniensis, Sow. (Ilicl; p. 594).- Alargada oblicuamente, algo llexnosa; valva izquierda más bombeada que la derecha; nates casi terminales; region anal truncada oblicmamente, formando con la charnela un án„zulo de unos $105^{\circ}$; region bucal ligeramente convexa: superficie con estrias finas radiantes: dientes cardinales pequeños y largos. Valmayor, à una legua de Fuenlabrada de los Montes.

\section{CONOCARDIUII.}

* 121. C. clathratum, Gold. (sp) $=$ C'arlium aliforme var. clathrata, Gold. (Trans. of the géol. Soc. of London; $2^{\mathrm{e}}$ série, 1. 6, p. $576,1.56,1.7$.$) - Casi Iriangular, con una espansion aliforme en$ la region bucal; la region opmesla es redondearla; charnela recta; superficie con numerosas costillas rarliantes, cruzadas por estrias de crecimiento muy finas. Adrados; Aleje. Ferroñes.

\section{CARDIUIM.}

122. C. palmatum, fiold. Peliefacte Germanior; 1. 2, p. 207, 1. 145, 1. 7.)-Especie pequena, oblicua, casi rectangular, de region cardinal, en ingulo casi reclo, nolable por no tener más que 8 à ? costillas planas, de 5 a 4 veces más anchas que los surcos que las separan. Dev. sup. asociado á la Posidonomya Pargai. Vern., en la Ciollada de Llama (Leon).

\section{MYTILUS.}

* 125. IM. dimidiatus, Gols. (sp).=Cardium dimidialum. Gold. (Ibid; p. 271, 1. 160, 1. 16.)-Ghillon, Guadalperal. 


\section{AVICULA.}

* 124. A. Paillettei, Vern. el Barr. (Bull. Soc. géol. de Fran$c e ; 2^{\mathrm{e}}$ série, t. 12, 1. 1005, 1. 29, 1. 5).-11ny bombeada, con seis costillas espinosas, las dos anteriores más proximas que las demis; entre ellas, estrias transversas cruzan longitudinales muy finas. Orejeta anterior, separada del resto de la concha por un sureo profundo: orejeta posterior, mis desarrolladia, con estrias transversas, pero sin estrias radiantes, lo que la distingue de las $A$. (Pterinea) costuta, Gold. y A. spinosa Phill (sp). Areniscas y gramwackas de Guadalperal y Chillon.

* 125. A. Leplayi, Vern. el Barr. (Ibid; 1. 29, f. 6).-Muy oblicua y poco bombeada; natcs casi terminales; orejeta anterior corla, casi perpendicular i la linea cardinal y separada de la concha por una depresion bien marcadia orejela posterior perfueña y reilondeada: las dos valvas son poco desiguales en espesor, y estim cubiertas de finas estrias radiantes, desiguales, bastaute separalas. Las A. peroblicua, Conr. y A. subradiala, Sow. lienen lisa la orejeta posterior; esta última se prolonga más allá del cuerpo de la concha en la A. Lineata, Gold. La A. Boylli, Conrad, ofrece estrias transversas que en su cruce con las radiantes se hacen escamosas y festoneadas.-Chillon.

* 126. A. Schulzii, Vern. el Barr. (Ibid; p. 1005, 1. 28, f. 7).-Inequivalva, muy inequilátera, ligeramente oblicna, mas larga que ancha, en la relacion de cuatro a tres, y bastante deprimida: orejeta anterior casi nula; la posterior ménos saliente que la concha, y destacada por una curva entrante bien marcada. Esta especie se distingne fácilmente por la desemejanza de sus valvas: la una es bombeada, con estrias concéntricas linas y espaceadas, señiladas tambien en la orejeta; la otra es plana, con pronumciadas estrias radiantes, redondeadas y separadas por intervalos, cuya anchura es próximamente igual a su espesor, y no indicadas en la orejeta.-Chillon y Guadalperal.

127. A. subcrinita, Vern. el Barr. (Ibid; p. 1004, 1. 29, 
f. 5).-Concha pequeña, globulosa, muy oblicua, muy inequivalva, ligeramente transversa, próximamente $1 / s$ más ancha que larga, alcanzando su mayor espesor mís cerca de la charnela que del borde inferior. Nates terminal; orejeta anterior muy corta, casi perpendirular, y separada por un surco del cuerpo mismo de la concha, en lugar de prolongarse segun la linea cardinal como en muchas aviculas: la orejela posterior, por el contrario, se une con la concha, y sul borde superior es recto. Esta especie es rara, y MIM. De Verneuil y Barrande la fumlaron sobre una sola valva, cuya superficie esti adornada de estrias radiantes, casi iguales, muy finas, muy regulares, separadas por surcos filiformes poco profundos. En el horde se cnentan 11 estrias en el espacio de cinco milimetros. La A. crinita, Roemer, es ménos oblicua; su borde posterior se inclina rápidamente hícia abajo, de modo que la concha parece truncada posteriormente y un ofrece la orejeta lan bien destacarla de nnestra avicula.-Cit'izal de Herrera del Duque (Badajoz).

128. A. lævis, Gold. (Petrefacte Germanice; t. 2, p. 126, 1. 119, f. 1).-Casi lisa, ó con ligeras estrias de crecimiento; una valva algo más bombeada que la otra. Areniscas y calizas de Chillon (Ciudad-Real).

* 129. A. fasciculata, Golil. (sp).=Pterinen fusciculata, Gold. (thid; p. 129, 1. 120, f. 5).-Valvas triangulares muy agulas en los nates, y bombearlas; 12 costillas radiantes en cada una, con cinco í siete entre cada dos principales, todas cruzadas por lineas concéntricas muy apretarlas, formando un estrecho enrejillado. Estas íltimas se marcan tambien en las orejetas; la anterior redondeada, con dos á cuatro costillas radiantes; la posterior triangular, muy desarrollada, con 18 a 20 costillas radiantes, priximamente ignales. Guadalperal, Almaden.

150. A. Neptuni, (iold. (Ihil; p. 118, I. 116, l. 4).-Próximamente tan larga como ancha; trapezoidal, con más de 60 costillas radiantes, desiguales, cruzadas por estrias concéntricas que forman un enrejillado muy prieto. Dudan MII. De Verneuil y Barrande si rarios fragmentos recogidos en Guadalperal y el Puerto del Ciervo (Mmaden) corresponden á esta ó son una especie nueva, muy notable por lo desigualmente adornadas de sus valvas. La una tiene 
costillas radiantes redondeadas y separadas por intervalos dos veces más anchos que ellas; la otra no tiene mis que finas estrias, contándose de 12 a $15 \mathrm{en}$ un espacio de 10 milimetros, mientras que en el mismo, solo se hallan de tres á cuatro en aquella.

\section{POSIDONOIMYA.}

\% 151. P. Pargai, Vern. (Bull. Soc. géol. de France; 2e série, 1. 7, p. 170, 1. 5, f. 3.)-Valvas bastante hombeadas, casi iguales, de vértice puntiagudo ligeramente encorvado hácia adelante, con dos orejetas, la anterior corta: La region posterior se prolouga de modo que da á las valvas una forma oblicua y muy inequilátera. La roncha debió ser muy delgada, pues de ella sílo nos rueda la impresion, que ofrece anillos concéntricos bastante desiguales en su anchura.-En los riñones de arcilla ferruginosa del devoniano siperior de la Collada de Llama, Sabero.

* 152. P. Becheri, Bronn (Goldfuss: Pelrefacta Germanir:; 1. 2, p. 112, 1. 115, f. 6.)-Difiere de la anterior por ser más aplaslada y tener mayor número de arrugas ó pliegues concéntricos. Alosno y otras localidades de la provincia de Huelva. Algumos autores la consideran carbonifera.

\section{TEREBRÁTULA.}

155. T. Archiaci, Vern. (Bull. Soc. géol. de France; $2^{\mathrm{e}}$ série, t. 7 , p. 175, 1. 4, 1. 2.)-Grande, aplastada, casi oval, adelgazarla hácia la region frontal, estrechada hácia la cardinal, lisa, de bordes cortantes y rectos, sin seno ui pliegues. Valva mayor, algo más gruesa que la menor; de nates casi recto, con un forámen muy pequeño en su extremo. Su aparato dentario nos ofrece una disposicion particular que hizo dudar á lo Verneuil si referir esta especie al género Terebrátula o crear para ella otro nuevo. Debajo del nates de la valva hay dos dientecilos rudimentarios, reunidos en el vértire en forma de $\mathrm{A}$, y apoyados sobre una masa tuberculosa compuesta de dos piezas soldadas con más ó ménos fuerza, provislas inferiormente de un surquito que las divide. Debajo de esta gruesa callosidad se destacan 5 costillas, que rematan en punta hácia el cenIme de la valva, parecilas a una horca de tres dientes. La valva 
menor liene junto á la charnela una foseta muy profunda destinada á alojar dicha callosidad, y en el fondo de lá foseta una cresta saliente. Ferroñes, Puerto de Cubiilas (Asturias); Colle; Sabero (Leon); Holdes, algunos parecidos á la T. caiqu, Vern. en Chillon, y à una legua al S. de Almaden. Validebreto y Levanza (Palencia).

* 154. T. Bordiu, Vern. (Ibid; p. 172, 1. 5, f. 8.)-Casi pentágona, lisa, finamente perforadli; bordes delgados; reğion frontal recla; valva mayor, algo más bombeada que la olra, de nates encorvado, con un forámen pequeño, separado de la region cardinal por un deltidimm. La $T$. virgo, Phill, es mís redondeada, y lleva linas estrias longitudinales; la $T$. elongata, Schı, del Harz, es mís redondeada, más gruesa; la reģion frontal ligeramente levantada por el seno de la valva mayor, y en el nates tiene un hoyo que parece ser el resultado de una rotura más bien que mo perforacion uatural. Sabero; Colle.

* 155. T. Schulzii, Vern. (Ibid; p. 175, I. 5, f. 7.)-Menor pero más alargada que la auterior; valva ventral más bombeada que la dorsal, con un pequeño forimen en su nates: longitud $18^{\mathrm{mm}}$, latitul 10; esp. 6. Colle; Sabero; Las Peñolas. Fombuena y Luesma; Nogueras.

\section{STRYGOCEPHALUS.}

131;. S. Burtini, Defr.=Terebratula porrecta, Sow (Murch. de Vern. et de Keyserling: Géologie de la Russie d'Europe el des mont. de l'Oural; t. 2, p. 105, 1. 8, l. 6).-Especie variable, existiendo individuos de nates poco retoreido, y de irea muy elevada, y otros en que aquel forma un gancho muy encorvado. Valva mayor, más frruesa que la menor, muy redondeada en su auchura, y poco segun su longitud; área, muy separada del resto de la concha por aristas corlantes; deltidium compuesto de dos partes soldadas, rodeando enteramente la abertura. Cercanias de Almaden.

\section{SPIRIFER.}

** 157. S. Pellico, de Vern. el d'Arch. (Bull. Soc. yéol. France; $2^{2}$ série, 1. 2, p. 472, 1. 15, f. 1).-Muy transversa, is sea formando 
gramdes alas en la region cardinal, y algo deprimida. Valvas ignalmente profundas: la menor con un nates pequenio, puntiagudo tocando el borde superior del área; ésta muy larăa, cóncava, de bordes casi paralelos; deltidium muy rebajado, compuesto de una límina estrecha, estriada oblicuamente, plegada en forma de tejado, redondeada por encima, flexnosa por abajo, haciendo sobre el área un saliente. Dos granillos situados en el vértice tocan la punta del nates. Abertura triangular, muy rebajada, apoyada sobre la linea cardinal; ángulo apicial, casi ignal á dos rectos; aristas cardinales formando con las aristas laterales un ángulo que varia de $50 \mathrm{i} 55^{\circ}$. Seno ancho, con un pliegue redondeado en su fondo y otros dos poco marcados á los lados. 1 cada lado del seno hay de 15 a 17 pliegues radiantes, separados por intervalos iguales, y tanto mirénos salientes, cuanto más se acercan á la charnela. Valva menor de nates pequeño y retorcido, con un bocel açudo y 17 a 18 pliegues radiantes á cada lado, semejantes á los de la otra valva, cruzados torlos por estrias concéntricas muy finas, apretadas y onduladas, que vistas al lente parecen algo gramulosas, Los mayores individuos tienen $5.5 \mathrm{~mm}$ de longitud, 80 de latitud y 222 de espesor. Se distingue una var. $A$, mónos deprimida, casi fusiforme.-Guadalperal. Ferrones; Trubia; San Claudio, Oviedo. Puerto de Cubillas; Adrados; Colle; Remolina; Valmoroso; Villayandre; Vozmediano; Nleje. Luesma; Fombuena. Nogueras.

158. S. Cytherea, D'orl. (Prodrome de Paléontologie; t. 1, P. 95).-Wuy alargada transversalmente, aguda lateralmente, con 14 rostillas á cada lado del surco. Serí tal rez una var. de la anterior. Ferrones.

* 159. S. speciosus, Schlot (sp).=Terebritula speciosa, Schlot (Mac. Coy: A systematic descr. of the british paleozoic fossiles in the géol. Museum of the Univ. of Cambrilge; p. 576).-Fusiforme transversalmente, dos veces más ancho que largo, valvas bombeadas en su centro; charnela muy larga, rematando aquellas por este lado en dos puntas agudas; bocel proeminente y redondeado, y seno muy profundo. A cada lado de ambos, de 5 á 6 costillas radiantes cruzadas por lineas concéntricas ağudas. Se distingue del anterior por su seno enteramente liso, los pliegues laterales redondeados, ménos numerosos y más anchos que los intervalos que los separan. Colle. Chillon. 
* 140. S. subspeciosus, de Vern. (Bull. Soc. géul. de France; 2e série, 1. 7, p. 179, 1. 4, f. 5).-De tamaño regular, ligeramente transverso, sin pliegues en el seno ni en el hocel; á cada lado de 10 i 12 pliegnes radiantes, redondeados y separados por surcos profundos de junal anchura: el seno y los surcos ofrecen señales de estrias longitudinales microscópicas. El S. speciosus se distingue por su forma más transversa, por sus pliegues ménos numerosos, más redondeados, ménos salientes y separados por surcos estrechos. Vallenegrillo (Ciudad-Real). Ferrones (Asturias). Colle; Crémenes (Leon.)

** 141. S. Rousseau, Rowault. (Ibid; 1. 10, p. 165, 1. 5, f. 1.)-Difiere del S. speciosus por su forma ménos transversa, los surcos más anchos y profundos y las estrías de crecimiento más senaladas. Calizas del cerro del Hierro, entre Hinarejos y la mina de carbon del Vapor (Cuenca). Fombuena y Luesma (Zaragoza). Nogueras ('Teruel). Levanza (Palencia). Entre Sigüenza y Atienza (Guadalajara).

* 142. S. Cabedanus, de Vern. el d'Arch. (Ilid; 1. 2, p. 475, I. 15, f. 5).-Casi globulosa y algo transrersa: valva mayor dos veces más profunda que la dorsal; nates proeminente, encorvado, y puntiagudo; área triangular más ó ménos elevada; abertura triangular, ancha, enteramente libre, limitada por dos láminas lineales: ángulo apicial $=120^{\circ}$. Las aristas cardinales forman un ángulo casi recto con las laterales, que por abajo se encorvan en arco de circulo: seno profundo dividido por un pliegue central, grueso y redondeado hasta la punta del nates; á cada lado del seno hay 12 pliegnues radiantes, redondeados, separados por profundos surcos tan anchos como aquellos. Valva menor semicircular, de nates pequeño; irea muy estrecha con una abertura triangular muy baja; bocel dividido en dos por un surco profundo; 12 pliegues radiantes á cada lado semejantes á los de la otra valva. Long. $=21^{\mathrm{mm}}$, lat. $=\mathbf{5 0}$, esp. $=17$. No hay otra especie en el género que presente un pliegne y un surco en el seno y el bocel respectivamente, en proporcion lan desarrollados como en esta.-Ferrones. Colle; Adratos; Cerro de Yuqueros; entre Candanedo y Orzonaga.

* 145. S. Cabanillas, de Vern. el d'Arch. (Thid; p. 475, $\$ 8$ 
I. 15, f. (i).-Concha casi globulosa, de contornos muy redondeados. Valva mayor, mucho más profunda que la otra; área cincava, arqueada, triangular, elevada, cruzala por estrias perpendiculares y lransversales; abertura grande, cercada i cada lado por una límina mis elevada, cortante y un poco encorvada. Angulo apicial $=93^{\circ}$. Seno ancho, profundo, redondeado, prolongado hasta la punta del nates, que es muy retorcido y puntiagudo; a carla lado de aquel de cuatro á cinco pliegues anchos y redondeados, separados por surcos poco profundos, adelgazirlos hácia da charnela. Valva menor, formando tres cuartos de circulo, con nates bastante elevado para dar espacio í un irea pequeña con una abertura ancha. Bocel redondeado, ensanchado rápidamente hícia la frente; cuatro á cinco pliesues à cada lado. En la superficie de la concha, ademas de estrias finas de crecimiento, se notan, en los ejemplares bien conservados, peiqueñas asperezas puntiagudas. Long. $=22^{\mathrm{mm}} ; \mathrm{lat}=50 ;$ esp. $=14$. EI S. strigoplocus, Vern., del devoniano del Ural, es menor y tiene. estrias microscópicas longitudinales en los pliegrues; el S. scxradialis, Phill, es de área más estrecha y de ménos pliegues; el $S$. insculpta, Phill, tiene estrias lamelosas concentricas. Ferrones; Pelapaya. Colle.

**14\%. S. Ezquerra, Vern. (Ilid; t. 7, p. 178, 1. 4, f. 6).Especie pequeña, transversa, írea estrecha; á cada lado cinco á seis pliegues radiantes, afilados, cruzados por estrías de crecimiento bien marcarlas. El seno y el bocel son tan estrechos, que apenas alcanzan la anchura de dos pliectues. Colle; Sahero; Adrados; Corniero. Ferroñes; Arnao; al N. de Olloniego.

* 145. S. Rojasi, Vern. (Ibid; p. 178, I. 4, f. 4).-De tamaño regular, algo transverso, casi cuadrangular; área poco elevada; seno con un pliegue central borroso; á cada lado de siete á ocho pliegues radiantes, redondeados, separados por surcos de igual anchura, y todos cruzados por estrias transversales festoneadas. El hocel es simple y redondeado, y en el borde ocupa el espacio de cuatro pliegues. Arenisca de fiuadalperal, Chillon. Colle; Meje; La Vid; Crémenes. Al S. de Higueruelas (Cuenca).

146. S. Paillettii, Vern. (Ihil; p. 177, 1. 4, f. 5).-Pequeno y casi triangular; valva mayor de área poco elevarla, á cada lado 
ron cinco á seis pliegues, y uno muy grueso en medio del seno que, con su correspondiente del hocel, forma una punta muy prolongada: estrias longitudinales microscópicas en los ejemplares mejor conservados: valva menor con idénticos pliegues que la grande. Colle, Sabero; La Grisuela; Adrados. Al N. de Olloniego.

* 147. S. disjuntus, Sow. $=S$. Lonsdalii, Murch. $=S$. Vernenili, Murch. $=S$. Archiaci, Hurch.$=S$. calcaratus, Sow. $=S$. inornatus, Sow. (Bull. Soc. géol. de France; t. 11, p. 251, 1. 2, f. 2 i 4). - Especie muy variable, más ó ménos transversa, teniendo su mayor anchura en la charnela que se prolonga en alas muy alarEadas (S. Verneuili, Murch.); ó poco (S. Archiaci, Murch). Valva mayor con un seno profundo en el que se cuentan de 12 a 17 costillas a veces bifurcadas, $y$ a cada lado del cual hay de 20 a 50 algo más sruesas; írea con frecuencia elevada, cóncava, triangular'y estriada; nates por regla general muy encorvado pero sin llegar á la otra valva. Esta tiene un nates poco saliente y un hocel yue como el surco se ensancha rápidamente hícia el márgen, y ya muy pronunciado $y$ angnloso, ya deprimido y redondeado, limitándole claramente dos surcos profundos. Valle Negrillo, Chillon, Puerto de Ciervo, Casa de la Vega y otros puntos de las cercanias de Almaden; Fuenlabradia; Cabeza de Buey. Ferroñes. Colle; Crémenes; La Velilla; La Vil; Las Peñolas; Valmoroso; Veneros. La Aliseda. En Ferques (Francia) caracteriza la parte superior del sistema.

* 148. S. Bouchardi, Murch. (Ibid; p. 255, 1. 2, f. 5.)-Diliere del S. Pellico, de Vern. el d'Arch. por'su menor tamaño, sus esIrias concéntricas escamosas muy pronunciadas, y por un surfuito que divide el bocel. Este es poco saliente; en el fondo del seno hay una costilla poco marcada, y á carla lado de uno y otro, de 16 á 18 costillas bastante gruesas. La var. que se encuentra en el Puerto del Ciervo y Cabeza de Buey es mayor que el tipo encontrado en Ferques donde caracteriza el devoniano superior. Se halla además en Colle; Crémenes; Corniero; Las Peñotas; Veneros. Carril del Zamorano, Herrera del Duque.

149. S. cultrijugatus, Roemer.-Sabero. Guadalperal.

150. S. Trigeri, Vern.-Castillejo. 
151. S. tenticulum, Vern. (Murchison, de Vernenil of Keyserling: Géologie de la Russie d'Europe el des monl. de l'Oural; 1. 2, p. 159, 1. 5, f. 7).-Pequeña, nolable por el desarrollo de su area que es plana y apenas encorvada, ignalando en allura a los " de la long. Lotal. La abertura carece de deltidium, por lo cual se la distingue de la Cyrthin Hispanica, dows., asi como por sus plieEnes radianles, fue son más finos y en uimero de 1 is i 20 á los litdos y 6 i i 8 en el seno. Este es muy profundo, y en cimbio el loocel to es muy poco y soilo esti señalido por 2 surcos un poco mís profundos que los demás. Ang. apicial $=95$ a $100^{\circ}$; long. $=15$ à $15^{\mathrm{mm}}$; lat. $=18$ á $21 ;$ esp. $=7$ á 9 . Chillon.

\section{CYRTHIA.}

* 152. C. Hispanica, D'orl. = Sprivifer heteroclitus, var. it, de Veru. el d'Arch.-(Bull. Soc. géol. de France; 2e série, 1. 2, p. 474, 1. 15, f. 4.)-Considerada desde luego por De Vernenil y d'Treliac, como una var. del Sprififer heterochius, Defr. (sp)., muestra especie es muy variable, presentando generalmente un área muy desarrollada, y de tan diversa altura, que las aristas cardinales se reunen en el vértice bajo íngulos distintos, pero siempre muy abier-tos. Lateralmente, y en la region frontal, esta concha forma un semicirculo sinuoso en su contorno por los pliegues que presenta. Valva mayor doble profunda que la otra; de nates recto, ó inclinado á la derecha ó á la izquierda, á veces algo torcido hácia adelante. Ahertura larea y estrecha, cerrada inferiormente por un deltidium, fur se extiende deste el centro del írea hasta el yértice, y deja ver, en muchos individuos, el semptum central que divide la concha en su interior. De 6 a 8 pliegnes á cada lado; seno y bocel bien pronuuciados, ocupando la anchura de dos pliegues. Guadalperal; Colle; Crémenes; Yupueros; Corniero; Las Penotas; Valmoroso. Ferronies: Muñon de Lena, al $\mathbf{N}$. de Olloniego.

\section{SPIRIGERA.}

* 15.5. S. concentrica, Buch. 'sp).--Terelmulula concintrier, Buch. (Mém. de ln Soc géol. de Firance; 1. 5, p. 214.)-Difiere de la 
signiente por ser ménos redondeada, de seno y hocel más señalados, sin surco central en el segrundo; con mis estrias concéntricas lamelosas, y teniendo su mayor anchura en el medio, mientras que en la $S$. sub-concentrica se halla en el tercio superior. Castillejo y Chillon. Aleje. Fuente de los Moros, Levanza.

* 154. S. subconcentrica, de Vern. el d'Areh. (sp).= Terelratula suboncentrica, de Vern. et d'Arch. (Bull. Soc. géol. de France; 2 e série, 1, 2, p. 465, 1. 14, Ґ. 1.)-Concha transversa redondeada, tendiemdo á alargarse y deprimirse con la edad. Valvas, casi ig̣ualmente profundas, con 9 à 15 estrias concéntricas lamelosas, cutre las que se ven otras más finas, tanto más numerosas cuanto más apartadas están de los nates. Nates de la valva mayor redondeado, poco saliente y poco encorvado, con una abertura ancha y redonda, apoyada sobre la valva dorsal, para cuyo nates se escota el horde cardinal. Angulo apicial $=100^{\circ}$. Aristas cardinales muy corlas, confundiéndose hácia el tercio superior de la concha con las aristas laterales, que son redondeadas y forman con la region frontal una curva continua, elíptica, algo simuosa en el medio, donde se marca ligeramente un seno. A este corresponde en la valva pequeña III bocel apenas perceptible, dividido por: un surco central, que sube hasta el nates. Aleje; Colle; Sabero; C'rémenes; Adrados; La Vecilla; Corniero. Ferrones; por detras de la Peña; entre Proaza y Teberga. Cercones de Carballido, Almaden.

* 155. S. undata, Defr. (sp) $=$ Tereluratula undata, Defr. (Ibill; 1. 12, p. 1008, 1. 29, f. 7.)-Difiere de las dos anteriores por ser proporcionalmente más ancha, de seno y bocel más pronunciados. Los ejemplares de las cercanias de Almaden se presentan al estado de moldes lisos y de impresiones, en las cuales se dibujan las estrías concéntricas que caracterizan estas especies. Se encuentra ademas en Levanza (Palencia). Sabero.

* 156. S. Pelapayensis, Vern. et d'Arch. (sp).=Terahratula Pelapayensis, Vern. el d'Arch. (Ibid; 1. 2, p. 405, 1. 14, f. 2.)-Se distingue de las tres anteriores por su menor talla, su forma más alargada y pentagonal y su ángulo apicial menor que un recto. Las dos valvas son igualmente prolundas y están cubiertas de estrias concéntricas regulares, apretadas, más ó ménos lamelosas y ondula- 
das. Forimen redondo, bastante wramde, tocando i la valva dorsal, que es redondeadia. Seno central poco profundo, prolongado hasta el nates y limitado imperlectamente por los pliegues redondeados, poco senalados; bocel poco mareado, dividido por un surco central ménos profindo que el de lia valva mayor, y con dos ligeras depresiones correspondientes á los dos pliegues de la otra valva. Pelapaya y Ferrones. Colle; Adrados.

*57. S. Campomanesii, de Vern. et d'Areh. (sp).=Teretrittula Campomanesii, de Vern. et d'Areh. (Ibid; p. 165, 1. 14, f. 5).—E's mayor que la anterior, más orbicular, más ancha, más cortante en los bordes, ménos bombeada hácia el centro, de pliegues concéntricos más anchos y más salientes. Abertura redonda, stande, oblicua á la charnela, y tocando por su horde inferior al corchete de la valva pequeña: ésta con mu bocel dividido en dos por un ancho surco central que sube hasta el nates y que produce un escote en la union con el de la crande; á cada lado del bocel hay un surco más ancho, que se corresponde con los pliegues que limitan el seno de lil valva opuesta; y en esta misma, más allá de estos últimos, se veu dos depresiones poco señaladas. Esta especie es bastante variable; alcanza á veces gran tamano; el surco central, casi siempre muy abierto, se hace estrecho y profundo en algunos ejemplares. Asociatda al anterior.

$* *$ 158. S. Ferronensis, de Vern. el d'Arch. (sp).=TerebritIula Ferronensis, de Vern. et d'Arch. (Ibid; p. 466, 1. 14, f. 1).Concha romboidal, con estrias concéntricas regulares, muy tinas, muy apretadas, onduladas, algo lamelosas. Angulo apicial $=85^{\circ}$ : valva mayor de nates ancho, redondeado, apenas encorvado: abertura grande, redonda; aristas laterales muy sinuosas; seno ancho, bien marcado hasta la punta del nates, limitado á cada lado por un pliegue saliente, ancho, redondeado y contimuo, más allit del cual hay otro, tambien á cada lado, que se adelgazan hácia el mirrgen,. dejando intermedias dos depresiones tan anchas $\dot{0}$ más que el seno, viniendo á quedar la valva dividida en cinco partes cóncavas, próximamente iguales, separadas por cuatro pliegues redondeados del mismo errueso. Valva menor con bocel saliente, dividido en su centro por un surco ancho, ménos profundo que el seno, y tambien con dos pliegues laterales, adelgazados hácia el horde. La circunstancia 
de ser más salientes todos sus pliegues haicia el nates, tendiendo a desaparecer hácia los extremos, sirve para diferenciar esta especic de las anteriores. Por lo demas, varia mucho en sus proporciones: hay ejemplares más anchos, yotros mis alargados; en otros los pliewues laterales no se marcan más que en su primera mitad. Adralos; Aleje; Colle; Corniero; Las Peñotas. Levanza. Ferrones; Proaza: Proacin; Candamo: Puerto de Somiedo: Villa-Alegre; Grandemeana.

** 1.59. S. Ezquerra, de Vern. et d'Arch. isp $=$ Tereliralula Ezquerra, de Vern. et d'Arch. (Ibid; p. 467, 1. 14, f. 5.)-Muy rariable en sus proporciones; heptágona, transrersa, deprimida, de contornos angulosos y lobados, y bordes cortantes. Valras igualmente profundas, con numerosas estrias filiformes, transversas, regulares, equidistantes y algo laminosas hácia la charnela. Ang̣ulo aljicial $=126^{\circ}$. Valva yraude con nates pequeño; poco saliente, forámen redondo, locanto el nates de la otra; seno profundo, limitado for dos costillas salientes, redondeadas de iøual @̣rueso desde el nates; desile este mismo arrancan otras dos que forman entre si un angulo obluso, y telerminan en el márgen dos inģulos salientes en la union de las aristas cardinales y laterales; la abertura de estas es de unos $80^{\circ}$. Valra menor de nates muy pequeño, con bocel dividido por un profundo surco, tan ancho como el seno, y limitado por dos custillas semejantes á las citadas, y á otras dos laterales de la misma valva. La superficie de ambas se halla, por lo tanto, dividida en cinco partes róncavas, desiguales y simétricamente dispuestas. Las estrias transversas, de que hemos hablado, se arquean y acomodan a las inflexiones de la superficie. Se distinguen, entre otras variedades, una que es más larg̣a, ménos transrersa, más deprimida, de estrias más finas, más apretadas y más lamelosas. Entre Boniella y Ferrones. Adrados; Aleje; Alejico; Argobejo; Colle; La Robla; Vozmediano.

** 160. S. phalæna, Phill. (sp'=Spirifera phalemu, Phill.= Terebratula Hispanica, Vern. et d'Arch.=Athyris phalena, Dar. Thiel; p. $468,1.14$, f. 6 y 7 . - Concha alada, la mís transversa lel género. Valvas ignalmente deprimidas, de bordes cortantes, con estrias finas concéntricas, onduladas, mis o ménos lamelosas, ig̣almente espaceadas y paralelas. Angulo apicial $=150$ á $155^{\circ}$. Charnela 
recta, formando con las aristas laterales un insulo redondeado de: 20 a $55^{\circ}$. Valva grande de males perpueño. apenas encolvarlo; aberlura redonda tocando el nates de la otra; semo profundr. limilado por dos anchos pliesues redondeados. Valva menor rm mu seno rentral en su bocel, easi lan profundo como el de la olla valva. Long.=22, lat. =5, rsp.=11 mm. Tha rariedarl existe mayor, más transversa y profunda, de estrias mas linas. Ferrones. Adrados; Colle.

* 16il. S. Toreno, Vern. et didreh. su.=Teredratula Tore-

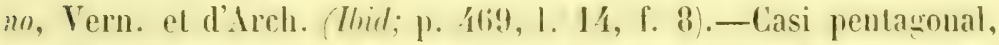
mis o mónos alargida. Valvas ignalmente prolundas, de bordes corlantes; ángulo apicial $=80^{\circ}$. Aristas rardinales ohlicuas. unidas á las laterales por una curva regularmente redondeada; region frontal amcha, ligeramente escolada hicia el medio. Valva grande, de nates poco encorvado; semo poco profundo, limitado por pliencues poco visibles, y con 12 a 24 estrias radiantes, fimas, desiguales, y á reces bifurcadas; estrias concéntricas, irrequlares, mis ó ménos finas. Valva pequeña, con otro seno parecido al auterior, $\dot{c}$ igualmente rayado por estrias semejanles. Lon $x_{0}=25 \mathrm{~mm}$, lat $=20, \mathrm{esp}=12$. Cerro de Ios Palacios. entre Belmez y Espiel Corlola). Ferrones. Fuente de los Moros, Levanza.

* 162. S. Collettii, Veln. sp .=Terehratula Collelli, Vern. Ibid; 1.7, 1. 175, 1. 5, 1. 9.-Considerada en un principio como una var. de la anterior, se distingue perfectamente por la existencia de cuatro costillas separadas por tres depresiones, que en el márgen conresponden i tantos senos entrantes, formando, en suma, un contoruo recortado, que contrasta con el redondeato de la anterior especic. Como ella, esta adomada de estrias radiantes que ocupan el rentro de las valvas, cuyos larlos son lisos. Ferrones. Colle; Aleje.

165. S.? mucronata, Verı. isl, = Relsia mucronalı, Veru. sp). = Terelsululu mucromata, Veru. (Ihid; ). 171, 1. 5, f. (i).-Tiene la forma de un romboedro, resultando las aristas cardinales paralelas i las litlerales; una arisla central en cada valva á modo de cabaHete de tejado, y que la hace terminar en punta; mi nates puntiasudo, separado del borde cardinal por un deltidium. La superficie parece lisa, pero, examinada con atencion, se ven en ella estrias ra- 
diantes muy delicadas $\dot{\delta}$ granulaciones dispuestas en séries lineales. Aparato braquial de soportes espirales, como en todos los géneros de la familia Spirifude.-Dabero.

\section{SPIRIGERINA.}

* 164. S. reticularis, Lineo $(\mathrm{sp}) .=$ Anomia reticularis, Lineo. $=$ Terelmalula prisca, Schlot. $=$ Atrypa reticularis, Dahm. (Davidson: A monogr. of the british fossil brach.-The silur. Irach; p. 129, I. 14, f. 1 a 22.-Paleontographical Society).-Concha oval, oblonga; su mayor anchura cerca de la charnela; nates perqueño, agudo, y tocando la valva menor en su vérlice, donde se halla un forámen circular pequeñito: valva menor hombeada, uniformemente convexa en declive gradual hácia el márgen; charnela extendida bajo exiguas orejetas; bocel poco ó nada marcado: valva grande, algo convexa posteriormente, haciéndose cóncava á los lados, que son redondeados; seno marcado en la region frontal. Superficie de una y otra valva con muchas costillas radiantes, pequeñas, redondeadas, irregularmente bifurcadas, anmentando en grueso y número hácia la region frontal, separadas entre si por surcos cóncavos más estrechos, y cruzados por una cantidad variable de espansiones foliáceas concéntricas. En Inglaterra abunda en el siluriano y devoniano. Castillejo (Ciudad-Real). Adrados; Aleje; Colle; Crémenes; Robledo; La Velilla; Las Peñotas; Peña Corada; Valcueva; Valdoré; Veneros (Leon). Arnao; Ferrones; entre Pena Aullan y Grullos; Puerto de Somiedo; Peña de Piélagon; Santianes de Pravia (Aslurias).

* 165. S. aspera, Schlot (sp).= Terebrabula asper Atrypa aspera, Dalm. (Murch., de Vern. el de Keyser: Géol. de lit Russie dEurope et des mont. de lOural; 1. 2, p. 95, 1. 10, f. 15).Esta especie difiere de la anterior por ser más gruesos sus pliegnes, por to tanto ménos numerosos, y porgue casi siempre el tamaño de la concha es menor. Aquellos no se bifurcan más que una vez, y están cruzados por líminas del crecimiento, regularmente esparcidas, arrolladas en forma de tubos salientes. $A$ pesar de estas diferencias, los tránsitos insensibles que de esla especie conducen á la anterior, han lado motivo para que varios autores las reunan en una sola. 
Se encuentra en todas las divisiones del sistema. Arhados; Colle; Crémenes; Las Peñotas; Valmoroso. Fuente de los Moros, Levanza. Luesma y Fombuena.

\section{RETZIA.}

* Iliti. R. Oliviani, Vern. el diseh. (spi.=-Terehaluda oliviani, Vern. et d'Arch. (Bull. Soc. géol. de France; 2e série, t. 2, p. 470, I. 14, f. 10).-Concha eliptica; valvas desigualmente profundas, con unas 80 estrias radiantes, finas, regulares, continuadas, sin interrupcion ni bifurcacion deste la punta del nates hasta el borde. Valva mayor regularmente encorvada, de nates reslondeado, pequeño, retorcido y poco saliente; abertura redomil, tocando la otra valva; ésta, la milad de profunda que la grande. Imgulo apicial= $95^{\circ}, \operatorname{long} .=25^{\mathrm{mm}}$, lal. $=20$, esp. $=12$. La S. Alinensis, Vern., de las calizas devonianas del Jral, tiene estrias dicolomas, y su males es ménos encorvado._Vallenegrillo; Chillon. Ferroñes.

* 167. R. Guerangeri, Barr. $\langle$ sp' $=$ Terebratula Fuerangeri, Barr.-Especie que parece intermedia entre la anterior y la signiente. Tiene unos 40 pliegues radiantes. Entre Atienza y Sigüenza. Hinarejos. Nogueras.

**168. R. Adrieni, Verı. el d'Arch. (sp).=Terelmatula Adrieni, Vern. el d'Arch. (Ihid; p. 171, I. 14. f. 11).-Valvas casi ignalmente profundas; la mayor de nates proeminente, redondeado, encorvado, casi en ángulo reclo, con un forimen en su extremidar. que se apoya sohre un deltilium ancho, formado de dos piezas; área cóncava, elevarla lasta el tercio inferior de la abertura; 17 a 20 pliegues radiantes, separalos por intervalos iguales y profundos, y no bifurcarlos. Angulo apicial $=80^{\circ}$. Seno apenas indicado por una depresion central ocupada por cinco pliegues. Valva menor de nates perqueño, y con 17 a 1 ! pliegues idénlicos á los dr la olıa valva. Long. $=20^{\mathrm{mm}}$, lat. $=18$, esp. = $\mathbf{L}^{2}$. Hay individuos más anchos, más deprimidos y de nates ménos grueso. La R. prominulı, Roemer, es oval, alargada, de nates ménos retorcido y de írea más elevada, claramente separada del dorso por una profunda estria. Levanza. C'olle. Al N. de Olloniego; Arnao; Ferron̂es. 
* 169. R. subferita, Vern. (sp).=Terelnalult subferita, Vern. (Ibid; t. 7, p. 174, 1. 4, f. 1).-Pequeña, puntiaguda en el nates, que se alarga en pico y tiene en su remate una abertura redonda, separada de la arista cardinal por un deltidium alargado, fuertemente unido al área y dividido longitudinalmente por una fajita central lanceolada. Entre este deltidium y las aristas cardinales hay una superficie lisa, cóncava, atravesada por una línea saliente, que del nates baja á la charmela. La valva ventral lleva seis costillas agudas, sepraradas por anchos surcos, y en su seno se distinguen una ó dos más delgadas. Ia menor liene otras seis costillas laterales, y dos menores en su seno, que levanta ligeramente en el margen el seno de la otra valva. En la R. feritn del Eifel sucede la inversa, y en su centro no tiene más que un pliegue casi tan elevado como los litterales, y bifurcado hácia el borde.-Colle. $\mathrm{Al}$ N. de Olloniegao.

\section{RHYNCHONELLA.}

* 170. R. Orbignyana, Vern. $(\mathrm{sp}) \cdot=$ Terebralula Orbignyana, Verı. (Bull. Soc. géol de France; 2e série, 1. 7, p. 175, 1. 5, f. 10).-Concha pequeña, redondeada, con 40 á 50 estrias linas, muy dicotomas: valva mayor con un seno muy ancho, en cuyo centro se eleva una costilla redondearla y estriada como el resto de la concha; nates pequeño, encorvado, con un forimen muy exiguo. Valva menor muy bombeada, con un surco central correspondiente a la costilla de la otra ralva. La comisura frontal parece como hundida. Tal vez deba reunirse à esta especie la $R$. pila, Schnur, abundante en Eifel. La R. Wahlenhergii, de estrias simples, y la R. primipilaris, de estrias más finas, no tienen la costilla central, que se observa en nuestra especie. Aleje; Colle; Las Peñolas; Remolina; Valdoré; Villallandre. Guadalperal; Casa de la Vega. La Aliseda. Arnao; Biescas al S. de Salas; Somiedo; Ferroñes; S. Pedro de Sograndio. Al S. de Higueruelas.

* 171. R. sub-Wilsoni, d'Orh.-Tan poco diferente de la anterior, que tal vez sea nada más que una variedad de ella, en la cual el bocel de la valva menor carece de surco. Adrados; Colle; Cerro de Yuqueros; Corniero; Las Peñotas. Puerto de Pineda; Orbó. Nogueras. Luesma y Fombuena. Entre Sigüenza y llienza. 
** 172. R. Pareti, Vern. (sp).=Ilemilhyris Pareti, Vern. (Ibiil; t. 7, p. 177, 1. 5, f. 11).-Bocel con cuatro pliegnes simples y agudos; cuatro a cinco á cada larlo: valva mayor con uales puntiagudo, bajo el cual, y lleganto a la charnela, hay un forimen oval, limitado lateralmente por algunas señales de deltidium. A cada lado del nates hay una depresion caracteristica que sirve para distinguir esta especie de las R. Duleidensis, Roemer, R. Livonica, Buch, y olras.-Ferrones. Sabero; Colle. Luesma; Fombuena. Nogueras.

** 175. R. IVariana, Vern. el Barr. (sp).=Terelrutult Hurium, Vern. et Barr. (Bull. Soc. géol. France; 1. 12, p. 1007, 1. 29, f. 8).-De bastante talla, más larga que ancha, casi tan gruesa como ancha; con pliegues longitudinales agudos, y tan encorvados a los lados, que casi se hacen perpendiculares a los bordes. Hay cinco pliegues en el seno, de cinco á seis en el bocel, y de 15 a 14 á los lados. En los moldes se ve el sitio de dos laminilas cortis, que divergen a partir del nates (este siempre roto en nuestros ejemplares). Los músculos, poco robustos, dejaron poca huella. El molde de la valva ventral indica que estaba provista de un septum central, que avanzaba hasta la cuarta parte de la concha. La R. Daleidensis, Roemer (sp), tiene ménos pliegues; la R. Stricklandi, Sow., del siluriano de Inglaterra, es de menor talla, de costillas más ensanchadas, y de nates más pequeño. Areniscas y grauwackas del Puerto del Ciervo, Cercones de Carballido, Guadalperal, Casa de la Vega y otros sitios de las cercanias de Almaden.

\section{PENTAMERUS.}

* 174. P. galeatus, Dalm. (sp).=Atrypa ynlena, Dalm. (Th. Davidson: A Monograph of the british fossil brachiopoda.-The silurian brachi.; p. 145, 1, 15, f. 15 i 25.-Paleontografical Society of London). -lluy variable de forma; entre oval y pentágono-redondeada, casi Ian ancha como larga, á veces casi circular, muy convexa, con fiecuencia globulosa. Valva mayor muy arqueada, mucho mis profunda que la opuesta, con un bocel central ancho, ligeramente elevado, señalado deste el medio de la concha; de nates muy retorcido y grueso, con frecuencia llegando hasta el umbo de la valva menor, que es casi circular, de márgen llexuosa, frente deprimida y con un 
seno ancho. Este y el hocel, generahmente con I it 4 costillas obhusis; y i los lados se marcan ligeramente algunas otras en ciertos ejemplares. En el interior de la valva mayor se extiende hasta un tercio de su longitud un septum i tabique central vertical que se une en la parte superior con las láminas dentales convergentes y encorvadas. En el interior de la valva menor se destacan hasta los dos tercios de su longitud dos largos tabiques longitudinales, con un espacio libre entre ellos. En Inglaterra se encuentra esta especie en los dos sistemas siluriano y devoniano. Adrarlos; Colle; Valmoroso; Peña del Cuervo; Pola de Gordon; Aleje; Alejico; Valdoré; La Velilla; Las Peñotas. Biescas de Salas; San Roque.

\section{$\because$ 175. P. brevirostris, Phillips. $=P$. globus, Bronn.=} Stringocephalus hrevirostris, Phill. (IItc Coy: A. syst. descr. of the Writish palceozoic jossils, etc.; p. 584).-Globuloso, ensanchado, casi orlicular: valvas igualmente convexas, de nates pequeño; superficie lisa. En los individuos adultos se marca ligeramente un bocel estrechn. Aleje; Colle; Corniero; Las Peñotas; Robledo; Valcueva.

\section{LEPT呢NA.}

* 17i. L. Phillipsi, Barr. (Bull. Soc. gèol. de France; 2e série, t. 12, p. $1009,1.28$, f. $10,1.29$, f. 9).-Concha bastante deprimida junto al nates, ligeramente hombeada hasta el medio de la longritud, donde se encorva en ángulo recto. La mayor anchura está en la charmela. Area estrecha y estriada en toda su extension; abertura estrecha y lanceolada, cerrada por un deltidium. La valva mayor, la ventral, tiene la mayor área, es convexa y es seguida en su curvatura por la menor. La superficie está adornada de estrias radiantes filiformes, ligeramente torcidas á los lados; entre ellas se interponen otras de igual grueso, y entre cada dos principales, se cuentan de 4 a 6 más finas. Las principales se aproximan entre si más hácia los bordes de la concha, que hácia la regiou cardinal. Abundan en Guadalperal moldes bien conservados, que permiten olservar su interior. Impresiones musculares de la valva ventral muy desarrolladas, rodeadas de un saliente, cuyas extremidades parten de la base de los dientes, siguen un contorno semi-circular y se remen en el centro de la valva, donde (como sucede en los mroducti) se encorvan bruscamente. El sitio del músculo aductor se 
ve a mo y otro lado de ma crestecilla central. Las grandes impresiones musculares estin recorlatas en forma de cintas. El resto le la concha se ve cubierto de linos granillos, excepto en la region central donde se distinguen surcos longitudinales, debidos tal vez á los vasos del manto. La valva menor liene bajo el nates mu aparato dividido en dos lobas, que parecen dientes, que seg̨un Davidson hubieran servido de punto de adherencia á los músculos cardinales. De apui nace una ligera arista central, que separa dos pares de cicatrices, donde, segun el mismo autor, estarian alojados los músculos aductores. Las cicatrices anteriores ofrecen dibujos ramificados, que recuerdan lo que se vé en los producti. El resto de la valva presenta granillos, señales de los ovarios para algunos paleonlologislas. El tipo de esta especie, perteneciente il las capas siluriumas smperiores de Bohemia, diliere de la var. de nuestro pais, por ser más regular en su curvatura. La $L$. imlrex, Pand., muy parecida en su exterior, es muy distinta interiormente; y la $L$. enylypha liene las valvas en posicion inversa, es lecir, que la mayor es cincava y la menor convexa. Levanza; Mudí.

* 177. L. MIurchisoni, var. A. de Tern. el d'Arch. (Ithid; 1. 2, p. 477, 1. 15, 1. 7).- Semi-orlicular y m!y geniculada: valva mayor muy convexa, de mates muy pequeño; área estrecha, de bordes paralelos, con estrias verticales pectinadas; charnela recta, igual a la mayor anchura de la concha; abertura muy estrecha, cerrada por un deltidium de la misma forma; superficie con 14 á 17 pliegues angulosos, cortantes, i veces iguales, con mmerosas estrias longitudinales, algunas de las cuales subeu hasta el nales. Valva menor cóncava, con pliegues, surcos y estrias semejantes a los de la otra. Long. $=55^{\mathrm{mm}}$, lat. $=44$, esp.=9. La especie lipo, procedente de Siegen (orillas del Rhin), difiere de nuestra var. por tener su charnela más larga proporcionahmente, ser mis alargarla, ménos bombeada, y de pliegues ménos angulosos. Adrados; Mleje; Colle; Crémenes; Corniero, Las Peñotas; Valdoré. Fombuena. Cerro del Hinojo. Guadalperal. Cerro del Hierro, Hinarejos. Muda; Ferrones.

$*$ 178. L. Dutertrii, Nurch. (sp)=Orhis Duterlii, Murch. (Ibid; 1e série, t. 11, p. 255).-Tan larga como ancha; valva mayor hemisférica, algo comprimida, con nmmerosas estrias finas, irregulares, radiantes, intercalándose, sin bifurcacion, otras pequeñas que 
no Ilesan al nates; área triangular muy rebajadi, con estrias rerticales pectiniformes; abertura lanceolada, agma, de base estrecha; ángulo apicial $=158^{\circ}$. Valra menor cóncara, acomodada í la convexidad de la otra; de área más estrecha, è igualmente estriada. N̦estros ejemplares se distinguen de los de Ferques Francia, donde caracterizan el der. sup., por su menor tamano y sus estrias casi todas ignales en el máruen. Calbeza del Buer. Casa de la Vega, Guadalperal, Chillon, Castillejo. Adrados; Alejico; Colle; Corniero. Ferrones y Vega de Gozon.

179. L. Sedgwicki, Vern. et d'Arch.=Orthis Sedyuichi, Vern. et d'Arch. (Trans. of the geol. Soc. of Louton; ge série, t. 6, p. $571,1.56$, f. 1).-Semicircular, charnela recta, percibiéndose apenas el nates en su parte media, de donde parten unas 20 estrias radiantrs, que pronto se bilurcan, subdividiéndose cada rez más hasta el márgen, donde se señalan de 106 a Lolo. Fruadalperal; Vallenegrillo.

"180. L. Maestreana, Vern. (Bull. Suc géol. France; 2e série, t. 7 , p. 185, 1. 4, f. 9).-Pequeña; más ancha en la region frontal que en la cardinal, con estrias radiantes de cuatro en cuatro Ina mis gruesa; área corta eu cada valva; la mayor ligeramente ąuda en su parte media; la menor alțo hombeada á los lados, y escabada en su centro por un seno ancho, algo profundo. Sabero.

- 181. L. Naranjoana, Vern. Slrophomena! Siranjoanu, Vern. Thid; p. 182, 1. 4, f. 10.-Elewante especie de forma transversa, Eeniculada hicia los bordes, lisa, ron brillo anacarado. Area muy rebajada y estriada; abertura triangular y deltidium casi borrados, risibles por transparencia. Valra menor plana en su primera mitad, cóncava hácia los bordes. Ferrones. Colle.

* 182. L. lepis, Gold. Difiere de la anterior por sus estrias radiantes y tener mís perceptible su exirua abertura. Las Peñotas.

\section{STROPHOMENA.}

* 18j. S. rhomboidalis, Wilckens sp).=Chonchita romhoidalis, Wilckens.=Prouluches depressus, Sow.=Lephena depressa, 


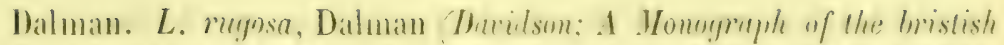

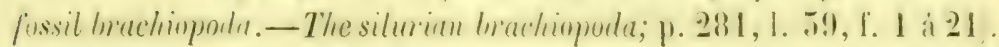
- Concha más ó ménos transversalmente semicirenbe o casi cuadraula; charnela recta, Lam larwa como la mayor anchura, con los ángulos cardinates redondeados. Valvas geniculadas; la mayor licreramenteconvexa en el nates, con mmerosis estrias rarlintes, cruzadis por lineas concéntricas onduladas, muy marcadis, y con un formen muy pequeño pue se cierral con la edad. La valra menor es róncava, sigue generalmente las curvas de la opuesta, y se halla adornada del mismo modo. Las impresiones musculares de la vilva mayor estin rodeadas por un creston semicircular que parte de li hase de los dientes; músculo aductor con una arrugra central pequeña; los músculos cardinales colocados laterabmente en la ravidad anterior. Eu el interior de la valra menor el proceso cardinal está dividido en dos lobas, y un crestoncillo central separa los dos pares de musculus aductores que estin cercados por arrugas salientes. Las impresiones vasculares, bifurcándose varias veces parten del centru de la valva hacia el máruen. Esta es ma de las especies de mas linra existencia; pues habiendo comenzado en el medio del sistema siluriano, cruzó todo el devoniano, y finalmente se la encuentra en el carbonifero. Guadilperal. Amao. Adrados; Cerro de Yuqueros; Colle: Cineto Burero; Las Peñotas; al S. le Güerga; Sabero; Aleje.

* 184. S. Bouei, Barr. spj.=Leplema Bouei, Barr.-Tal rez una variedarl de la anterior. Nogueras.

\section{STREPTORHYNCHUS.}

$\because$ 13.. S. crenistria, Phill. spl.=Spripre crenistrin, Phill. = S. seniles, Phill.=Wrthis arachnoiden, Ver't.=0.umhraculum, Port. =

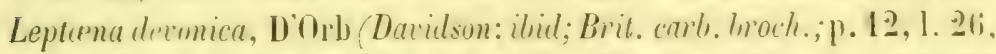

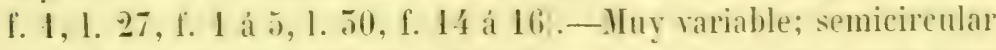
transversal i longifulinalmente; charmela rech, nn poco más ó un poco ménos larea que la mayor anchura de la concha; ángulos cardinales redondeados a prolongados en terminaciones aqudas; area de la valva mayor rariable en anchura, deprimida alertura. cubierta con un pisendo-deltidium; area de la otra valva lineal. Valva raude de diversis rurvaturas, ya ligeramente convexit hicia el 
nates y parcialmente cóncava hácia el márgen, ya más ó ménos convexa por toda su superficie; nates recto ó irregularmente torcido i un lado. Valva pequeña más ó ménos convexa. Cuando es algo cóncava hácia el medio, constituye la var. S. arachnoidea, Phill (sp). La superficie de las dos valvas lleva estrias radiantes, redondeadas, rectas en el centro, encorvadas en los lados, intercalándose doble número de otras más finas; en total, pasan de 100 las que se cuentan en el borde. Villa Alegre, Avilés. Colle. Iudá. Nogueras.

\section{ORTHIS.}

* 186. O. Beaumonti, Vern. (Bull. Soc. géol. de France; $2^{\mathrm{e}}$ série, 1. 7 , p. 180, 1. 4, f. 8).-(xrande y hermosa especie, casi orbicular y algo transversa, con 200 á 250 estrias radiantes, muy finas, que á partir del nates se encorvan á los lados, aumentándose en los bordes por la insercion de otras nuevas entre las primitivas; algunas se engruesan de trecho en trecho. Valva mayor ménos bombeada yue la otra, más hinchada hácia el nates, casi cóncava en el márgen; área poco elevada; abertura triangular, bajo la cual se dibujan en el interior dos impresiones cóncavas alargadas, separadas por una cresta central. Valva menor bombeada, con un seno profundo que se extiende desde el nates hasta el borde. En su interior hay dos impresiones musculares más anchas que las de la otra valva, de donde arrancan 5 costillas poco salientes, cuyas impresiones, atravesadas ligeramente por una arista, están separadas por un septum unido á una lámina delgada, colocada en medio de la charnela. El o. Keyserlingiana, lion., es menor, más globuloso, más transverso y tiene un seno más profundo. Guadalperal. Sabero; Colle; Nleje; La Velilla. Luesma. Nogueras. Arnao; Cuero; Ferroñes; Puerto de Somiedo; Santiago de Pravia; Villa Alegre. La Aliseda.

* 187. O. Dumontiana, Vern. (Ibid; p. 181, 1. 4, f. 7).De regular tamaño; estrias radiantes, salientes, muy arqueadas á los lados, y varias veces bifurcadas: valva mayor algo más gruesa que la otra, ligeramente cóncava hácia los borles; área elevada, pero muy inclinada; forimen en parte obstruido por el triple diente dr la valva menor. Esta es hombeada, con un seno profundo en su parte media; su área en el plano longitudinal de la concha; dos dientes laterales y un diente central triple en la charnela. Aleje; Colle. 
188. O. resupinata, Martin (sp).= Immites'esupinutus, Mar-

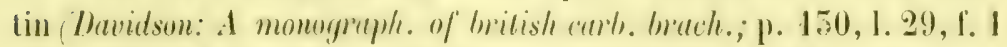
i 6,1 . 50, l. I i i i).-C'ransversalmente oval ó eliptica; valvas convexas; charnela recta, mucho mís corla yue la mayor anchura de la concha, cuyos ángulos cardinales son redondeados. Valva menor, generalmente más gruesa que la otra, convexa con regularidad ó alg̣o deprimida hicia el medio. Valva grande, variable en su curvatura, haciéndose algo cóncava hácia el márgenen; nates pequeño y algo encorvalo; área triangular. Superficie de una y otra valva con numerosas estrias radiantes, que aumentan por interposicion y bifurcacion á distancias variables del nates, y engruesando ellas mismas en peyueñas proeminencias á modo de espinitas ó nudos tubulares, sobre todo hácia el márgen. Esta especie se extiende hasta el carlunifero, donde tal rez abunde mis que en el devoniano. Arnao; Villa-Alegre. Muda; Levanza.

* 189. O. Michelini, Eveillé (sp).=Terebralula Michelini, Eveillé (Dovidson: Ihid; p. 152, 1. 50, f. 6 a 12).- Se distingue de la anterior, sobre todo por su charnela, tan estrecha, que apenas llega a $1 / 3$ de la mayor auchura, la cual se mide hácia el márgen. La valva mayor tiene tambien una ligera depresion central; y su área, amyne pequeña, es un poco más ancha que la de la valva opuesta. Tambien es comm al devoniano y al carbonifero. Ihurias, al 0. de Arnao. Mudá. Nogueras, Luesma y Fombuena.

* 190. O. striatula, Schlot (sp).= Terebratulites striumus, Schlot, Köninl: Description des animaux fossiles que se trouvent dans le Lerrain carl. de Belyique; p. 224, 1. 15, 1. 11).-Aunque parecida al 0. resupinah, se distingue fácilmente por tener, al revés de lo que pasa en los demas Orthis, li valva dorsal más bombeada y larga que la ventral. Ademas, 10 estrias longitudinales del 0 . striatulı ocupan tanto espario como 12 a 15 del 0 . resupinata. A veces se hace tan grande, fue alcanza una anchura de $60 \mathrm{~mm}$. Como las dos especies anteriores, es comun al ilevoniano y al carbonifero. Ferrones; Lena. Colle.

* 191. O. opercularis, de Verm. et lieys. (liéol. de la Russie d'Europe et des mont. de l'Oural; t. 2, p. 187, 1. 15, 1. 2).-Poco inuesa, de contorno semicircular, algo más ancha que largą valva 
ventral poco bombeada, ligeramente angular hácia el nates, que es muy pequeño, encorvado, viniendo á colocarse en el plano de las aristas laterales; área muy reducida, limitada casi al nates: valva dorsal casi plana, opercular, escavada ligeramente hácia el centro por un surco poco profundo, con área tambien muy pequeña, perpendicular al eje longitudinal de la concha. Las estrias radiantes de la superficie son arqueadas, muy finas, dicotomas, cruzadas por otras de crecimiento; alguras engruesan de súbito, como en las especies anteriores, dando origen á espinas redondeadas, dispuestas hácia adelante. Sobre toda la superficie se cuentan unas 150. Longitud $=16^{\mathrm{mm}}$, lat. $=20$, esp. $=5 .-$ Sabero.

* 192. O. orbicularis, Vern. (no. Sow.) (Bull. Soc. géol. de France; 2 e série, 1. 2, p. 478,1 . 15, f. 9).-Muy parecida á la anterior, de la cual se distingue por su àrea y charnela, mucho más largas, siendo su region cardinal mucho más ámplia. Es notable en el interior de su valva dorsal el hoton tripartido, que es muy promunciado y viene á cerrar la abertura triangular de la otra valva. Ferrones; Pelapaya. Colle; Aleje. Castillejo. Luesma y Fombuena.

* 193. O. Gervillii, Vern. (Inédita?)-De ignal tamaño que las dos anteriores, esta especie se distingue por su valva ventral más hombeada; la dorsal es casi plana, ligeramente cóncava hácia el centro; hay de siete á diez costillas radiantes, que llevan numerosas estrias muy finas, asi como los surcos que las separan, cruzados estos y aquellas por lineas concéntricas de crecimiento. Aleje; Corniero.

194. O. Eifeliensis, Vern. (Inédita?)-Veneros.

195. O. hipparionix, Vanauxem.-Guadalperal.

\section{PRODUCTUS.}

* 196. P. Murchisonianus, Kon. $=P$. spintlosus, Buch.= Wrthis productoides, Murch.=Strophalosin productoides, King. (L. de Koninck: Recherches sur les animux fossiles. Monographie des genres Produchus el Chonetes; p. 158, 1. 16, f. 5).-De talla mediana, casi orbicular: valva mayor regularmente bombeada, sin seno, con arru- 
gas concentricas, imregulares, onduladas; numerosos lubos dirigidos paralelamente al radio de curvalura de los bordes de la valva, largos de 2 a $5^{\mathrm{mm}}$, irregularmentr dispuestos. Region cardinal algo mís corta que la mayor anchura; irea muy rebajada, mis cortia que lit charnela; abertura triangular estrecha y corrada por un psendo-deltidium ligeramente bombeado. Orejetas aplastadas, peyueñas, con una fila de tuhos semejantes á los del resto de la concha. Valva menor poeo concava, con arrugas concéntricas, irregulares, y mís lamelosas que las de la mayor; generalmente, los tubos reemplazados por fosetas; area y psendo-deltidium mu estrechos. Diente cardinal bifido, sostenido por una limina central saliente, yne ocupa los ${ }^{\overline{ }}$, de la long. tolal de la concha; aprifisis hepaiticas ovales, lisas; callosidades reniformes, muy desarrolladas, rodeadas de una cresta saliente, circunscrita por un surco paralelo y estrecho; bordes erizados en su interior de asperezas oblongas. Long.= $20^{\mathrm{mm}}$, lat. $=25$, esp. $=8$. King colocó los producti que, como este, tienen área, en el género Strophalosia, que forma, para algunos paleontologistas, el trínsito al Chonetes. Su distribucion geográfica es immensa, y es una de las mis caracteristicas del sistema. Chillon, Casa de la Vega, Guadalperal y otros puntos de las cercanias de .11maden; Valmayor, cerca de Fuenlabrada. Adrados; Las Peñotas. Mudá.

* 197. P. subaculeatus, Murch.=Leptena fragaria, Sow.= Strophalosia subaculealn, King. (Ibid; p. 142, 1. 16, 1. 1).-Muy parecida á la anterior, de la que se distingue por su menor tamaño, ser más globulosa su valva ventral, más concava la dorsal, y su área mís estrecha. Los tubos estin distribuidos más irregularmente, viénlose más próximos hácia las orejetas. P'eña de la Venera; Colle.

\section{CHONETES.}

* 198. C. sarcinulata, Schlot (sp).=Terelnatulites stercimulıuts, Schlot (Ihil); p. 210, 1. 20, f. 15).-Casi semicircular transversalmente, no siempre mile su mayor ancho en la arista cardinal, que lleva i cala lado 4 a 5 Lulos. Valva mayor bombeada; orejetas planas, lisas, muy delgadas; area muy rebajada, con $u$ pseudodeltidium ligeramente escotado en la base. Valva menor no muy 
cóncava, con diente central formado de 5 lobas, y con tantas fosetas como tubos cardinales hay en la ventral. Las 16 a 18 costillas radiantes que hay cerca del nates, se aumentan al doble por su bifurcacion desde el medio de la concha hasta el borde, donde se borran casi del todo, a causa de las numerosas estrias concéntricas de crecimiento que hay en esa parte.-Herrera del Duque. Chillon; Valmayor. Levanza. Llamafalla. Entre ltienza y Sigüenza. Se extiende por todas las divisiones del sistema.

\section{CALCEOLA.}

** 199. C. Sandalina, Lineo (sp).=Anomia samdalium, Lineo. (Bromn: Lethera !eognostica; 1. 5, f. 5).-Hny inequivalva, simétrica; valva mayor casi piramidal, redondeada por un lado, y por otro con un área casi plana muy desarrollada; valva menor perfueña, casi plana ó poco convexa, opeculiforme y semicircular. Nates largo y puntiagudo; region cardinal recta y tan larga como la mayor anchura de la concha, que mide casi tanto come su longitud. Estrias concéntricas de crecimiento, muy apretadas en toda la superficie. Arnao.

\section{FENESTRELLA.}

*200. F. antiqua, fiold. $(\mathrm{sp}) \cdot=$ Retepora antique, Gold. $=R$. infundibuhm, Mich. (Michelin: Leonographic Zoophylologique; p. 191, 1. 49, f. (j).-Colonia de forma conoidea con espacios radiantes cincavos, interpuestos entre los convexos que son mas extensos, y adherente á las rocas por un pedinculo. Celdillas ovales, cincavas, dispuestas en lineas longitudinales regulares, separadas por espacio casi plano.-Arnao.

\section{PENTRETMITES.}

** 201. P. Pailleti, Vern. (Bull. Soc geol. de France, 2e série, Ł. 1, p. 215, I. 2, p. 479, I. 15, f. 10 y 11).-Cáliz alargado, compuesto de 5 piezas basales y j piezas superiores casi iguales; vér- 
lice amcho, aphastarla: i ambulares petaloides, radiantes, igmales, simcricos y alargates, radi nuo dividido por un sureo medio en dos partes iguales, compuestas do li articulaciones transversales. Iticia el rentro de la estrella cala rama se ume a la yue le es conligna por un pliegue elevalo, contra el cual se apoya la primera articulacion de cala radio. En ol mismo centro hay un hueco esteliforme, cuyas punlas eorresponden al sureo medio de carla ambularero. Estos últimos estim hastante humdidos en cada ma de las 5 piezas superiores, á cuyos ingulos sulientes corresponden. El P. penfamyularis, Miller, del sistema carhonifero, es mayor, de base menos delgada y ámonlos mis agulos; el P. Orbignymus, Kon., lambien del carbonitero, es ménos anguloso y de ambulacros más estrechos y ménos hundidos.-Ferroñes; Candamo. Colle.

202. P. Schulzii, Vern. et d'Arch. (Ibid; 1. 2, p. 479, 1. 1i, f. 12 y 15).-Cáliz coto, poco más lareno que ancho. Tallo delcato, fusiforme, alargalo, sosteniendo tres piezas basales pentigouas, estrialas, solme las que se apoyan cinco piezas superiores, eu forma de exigonos alargados, irregulares. El ingule inferior de eslas últimas corresponde al ingulo entrante de las dos piezas basales continuas, y el superior forma un saliente exterior hácia arriba. Las piezas superiores estiu estriadas como en la especie anterior, y la disposicion de las estrias es iléntica. La remion de estas piezas forma en el vérlice un decágono de cinco ángulos salientes y cinco enlrantes, inserito en un pentigono regular: cinco ambulacros petaloiles anchos, de limbo redondeado, y estrechados en la base, lienen sus vertices correspondientes en los ingulos del pentigono. De carla nuo de los entrantes del decagono parte un tabinue poco saliente, „que, diriciondose hácia el centro, separa dos ambulacros contiguos: un surco central divide cada ambulare en dos partes iguales, carla una de las cuales eslit a su rez cruzala por 12 a 15 surcos transversos, algo flexnosos hicia los hordes. Fermones. Colle: Meje.

205. P. inflatus, fillo. (J. Phillips: Illustr. of the licolog!y of

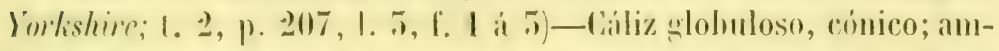
hulacros muy restrechos y largos, con muncrosas placas porileras dentelladas.-Aleje; Las P'enotas.

204. P. acutus? Gilb. (Ibid; 1. 5, 1. 1)-Cíliz en forma 
de cono prolongado; ambulacros muy estrechos y salientes en ol fondo de las paredes que forman los espacios interambulacrales; estos últimos se destacan en ángulos triedros, cuyas capas exteriores son la prolongacion del cáliz; las interiores, linamente estriadas á lo largo, se reunen bajo un ángulo de $60^{\circ}$, levantindose las ciuco aristas sobre el nivel superior del cáliz.-Colle; Aleje.

* 205. P. oblongus, (iilb. (Ibid; 1.5, l. 11 y 12).-Cíliz alargado y muy reducido en su vertice, donde se perciben, ademas de la ahertura bucal pentagonal, otras cinco oblongas en el vértice de los espacios interambulacrales. Estos, formados por dos caras convexas que hacen $u$ angulo entrante. Ambulacros estrechos, prolongados hasta la base del cáliz.-Las Peñolas.

\section{CYATHOCRINITES.}

* 206. C. pinnatus, (rold. (Pelrefacta Germunie; L. 1, p. 190, 1. 58, f. 7).-En todas las localidades que llevamos mencionadas se encuentran fragmentos de tallos a articulos sueltos de crinoides, cuya determinacion, no especifica, sino siquiera genérica, es muy dudosa. Pero en medio de las diversas figuras de crinoides que hemos examinado, á ninguna creemos se pueden referir mejor la mayor parte de nuestros ejemplares que à la senalada por Goldfuss con el nombre de $C$. pinnatus, cuya existencia tenemos por cierta en los diversos términos ya citados, a uno y otro lado de la cordillera cantábrica (Asturias, Leon y Palencia); en las cercanias de Nmaden (Cindarl-Real); en la Mliseda (Cáceres); entre Panticosa y Sallent y valles de Benasque y Gistain (Huesca).

\section{PRADOCRINUS.}

* 207. P. Baylii, Vern. (Bull. Śro. giul. de Frence; 2e série, I. 7, p. 184, I. 4, I. 11).-Cáliz de seccion eliptica, compuesto de tres piezas basales exigonas, iquales entre si: seis primeras piezas intermedias, exácronas i igntales; 12 sesundas piezas intermedias, Lodas exágonas, ménos la correspondiente a la region bucal; 18 terceras pentigonas, exágonas y ‘eptigonas; 24 cuartas y 34 superiores, 
solue las cuales salen los brazos remidos en cinco supos, de los cuales dos estin más spparados por mo espacio más considerable,

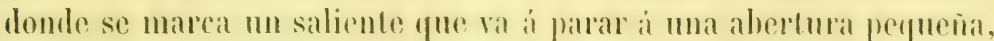

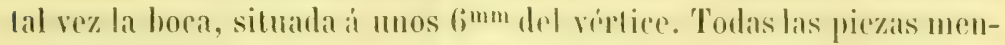
eionadas estin adormalats de estrias perpendiculares i cada mon de los lados, y que arrancau de cada verlice respectivo. Lal parle superior del cáliz está cerrala por nu gram numero de piezas bastante irrewulares, casi lisas. La mullpulicacion por di le las piezas del cáliz, es excepcional en los crinoides. Clolle.

\section{PLEURODYCTYUIM.}

* 208. P. problematicum, Cioll. Milno-Eilnar. ct J. Mni-

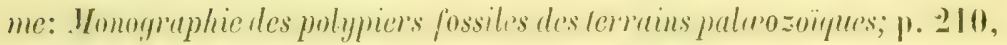
1. 18, 1. 5 a (i).-Polipero discoide libe of fijo sobre ma concha, is mis generalmente solore un cuerpo serpuliforme en S. Meselat inlerior, con una epiteca luerle con plicunes concentricos. Poliperitos corlos prismáticos, terminamlo en mat superficie ligeramente convexa; rilices poligonales algo designales, de 5 a $5^{\text {mm }}$ de anchura; poros

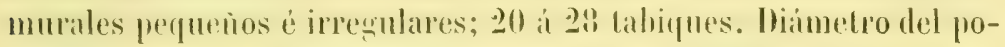
lipero $=5$ á $4^{\mathrm{cm}}$. -Guadalperal. Neje; Ocejo; Valdoré.

\section{SYRINGOPORA.}

21)!. S. cæspitosa, fiold. (Ihid; l. 294).-Tal ve\% no sea mis que una variedad de la $S$. reticululu, Gold., en que sus poliperilos se hallen más aprelados, es lecir, ménos riistantes entre si que sul diámetro, el cual es de I it 2mm. Los tubos de conexion gruesos, irregularmente dispuestos y distantes cntre si de 5 i $\mathbf{4}^{\mathrm{mm}}$.-Colle.

\section{ALVEOLITES.}

** 2111. A. suborbicularis, Lamarek.=Calımopora spongi-

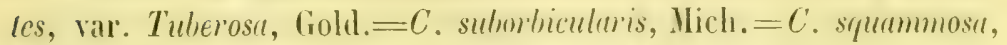
Mich. (Ibid; p. 25i).-En masa inregular, incruslante, lormada de capas sobrepuestas, de superticie desigual. Cálices muy obli- 
cuos, apretados desigualmente, alargados á través, casi triangulares, vueltos hácia la periferia del polipero; el lado inferior ó extermo de estos cálices, presenta dentro una crestecilla alargada, que parece representar un tabique principal, y que está opuesto á una escotadura pequeña. Diámetro mayor de los cálices, 1 mm 0 algo más; diámetro menor poco más de medio.-Cerro de Yuqueros; Colle.

\section{FAVOSITES.}

**211. F. Goldfussi, De Vern. et J. Haime.=Calamopon:a Gothlandica (pars), Gold. (Ibid; p. 255, I. 20, f. 5).-En masa redondeada más ó ménos convexa; cálices algo desigouales, de $5^{\mathrm{mm}}$ de diámetro los mayores; interior de las murallas erizado de puntas; caras murales desiguales y presentando, segun su anchura, de 1 a 5 lilas de poros redondos, ya alternos, ya opuestos. Aleje; Colle; Adrados; Las Peñotas; Millar; Valcueva. Cervera. $\Lambda$ I S. 0. de Curero; Ferrones; Villa.

**212. F. polymorpha, Gold. (sp).=Calamopora polymorpha, Gold. var. luberosa. (Itrid; p. 257). - En masa irregular; cálices desiguales, de 1 a $2^{\mathrm{mm}}$ de diámetro; caras murales con una sola fila de poros, distantes entre sí $1^{\mathrm{mm}}$. Asociado al anterior.

* 215. F. basaltica, Gold. (sp).=Calamopora basallica, Giold. (Ilidi; p. 256).--Difiere del anterior por sus poros más espaciados y sus cálices mayores, hasta de $5^{\mathrm{mm}}$ de dímetro. Con el anterior.

* 214. F. alveolaris, Gold. (sp).=Culamopora alveolaris, Gold. (Ilbid; p. 251).-Polipero en masa, de superficie casi plana; cálices desiguales, los mayores de 5 a $4^{\mathrm{mm}}$ de diámetro; pisos con 4 à 8 fosetas junto à las murallas; tabinues formados por séries de puntas; poros murales muy próximos, colocados en los ángulos. Colle. Punta del Cuerno, Arnao.

*215. F. reticulata, Blain. (sp).=Calamopora spongites var. ramosa. Gold. =Alveoliles reticulata, Blain. =Favosiles Orbigmyana, Vern. et Ilaime (Ihil, 241).-Polipero dendroide en haces de ramas de 1 a $2 \mathrm{~cm}$ de grueso, entremezcladas y con frecuencia coalescen- 
tes; murallas espesas; cádices de $I^{\mathrm{mm}}$ de diámetro. Pelapayal Ferroñes; Pravia; Perran; Vega de Gozon. Valcueva.

*216. F. cervicornis, Bain. (sp).=k. rmmigen, Haime=

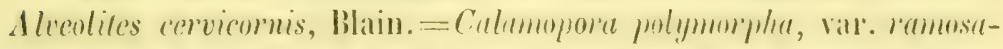

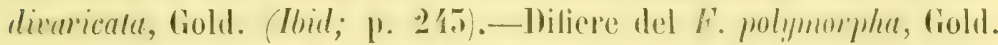
(si) por ser ramoso y tener ménos poros murale's, milyores y ménos regulares. Guadalperal. Crémenes. Cervera. Ferroñes.

217. F. fibrosa, Gold. (sp).=Culamopore fimosil, vitr. luherosoramosa, Gold. (Ibil; p. 2.19).-Polipero en masa muy convexa; poliperilos prismíticos, rectos ó un poco llexuosos, de medio á dos tepcios de milimetro de diámetro; pisos muy apretatos, cinco í seis en el espacio de $\mathrm{I}^{\mathrm{mm}}$; poros murales proporcionialmente grandes, ipretados, dispuestos en séries verticales simples en los ángulos de los prismas murales. Entre Atienza y Sigüenza. Hinarejos.

\section{EIMIMONSTA.}

218. E. hemispherica, Yandell ot Shmmal (sp).= liavosites hemisphericu, Yimdell et Shumard (lbil; p. 277). - Lin masa casi esférica, a veces muy elevala y lormada de pisos solurepuestos, espaciados de $1 / 3$ a $1 / 4$ de milimetro. Cálices irregnlares, pentigonos, de 1 it $2 \mathrm{~mm}$ de dismetro; 12 radios, lien desarrollados, yue llegan hasta el centro; poros murales grandes, distantes entre si ${ }^{2} / 5$ te milimetro. Arnao.

\section{IMICHELINIA.}

* 219. TI. geometrica, Elw. el Ilaime (Ilbirl; p. 252, I. 17, f. 7).-Polipero plano, con 28 estrias septales; cílices poco profundos, en forma de exágonos regulares; de à a $7 \mathrm{~mm}$ de diimetro. Piso superior de superficie muy granosa. Las Peñotas.

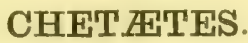

* 220). Ch. Torrubiæ, Iaime (Ibid; p. 2(i8, I. 20, 1. 5).-l'olipero en ramas de 1 a $2 \mathrm{~cm}$ de dibimetro. P'ezones redondeados, algo salientes, bastante compactos, distantes entre si dos a tres veces su 
anchura, que es de $2^{\mathrm{mm}}$. Cálices algo desiguales, casi todos poligonales; los de los pezones son los mayores, de medio á dos tercios de milimetro. Ferrones. Aleje; Colle.

* 221. Ch. petropolitanus, Pander (sp).=Favosites petropolitames, Pander.=Calamopora fibresa (pars), Gold. (Ibid; p. 265).De base plana í cóncava, con epiteca plegada concéntricamente; superficie superior regularmente convexa, y en general hemisférica, presentando tuberosidades redondeadas, obtusas, de $5 \mathrm{~mm}$ de anchura, pero muy variables en saliente en los diversos individıos. Cálices bastante desiguales, generalmente poligonales, á veces casi circulares, los mayores apenas de medio milimetro de diámetro. Pisos horizontales, completos, distantes entre si $1 / \%$, de milimetro. Auncue en Rusia, Inglaterra y los Estados-Unidos caracteriza el siluriano inferior, creemos pertenecen á esta especie varios ejemplares de las capas devonianas de Idrados, Aleje, Colle y Crémenes.

\section{THECOSTEGITES.}

222. Th. auloporoides, Vern. et Haime (Ibid; p. 298).Casi ramiticado; poliperitos trepantes en la superficie como las auloporas; cílices desigualmente apretados, de dos tercios de milimetro de anchura; 12 dientes septales.-Ferroñes.

225. Th. parvula, Vern. el Haime (Ibid).-En lámina delgada ó encostrante; cálices iguales í igualmente espaciados. Poliperitos rectos, poco salientes, bastante espaciados, de ${ }^{1 / 4}$, te milimetro de diámetro. Una secrion vertical muestra un cenenquima casi compacto, y pisos horizontales espaciados.-Ferrones. Adrados.

\section{CYSTIPHYLLUIM.}

224. C. vesiculosum, Gold. (sp).=Cyathophlyllem vesiculosum, Gold. =C. secundum, Gold. (Ibid; p. 462). - Mlargado, casi cilindrico, algo retorcido; epiteca muy fuerte, con rebordes pronunciados horizontales; foseta calicinal algo profunda; estrias septales marcarlas hacia la parte externa; vesiculas desiguales, las mayores en el centro, de 2 at $5^{\mathrm{mm}}$ de anchura. Nltura de 7 a $50^{\mathrm{cm}}$, diámetro de 4 à $8 .-$ Hillar; Colle. 


\section{COMBOPHYLLUM.}

*225. C. leonense, Verin. et Ilaime.=Discoplyyllum Le'onense, Vern. el Haime (Ibid; p. 559, 1. 6, I. 6).-Discoide muy delgato, de superticie inferior plana, estrias costales bastante limas, rectas, encontrindose por su extremidad interna las mís pequeñas con las mayores. Cailiz casi plano; foseta septal bien marcada, extendiéndose desde el borde hasta el centro; 26 tabiqunes principales, fuertes, gruesos, sobre todo en su mitad interna, con tendencias a formar 4 grupos hícia el centro y alternantes con otros tantos rudimentarios. Altura 2 á $5^{\mathrm{mm}}$, diámetro 12. Guadalperal. Peña de la Venera; Adrados; Colle. Al N. de Cervera.

* 226. C. Marianum, Haime (Bull. soc. géol de France; 2e sírie, p. 1012, 1. 28, f. 11).-Difiere del anterior por su mayor tamano, y sus costillas relativamente mís tinas y más numerosas, de 76 i 90 . Varias de estas siguen una direccion oblicua á cada lado de otras, que están más desarrolladas. La foseta septal es ménos pronunciada, la parte lisa del piso más extensa, y los tabiques estrechos son alternativamente muy desiguales. Guadalperal.

\section{AMPLEXUS.}

* 227. A. annulatus, de Vern. el Haime (Milne-Eduards et J. Ituime: Monographic des polipiers fossiles des terrains pulceozoiques; p. 545).-Polipero muy largo, ligeramente flexuoso, con una epiteca, presentando á distancias de $2^{\mathrm{cm}}$ bordes muy salientes; 52 tabiques, algo separados, delgados; pisos apretados. Long. $110^{\mathrm{mm}}$, diametro 18.-Ferrones; Sabero.

\section{ZAPHRENTIS.}

228. Z. gigantea, Lesueur $(\mathrm{sp})=\mathrm{Z}$. Clappi, Haime.=Caryophyllia gigantea, Lesueur (Ibil; 1. 540).-Cilindroide, muy largo; bordes de crecimiento anchos y poco salientes; foseta septal proporcionalmente pequeña, situada junto it la muralla. Unos 70 tabiques iguales delgados, algo flexuosos en el centro, y otros tantos rulimentarios. Pisos muy grandes. Long. 40 a $50^{\mathrm{cm}}$; diám. 7 á 8 . Colle. 


\section{AULACOPHYLLUIM.}

229. A. Elhuyari, Vern et Ilaime (Ibid; p. 555).-Polipero en cono alargalo y encorvado, adelgazado inferiormente; cáliz casi circular, algo inclinado; foseta perqueña; unos 40 tabiques bien desarrollarlos, ligeramente flexuosos hicia el centro; otros $\mathbf{1 0}$ intermedios. Alt. 40 à $50^{\mathrm{mm}}$; diảm. 2 á 5 .-Colle.

\section{BARYPHYLLUMI.}

2.50. B. Verneuilanum, Edı. et Haime (Itid; p. 552, 1. 6, f. 7).-Dolipero muy corto, de superficie inferior un poco convexa, casi lisa en su centro; gruesas costillas muy semejantes á los tabiyues; estos muy gruesos, sobre todo el primario opuesto a la foseta septal que es alariada y poco marcada: 6 tabirques principales que son tambicu ligeramente sinuosos y 7 derivados, colocados de modo que su horde interno encuentra el tabique primario segun un ingulo agudo. Alt. 5 á $7^{\mathrm{mm}}$, diám. 20 á 25 . Colle.

\section{CYATHOPHYLIUIM.}

*251. C. ceratites, Goll.=C. Iurhinatum Gold. (Ihil; p. 561). -Turbinarlo, alargado, alyo encorvado, con rebordes de crecimiento bien marealos; epiteca muy fuerte; cáliz hastante profundo, de hordes delgados; una ó dos fosetas septales rudimentarias; de 60 i 120 tabiques delgados, dentellados, alternativamente grandes y pequeños, pero muy poco designales, estrechos por arriba, rectos sin llegar al fomlo de la foseta, que es algo vesiculosa, asi como las címaras. Diám. $70^{\mathrm{mm}}$, long. $150 \mathrm{en} \mathrm{los} \mathrm{mayores} \mathrm{ejemplares.} \mathrm{Colle.}$

252. C. IVichelini, Vern. et IIaime.-C. dianthus, Mich. (nom Gold). (Ihid; p. 566). - Turlinado, corto, algo encorvado en la base; epiteca fuerte; pliegues de crecimiento bien marcados; cáliz circular, de cavidad grande y profunda; foseta septal rudimentaria, del lado de la mayor curvatura: 60 tabiques delgados, algo contorneados hácia el centro. Alt. diảm. 2 ả $5^{\mathrm{cm}}$.-Ferroñes. 


\section{DISPHYLLUM.}

** 25.5. D. cæspitosum, frohl. (sp).=Cyalhophlyllum cerspritosum, Cold. (Ilid; p. 58 亿).-Compuesto de poliperilos cilindroiles, dispuestos en haces. Cálices circulares, a veces poligonales, baslante profundos, de 8 a $10^{\mathrm{mm}}$ de diamelro. De 90 a 50 taliques, alternalivamente algo desiguales, delgados, con mna loha pequeñita hicia el centro. Pisos bien desarrollados.-Canfranc (IIuesca).

* 254. D. radicans, Gold. (sp). = Cyalhophyllum radicans, Gold. (Ibid; p. 588, 1. 15, 1. 5).-En haces algo irregulares, poliperilos casi cilindricos, con epileca plegada, yue forma á um laulo pies a raices, que se unen al poliperito immedialo en loda su longiIul; 24 it 26 tabiques delgados, apretados; cillices cirrulares poco profundos.-Sabero.

\section{DIPHYPHYLLUIM.}

255. D. antiquum, Bronn. (sp).=Cladocore antipua, Bronn. =Lithodendron co'spilosum, Gold.=Lilhostrotium antiqum, Edw. el Haime (Thil; p. 458).-En haces, poliperitos alargados, cilindricos, le 5 a $6{ }^{\mathrm{mm}}$ de dicimetro; epileca rlelgada y finamente plegada; colımnilla algo sruesa y comprimida; 52 a 5 个 tabiques muy delgarlos, alternativamente algo desiguales, desbordantes redondealos por arriha; traviesas exteriores distantes entre si medio milimetro. Ferl'oûes.

\section{POLYPHYLLUIM.}

256. P. helianthoides, Gold. (sp))=Cyathophyllum helianlhoides (pars.) Gold. (Ihil; P. 575).-Compuesto de poliperitos midos lateralmente entre si y limilados por lineas poligonales poco salientes; cálices poligonales de 25 a 50 (i) mas milimetros de diámetro; en los mayores, de lio a 80 tabiques bien desarrollados, tortuosos en el centro, donde presentan peruenas lobas paliformes, que por su remion forman ma corona en la foseta calicinal.-Colle. 


\section{ACERVULARIA.}

* 257. A. Goldfussi, de Vern. et Ilaime.=Cyalhophlyllum anmas, Gold. (Inid; p. 417). - En masa astreilorme; lineas poligonales de la superlicie superior, algo en zig-zag; diagonal mayor de los poliperitos $=7$ a $8^{\mathrm{mm}}$. Nhralla interior bien marcada y algo fuerte, algo desbordada por los habiques, y de $2{ }^{1 / 2}{ }^{m}$ me diámetro. Te 24 á 26 labiques delgados; traviesas bastante próximas.-Sabero; Colle; Aleje; Las Peñolas. Valdehreto.

* 258. A. Hennahii, lioemer. (sp) $=A$. Roemeri, de Vern. el I'Arch.=Astrea IIennahii, Roener. (Ilidi; p. 120). - En masa, de superficie casi plana. Poliperitos prismálicos intimamente soldados; murallas exteriores muy delgadas, y á veces dificiles de distinguir: diagonal mayor $=6$ it $8 \mathrm{~mm}$; dimetro de la muralla interior $=2$. De 26 i 28 radios septo-cortiales, muy delgados y muy flexuosos afuera.-Pola de Gordon; Colle.

* 259. A. Pradoana, Ilaime (Bull. Soc. géol. de France, $2^{\mathrm{e}}$ série, 1. 12, p. 1011, 1. 29, f. 10).-Parecida á la A. Goldpussi, Haime, de la que se distingue por el diámetro de sus murallas internas, que es mayor con relacion al de Jos poliperitos; de estos es de 6 a $7^{\mathrm{mm}}$ y el de arnellas de 5 . De 28 a 52 radios septo-costales, allernativamente designales, rectos, muy delgados. Chillon.

\section{SYRINGOPHILLUIM.}

210. S.? cantabricum, de Vern. el Haime.=Phillipsastrea cantulnica de Vern. el IIaime. (Ehluard et Haime: Monogruphie des polypiers fossiles des térrains palerozöques; p. 451).-Polipero en masi casi plana; cilices desigualmente distantes, en general una ve\% su diámetro que es de 5 a $4 \mathrm{~mm}$. Costillas irregularmente confluentes, largas, flexosas, iguales, delgadas; 15 a 16 principales de horde arqueado y finamente dentellado, llegando á corta distancia del centro, donde se adelgazan mucho y presentan mua loba pequeña y alternantes con igual número de otros pequeños. Muralla 
hien mareada y algo wr'tesa; columnilla algo comprimida. Pola de Gordon; Aleje; Colle; Las Penolas.

211. S.? Torreanum, de Vern. et Ilaime =Phillipsastrea Torreama, de Vern. el Ilaime (Ibid; p. 132). - De superfieie plana; cílices bistante salientes, distantes dos veces al ménos su disimetro, que es de $212 m m$; 20 i 24 rostillas, irregularmente conlluentes of formando ángulos en los puntos en que se encuentran, muy delgatdis, lodas iquales, separadas $1^{\text {mm }}$; columnilla redonda, jequeña, saliente; 10 it 12 tahiques principales, alternantes con otros tantos pequeños; murallas bien mareadas, pero muy delgadas.-Sabero.

\section{AULOPORA.}

* 242. A. repens, Knorr. el Walch. $(s p) .=A$. serpens, fold. =IIlleporites repens, linorr. et Walch. (Ibid; p. 512)-Polipero trepante, siempre mity poco elevado y formando ma red ó una placa delgata en la superficie de los cuerpos en que se fija. Poliperilos cilindrico-turhinados, con epiteca, acostados, excepto en su extremidad superior, donde el ciliz liene un horde circular y presenta en su interior 12 dientecitos. La longitul de cada individuo es de 5 a ¿ $^{\mathrm{mm}}$; diámetro de los cálices de medio á milimetro y medio. Ferrones.

Reducida nos parece la cilra de especies devonianas que constan hasta la fecha; pero tenemos la esperanza que en breve ha de doharse su número. Tenemos indicadas ya otras muchas en muestras colecciones, de las cuales vamos á dar una ligera idea por via de apéndice.

1. Procedentes de las cercanias de Almaden (Guadalperal, ChiIlon, Casa de la Vega, etc.), los signientes: Un Dulmumiles, tal vez especie nueva, cuyas puntas del coccix se hallan muy desarrolladas; varios Orlhoceratites, un Bellerophon; diferentes bivalvas de los géneros Sanguinolites, Edmondia, Isocardia, Nucula, Avicula, etc.; diversos braquiopodos, entre ellos un Productus de espinas muy delgadas; crinoides que se presentan al estado de moldes y algunos coralarios.

2. ${ }^{\circ}$ Recogidas en la cordillera Cantábrica (Levanza, Mudi, Valdebreto, Colle, Sabero, Ferrones, eic.), numerosas especies, algumas 
quizás nuevas, entre ellas un Ilarpes, que recuerda el II. venulosus, Corda, del siluriano superior de Bohemia; otro parecido al $H$. crassifrons, Barr. por el borde espeso que separa el limbo de los carrillos; un Acidaspis casi idénlico al A. Leonhardi, Barr.; un Homalonotus muy semejante al II. bisulcatus, Salter, probablemente igual a una especie de Normandia, que creemos no está descrita todavia; otros varios trilobites de los géneros Proelus y Cyphaspis; una ConuLaria muy estriada á través asociada en la Collada de Llama í la Posidonnmya Pargai, Vern.: varias especies de Capulus y Calyptrara; diferentes braquiopodos, entre otros el Spirifer inflatus, Schlot; unos cuantos crinoides, tales como los Eleacrimes Verneuili, Troost; Cupressocrimes elongatus, Gold.; Platycrimus laciniatus, Gillb.; y por último, un gran número de poliperos, entre los que creemos reconocer las especies IIeliolites porosa, Blain.; Lyellia glabra, Edw et Haime; Chateles Trigeri, Edw et Haime; Favosites dubia, Blain. (sp); Amplexus cormu-bovis, Nich. (sp); Zaphrentis cliffordana, Edw et IIaime; Cyathophyllum vermiculare, Gold.; Smithia Pengillyi, Edw et IFaime, etc.

$5 .^{\circ}$ Encontradas por el Sr. Donayre en Luesma, Fombuena y Nogueras diversas especies, además de las mencionadas, entre las cuales llama la atencion un IIomalonotus, que tal vez sea una variedad del II. bisulculus, Salter, en la cual la prolongacion del eje del coccix parece ser mayor que en el tipo. El carapacho, de un color más oscuro que la roca en que se ofrece, se halla cubierto de numerosos hoyuelos a puntos hundidos redondos, diminutos, que debieron producir una granulacion muy fina en la costra interna de aprel, a juzgar por los moldes. Nueve anillos se cuentan en el eje del coccix, que es algo más estrecho que las lobas laterales, de las cuales está separado por surcos poco profundos anteriormente, pero bien marcados en la parte posterior. Las siete articulaciones laterales se corresponden con los siete primeros anillos del eje, y se encorvau suavemente de modo que las dos últimas casi son paralelas á aquel, dejando un espacio triangnlar intermedio, donde se indica una octava articulacion rudimentaria. 


\section{SISTEMA CARBONÍFERO.}

De la misma manera que el devoniano, en relacion con el cual se presenta en las diversas regiones de Espana, el sistema carbonifero liene su mayor desarrollo á mo y otro lado de la cordillera Cantibrica, desde las sierras de Sóbia y Agüeria hasta La Liévaina, ocupando una gran parte de las provincias de Oviedo y Leon, y una fraccion considerable de las de Santander y Palencia.

En Asturias ha sido objeto de muchos estudios, efectuados por varios gecilogos é ingenieros del Cuerpo de Minas, y dehemos citar entre otros á los Sres. Schulz, Paillette, Prado y De Verneuil.

El principal depósito en nuestra primera provincia hullera empicza por el 0 . en la sierra de $\Lambda$ gülería, el concejo de Quirós, el Aramo y el concejo de Riosa; luerce por el N. E. hácia el puente de Olloniego y Tudela, envolviendo los concejos de Lena, Mieres, Langreo, Aller, Laviana, Bimenes y Rey Aurelio, tan ricos en capas de comlustible. Entre Siero y El Infiesto queda cubierto por la laja cretácea del centro de la provincia, para reaparecer al 0. de EI Sueve, tocando la costa entre Colunga y Rivadesella hasta más allá de Colomhres, donde el creticeo y el numulitico vuelven á estar sobrepuestos.

Relacionados con este manchon principal, existen otros pequeìos, ya apoyados en los sistemas devoniano y siluriano que rodean it apuel, ya cercados por las formaciones del terreno secundario. CiLaremos, entre otros, la faja carbonifera de Maravio y Teberga, que principia en Tamera, y por el puerto de Ventana penetra por Torreharrio y Genestosa en las montanas de Leon; un depósito muy reducido, pero con una capa de carbon de mucha potencia, en la costa de Arnao; un grupo pecqueño en Ferrones; ofro en el Naranco, cerca de Oviedo; una faja que desde Tineo se prolonga hasta Cangas, á la izquierda del Narcea, y reaparece más al S. en Posada, Vega y 
la sierra de Santarbás, y otro islote que se re en Tormaleo, á la izquierda del Ibias, no muy distante del Vierzo (1).

A este lado de la cordillera Cantábrica, la formacion hullera estí representada en las provincias de Leon y Palencia, por una superficie de 500 libimetros cuadrados. En la de Leon es notable, sobre todo, el valle de Sabero, cercado por la caliza de Ilontaña y el devoniano, y осира su fondo el grupo IIullero con idénticos caracléres que en Asturias, existiendo algnnas capas de carbon (por regla general muy inclinadas al SO.), con potencia de $\mathrm{I}^{\mathrm{m}} 50^{(2)}$.

En la provincia de Palencia son notables aleunas capas de carbon yne alcanzan hissa $2^{m}$ de espesor, é inclinan generalmente de 50 á $90^{\circ}$. El grupo Hullero se prolonga desde Orbó á Barruelo y Lorés, y desde el valle de Santullan hasta Traspeña, pasando por San Cebrian, Vergaño, San Felices, Rubanal, Cervera y Castrejon, ocupando la parte más interesante mos 25 kilómetros de longitud. Análogamente à lo que sucede en la provincia de Leon, estos depósitos están en parte cubiertos por los sistemas triásico, jurásico y cretáceo; y por el E. se extienden hácia la Liévana (Santander). En esta comarea domina exclusivamente la caliza de Montana, yue constituye las elevadas regiones de los Picos de Europa.

Las dos grandes divisiones del sistema, í sean la caliza de Montaña y el grupo Hullero, se hallan muy desarrolladas en los depósitos que acabamos de enumerar. La caliza es casi siempre compacta, muy sonora, de colores claros, y tan parecida á la devoniana, que, fuera de los caractéres estratigraficos, no siempre bien discernibles, no hay más remedio que acudir á los fósiles para poderlas diferenciar. Con ella alternan á veces cuarcitas, areniscas y pizarrillas $\dot{o}$ cayuelas. El grupo Inllero empieza por lechos calizos, bastante delwados, que alternan con las primeras capas de carbon; sobre estas vienen los conglomerados y areniscas alternantes con arcillas pizarrosas, é interpuestos casi todos los yacímientos de combustible, sumando entre toda la série un espesor que no baja de 2,000 metros. En la provincia de Oviedo ocupa el sistema una extension de

(1) Véase la descripcion física y geológica de Astúrias, por D. G. Schulz.

(2) Véanse, para su estudio, las diferentes Memorias de Prado, y la de los Sres. Bernaldez, Lasala y Rua Figueroa, publicada en la Revistu Minera, t. 5. ${ }^{\circ}$, p. 720. 
2,700 kilimetros cuadrados, de los cuales 5/70 próximamente corresponden á la parte rica en carbon.

La cuenca de Belmez y Espiel ocupa una extension de unos 120 lilimetros cuadrados, comprendiendo parte de los tirminos de los dos puehlos citados, y Fuente Ovejuma, Villanueva del liey y Villaharla. En los cerros pre la rodean domina la caliza de montaña gris azuladia, cruzada por vetas de caliza espática. El sprupo Hullero estí ronstituido por bancos altermantes de conglomerados, areniscas y pizarras arcillosas, en general muy inclinados, y comprentiendo entre ellos de diez á doce capas de hulla, dos de ellas hasta de 1.5 í 20 metros de espesor (1).

La cuenca de Villanueva del Rio se halla al N. del pueblo del mismo nombre, situada en un valle de $11 n 0 \mathrm{~s} 1,500$ metros de ancho, atravesalo por el rio Huesua. Sólo se presenta la formacion carbonifera al descubierto en la extension de 3 kilómetros cuadrados, descansando, por el N., en estratificacion discordante, sobre las pizarras silurianas levantadas por el cranito que está á corta distancia, y cubierta en los otros rumbos por el mioceno marino, con un espesor de 50 a 60 melros. Por la denudacion de este villimo vuelve á aparecer el carbonifero mas al 0., hicia Cantillana y Castilbanco, en el valle del Biar (2), componiéndose en toda la enenca de areniscis á veces de grano tan grueso que pasan á una pudinga, alternante con lechos delgados de pizarra arcillosa blanda, de color negruzco, formando un espesor de 4 a 5 metros, debajo de la que viene el carbon yacente sobre otros bancos de arenisca y pudingas de cantos muy gruesos. Segun el Sr. Kith (3), en esta cuenca debe coutarse por lo ménos con $2.000,000$ de toneladas de combustible.

Con esta cnenca y la de Belmez deben relacionarse los depósitos carboniferos, comprendidos entre Zafra y Llerena, que ocupan una tran extension, segun el Bosquejo de De Vernenil y Collomb; pero hasta la fecha sin importancia industrial.

La cuenca de San Juan de las Abadesas, cuya extension parece

(1) Véanse, para mayores detalles, las Memorias de los Sres. Fernandez, Ramos, Parran y otros geólogos é ingenieros.

(2. Notes de Voyage sur la Sierra-Morena et sur le Nord de l'Andalousie, par M. Lan. An. des mines, 5e série, t. 12, p. 561, y Memoria de D. Ramon Pellico, publicada en la Revista Minera, t. 8, p. 229.

(3) Revista Minera, t. 8, p. 609. 
ser de unos 50 kilónetros cuadrados, se compone, seğm los ingenicros de Minas Sres. Maestre y Rodriguez, de areniscas y conglomerados cuarzosos en alternacion con calizas, pizarras y lechos de hulla. Has al 0., inmediato al valle de Aran en la provincia de Lérida, existe otro afloramiento carbonifero en Eril-Castell.

Aunque de reducidas dimensiones, existen además de los cilalos, otros yacimientos carhoniferos de que ligeramente vamos á dar cuenta. En el territorio de Juaros, á pocos kilómetros al S. E. de Búrgos (San Mtrian, Brieba, etc.), yacen en estratilicacion discorlante sobre las pizarras metamórficas, varias capas de arenisca y arcilla pizarrosa, con algunos lechos de carbon.

Pizarras hulleras existen tambien en Valdesotos y Retienda (Guadalajara.)

El depósito carbonifero de Hinarejos (Cuenca) señalado en la base por bancos de pudinga, allora sólo en las orillas del arroyo Castillejos, en una extension de unos 6 hectómetros. Las capas de carlon son de poca potencia, y alternan con psamilas y pizarras arcillosas en posicion casi horizontal.

En Puertollano ha sido recientemente reconocido el grupo Hullero, senalado por areniscas amarillas y arcillas carhonosas de color gris con algumos restos orgánicos; pero no sabemos si su importancia industrial responde i los trabajos de investigacion que se están practicando.

Segun recientes exploraciones que hemos efectualo en los Pirineos de Aragon, lal vez correspondan al grupo Hullero alğunos depósitos de reducidas dimensiones que hemos encontrado en la subida de Torla al Puerto de Gavarnie, a muy corta distancia de la frontera francesa, y el yacimiento antracifero de Sallent (valle de Tena), conocido ya hace tiempo y hoy abandonado. En ambos puntos hemos encontrado restos vegetales que asi nos lo hacen suponer. l)e todas maneras, su importancia industrial es escasa, ó más bien nula.

\section{PHILLIPSIA.}

* 245. Ph. Derbyensis, Mart. (sp).=Ph. seminifera, P'hill $(\mathrm{sp}) \cdot=$ Asaphus grameliferus, Phill. $=$ A. seminiferus, Phill. $=$ A. raniceps, Phill (Konincli: Descrip. des animaux foss. qui se trouvent dans le terrain carl. de Belgique; p. 601, 1.55, f. 2).-Cabeza algáo más 
larga que ancha, rodeada de un limbo extriado que termini en dos puntas muy cortas y agndas. Giabela regularmente bombeada $y$ muy poco ensanchadia por delinte; surcos laterales poco profiundos, que á veces desaparecen por el roce (A reniceps, Phill); los dos anteriores inclinados hícia adelante; los dos medios horizontales; los posteriores partiendo del centro del ojo hicia atrás; ojos grandes reniformes, finamente reticulados, minos elevados que la glabela. Eje del torax algo más ancho que las pleuras, con 10 segmentos. Coccix semicircular, con mu limbo redondeado; 12 anillos en el eje y 9 a 10 costillas a cada lado. Le adlornan, sobre todo en la cabeza, granillos que saltan fícilmente. Calizas de Melendreras; Valles de Mieres, Nller y Lena.

244. Ph. globiceps, Phill $(s p)_{\circ}=$ Asephus globiceps, Phill (Ibid; p. 599, 1. 55, f. 1).--Difiere de la anterior por su glabela muy dilatada y bombeada por delante; por sus ojos pequeños, ovales y oblicuos, y porque las puntas genales en que termina el limbo de la cabeza, que tambien es estriado longitudinalmente, son algo más largas. El torax es proporcionalmente más corto; pero en cambio el coccix ocupa //, de la longitud total, y lleva 14 segmentos en el eje y 12 a 15 á los lados, limitados por un limbo plano. Si como supone De Koninck, la cabeza tiene por hase un anillo occipital con pleuras iguales á las torácicas, tanto en esta especie como en la anterior, habremos de contar 9 segmentos en el torax en vez de 10. Asociada á la anterior.-Calar de Ledo. San Felices.

245. Ph. Eichwaldi, Fischer $(\mathrm{sp}))_{0}=P h$. mucronata, Mac Coy. =Asaphus Eichualdi, Fisch. (Murch., de Vern. et de Keysert: Gicol. de la Russie d'Europe et des mont. de l'Oural; v. 2, p. 276, 1. 27, f. 14). - Suponen De Vernenil y De Keyserling, que el coccix de las especies del género Phillipsic seria muy fácilmente separable del resto del cuerpo y más resistente á la descomposicion, porfue esta parte es la unica que se encuentra generalmente, siendo nuy raros los individnos completos. El coccix de la Ph. Eichuraldi es semi-eliptico, tiene un borde $i$ limbo ancho con una prolongacion caudiforme muy pequeña, correspondiente al eje, que, compuesto de 14 articulaciones, es casi tan ancho como las lobas laterales, en las que se cuentan de 9 a $\mathbf{1 0}$ algo más anchas. Longr. $1 \mathrm{I}^{\mathrm{mm}}$, lat. 15. Carece de los granillos que se ven en las anteriores. La Ph. Brom- 
yninrli, Fisch (sp), à la cual refiere esta especie M. Ie Koninck, sólo liene 11 segmentos en el eje del coccix, el cual es más ancho que las lobas laterales.-Astúrias.

\section{ORTHOCERATITES.}

* 246. O. cinctus. Sow. (Konnink: descri. des an. foss. qui se trouvent dans le tèrr. carb. de Belgique; p. 512, 1. 45, f. 6, 1. 44, f. 5, 1. 47, f. 5).-Especie del grupo Anuulutu, caracterizado por tener su superficie cargada de anillos transversos. En forma de un cono regular muy alargado, cuyo íngulo apicial no pasa de $8^{\circ}$; sifon central, estrecho y regular; tabiques poco profundos y muy distantes entre si, relativamente al perfueño diámetro de la concha, que en nuestros ejemplares llega rara vez á un centímetro: los anillos transversos rue la adornan son finos y salientes, separados porsurcos tan estrechos como ellos y ocupando 5 á 5 la anchura de 111 milimetro. Caliza arcillo-carbonosa de Revilla y Valdebreto.

*217. O. dactyliophorum, Kon. (Iliel; p. 518, 1. 17, 1, 2). -Adorinan toda su longitud gruesos anillos regulares redondeados, que distantes entre si de 6 a $8 \mathrm{~mm}$, corresponten cada uno it mu cámara. Tabiques muy hombeados en su centro, separados á distancias algo menores que $1 /$, de su diámetro; sifon central $1 / \mathrm{s}$ del diámetro de la concha, que es de $25^{\mathrm{mm}}$ en el único fragmento que tenemos á la vista.-Caliza de Lavanza.

\section{LITTORINA.}

248. L. biserialis, l'hill, $(\mathrm{sp}) \cdot)=$ Turho biserialis, Phill (Koninck: Deser. des an. Joss. qui se trouvent dans le ter. carb. de Belgiquu?; p. 458, 1. 40, f. (i).-Casi cónica, algo más larga que ancha, compuesta de o a 6 vueltas ligeramente deprimidas hicia el medio, con una dohle fila de pliegues arqueados transversales; de las cuales, la superior no se ve mís que en la última vuelta: en algunos ejemplares jóvenes, las dos filas se remnen y forman costillas seguidas; en otros, Turbo semisulcalus, Phill, sólo se encuentra la fila inferior. La boca es pequeña y oblonga, con una callosidad aplastada en el borde columelar; cel sutural presenta una depresion en forma de canal. Caliza de Las Caldas de Oviedo. 
299. L. Ciana, Vern. (Inidita?).-Concha globulosa, compuesta de cuatro ó cinco vueltas, siemdo la íltima tres veces mayor ytue lit suma de las demis, y todas con numerosos granillos, dispuestos en tresholillo, que ammentan en rolímen gradualmente deste las primeras vueltas a la bllima. Nhertura oval, mis larga que ancha.

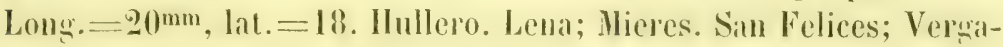
ño; Peña Castilla.

\section{CHEIMNITZIA.}

* 250. Ch. rugifera, Phill $($ sp).$=$ Melmin mifera, Phill.= Loxonemu rugifera, Phill (lbill; p. 462, I. 41, 1. 2).-Alargada, compuesta de 14 i 1 li vueltis de espira, convexas, con grmesas costillas longitudinales, ligeramente oblicuas, que ocupan los tres cuartos anteriores de la auchura lotal de cada vuelta, quedando el cuarto posterior, quie es deprimido, liso a simplemente estriado á traves. En la última vuelta se cuentan de 12 á 15 costillas, y además se divisan finas estrias de crecimiento, irregulares y arqueadas. Boca oval; columnilla con una callosidad delgada. Long. $=50 \mathrm{~mm}$, lat. $=$ 16; ang. espiral =18. Es comm a los sistemas devoniano y carbonifero.—Valles de Lena, Mieres y Aller. Vergaño.

**251. Ch. scalarioidea, Phill (sp).=M"lania scalarioidea, Phill (Ibid; p. 465, I. 41, f. 4).-Concha pequeña, cónica, compuesta de siete á ocho vueltas, regularmente convexas y adornadas con 55 a 78 rostilliks argueadas, cortantes, dirigidas en el sentido de la longitul y ocupando todo el espario visible de cada vuelta. La parte superior de la última es lisa; la hoca oval; la columnilla arqueada. Long. $=15 \mathrm{~mm}$, lat. $=6$. Caliza de Ilontana. Las Caldas de Oviedo; Valdehreto. Hullero de los valles de Mieres, Lena y Aller. Vergaño; San Felices; Barruelo; Celada.

\section{MACROCHEILUS.}

*252. IM. acutus, Sow. (sp).=Buccimem aculum, Sow. (Ilvid; p. 475, 1. 40, f. 10, I. 仕, f. 15).-Nlarwada, alyo fusiforme, muy puntiaguda, lisa ó con finisimas estrias de crecimicnto, compuesta de nueve á diez vueltas convexas, de las cuiles la hiltima ocupa más 
de la milad de la longitud total, que por término medio es de $50 \mathrm{~mm}$. Abertura mucho más larga que ancha, y casi oval; columnilla con un pliegue oblicuo, i veces dos, y una callosidad delgada, semicircular, que desaparece hácia el medio de la boca. Caliza de Montaña y Hullero. Las Caldas de Oviedo; Valles de Lena, Mieres, Aller y Teberga. Vergaño. San Felices.

\section{EULIIVA.}

* 25. E. Donayreana, nov. sp,-Concha alargada, lusiforme, lisa, compuesta de unas 14 vueltas, las últimas más convexas que las primeras y separadas por $11 \mathrm{~m}$ surco bien señalado, pero no profundo; la parte superior de la última vuelta es convexa y prolongada con regularidad; abertura estrecha, oval ó redondeada por arriba, angulosa inferiormente. Se distingue de la $\boldsymbol{E}$. Phillipsia$n a$, Kon., cuya existencia sospechamos tambien en España, por ser mucho más alargada proporcionalmente, y más prolongada en la parte superior. El áng. apicial de la especie belga es de $29^{\circ}$; nuestra especie, procedente de Vergaño (Palencia), solo mide $15^{\circ}$. Su long. $=60^{\mathrm{mm}}$, lat. $=14$. Dedicamos esta especie à nuestro estimado Jefe D. Felipe Martin Donayre.

\section{NERITA.}

* 254. N. variata, Phill $(\mathrm{sp}) \cdot=$ Natica variala, Phill (Ihid; 1. 481, I, 22, f. 8).-Globulosa; de espira corta, pero puntiaguda; muy gruesa; compuesta de 5 á 7 vueltas convexas, separadas por una sutura poco profunda. La íltima vuelta envuelve á las demás, ocupando los \% de la long. Lotal. Superficie cubierta de numerosas estrias de crecimiento, regulares, oblícuas, más pronunciadas hácia el borde sutural; abertura grande y semilunar, limitada por una fuerte callosidad desde el ángulo sulural hasta la extremidad anterior. Algunos ejemplares llegan á tener hasta $6^{\mathrm{cm}}$. Hullero. Lena, Mieres y Aller.

**255. N. plicistria, Phill (sp).=Natica plicistria, Phill (Ibid; p. 485, 1. 42, f. 5, $a, b, c)$-DDifiere de la anterior por ser 
más delgada y ménos globulosa, teniendo sus a a 7 vucltas ligeramente deprimidas hácia la sulura, que es bastante profumda; y por tener su columuilla cargada en sus dos tercios inferiores de pliegues

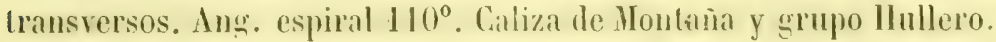
Las Caldas de Oviedo. Vergaño; Barruelo; San Felices.

236. N. spirata, Sow.= Nulicu planispira, Phill.=N. cllip-

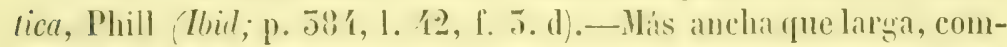
puesla de 4 á 5 vueltas comvexas en la parte anterior, deprimidas y hasta concavas en la posterior. Inebajo de su epidermis se muestran estrias finas de crecimiento, muy regulares y del mismo frueso cu toda su extension. Mbertura casi circular; colmmulla ancha, con pliegues transversales en su milad inlerior; cóncava, aruneada y á veces surcada en el centro en su mitad superior; ang. espiral $=140^{\circ}$. Asociada á la anterior.

* 25\%. N. ampliata, Phill $(\mathrm{sp}) \cdot=$ Valica ampliala, Phill (Ibid; p. 485, 1. 42, f. 2.)-Mucho más ancha que larga, compuesta de cuatro vueltas, de crecimiento muy rápido, con mumerosas esIrías, de crecimiento muy apretadas, debajo de la espesa epidermis yue cubre la concha; boca muy transversa, columnilla aplastada, lisa, escotada ligeramente en un horde externo. Por su espira, apeuas saliente, y por su anchura proporcionalmente mucho mayor, se distingue bien esta especie de las anteriores, con las que vicne asociadla.

\section{TURBO.}

253. T. Hæninghausianus, Kon.=(Descr. an. foss. du tèrrain carb. de Belgique; p. 155, 1. 40, 1.5.)-Globulosa, compuesta de cinco vueltas, ocupando la última los tres cuartos de la longitud total; lisa, sin ombligo: culumnilla aryueada, con una callosidad semilunar bastante ancha, y á veces dividida en dos partes iğuales por un surco longitudiual; abertura ligeramente oval. Hullero. Valles de Lena, Mieres y Aller.

\section{SOLARIUIM.}

259. S. fallax, Kon.=\$. antiqum, Kon.=\$. semistriatum, lion. (Ibid; P. 440, 1. 24, 1. 15 y 16.)-Concha pequeña, globulosa 
y redondeada, lisa ó con estrias muy linas de crecimiento, compuesta de cinco à siete vueltas, deprimidas en su parte superior; linea sutural profunda; ombligo estrecho, rodeado de una quilla saliente. lioninck hace notar que esta especie es intermedia por su forma entre el Solarium y el Euomphalus. Nuestros ejemplares son de menor tamaño que los de Bélgica é Inglaterra, pues rara vez llegan á 10 milimetros de diámetro._San Felices.

\section{EUOIMPHALUS.}

* 260. E. pentangulatus, Sow. (Koninck: Descr.des an. foss. qui se trouvent dans le terr. carb. de Belgique; p. 450, 1. 24, f. 9).Concha discoide, compuesta de seis i ocho vueltas arrolladas en un plano por la parte inferior, por cuyo centro se extiende una quilla saliente; boca próximamente pentágona, de ángulos redondeados, a excepcion del sulural y anterior; ombligo muy ancho y profundo. Toda la superficie esta adornada con estrias transversas, que se encorvan muy poco hicia atrás sobre la quilla. Las primeras vueltas llevan tabiques en su interior. Algunos ejemplares alcanzan grandes dimensiones. Penia de Gobezanes; Peña Deboyo; Valles de Mieres, Lena y Aller. Vergaño.

* 261. E. catillus, Mart. (sp). (Ibil; p. 427, 1. 24, f. 10).Discoide y redondeada; espira cóncava, compuesta de siele á ocho vueltas, apoyadas unas contra otras, angulosas á los lados, convexas exteriormente, con una quilla inferior y otra superior, ménos pronunciada, por el paso de las cuales se encorvan hácia atrás las estrias transversas que la adornan: sutura profunda; abertura casi trapezoidal, redondeada, tan alta como ancha; labro proeminente y redondeado oblicuamente. Algunos ejemplares llegan á tener $65^{\mathrm{mm}}$ de diámetro. Teberga; Laviana. Vergaño.

262. E. tabulatus, Phill (sp).=Cirrus talulatus. (Ibid; p. 429, 1. 24, f. 11). - Tal vez no sea más que una variedad de la anterior, cuya parte lateral de la última vuelta es plana en vez de convexa. Lena; Mieres; Aller.

$*$ 265. E. pugilis, Phill. $=E$. bifrons. Phill (Ibid; p. 422, 100 
1. 25, 1. 4.) Orbicular y muy deprimido, de espira plana ó ligeramente cóncava, compuesti de 7 it 8 vuchtas, algo comprimidas lateralmente y convexas en su interior; ron dos quillas, la inferior simple y regular en la juventud, tubereulosa en la illtima ó billimas rueltas de los adultos; lis superior es siempre tuberenlosi y limita el ombligo, que es muy ancho. En cada una de aquellas se cuentan de 16 á 17 tubéreulos por vuelta. Boca en forma de trapecio, crya hase estuviera formada por el labro; de seno muy pequeño, situado en la quilla inferior, en donde se hacen algo sinnosas las estrias de erecimiento que lleva la concha. En el interior hay tabiques, redondeados hácia atrás hasta la penúltima vuelta. Valles de Mieres, Lena y Aller. Bergaño; San Felices.

204. E. helicoides, Sow. (sp). = Ampullarin helicoides. Sow. (Ibil; p. 140, 1. 56, f. 5).-En general de sran tamaño y muy variable de forma, pues i veces es globulosa (Pleurolomaria ovoidea, Phill) y otras es muy deprimida (P. glabrala, Phill), existiendo todas las formas intermedias que ligan ambos extremos. Se compone de fi vucltas muy courexas y lisas, la viltima muy ámplia, que en su arrollamiento dejan un omblign el cual, aunque estrecho, permile ver por su iuterior lodas ellas, y está limilado por un ám @ulo redondeado; ahertura casi trapezoidal, redondeada por arriba; borde columelar recto y cortante. Caliza de Montaña; Las Caldas de Oviedo.

\section{PLEUROTOMARIA.}

265. P. pulchella. Kon. (Ihirl; p. 579, 1. 55, f. 6).-Concha pequeña, cónica, algo mís larga que ancha, compuesta de 6 vucltas muy convexas, separadas por una sulura profunda, y adornadas inferiormente por un enrejillado que le forman 5 a 4 costillas longiundinales pequeñas, cruzadas por otras oblicuas del mismo grrueso. Eucima de esta red hay otras dos rostillas lisas, entre las cuales se extiende la banda del seno, acompañadas de otra costilla marginal tuberculosa. La parte superior de la iltima vuelta lleva de 10 á 11 costillas longitudinales lisas, $\dot{o}$ atravesadas por otras de crecimiento apenas visibles: ombligo peqqueño y poco profundo; abertura ligeramente sinuosa en el lado columelar. Ang. apicial $=64^{\circ}, l_{0 n g} .=8^{\mathrm{mm}}$, lat. $=5$ á 6. - -Las Caldas de Oviedo. 
266. P. conica, Phill (Ibid; p. 595, 1. 51, l. 5).-Cónica compuesta de 10 a 11 vueltas, con dos quillas superiores lisas y poco distantes, entre las que se extiende la banda del seno, que lleva estrias escamosas encorvadas. El resto de la superficie está cubierto de una redecilla formada por el cruce de estrias longitudinales y transversales muy finas. Ombligo cerrado por una callosidad; boca algo oblicua y de forma entre ovoide y rombal. Asociada á la anterior.

* 267. P. Ivanii Leveillé $(s p)=P$. concentrica, Phill $=$ Trochus Ivanii, Leveillé (Ibid; p. 590, 1. 27, f. 1 y 7).-Cónica y turriculada, muy variahle, ya deprimida, ya muy alargada, compuesta de 7 i 8 vueltas, plegadas en su medio en ángulo casi recto, y dispuestas en escalinata unas sobre otras. La parte inferior es más ó ménos inclinada, á reces casi horizontal; la superior es vertical y paralela por lo tanto al eje de la concha. Cada una de estas partes lleva, a lo largo de las vueltas de espira, de 4 a 7 costillas salientes un poco desiguales, y situadas las más grruesas junto al ánģulo, donde á veces se reunen de 5 á 4 pequeñas que figuran la banda del seno. Todas están cruzadas por estrias de crecimiento oblicuas y apretadas. La última vuelta es convexa, y lleva en la parte superior de 15 á 25 estrias concéntricas al ombligo, el cual está casi siempre cubierto por el borde de la columnilla. Abertura casi semicircular, más ó ménos transversa, segun la diferente depresion de los individuos, $\Lambda$ g. espiral entre 60 y $95^{\circ}$. Nuestros ejemplares, procedentes de las calizas arcillosa y arcillo-carlonosa de San Felices, parecen ser algo menores que los de Bélgica, pues solo miden una long. $25^{\mathrm{mm}}$ por una latitud de 20.

268. P. Vidalina, nov. sp.-Especie del grupo de las $P$. globost", compuesta de 5 vueltas de espira regularmente convexas y redondeadas, de las cuales la última, que ocupa más de la mitad de la longitud, forma por la parte superior una depresion casi plana, sin ombligo perceptible junto á la columnilla. Linea sutural profunda, y paralela i ella adornan toda la superficie de la concha costillas salientes, separadas por anchos surcos, de las cuales las inferiores son algo mís gruesas. En la última vuelta se cuentan diez de esas costillas por bajo de la banda del seno, que es ancha y lleva dos pliegues poco perceptibles, y por encima de la misma se extienden 
mans 18 a 19 concentrieas, algo mís delgadas que las primeras. Todas ellas "stim cruzadas oblienamente por estrias de crecimient" mis apretadas en las primeras vuchas y en la parte superior de la íltima. Boca angulosia. Longr. =2/mm, lat.=25. En un principio referimos varios ejemplares a la P. radula, lion, cuyas vueltas son menos redondeadas, li úllima ménos deprimida en su parte superior; las costillas designales, interealindose otras perfuenas entre las principales, y las estrias de crecimiento mis apretadas. Tenemos un placer en dedicar esta bonita especie á nuestro querido companero D. Luis M. Vidal. Pizarras arcillo-carbonosas de Langreo, Mieres, Aller, Lena y Riosa. Al N. de los Picos de Europa. Vermaño.

\section{IMURCHISONIA.}

* 269. Mi. angulata, Phill (sp).=Rostellaria angulala, Phill (Ithil; p. 412, 1. 58, f. 8, 1. 40, 1. 8).-Wuy variable, regularmente cónica y muy alilada, compuesta de 16 a 18 vueltas de espira, formada cada una de dos bandas planas de igual anchura reunidas en el medio, bajo un ámgnlo de $115^{\circ}$. Los adornos varian considerablemente: el tipo de la especie liene una costilla á lo largo de las vuettas en medio de cada banda; la var. a es lisa; en la var. $c$ cada banda estí divilida en tres partes iguales por dos costillas; en la var. d ( $M$. antiquata, Kon.) hay (res. Todas estas variedades llevan estrias oblicuas, pocas veces perceptibles à simple vista. Ang. esp.=14 á $16^{\circ}$, long. $=\mathbf{4} 0^{\mathrm{mm}}$, lat. $=8$ à 9 . Hullero. Denués; San Felices.

270. MI. abbreviata, Sow. (sp).=Turritella ablreviata, Sow. (Ilicil; p. 415, 1. 38. f. 5 y 6).-Cónica, compuesta de 8 a 10 vueltas, con dos quillas salientes, entre las cuales se extiende la banda del seno. En algunos ejemplares hay debajo otra tercera quilla mücho más fina. La última vuelta es muy aplastada por encima y lleva de 4 a 5 cordoncillos a lo largo: columnilla simple; loca redondeada casi del todo; Ang. esp. $=25^{\circ}$. Valles de Lena, Miéres y Aller. San Felices.

\section{CAPULUS.}

271. C. vetustus, Sow. (sp).=Pileopsis velusta, Sow. (Iloid; p. $552,1.22$, f. $7,1.25$ his, f. 2 ). - Vértice muy excéntrico hicia atrís, a reces arrollado dos veces sobre si mismo, ya en el plano 
que pasa por el eje de la concha, ya algo torcido á su derecha. Boca circular ú oval anteriormente, de hordes divididos en varias lobas (de 5 a 12); la posterior levantada hácia arriba de modo que casi la toca el vértice. Estrias concéntricas irregulares.-Vergaño.

272. C. neritoides, Phill (sp).=Pileopsis neritoides, Phill (Ibiil). -Difiere del anterior por su vértice más grueso, mucho más retorcido, más excéntrico, casi tocando al horde posterior, que, asi como Jos anteriores, es delgado. Abertura oblicua, comprimida, ligeramente sinuosa._Las Galdas.

\section{BELLEROPHON.}

** 275. B. hiulcus, Mart. (sp). $=$ B. Munsteri, d'Orb. (Koninch: Descrip. des an. foss. qui se trouvent dans le ter. carb. de Belgique; p. 548, 1. 27, f. 2).-Globulosa, tan larga como ancha, á veces transversa, con numerosas estrias transversas, finas, Iaminosas, encorvadas hácia atrás en la quilla, que es ancha. Nhertura corta y muy ancha. Ombligos cerrados por una gruesa callosidad, que deja. una ligera depresion. Algmos ejemplares llegan á tener $8^{\mathrm{cm}}$ de diámetro. Hullero. Miéres. Barruelo; San Felices; Valdebreto; Vergaño.

* 274. B. vasulites, Mont. (Ilidi; p. 550, 1. 27, f. 5).-1)e regular tamaño, casi del todo redondeada y globulosa, con estrías transversas muy marcadas que se encorvan á su paso por la quilla, que es saliente y escamosa; tiene esta concha la abertura bastante grande y reniforme, y en los ejemplares adultos se hallan cerrados los ombligos por una callosidad. Caliza de Montaña. Las Caldas de Oviedo.

275. B. Dumonti, d'Orh. (Ihid; p. 551, 1. 28, f. 6).-Ménos globulosa que la anterior, es notable por las callosidades laterales, que, cerrando los ombligos, producen en su lugar nna proeminencia, extendida en semicirenlo al rededor de las extremidades de la aliertura, que es semilunar y de horles laterales muy gruesos. Las estrias de crecimiento son finas y se encorvan tambien al pasar por la quilla, que es poco proeminente y estrecha. Caliza de Montaña. Las Caldas de Oviedo. 


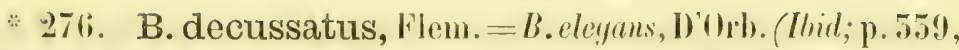
1. 29, f. 2 у 5, 1. 50, f. 5).-Concha Globulosa, delgada, frígil, y casi siempre de pequeña talla, adornada en cada lado por 60 á 70 estrias longitmdinales, que á veces en los adultos se horran hácia la quilla y ombligo, y cruzadas por estrias finas de crecimiento. 0mhligos pequeños, pero profundos, en parte obstruilos por la prolongacion lateral del labro, que en esa parte se engruesa y encorva ligeramente hácia fuera, y es afilado en el resto de la aberturit. (Quilla ancha y redondeada. Valles de Lena y Miéres. Vergaño.

277. B. tenuifascia, Sow. (Ibit; P. 547, 1. 27, f. 4):-C'oncha delgada y slobulosa con estrias finas de crecimiento, muy apretadas, apenas arqueadas y en ángulo casi recto con la quilla, que es muy estrecha, poco saliente, y, aunque parece lisa á simple vista, deja notar, examinada al lente, estrias encorvadas, indicando la forma y longitud de la hendidura central del labro, que es muy estrecha. Abertura casi reniforme, poco prolongada lateralmente, ombligos anchos, en forma de embudo, algo obturados en los adultos por la callosidad de las partes laterales de la abertura. Caldas de Nontaña. Las Caldas de 0viedo.

*278. B. Urii, Flem. (Ibid; p. 556, 1. 50, f. 4).--Tan larga como ancha, se distingue fícilmente de las anteriores por las costillitas pequeñas, que, en número de $\dot{3} 6$ a $\mathbf{5 8}$, adornan la mitad inferior de su última vuelta: la otra mitad es lisa, y en vez de quilla liene un surco ancho poco profundo. Los ombligos están reemplazados por fosetas redondeadas poco profundas. Nbertura semilunar, muy transversa; hendidura ancha y poco profunda. Caliza de montaña de Arenas de Cabrales. Vergaño.

* 279. B. sub-Urii, nov. sp.?-Dudamos si un ejemplar que tenemos á la vista procedente de Iliéres, corresponde á la especie siEniente, si es en realidat nneva, $\dot{o}$ si más bien debe considerarse como una variedad de la anterior, de la que se distingue por ser ménos wobulosa y no tener más que 8 i 9 costillas longitudinales á cada lado del surco dorsal, donde se percibe otra costilla mís delgada que las laterales. Lstas, que son filiformes, se hallan separadas por espacios casi planos de uno y medio á dos milimetros de anchura, y desaparcen en la última vuelta como en el $B$. Irii, Flem., mar- 
cimlose tambien algumas estrias de crecimiento encorvadas. Ilullero.-Mieres.

230. B. Naranjoanus. Vern.-Creemos que esta especie se halla inédita, y no la encontramos indicada en las colecciones. En su lugar tenemos á la vista la anterior y la siguiente, que dudamos si alguma de ellas corresponderá á la recogida en Astúrias. Provisionalmente, y en tanto este punto se aclara, damos los caractéres propios de cada una de las que poseemos, y que, por otra parte, no podemos referir á ninguna de las conocidas.

* 281. B. gracilis, nov. sp.?-Especie pequeña y elegante en la cual, además de la quilla dorsal muy saliente, hay otras dos laterales casi tan sen̂aladas como aquella en casi lodos los ejemplares, y separadas cntre sí por dos espacios cóncavos muy hundidos. Adornan la concha finas estrias filiformes longitudinales, que con otras de crecimiento casi microscópicas, forman un espeso enrejillado. La boca es muy transversa, de contornos sinuosos, plesada hacia afuera y dilatada lateralmente ocullando los ombligos. Su longitud, ó sea la mayor anchura de la concha, es de $11^{\mathrm{mm}}$. Hullero. San Felices.

\section{DENTALIUIM.}

* 282. D. ornatum, Koninck (Descr. des an. foss. qui se trouvent dans le ter. carb. de Belgique; p. 518, 1. 22, 1. 5).-Ligeramente encorvada y comprimida lateralmente, con unas 90 costillas longitudinales, cruzadas por estrias de crecimiento apenas perceptibles. Abertura anterior muy oblicua; la posterior truncada en una direccion opuesta a aruella, y en parte cerrada por un diafragma liso que lleva una hendidura. Algunos ejemplares alcanzan hasta $10^{\mathrm{cm}}$ de longitud. Caliza de Montaña y IIullero, Cabrales; Fuente de los Pastores en la sierra de Covalierda. San Felices.

\section{PHOLADOMYA.}

185. Ph. regularis, King. (sp).=Allorisma regularis, King. Murch., Vern. el Keys: Géol. de la Russie d'Europe et des mont. de 
loural; 1. 2, p. 298, 1. 19, l. 6, 1. 21, 1. 11).-Muy inequilátera, alargada transversalmente, dos veces y media mís ancha que larga. Valvas redondeadas en su extremilad anal, ligeramente truncadas en la bucal, que es muy corta, por cuyo molivo los nates casi son terminables. La superficie esti cubierta de pliegnes transversos, anchos y salieutes, paralelos í losbordes, y redondeados en un saliente apeuas sensible, que atraviesa diagonalmente la concha: a $10^{\mathrm{mm}}$ del nates se cuentau 12 i 15 en un espacio de $20^{\mathrm{mm}}$. Long. $=32$, lat. $=75$, esp. $=24$. Hullero: valles de Lena, Mieres y Aller.

284. Ph. sulcata, Phill $(\mathrm{sp}) \cdot=$ Sanguinolaria sulcala, Phill. (Gíol. of Yorkshire; 1. 2, p. 209, 1. 5, f. 5).-Difiere de la anterior por tener en su region anal arrugas que se dividen en dos í tres más estrechas al prolongarse en la parte media de la concha. En los moldes se ve que el soporte ligamentario es vertical con relacion al borde cardinal, mientras que en la especie anterior la impresion de esa límina interua, es paralela á este último. Caliza de Montaña. Las Caldas de Oviedo.

\section{CYPRICARDIA.}

285. C.? tumida, Phill $(\mathrm{sp}) \cdot=$ Nucula tumida, Phill (Ibid; p. 210, 1. 5, f. 15).-Concha pequeña y globulosa, concéntricamente estriada; nates muy reducidos; region luncal muy corta; region anal más estrecha y redondeada. IIullero: Valles de Lena, Hieres y Aller.

\section{CONOCARDIUIY.}

* 286. C. alæforme, Sow. (sp).=C. elongahum, Bronn. $=C a r-$ dium alcefore, Sow. (Koninck: Descr. des an. foss. qui se trouvent dans le terr. carb. de Bely.; 1. 85, 1. 4, f. 12).-Triangular y transversa, hombeada; con numerosas costillas radiantes aplastadas; las menores en la parte media de la concha, las más gruesas en la region anal, y cruzadas por numerosas estrias de crecimiento muy onduladas. Region bucal truncarla y aplastada, con una prolongacion alargada en forma de pico, que tiene la misma direccion que el borde cardiual, y es en proporcion tanto mís largo cuanto más jóven es 
el individıo. La superficie truncada y casi plana que rodea este pico es cordiforme, y está limitada por un surco, del que parten oblicuamente costillas regulares y paralelas entre si, que no se muestran más que en la base del mismo. Reģion anal casi cónica, muy prolongada, y nates muy encorvados y próximos, situados muy inferiormente; borde cardinal recto; charnela con un diente en la valva derecha, colocado debajo del nates y destinado á alojarse en una foseta de la otra valva. El horde de la region bucal tiene señaladas interiormente de 20 a 50 dentelladuras, que se corresponden con las costillas de la superficie aplastada cordiforme; el borde frontal (opuesto á la cliarnela) es liso; y el anal, en su mitad extrema, liene pliegues, y parte del más elevado; una lámina interior oblicua, que, segun Koninck, parece reemplazar el diente lateral de la region anal. Hullero: valles de Lena, Mieres y Aller; Vergaño.

* 237. C. Ouralicum. Vern. et Keiys. (Géol. de la Russie d'Europe; 1. 2, p. 501, 1. 20, f. 11).-Wac Coy refiere esta especie al C. rostrahum. Mart. (sp.) y $\Lambda$. D'Orbigny al $C$. minax, Phill (sp.), que á su vez es para el primer autor citado una sinonimia del $C$. alceforme. Sow. (sp.) En tanto se decide su verdadera colocacion, suponemos que la especie rusa está representada en nuestro pais por un ejemplar procedente de Muñon de Lena, y caracterizada por su region bucal redondeada, y no cordiforme ni cóncava como la del $C$. alceforme, Sow., siendo reemplazado el pico de esta por una orejeta pequeña en cada valva. La region anal es muy alargada y entreabierta, y está separada del cuerpo de la concha por un surco profumlo que produce en el borde una escotadura. En ambas valvas hay costillas radiantes cuneiformes, anchas en su terminacion, estrechas en el limbo y separadas por surcos muy estrechos.

* 288. C. Cortázari, nov. sp.-Concha triangular y muy transversa, compuesta, como todas las especies del género, de dos partes, el cuerpo de la concha y la expansion aliforme. Aquel es boubeado y deprimido en el lado bucal, de donde sale por la region cardinal, como en el $C$. aleforme, Sow, una prolongacion cilindrica en forma de pico. Nates tan encorvados, que parecen arrollarse uno sobre otro: charnela recta. Un surco profundo separa el cuerpo de la concha de la expansion aliforme, que es triangular, cilindroide, mís gruesa en la region cardinal que en la frontal; entreabierta y 108 
adornada con 2i a 50 costillas radiantes filiformes, separadas por surcos ó depresiones cuatro reces más anchas que su grueso. El cuerpo de lia concha estí cubierto de una epidermis gruesa, en la que se senalan numerosas estrias concéntricas de crecimiento, alugo onduladas, debajo de las cuales se descubren por el desgaste en cada valva, unas lis it 20 costillas radiantes, anmulosas, en forma de tejadillo, separadas por estrechos y profundos surcos que dejan en los bordes, y por lo tanto en los moldes, otras tantas dentalladuras bien marcalas. A su vez los surcos ofrecen á la lente finisimas estrias longitudinales y trasversales. En algunos ejemplares donde el descaste ha sido mayor, aparece cada costilla compuesta de tres, dos laterales filiformes y una central algo más gruesa y erizada de espinas. Longitud del cuerpo de la concha $=27 \mathrm{~mm}$; longitud del surco yue le separa de la expansion aliforme $=24$; longitud de la rewion cardinal, ó sea anchura total de la roncha $=\mathbf{4 6}$. Inullero. San Felices, (Palencia). Tenemos un placer en dedicar esta especie á nuestro estimacio amigo y compañero D. Daniel de Cortázar.

\section{CARDINIA.}

* 289. C. subovalis, nov. sp.-Concha casi oval, de superficie convexa, deprimida hácia el corselete, que es alargado, profundo y lanceolado, y está limilado por dos quillas salientes, rectilíneas, que desde el nates llegan hasta cerca de la extremidad anal, la cual es redondeada y casi tan aucha como la bucal. Nates pequenos, comprimidos y situados en el tercio iuferior; lúnula lanceolada, profunda y limitada por dos quillas agudas algo cóncavas. La superficie se halla cubierta de unas 50 estrias concéntricas, como la C. oralis, Mart. (sp), la cual tiene su region anal más prolongada y estrecha proporcionalmente. Long. $=20^{\mathrm{mm}}$, lat. $=15$. Hullero. San Felices. Orbó.

\section{AVICULA.}

* 290. A. virgula, Kon. (sp).= Mijalina virgula, lion. (Deser. des an. foss. de Bely.; 1. 127, 1. 6, f. 5).-Mlargada oblicuamente, redondeada por la region anterior, sinuosa por la posterior, que se prolonga en ala; nates muy pequeños, apenas encorrados, region 
cardinal doble de gruesa (en los moldes) que la opuesta. Hullero. Vergaño.

\section{POSIDONOIMYA.}

* 291. P. vetusta, Sorv. (sp).=Inoceramus velushus, Sow. (Kon: Descr. des an. foss. de Belg.; p. 141, 1. 6, f. 1).-Concha alargada, de vértice puntiagudo y bombeado; redondeada inferiormente; region posterior prolongada en ala pequeña; region anterior escotada, aplastadla de adelante para atrás, determinando una especie de lúmula oval bastante grande. La superficie está ondulada por gruesos pliegues $\dot{\delta}$ arrugas transversas, bastante regulares, concéntricos, en número de 12 á 20.-Caliza de Montaña. Levanza.

\section{TEREBRATULA.}

292. T. hastata, Sow.-(Davidson: Monograph of british carloniferous brachiopola; p. 11, 1. 1, f. 1 à 12.-Palrentografical Sociely. London, 1857). - Concha alargada, oval ó ligreramente pentágona, más o ménos truncala en la region frontal, rematando en punta hácia los nates. Valvas casi igualmente convexas, con una depresion central ancha en los adultos; forámen ancho, oval, interesando bastante el deltidium; superficie con algunas lineas concéntricas de crecimiento poco marcadas, y algunas listas rojizas en los ejemplares muy bien conservados.-Caliza de IIontaña. Las Caldas de Oviedo; Teberga.

\section{SPIRIFER.}

$\%$ 295. S. Striatus, Martin $(\mathbf{s p}) .=$ S. altenualus. Sow $=S$. condor, d'Orl).=Anomitis striatus, Martin (Ibid; p. 19, 1. 2, f. 12 a 21,1.5, f. 2 i 6 ). - Muy variable, transversalmente semicircular ó casi rombal, de valvas casi igualmente convexas, de las cuales la mayor (inferior ó dorsal) lleva un bocel de regular elevacion, mientras que el seno de la opuesta es muy variable en su ancho y profundidad. Charnela un poco más corta que la mayor latitud; ángulos cardinales más ó ménos redondeados en los adultos; área de moderada anchura, con una fisura triangular parcialmente cubierta por pseudo- 
deltidium. Superlicie de la concha adornada por un numero variable de costillas radiantes que ammentan a distancias variables del nates por la intercalacion de otras, contimlose en el míryen de 60 a $90 \mathrm{en}$ cada valva, de las cuales corresponden al seno y al bocel de 15 a 50 segun los individuos: a todạs ellas las cruzan fimas estrias de crecimiento. En el interior de la valva menor hay ma foseta alargada á uno y otro lado del proceso cardinal, y 4 impresiones musculares producidas por el músculo aductor. Los conos espirales de su aparato hraquial están formados por 20 a 22 vueltas cada umo. En el interior de la valva mayor hay á cada lado de la base de la fisura un fuerte diente cardinal. Caliza de Montaña y Hullero. Concejos de Caso, Lena, Mieres, Aller y Riosa. La Florida; Vergaño; San Felices.

$\because 294$. S. mosquensis, Fischer $(\mathrm{sp}) .=$ (Choristites mosquensis, Fischer.$=C h$. Sowerlyi, Fischer.-Ibid; p. 22, 1. 4, 1. 15 y 14).Semi-oval ó semi-circular, mís ó ménos alargada en los adultos; charnela generalmente tan larga como la mayor anchura de la concha; área con una fisura triangular, cubierta en parte por un psendo-deltidium; nates encorvados y próximosentre si. Valvas á veces muy convexas, adornadas cada una con 55 a a fí costillas radiantes, estrechas, desiguales, de las cuales 12 a 16 ocupan el seno, que es superficial, y el bocel, que es poco elevado. Se señalan ademís lineas concéntricas de crecimiento, sobre todo en la region marginal. Se distingue de la especie anterior por su forma ménos transversa; y por el interior de la valva ventral, cuyos dientes cardinales se prolongan en dos láminas anchas y verticales hasta los $\%$ de la longitud. Caliza de Montaña de Caso, Puente Lorio, La Mnnèa, Linariegas, Cordal de Laviana, San Emeterio. Valdebreto; Celada. Hullero de Lena, Nieres, Riosa, Aller y Teberga. San Felices.

* 295. S. crassus, Kon. (Ibid; p. 25, 1. 6, f. 20 a 22).Transversalmente oval; valvas casi igualmente convexas; charnela bastante mís corta que la mayor anchura, carácter que le diferencia de las dos especies anteriores. Area triangular, redondeada en sus extremos, con estrias verticales muy visibles; nates pequeño, sin ocultar al retorcerse más que una parte pequenia de la abertura, que es ancha. Superficie con 45 a 70 costillas redondeadas, desiguales, bifurcadas é intercaladas unas en otras, de las cuales de 7 i 12 ocu- 
pan el seno y el hocel que son poco pronumciados Caliza de montaña y Hullero. Melendreras; Riosa. Valdebreto; Vergaño.

\section{* 296. S. convolutus, Phill (Ilidi; p. 55, 1. 5, f. 2, a 15).-} Concha fusiforme, tres á cuatro reces mís ancha que larga; charnela recta; irea estrecha con una fisura triangular en parte cubierta por un pseudo-deltidium; nates pequeños y encorvados; extremos cardinales muy agudos; valva ventral algo más convexa que la opuesta, con un seno de variable profundidad y anchura, al que corresponde un bocel saliente en la dorsal. En cada una de ellas hay de $\mathbf{5 0}$ á $\mathbf{4 0}$ costillas radiantes, gruesas las centrales, más delgadas las cardinales, ocupando de tres á cuatro el seno y el bocel._Caliza de Montana y Hullero. Melendreras. Vergaño.

* 297. S. planatus, Phill (1) (lbid; p. 26, I. 7, f. 25 a 56).Concha pe(fuena, casi circular ú oval-trigona, tan larga como ancha, de charnela corta y área pequeña. Valva dorsal medianamente convexa, indicándose casi siempre en ella un bocel central por medio de dos surcos más profundos que los que separan las costillas radiantes, que son en número de 50 á 50 en cada valva, ocupando cuatro á cinco el bocel. Valva ventral ó superior mucho más convexa que la dorsal, con un seno estrecho que produce una ligera inflexion marginal, y nates prominente y encorvado. Caliza de Montaña. Valdebreto.

* 298. S. bisulcatus, Sow.=S. trigonalis, Sow., non Mart. (Ilbid; p. 51, 1. 5, f. 1, 1. 6, f. 1 á 19, 1. 7, f. 4).-Semicircular ó casi romboidal, algo mis ancha que larga, de valvas casi igualmente convexas, charnela algo más larga que la mayor anchura, con los extremos cardinales ya redondeados, ya angulares, y área con una abertura triangular cerrada en parte por un psendo-deltidium, licne los nates muy encorvados y próximos entre si. En cada valva hay de 50 á 40 costillas redondeadas, á veces aplastadas, rara vez bifurcadas, intercalándose las secundarias á distancias variables del nales, y ocupando unas 7 el seno, que es de mediana profundidad, y 7 á

(1) La mayor parte de los autores ingleses admiten el nombre de Spirifera, y no Spirifer; y así, Phillips y Davidson dicen S. planata, S. cras$s a$, etc. 
9) borel, donde se agrupan en treshaces separados por surcos algo mis hondos. - El s. trigmulis, Mart. (non Sow.), ron el cual te han confuntido varios autores, es alyo menor; tiene solo unas 25 costillas radiantes, y su bocel es clevado, angular y prolongado, en vez de ser muy deprimido y redondeado. Caliza de Montaña de Arenas de Cabrales; caliza arcillosa de Melendreras y Vergaño.

299. S. pinguis, Sow. $=$ S. rotundufus, Sow. (Ibid; p. 50, 1. 10). - Nuy rariable, oblonga u oval transversalmente; con frecuencia tan ancha como larga; rara vez más larga que ancha; charnela mis corta que la mayor anchura; ingulos cardinales redondeados; valva dorsal (la inferior, ó sea la menor) no tan convexa como la opuesta, con un hocel ancho, liso y deprimido en su centro; valva ventral muy bombeada, de nates muy encorvado, ocultando en parte el área, que es ancha; seno más ó ménos profundo, ancho, con dos ó más costillas longitudinales, á veces poco señaladas: en cada valva hay de 16 a 50 costillas redondeadas y deprimidas; en algunos ejemplares bifureadas y desiguales. Caliza de Montaña. Las Caldas de Oviedo. Vergaño.

500. S. integricosta, Phill (Ibil; p. 55, 1. 9, f. 15 a 19).Oval transversal ó longiludinalmente, casi circular cuando jóven; con 20 i 24 costillas redondeadas en cada valva, de las cuales tres ocupan el bocel; charnela mís corta que la mayor anchura; valva ventral mas convexa que la dorsal. Se distingue del S. ovalis, Phill, porque esle tiene su bocel sin costillas. Caliza de Montaña: Peña de liobezanes y Peña Dehoyo, Caso; Puente Lorio, Laviana. Hullero: Riosa y Teberga.

* 501. S. glaber, Martin (sp.)=S. obtusus, Sow.=S. oblatus, Sow. $=S$. lovigatus, Buch. (Ibid; p. 59, 1. 11, f. 1 á 9, 1. 12, f. 1 á 5,11 y 12).-Muy variable; oval transversalmente, casi siempre más ancha que larga, lisa en general, rara vez con pliegues redondeados hácia el márgen poco marcados (var. S. linguifera, Phill). Charnela mucho más corta que la mayor anchura; nates encorvados y próximos entre sí, muy torcido el de la valva ventral. El seno es muy variable: en la mayor parte de los ejemplares es ancho, aplanado y mal definido; en otros es muy hondo y como surcado en su centro: su forma influye necesariamente sobre la del bocel, que 
es más ó ménos elevado, y á reces deprimido en el medio. Muy abundante en la caliza de Montaña de todos los paises, tambien se ha encontrado en el devoniano de Inglaterra, Bélgica, Alemania, etc. Valdebreto; Vergaño; Celada.

* 502. S. lineatus, Martin (sp.)=Terebralula lineala, Sow. $=$ T. imbricatu, Sow. (Ibid; p. 62, I. 15, f. 1 a 15).-Wás globulosa que la anterior, tiene tambien la charnela mucho más corta que la mayor anchura, y sus ángulos cardinales redondeados; pero el seno y el bocel apenas se indican respectivamente por una ligera depresion ó relieve, siendo uniformemente convexas una y otra valva. Toda la superficie está marcada con numerosas estrias concéntricas, lamelares, finamente festoneadas en los bordes de los ejemplares, muy bien conservados: estrias radiantes muy finas, raras veces visibles á la simple vista, las cruzan en ángulo recto. Area peqqueña. Caliza de Montaña: Las Caldas de 0viedo. Hullero: Mieres, Riosil, Lena. Vergano; Valdebreto.

505. S. Lamarckii, Fischer (sp).=Choristites Lamarckii, Fischer (Murch., Vern. et Keys: Géol. de la Russie d'Europe et des mont. de l'Oural; p. 152, I. 6, f. 8).-Valvas muy bombeadas, sobre todo la superior ó ventral, que tiene el nates encorvado. La superficie está finamente estriada y lleva además dos pliegues muy salientes y agudos en el bocel, y otros tres con iguales condiciones á cada lado, empezando todos a $1 / 5$ de la longitud, y produciendo festones muy dentellados en los bordes. Hullero. Lena y Mieres.

504. S. incrassatus, Eichw. (sp).-(Ibid; p. 166, 1. 6, f. 5). -Especie parecida al S. bisulcalus, Sow., del que se distingue por' sus pliegues redondeados, separados por surcos más estrechos y profundos; en el bocel hay tres algo más anchos que los laterales, que son en número de 24 en cada valva. Caliza de Montaña y Hullero de Laviana, Lena y Mieres.

\section{SPIRIFERINA.}

305. S. cristata, Schlot. (sp.); var. Spirifer octoplicalus, Sow. (Davidson: A. monograph of the britsh carboniferous brachiopoda; p. 58, 
1. 7 , f. 57 a 47 . Concha pequenita, transversa, de charmela tan larga como su mayor anchura, y de valvas igualmente convexas, cadia mua de las cuales lleva de 8 i 12 costillas angulares y salientes, cruzadas por líminas de crecimiento escamosis, que erizan de asperezas la superficie, acribillada ademas de numerosas perforaciones. Los ángulos cardinales son agudos ó ligeramente redondeados; el área, cúncava y de variable anchura, tiene su forámen cubierto en parte por un pseudo-deltidium; el nates es pequeño y retorcido; el bocel, constituido por un pliegue central más ancho que los laterales, se ofrece a veces trilobado en la region frontal; y el seno, profundo y agudo, presenta en alguma que otra ocasion una costilla rudimentaria hácia el márgen. Caliza de Montaña. Peña de Gobezanes y Peña Deboyo, Caso.

\section{SPIRIGERA.}

506. S.planosulcata, Phill (sp).=Spiriferaplanosulcala, Phill. $=$ Terelnatula de Ronyssyi, Vern $=T$. planosulcata, Kon. $=$ A trypa planosulcala, Sow.=A. oblonga, Sow. =Allhyris plemosulcata, Dav. (Ilid; p. 80 , I. 16, f. 2 a 15).-Confusamente pentaedra ú orbicular, con numerosas expansiones laminosas concéntricas solo salisfactoriamente conservadas en los buenos ejemplares, tiene las dos valvas igualmente convexas, á veces con una ligera depresion en la region frontal. Nates de la valva ventral pequeño, algo encorvado y con un diminuto forámen que toca al nates de la otra valva. Lena y Ilieres.

\section{RHYNCHONELLA.}

* 507. R. acuminata, Martin (sp).=Terelralula acuminata, Sow. (Davidson: Ilbid; p. 95, 1. 20 y 21).-Sumamente variable, mís ó ménos trigona, en forma de corazon ó confusamente pentágona, unas veces lisa, otras plegada, con un seno muy levantado y agudo en unos ejemplares, $\dot{o}$ redondeado y mucho más corto en otros, tiene la valva dorsal (la inferior) convexa, con frecuencia muy bombeada y muy elevada en su region frontal, deprimiéndose rápidamente sus porciones laterales, y la ventral con nates pequeño y encorvado, bajo cuya punta se vé un diminuto forámen rodeado de un deltidium. Seno cóncavo-redondeado ó angular, muy ancho y de 
variable profundidad. En medio de las diferentes variedades que hacen muy dificil la descripcion de esta especie y muy intima su relacion con otras, se distingue de la más afine, la $R$. cordiformis, Sow., por sus pliegues más redondeados, y el menor espesor de su loba ó parte media. Caliza de Montaña y Hullero. Valdebreto; Peña, Castillo; Vergaño.

** 508. R. pugnus, Martin (sp).=Terebratuln purmus, Sow. (Ibid; p. 97, 1. 22).- Tan variable como la anterior, es de forma algo más oval; más ancha que larga, adornada en cada valva con 9 a 14 costillas, de las cuales de $\breve{3}$ á 6 ocupan el bocel y el seno. Valva dorsal bombeada, convexa por igual hácia el limbo y más elevada hácia la region frontal, con un bocel ancho. Valva ventral (la superior ó perforada) ménos convexa, con un seno medianamente profundo que se extiende hácia la region frontal desde cerca del nates, el cual es muy retorcido y tiene un forámen muy pequeño, raras veces visible en los adultos. Algunos autores han reunido esta especie á la anterior, de la que se distingue por sus pliegues laterales, que muy rara vez se indican en la $R$. acuminata, mientras que en la $R$. purnus son constantes y hacen muy dentelladas ó sinuosas sus comisuras laterales y frontal. Hullero de Nieres, Lena y Aller.

* 509. R. pleurodon, Phill (sp).=Terehratula pleurodon, Phill (Ibid; p. 101, 1. 25).-De menor tamaño que las anteriores, se distingue de ellas por sus pliegues angulosos que cubren toda la concha, tambien muy variable y raras veces más larga que ancha. Valvas más ó ménos convexas, á veces muy bombeadas; nates puntiagudo, algo encorvado, con un forámen circular pequeño; bocel ancho, casi cuadrado, muy levantado en la region frontal. En el seno de la valva ventral, que es medianamente profundo, hay por regla general cuatro pliegues casi rectos; pero ese mimero puede variar entre 2 y 8 , asi como entre 5 y 9 los correspondientes al bocel de la valva opuesta, si bien lo más frecuente es que estos sean 5 bastante torcidos, y otros 5 á 9 á cada lado. Hullero. Levanza; Orbó.

510. R. flexistria, Phill (sp.)=Terebratula flexistria, Phill.= T. tumida, Phill. (Ibid; p. 105, 1. 24, Г. I á 8).—0val y bombeada, sobre todo hácia el nates, que es muy pequeño y retorcido; tiene la valva dorsal más convexa que la ventral, y la superficie de las dos 
con 15 a 40 costillas, siendo respectivamente las del seno y el bocel mis gruesas que las laterales, cuyas úllimas se hacen numerosas por la intercalacion ó bifurcacion i distancias variables del umbo de otras intermedias; caricter sue sirve para diferenciar esta especie de la anterior, con la que viene asociada.

* 511. R. angulata, Liueo (sp.)=Terebralula excavan, Phill. (Ibid; p. 107, 1. 19, f. 11 i 1 (b).-Fácilmente distingnible por su region cardinal puntiaguda y excavadia á los lados del nates hasta cerca de la mitad de la concha, que tiene por lo tanto un aspecto cuneiforme: la mayor anchura se halla en la reggion frontal, y á corta distancia del umbo radian de seis á nueve pliegues angulares y anchos, de los cuales dos á cuatro ocupan el bocel, y uno á tres el seno.-Valdebreto.

\section{CAMAROPHORIA.}

* 512. C. crumena, Martin (sp.)=Terebratula Schlotheimi, Buch. (Ibid; p. 115, I. 25, f. 5 a 9). -Tan ancha como larga, confusamente romboide $\dot{o}$ deltoide; mny ensanchada hácia el márgen, adelgazada hicia el nates, que es saliente y tiene un diminuto forámen. Valva ventral, con un seno deprimido de variable anchura; valva dorsal más convexa, de perfil arqueado, con expansiones laterales y un hocel saliente. Del centro de la concha parten de 15 a 24 costillas radiantes en cada valva, de las cuales de tres á seis ocupan el bocel y de dos á cinco el seno.-Caliza de Montaña y Hullero. Celada; Vergaño; Barruelo; Valdebreto.

\section{STREPTORHYNCHUS.}

185 bis. S. crenistria, Phill.-Vergaño; Valdebreto; Valles de Lena y Mieres.

\section{ORTHIS.}

188 bis. O. resupinata, Mart.—Caliza de Montaña de las Peñas de Gobezanes y Deboyo, Caso; Puente Lorio, Laviana; Las Caldas de Oviedo; Teberga. 
189 bis. O IVichelini, Eveillé (sp).-Pizarrilla hullera al S. 0. del Infiesto; Caliza de Montaña de las Caldas de Oviedo.

\section{0 bis. O striatula, Schlot.—Asociada á las anteriores.}

515. O eximia, Eichw. (sp).=Productus eximius, Eichw. (M., Vern. el Keys. Géol de la Russie d'Europe; v. 2, p. 192, 1. 11, f. 2). -Mucho más ancha en el medio que en el borde cardinal, con finas estrias radiantes, y 10 a 12 pliegues longiludinales, anchos y redondeados; tiene una larga apofisis que se destaca del vértice de la valva dorsal; y la ventral un área muy alta. Hullero. Lena y Mieres.

\section{PRODUCTUS.}

** 514. P. striatus, Fischer. (sp).= Mytilus striatus, Fischer. (Davidson: A. Monograph of british carb. lrach.; p. 159, 1. 54, f. 1 a 5).-Concha delgada, de forma variable; generalmente alargada, triangular, redondeada en la region frontal, y aguda en la cardinal; a veces ancha y semicircular transversalmente; charnela más corta que la mayor anchura de la concha. Valva ventral regularmente convexa, sin seno; orejetas pequeñas, deprimidas con numerosas espinitas. Valva dorsal cóneava, acomodada á la otra. Ambas con numerosas estrias radiantes, onduladas, filiformes, interpolándose otras más finas á variables distancias del nates. Pocas espinas é irregularmente esparcidas por la superlicie. Long. $=78^{\mathrm{mm}}$, lat. $=\mathbf{4 0}$. Hullero. Vergaño; Vidrieros.

* 515. P. giganteus, Martin (sp).=Anomyles giganteus, Mart. (Ibid; p. 141, 1. 57 i 40). - Como indica su nombre, suele alcanzar esta especie grandes dimensiones. Aunque muy variable, siempre es más ancha que larga, y su charnela recta se prolonga en orejetas más ó ménos dilatadas y arrolladas. Valva ventral, más ó ménos bombeada, bastante griuesa hácia el medio y de nates retorcido. Valva dorsal delgada y cóncava. Una y otra con estrias longitudinales flexuosas, bifurcadas, desapareciendo algunas de pronto para reaparecer algunos milimetros más hácia el borde, donde se cuentan de 5 á 7 en el espacio de $2^{\mathrm{mm}}$; á veces son contiguas, pero en gene- 
ral estin separadas por surcos, flexuosos lambien, de variable anchura y dispuestos rasi siempre con mucha irregularidad. Arroyo del Algibe, Villanneva del Rey; arroyo del Valle, Espiel.

* 516. P. Cora, D’Orb.=P. comoides, Kon. (Ibid; p. 148, I. 56, f. 4 y 42, f. 9).-Concha delgada, oval longitudinalmente, más larga que ancha, con numerosas estrias longiludinales, redondeadas, rectas i ligeramente flexnosas, separadas por sureos algo más estrechos, entre las cuales se intercalan otras mis delgadas. Charnela proximamente tan larga como la anchura de la concha. La valva ventral es muy bombeala y convexa, un poco deprimida hácia el centro, y la dorsal cóncava, con numerosos pliegues concéntricos, irregulares, ondulosos y á veces interrumpidos. Ancho y encorvado es el nates; pequeñas las orejetas, y estas van cruzalas por 4 á 5 arrugas onduladas, "que se prolongan hasta alguna distancia por las partes laterales de las valvas. Alguna que otra espina se nota reparlidla por estas, pero su número es mayor en las orejetas. Caliza de Montaña: Arenas de Cabrales; Las Caldas de Oviedo; Valdebreto. Hullero de los valles de Lena, Mieres, Aller y Teberga. San Felices.

**517. P. semireticulatus, Mart. $(\mathrm{sp}) \cdot=$ P. Martini. Sow. $=$ Anomiles semireticulahus, Mart. (Ibil; p. 149, 1. 45).-Muy variable, oval transversalmente, casi cilindrica 0 alargada, con charnela tan larga $\dot{o}$ algo más corta que el ancho de la concha; liene su valva veutral hombeada, más ó ménos arqueada, con una ligera depresion longitudinal, y las orejetas medianamente desarrolladas: el nates es ancho, encorvado, con arrugas de crecimiento irregulares, concénIricas y onduladas, que se extienden hasta las orejelas, donde son más anchas y profundas, mientras que en el resto de la superficie predominan estrias longitudinales redondeadas que, señalándose ya desde el mismo nates, van aumentando en número hácia el márgen, donde se cuentan 4 a 5 por cada $2 \mathrm{~mm}$. Las espinas varian en número y longitud en los diferentes ejemplares, pero siempre abundan más en las orejetas. El P. Martini, Sow., debe considerarse como una variedad cuya valva ventral es geniculada, a veces prolongada anteriormente de un modo muy irregular. Caliza de Montaña y grupo Hullero. Valles de Lena, Aller, Nieres, Riosa y Langreo; Caldas de Oviedo; Rivadesella; Ortiguero de Cabrales. Valdebreto; Orbó; Santullan; Celada. Belmez y Espiel. 
* 518. P. costatus, Sow. $=P$. sulcalus, Sow. (Ilidi; p. 152, 1. 52, f. 2 a 9). - llás ancha que larga, con una charnela que ocupa casi todo el ancho; tiene su valva ventral muy bombeada y casi geniculada, con una depresion ó seno central que la divide más ó ménos profundamente en dos lobas. Las orejetas, a veces muy desarrolladas, siempre bien destacadas del resto de la concha, con una arruga ó pliegue saliente oblicuo á la charnela, llevan cuatro ó seis espinas tubulosas, largas y gruesas. Otras mis ilelgadas se ven esparcidas irregularmente por el resto de la superficie, que está cubierta de costillas longitudinales redoudeadas, desiguales, tres ó cuatro veces más anchas que los surcos que las separan, las cuales se bifurcan y dejan espacio a otras más pequeñas que entre las mismas se interpolan. La valva dorsal, que como es lo general, se amolda á la curvatura de la ventral, es á veces geniculada, y presenta una ligera elevacion que se corresponde con el seno de su opuesta. Por la parte interna, las impresiones hepáticas de esas dos valvas son bastante diferentes: ramificada y dividida por ma lámina central la de la dorsal, y muy pequeña y poco ramificada la de la otra. Vergaño.

* 519. P. longispinus, Sow $=P$. Flemingii, Sow $=P$. spinosus, Sow. $=P$. lobalus, Sow. (Ibid; p. 154, I. 55, f. 5 á 17). - De forma muy variable, pequeña, ligeramente transversa, rara vez más larga que ancha, es la charneli más larga ó un poco más corta que la mayor anchura. Valva ventral globulosa, més ó ménos dividida en dos lobas por un seno que empieza cerca del nates; este es muy encorvado. Orejetas pequeñas, con dos á tres tubos grmesos y oblicnos en el borde cardinal. Valva dorsal uniformemente cóncava, con un bocel central poco marcado. La superficie de las dos valvas lleva numerosas costillas longitudinales, delgadas y redondeadas, á las que se agregan otras por bifurcacion é intercalacion. Las espinas tubulares son pocas, pero en cambio largas, sobre todo, dos situadas hácia el medio de la valva ventral, à derecha é izquierda de su surco central. Su region visceral se ofrece cruzada por numerosas estrías concéntricas, pequeñas y onduladas, que principalmente se señalan hácia las orejelas. La valva dorsal se articula por medio de un diente muy corto y bifurcado, sostenido por una pequeña callosidad aplastada, debajo de la cual se extienden las apófisis hepáticas, que son anchas, cortas y poco ramificadas, mientras que una lámina 
aguda y longitudinal se dirige hasta el medio de la valva, separando a nno y ofro larlo olras callosidales reniformes. Marcase lambien i las inmediaciones de los bordes ma ligera prominencia paralela í los mismos, y el resto de la superfieve interna es eramulado. Caliza de Montaña y IInllero. Pola de Lenar Mieres; Mller; Melendremas y Covalierda, al S. de Onis; Arenas de Cabmales; Peña de Gobezanes y Peña Deboyo; Muñera y Linariegas, Laviana.

* 520. P. sinuatus, Kon.=Leplome simuata, Kon. (Ibid; p. $157,1.55$, f. 8 i 11).-De mis longilud gue latilud, con su charnela tan larga como la mayor anchura, y los ángulos cardinales redondearlos, es su valva ventral feniculada, profundamente dividida en dos lobas muy convexas por un profundo seno, que parte a corta distancia del nates, el cual es pequeño. Orejelas anchas; drea cardinal estrecha, dividida por una lisura pequeña, cubierta por un pseudo-dellidium. La valva dorsal lleva mu elevacion central, que corresponde al centro de la otra, y en las dos hay estrias longitudimales, pequeñas, redondeadas, á veces bifurcadas, cruzadas por otras numerosas de crecimiento; muy señaladas, sobre torlo, hícia el medio, y muy poco hácia el márgen. Lnas catorce espinas tubulares Jargas y delgadas están dispuestas en dos filas en el borde cardinal. Valdebrelo, Celada, Vergaño.

* 521. P. carbonarius, Kon. (Ilicl; p. 160, 1. 54, f. 6).-Tan ancha como larga ó ligeramente transversa; valva ventral muy bombeada, redondeada por igual y sin seno; expansiones anriculares muy peymeñas; charnela casi lan larwa como la mayor anchura de la concha; superficie adormada con estrias radiantes filiformes, por entre las cuales salen á cortos intervalos numerosas espinas delgadas; nates perqueño, muy encorvado y con ligeras lineas de crecimiento concéntricas. - Valdebreto.

\section{** 522. P. undatus, Defr. (Ihid; p. 161, 1. 54, f. 7 à 15).-} $A$ reces casi orbicular ó ligeramente transversa; charnela algo más corta que la mayor anchura; valva rentral sin seno, muy convexa, bombeada con regularidar; nates pequeño y redoudeado; superficie con numerosas arrugas concéntricas, onduladas, interrumpidas, más anchas y salientes en los adultos. Las valvas estín además adornadas de numerosas costillas redondeadas, filiformes y separa- 
das por surcos estrechos, próximamente cn numero de lres en la extension de mna línea. Caliza de Montana. Jas Caldas de Oviedo. Vergaño; Santullan; Valdebrelo.

* 525. P. proboscideus, Vern. (Ibid; p. 165, 1. 55, f. 1 à 4). -Concha más bien pequeña que de regular tamaño, muy variable de forma por la singular prolongacion de su valva ventral. Se compone esta de dos partes: la primera, en relacion con la valva dorsal, es circular, moderadamente comvexa, casi tan ancha como larga, de nates y orejetas muy pequeños, y consta la segunda parte de una prolongacion marginal en forma de tubo cilindrico más ó ménos largo y retorcido. La valva dorsal es pequeña, cóncava, algo transversa, y la charmela mis corta que la mayor anchura de la concha, á la cual adoruan estrias nuy finas cruzadas por olras de crecimiento, y numerosas espinas largas y delgadas, proyectadas hácia afuera desde las expansiones laterales de la valva ventral. Caliza de Montaña. Valdebreto.

* 524. P. ermineus, Kon. (Ibid; p. 164, 1. 55, f. 5).-Difiere de la anterior por carecer de la prolongacion tubiforme de la valva ventral, y por acomodarse á la curvatura de esta la dorsal. Su charnela es mucho más corla que la mayor anchura. Asociada á la anterior.

* 525. P. aculeatus, Mart. (Ibid; p. 166, 1. 55, f. 16 a 20.Pequena, oval $\dot{o}$ semicircular; charnela corta, valva veutral bombeada, de nales muy encorvado; superficie con numerosos tubéreulos dispuestos irregularmente y saliendo de ellos espinas encorvadas. Asociarla á la anterior.

* 526. P. pustulosus, Phill. (llid; p. 168, 1. 41, f. 1 i 6 , 1. 42, f. 1 a 4).-Delgada, más ancha que larga; charnela más corta que la mayol anchura; valva ventıal con un seno más ó ménos profundo; nates medianamente encorvadn; orejetas anchas, casi rectamgulares. Superficic con numerosas lineas de crecimiento onduladas é interrumpidas, entre las cuales se destacan en filas irregulares numerosos tubérculos alargados, que llevan espinas delgadas. La disposicion de estos y de la lineas concéntricas varian mucho de unos ejemplares á otros. Valva dorsal ligeramente cóncava, con un bocel poco saliente. Asociada í las anteriores. 
* 527. P. scabriculus, Marl. (sp). (Ibril; p. 169, 1. 12, f. ప á 8).-Difiere de la anterior por tener sus Luhérculos dispuestos con más regularidad y en filas radiantes que toman la apariencia de costillas, y por tener el septum medio del interior de su valva dorsal dividido en dos ramas, mientras que en el $P$. pustulosus es simple. Caliza de Montaña. Peña de Grobezanes y P'eña Deboyo, Caso. San Felices.

* 528. P. fimbriatus, Sow. (Ihid; p. 171, 1. 55, f. 12 a 15). Oval longitudinalmente; charmela algo más corla que la anchura mayor; valva ventral uniformemente convexa y muy arqueada; nates muy encorvado; orejetas pequeñas; valva dorsal moderadamente cóncava ó deprimida: superficie con numerosas lineas concéntricas formando pliegues aplastados, en cada uno de los cuales hay una fila de tubéreulos alargados, de los que salen espinas cilindricas largas. Caliza de Montaña. Valdebreto; Celada.

* 529. P. punctatus, Mart. (sp.) (Ibid; p. 172, I. 4.4, f. 9 á 1(i). Concha delgala, por regla general de mayor tamaño que la anlerior, de la que se distingue por tener un seno, annque poco profundo. Los pliegues concéntricos de su superficie forman fajitas aplastadas y escilonadas por otras lisas más estrechas, detrás de las que hay una fila de tubérenlos alargados ó espinas delgadas. Debajo de aquella el espacio restante en cada zona está lleno de espinas pequeñas, muy apretadas, irregularmente esparcidas, apiñadas unas solvre otras. En casi todos los ejemplares han dejado en su lugar las cicatrices ó puntos humtidos dispuestos en filas irregulares. Valva dorsal poco concava, con una ligera elevacion central. Caliza de Nlontania ý Hullero. Lena; Hieres; Nller; Riosa; Teherga. Valdebreto; Vergaño; Orbó.

\section{CHONETES.}

550. Ch. Hardrensis, Phill. (Ibid; p. 186, 1. 47, f. 12 a 25).-Why parecilo al Ch. sarcimulatu, Schl, con el cual tal ve\% llegne á refundirse; es una concha semicircular más ancha que larsa, con numerosas estrias radiantes filiformes, con frecuencia bifurcadas, aumentando en número hasta contar más de ciento en el már- 
gen, por interposicion de otras, á distancias variables del umbo. Charnela recla, poco más ó ménos tan larga como la mayor anchura; valva ventral poco convexa, medianamente hundida hácia el medio y algo deprimida hácia los extremos cardinales, con una área dividida en su centro por una lisura pequeña cubierta en parte por un psendo-deltidium; valva dorsal cóncava, un poco elevada en el medio y con área mas estrecha que la de la ventral. En los adultos hay de 10 a 18 espinas cardinales, y en algnunos ejemplares, algunas otras mucho más pequeñas á distancias irregulares del márgen.-Caliza de Montaña de Valdebreto y Muda.

\section{FENESTELLA.}

* 351. F. retiformis, Schlot. (sp.)=Keratophyles retiformis, Schl. = Gorgonia infundibuliformis, Gold. = G. retiformis, Kon. (Descr. des an. foss. qui se trouvent dans le tér. carb. de Belgique; p. 4, 1. A, 1. 2 y 5).-Briozoario compuesto de una red muy delgada en forma de embudo ó de abanico, de mallas muy pequeñas, formadas por un cantidad considerable de ramillas ó séries, que aumentan por las ummerosas bifurcaciones que se intercalan. Los ejes llevan estrias, ya simples y longiludinales, ya entrelazadas por otras transversales y más finas; la capa cortical parece delgada, y muestra pequeños unbérculos colocados en los bordes de las mallas; estas últimas se hallan dispuestas en tresbolillo, y cada espacio intermedio viene á ocupar medio milimetro de superficie próximamente, siendo á primera vista de seccion cuadrada, pero oval cuando se la examina á la lente. Hullero de Astúrias, donde viene asociada con otras especies de briozoarios.

\section{ACTINOCRINUS.}

552. A. triacontadactylus, Mill. Con frecuencia se hallan en la Caliza de Montana fragmentos de tallos de crinoides, pero en su mayor parte difíciles de determinar. Asi no es extraño que de todas las especies del órden de los crinoides no veamos citada más que la presente, por los diversos autores que mencionan fósiles carboniferos de nuestro país. Lena, Aller, Mieres.

Ademís de esta especie, sospechamos la existencia de los Pole124 
riocrimes crassus, Mill., y Actinocrimes Lervis, Mill., representados únieamente por algunos fragmentos, sin que hayamos tenido hasta la fecha un sólo cáliz á nuestra vista.

\section{CH开TETES.}

555. Ch. radians, Fischer. (II. Edu'. ct IIaime: Monogr. des pol. fos. des lérr. paleroz; p. 265, 1. 20, f. 4).-Polipero en masa elevada, piriforme, de superficie muy convexa; murallas imperforadas y bien desarrolladas; cálices designales en anchura, de $\%$ de milimetro próximamente, ya alargados en un sentido, ya más triangulares, tetrígonos ó exágonos; poliperitos muy largos, radiantes desde la hase del vértice; pisos horizontales distantes entre $s^{2} / \%$ de milimetro. Asturias.

\section{AMPLEXUS.}

554. A. coralloides, Sow. (Milne Edwards el J. Haime: Monographie des polypiers fos. des terr. paluroz; p. 542). - Solo se hallan fragmentos desde 6 a $50^{\mathrm{mm}}$ de grueso, pero bastante grandes para demostrar que este polipero era muy largo. Era cilindrico, irregularmente contorneado, con nullos de crecimiento poco marcados y con una epiteca que las más de las veces ha desaparecido, permitiendo ver las lineas verticales equidistantes, correspondientes al horde externo de los tabiques. Estos son iguales, delgados, marginales y en número de 28 á 58 . Los pisos están muy desarrollados, y muy próximos entre si; lisos en casi toda su extension. Junto al borde se observa una ligera depresion correspondiente á la foseta septal, que es muy pronmuciada en el último piso. Caliza de Montaǹa. Peña de Gobezanes y Peña Deboyo, Caso.

\section{FUSULINA.}

555. F. cylindrica, Fischer. (Murch., de Vern. el de Keys: Géol de la Russie d'Europe et des mont. de l'Oural; t. 2, p. 16, I. 1, f. 1).= Foraminifero grueso, casi liso, oblongo, adelgazado en sus extremos, hinchado en el centro, haciéndose con la edad cada vez. 
más fusiforme. Cámaras numerosas apretadas, con frecuencia flexuosas ú onduladas, convexas, separadas por depresiones bastante marcadas; tabiques plegados en festones en su terminacion, formando compartimentos redondeados muy singulares; abertura lineal aplicadi contra la vuelta de espira en la parte central de las cámaras, y ocupando la mitad de la altura de los tabiques internos. Long. $=7 \mathrm{~mm}$ lat. $=5$. Valles de Mieres y Lena.

\section{XILOMIDES (1).}

556. X. eradiatus (?), Areitio. (Anales de la Soc. Española de Hist. Nat.; t. 5, p. 256).-Al fraccionar un ejemplar de Lepidodendron aculeatum, procedente de la cuenca de Espiel y Belmez, el señor Areitio pudo observar en el interior de la pizarra un hongo circular, craso, umbilicado, de 2 á $2 \% \mathrm{~mm}$ de diámetro, constituyendo agrmpaciones de las que cada individuo se podia destacar integro fácilmente, y en el que, examiuado al microscopio, no se notan indicios de radiacion. La descripcion, agrega el Sr. Areitio, que del estado jóven del $X$. asteriformis, Fr. Br., da Mr. Schimper, conviene perfectamente á este pequeño hongo; $y$, sin embargo, se puede sospechar sea una especie nueva el $X$. eradiatus, Areitio, en razon al yacimiento en que se presenta, pues la especie de Veitlahm (Franconia) es triásica.

\section{EQUISETIDES.}

537. E. giganteus, Lind. et Ilutt. (sp).=IIippurites giganteus, Lind. et Hult. (Fossil Flora of Great Britain; v. 2, p. 37, 1.114).-Entrenudos de 6 a $7^{\mathrm{cm}}$ de longitul, con un gran nimero de dentelladuras puntiagudas de unos $15^{\mathrm{mm}}$ de largo, separadas entre si por espacios de 2 a $5^{\mathrm{mm}}$ y con señales de una costilla central. La superficie del tallo parece en general lisa, pero en varios puntos presenta algunas lineas de crecimiento transversales. - Puerto de Leitariegos.

(1) Para el estudio de los vegetales fósiles no podemos ménos de recomendar á nuestros lectores el Traité de Palćontologie végétale de M. Schimper, recientemente publicado. 
558. E. rugosus, Schimper. = Équisetites infundiludiformis, Bronu. Geinitz: Die Versteinerungen der Stein-Kohlenfurmation in Sachsen; 1. 10, โ. 4 a 8 y I. 18, โ. 1). -Especie de menor talla que la anterior, no midiendo su dímetro mis de 5 a $4^{\mathrm{cm}}$. La superficie Ileva estrias longitudinales desiguales en anchura y profundidad, lo que la da una apariencia rugosa: los nudos distan entre sille 1 a $5{ }^{\mathrm{cm}}$, y los entrenulos son con frecuencia cóncavos, alguna que ofra vez convexos, y con suma rareza perfectamente cilindricos.-San Mdrian de Juarros.

\section{CALAIMTTES.}

** 559. C. Suckowi, Brong. =C. communnis, Euting.= $=\dot{C} \cdot r^{*}(t-$ mosus, Artis. =C. undulatus, Stern. (Brongniart: ITistoire des végétau, fossiles; p. 124, I. 15, f. 1 á $6 ; 1.16$, f. 2 á 4).-Especie bastante variable, más ó ménos comprimida; nudos más ó ménos distantes entre si, los inferiores espaciados de 5 a $6^{\mathrm{cm}}, \operatorname{los}$ superiores de 6 á 20 ; cicatrices de las hojas ovales, más ó ménos alargadas; costillas semicilindricas, de $2^{\mathrm{mm}}$ de anchura próximamente. El $C$. undulatus, Stern., se fundó en ejemplares de esta especie, cuyas costillas se han hecho ondulosas á consecuencia de una presion vertical. Valles de Langreo, Bimenes, Laviana, Turon, Nieres, Riosa, el Roton, puente de San Andrés; Cangas de Tineo (Asturias). Matallana (Leon). Barruelo (Palencia). San Adrian de Juarros (Búrgos). San Juan de las $\mathrm{Abadesas} \mathrm{(Gerona).} \mathrm{Puertollano} \mathrm{(Ciudad-Real).} \mathrm{Villanue-}$ va del Rio (Sevilla).

* 540. C. Cistii, Brong. (Ibid; p. 129, 1. 20).-Difiere de la anterior por sus costillas más salientes, en forma de quilla redondearla, de $1^{\mathrm{mm}}$ ó poco más de anchura, separadas por surcos más anchos, ménos agndos; nudos espaciados de 4 i $8^{\mathrm{cm}}$. En la base de las costillas se ven á veces tubérculos ó cicatrices de las hojas, y en algunos ejemplares existen á uno y otro lado del nudo. Valles de Langreo, Mieres, Riosa y Aller. Sabero, Barruelo; Orbó, San Adrian de Juarros. San Juan de las Abadesas; Belmez y Espiel. Puertollano.

** 541. C. dubius, Artis. (Ibid; p. 150, 1. 18, f. 1 à 5).Difiere de las demás especies del género por la forma de los surcos 
que separan las costillas, formadas de dos estrias profumdas, entre las que existe ma superficie plana. Mieres; Langreo; Armao; Ferrones. Sabero; Guardo; Oribo. San Adrian de Juarros. San Jıan de las Abadesas.

* 542. C. approximatus, Schlol. (Ibid; p. 155, 1. 15, f. 7 y 3, 1. 24.=Schimper: Paléont. Végét; v. 1, p. 514, 1. 18, f. 2, 1. 19, f. 1).-Notable por la cortedad de sus entrenudos inferiores, que sólo tienen $1 \%$ á $2 \mathrm{~mm}$; en la parte superior aquellos se alargan a veces bruscamente. Cicatrices de insercion, grandes y circulares, converyiendo hicia ellas las costillas que les son immediatas. La corteza (convertida en carbon) es tanto más gruesa, cuanto más cortos son los entrenudos. Costillas de $2^{\mathrm{mm}}$ de anchura. Concejos de Langreo, Mieres, Quirós, etc. Puerto de Leitariegos. Barrue10. San Adrian de Juarros. San Juan de las Mbadesas. Espiel y Belmez.

* 545. C. cannæformis, Schlot. $=C$. decoratus, Brong. $=C$. nodosus, Schlot. (Schimper; Pal. Veg.; v. 1, p. 516, 1. 20, f. 1 y 5). -Difiere del $C$. Sucliovii, Brong, por sus costillas más convexas y mạs anchas, pues son de 4 a $5^{\mathrm{mm}}$ de anchura y están separadas por surcos más anchos y ménos profundos. La base del ta110 ó tronco es conoide, y en esta parte los entreuudos distan entre si de 1 a $2 \mathrm{~cm}$. Ilácia arriba se van separando cada vez más hasta hallarse espaciados en la parte superior de 10 á $15^{\mathrm{cm}}$. Las cicatrices de las hojas son cóncavas, y están producidas por la caida de los tuhérculos, yue no son otra cosa yue los moldes de los haces vasculares, trumcados, á consecuencia de la caida de las hojas. Arnao; Pajares. Sabero; Canteras de Villablin; entre Arlanza y Noceda. La Florida; Barruelo.

544. C.? tenuifolius, Etlingr. (Ibid, p. 520).-Tallo deprimido, de 5 a $6^{\mathrm{cm}}$ de anchura; costillas planas de 1 a $2^{\mathrm{mm}}$ de latitud; cicatrices de las hojas muy perueñas ó nulas. Euingshausen reune con este tronco los Calamocladus, longifolius y $C$. tenuifolius, Brong. (sp).-Puertollano. 


\section{CALAIMOCLADUS. ${ }^{(1)}$}

* 545. C. longifolius, Bron. $\langle s p\rangle=$ Asterophyllites longifolia, Brong.=A temuifolin, Brong.=Calamiles remnifolius, Etting. (Geinilz: Steinli. r. Sachsen; p. 9, 1. 18, f. 2 y 5).-Nudos distantes entre si de 1 a $5 \mathrm{~cm}$, siendo los entrenudos de la var. tenuifolius, siempre muy cortos y con frecuencia más anchos que largos. Las hojas de los ramos principales, tienen hasta $5 \mathrm{~cm}$ de longitud; son muy estrechas, casi filiformes y de nervio central apenas sensible. Mieres; Ferroñes; al N. de Sorriba, entre Cangas y Tineo. Sabero. Surroca.

* 54ti. C. equisetiformis, Schlot. $(\mathrm{sp})=$ Asterophyllites equisetiformis, Brong. =Calamiles equisetiformis, Etting. (Schimper: Paléont. vig.; r. 1, p. 324, 1. 22, f. 1 á 5 ).-Entrenudos de 1 a $4^{\mathrm{cm}}$ de longitud, estrechados hácia los nudos; de cada uno de estos, se levantan, ligeramente arqueadas, hojas casi filiformes, casi iguales, lanceoladas, de 5 a $4^{\mathrm{cm}}$ de longitud. Varios autores consideran esta especie como ramas del Culumites Cistii, Brong. Orbó y Sabero. Barruelo? San Juan de las Abadesas.

* 547. C. grandis, Sternl). (sp). =A sterophyllites dubia, Brong. $=A$. delicatuh, Brong.=A. grandis, Geinitz. (Steinli.von Sachsen; I. $17,1.4$ à 6$)$.-Varios autores refieren esta especie á la anterior, con la yue lal rez deba reunirse definitivamente. En vista de la diversidad de opiniones sobre la nomenclatura de los Asterophylliles, hacen falla, dice II. Schimper, numerosas comparaciones y larzos estudios, para llegar á fijar con alguna certeza la colocacion en el método de estos ramos y ramitos, dispersos generalmente de un modo irregular, entre los fragnentos de las diversas especies de que proceden. Barruelo? Nieres, Langreo, Riosa. San Juan de las Abadesas?

540. C. foliosus, Lind. et. Ilult. sp = Asterophyllites foliosu, Lind et Hutl. Barruelo?

(1) Ramas y ramitos foliosos de los calamites. 


\section{MACROSTACHYA.}

349. M. infundibuliformis, Bron. (sp).=Equisetum infuntibuliforme, Bronn, in Bischoff.=Equisetites infundibuliformis, liein. = Calamites verlicillatus, Lind. et Hutt. (Schimper: Ibid; P. 552, I. 25, I. 15 a 18). -El tronco ofrece un espesor considerable; entrenudos muy cortos; hojas apininalas, angulosas; las cicatrices que estas dejan son transversales y contiguas, y las que se hallan en las ramas y ramilos muy grandes y circulares. En San Juan de las Abadesas se han encontrado espigas, que son muy grandes, pues alcanzan hasta $16^{\mathrm{cm}}$ de longitud, y que á juzgar por la curva que describen desde su base, debieron haberse insertado directamente en el tronco.

\section{SPHENOPHYLLUIM. (1)}

350. S. Schlotheimii, Brong.= $=$ S. emarginatum, Gein. (Verstein, d. Steink.v. Sachsen; p. 12, I. 20, f. 2, 1. 2 y 7).-Articulaciones de $1^{\mathrm{con}}$ ó poco más de longitud por una anchura de 2 á $4^{\mathrm{mm}}$; verticilos compuesto de (i a !) hojas; estas son enteras, ligeramente lestonearlas en su extremidad por 15 á 20 lobas redondeadas, muy pequeñas, á cada una de las cuales corresponden un nervio, procedentes todos de las sucesivas bifurcaciones del principal, que se divide por primera vez muy cerca del punto de insercion 0 adherencia. Espigas cilindricas, en doble série y con una longitud de 9 a $10 \mathrm{~cm}$ por una anchura $5^{\mathrm{mm}}$.-Puerto de Leitariegos.

\section{* 551. S. emarginatum, Brong. (non. (ieiu).=S. Schlothei-}

1. El género Sphenophyllum forma un grupo muy natural, que no tiene su análago ni en la flora antigua ni en la actual. Difiere de los géneros A mularin y Calumocludus ó Asterophyllites por sus hojas ménos numerosas, uniformes, con frecuencia divididas, cruzadas por nervios dicotomos, y por los surcos del tallo no alternantes. Las articulaciones están separadas por nudos circulares salientes, lo que permite distinguirlas, aunque no lleven hojas, de los ramitos de los calamites. Sin duda fueron plantas acuáticas flotanteś por su parte superior. 
mii, Lind. et Ilutl. (Ibid; 1. 20, I. 1, 5, 4).-Diliere del anterior por sus hojas ménos ensanchadas hícia el márgen, donde tienen solo de 6 a 12 lobas, a carda una de las cuales corresponde un nervio. Casi todos los nervios confluyen ileste la base. El verdadero tipo (para el que propone $\mathrm{II}$. Schimper el nombre de S. (runcatum) no tiene hendida la parte central de las hojas; mientras que lo estan más ó ménos las de la vall. (S. Brongniartianum). Valles de Langreo y Micres, Orzonaza. Berlanga. P'uertollano. San Adrian de Juarros.

5.2. S. erosum, Lind, el llutl.二S. dentrum, Brong.=S. imurginatum, liein. (pars) $=S$. fimbratum. =S. quadrifulum. $=S$.

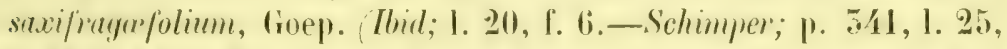
f. 10 a 14). - El número de las hojas de un verticilo es de 6 ; y cuando hay 12 , cada dos representan una completa; en los verticilos inferiores la division llega hasta 18. Esta especie se distingue por la mảrgen de sus hojas, en general, aguda y delicadamente dentadas, formando en cada una 6 lobas estrechas y mís a ménos largas, á cada una de las cuales corresponde un nervio. Del punto de insercion ó adherencia parten 4 , y de ellos, los dos centrales se bifurcan hácia el medio de la hoja. La var. saxifragefolium abunda más que el tipo, del que se distingue por la márgen de las hojas fuertemente dentadas. Valles de Langreo y Mieres. Orbó. San Adrian de Juarros.

555. S. oblongifolium, (ierm. (Geinitz: Ibid; I. 20, f. 11 á 15).-Se distingue del anterior por sus hojas oblongas más cortas y estrechas, y por sus dientes ménos pronunciados. Barruelo?

\section{ANNULARIA.}

* 854. A. sphenophylloides, Zeuk. $(s p)=$ A. Lrevifolia, Brong.=Galium sphenophylloides, Zenk. (Schimper: Traité de Paléont. végét.; 1. 1, p. 547, 1. 17, f. 12 y 15).-Las annularias eran probablemente plantas herbáceas acuáticas, de tallo articulado, estriado, con ramitos disticos. Los entrenudos $\dot{\alpha}$ meritallos eran huecos y estaban separados por diafragmas sólidos de bordes gruesos; los cuales, colocados horizontalmente en el mismo sentido que los ramitos y las hojas, se senialan en las impresiones bajo la forma de

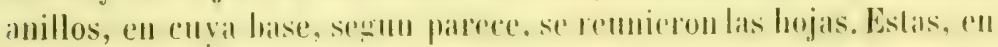


número de diez á treinta en cada verticilo, son libres hasta la base, lanceolado-espatuladas, y terminadas en punta; extiéndense en el mismo plano que los ramitos, y son mís largas hácia el lado anterior del verticilo, que del posterior, lo que indica que eran flotanles. Con frecuencia, sin embargo, se alargan tambien en el sentido transversal, de modo que las hojas laterales son algo más largas que las anteriores y posteriores. Las hojas tenian una consistencia más sólida, $\dot{o}$ un tejido más consistente que las de loscalamites; el nervio es fuerte y saliente en forma semi-cilindrica en el dorso de la hoja, mientras que en su parte anterior está escabado en canal. Las espigas son largas, cilindricas, de raquis grueso, probablemente algo carnoso, y compuesto de entrenudos muy cortos y asurcados. Las bracteas son muy numerosas, estrechas, lanceoladas y muy apretadas; extendidas horizontalmente en su parte inferior, y levantadas en arco verticalmente. Los esporangios son grandes, globulosos, dispuestos al parecer en dos séries verticales. La A. sphenophylloides, Zenk., es de tallo muy ténue, y liene en rada verticilo de doce á veinte hojas, cuya anchura es de 2 á $5^{\mathrm{mm}}$, y su long. de 5 á 6 . Mieres. Puerto Manzanal. Orbỏ.

* 555. A. longifolia, Brong. =A sterophyllites equisetiformis, Lind. et Hutl. (Ibid; p. 548, 1. 22, 1. 5 a 10).-Difiere de la anterior por tener más hojas en cada verticilo (de 20) a 26), y ser más largas y estrechas proporcionalmente. La anchura de estas es de 2 a $5^{\mathrm{mm}}$ y la long. de 40 a 50 en los ramos y de 10 a 15 en los ramitos. Mieres; Langreo. Las Bolias; Toreno y Cuesta de la Torre á Branuela. Otero de Dueñas; Barruelo; Orbó. Arroyo Palancar; Tortuera y Valdesotos.

* 556. A. radiata, Brong. (sp).=Aslerophyllites radialus, Brong. (Geinitz: Steinli, von Sachsen; p. 11, I. 18, 1. 6 y 7).-Difiere de la anterior por sus hojas más estrechas, casi aciculares de $f^{\mathrm{mm}}$ de anchura por 8 a 14 de long._Orbó. San Juan de las Abadesas.

\section{SPHENOPTERIS.}

* 557. S. trifoliata, Brong.=Filicitestrifolintus, Artis (Brongniart: Histoire des véget. foss; p. 202, 1. 55, 1. 3).—Con esta espe- 
cie principiamos la descripcion de las del órden de los helechos (Filiceue, que son plantas vivares, herbireas ó ardorescentes, alcanzando a reces ma altura de 1 i lit metros (1). El rizoma es generalmente ramificado ó dividido por dicolomia; el tronco recto y por lo resular simple. Los helechos arborescentes tienen el aspecto de la palmera; pero á su tronco más esbelto y adornado de cicatrices dispuestas en tresbolillo, agregan una copa más graciosa lodavia por la elegancia y finura de sus hojas. Las cicatrices del tronco merecen, sobre todo en los helechos fósiles, una atencion especial, no súlo porque caracterizan el órden, sino que por si solas permiten distinguir las de los troncos fósiles, de que no se tienen mis que impresiones exteriores. Estas cicatrices estan dispuestas en tresbolillo ó en espiras, cada vez más espaciadas hácia la parte inferior. Su forma es muy regular y simétrica, asi como la disposicion de las cicatricillas dispersas de su superficie y procedentes de los haces rasculares que se extendian á las fronles. El eje mayor de la cicatriz es siempre paralelo al eje del tronco, al revés de lo que se vé en los troncos de las palmeras, $y$ de otros monocotilédones. Entre las grandes cicatrices foliares se encuentran en los troncos y rizomas numerosas cicatrices lineales pequeñas, transversales, irregulares en su disposicion, que proceden de pelos pajiformes ó ramentaceos, lineales ó aplastados, á veces muy largos, que segun su forma y magnitud pueden denominarse sencillamente pajilas, vainillas, rmmenlos ó raspaduras. Las hojas, llamadas fromdes, están dispuestas en tresbolillos $\dot{0}$ en espiras, y su prefoliacion es circinada. Casi siempre son pecioladas, rara rez sentadas, y su limbo, entero en algunos géneros, es con muchísima más frecuencia pinatifido, bipinatifido ó tripinatifido, por volverse à hendir una io dos veces sus primeras divisiones. Esa division es por Jo regular completia en el rapuis principal y sus primeras ramificaciones, y ménos en el resto de la fionte

(1) Tomamos del excelente Trutudo de Pulcontologíu regetal de MI. Schimper las gentralidades que creemos más indispensables para el estudio de los helechos fúsiles. La importancia que estos tienen en el grupo hullero, la abundancia con que se ofrecen en nuestras cuencas, y sobre todo, el ser ménos comun el conocimiento elemental de los vegretales fósiles que el de los animales, nos ha inducido á ser aquí algo más extensos, sin dejar por ello de volver á recomendar el libro de que acabamos de hacer mencion. 
lrondes pinadas, hipinadas, tripinadas; pero como a pesar de lodo, las subdivisiones del raquis y de los nervios están contiguas, lo mismo que las del limbo, las hojas de los helechos no pueden considerarse, en general, como compuestas á la manera de las leguminosas y otras fanerógamas, sino como divididas en lobas, segun se ve en las compuestas, umbeliferas, etc. Hay, sin embargo, helechos de hojas cuyas divisiones de primero y segundo órden se desarticulan á consecuencia de la interposicion de una lámina celular entre la base de la loba y su punto de adherencia. El limbo está organizado como en los denıs vegetales vasculares: á excepcion de los Hymenophyllites, en que no hay más de una capa de células, siempre se compone de un tejido parenquimatoso más ó ménos desarrollado, cubierto de uma epidermis perforada de estomas en su parte posterior. Los haces vasculares que la recorren bajo forma de nervios, raras veces son simples, casi siempre dicotomos, tricotomos, etc. El fruto de los helechos es notable por fijarse en el limbo de las hojas, generalmente en la superficie posterior donde se forman à expensas del parenquima. En ciertas especies, el parenquima de una parte de las pinulas ó de todas ellas, se trasforma enteramente en esporangios, y entonces la fronde toma el aspecto de una panoja. En otras, los esporangios se reunen en wlomérulos, llamados soros (sori), de formas muy variables, seģu los géneros, ya redondos, ya semicirculares, ya alargados, y á veces lineales. Están cubiertos generalmente, ya del todo, ya en parte, por un disco membranoso circular reniforme ó semilumar, á veces muy rudimentario, persistente ó fugaz, á que se da el nombre de indusio. La presencia 0 ausencia de este indusio, así como su forma, ejercen wran influencia en la clasificacion actual

Pocas plantas lay cuya vegetacion, más ó ménos intensa, dependa Lanto de la humedad como los helechos. Estos son verdaderos higrómetros naturales, cuyos desarrollos individual y numérico están siempre en razon directa de la lumedad del clima en que viven. Este doble desarrollo alcanza su maximum en las comarcąs que á la vez son himedas, de rica vegetacion, montañosas y pedregosas. 'Tenemos un ejemplo en las provincias de Astúrias, Santander y las Vascongadas, en cuyas montañas tantos helechos vegetan. Hoy dia se conncen más de $\mathbf{5}, 000$ especies vivientes. M. Unger enumera en su Genera et species unas 450 especies fósiles, sin contar los troncos, rizomas y peciolos. Indudablemente se reducirá esta cifra cuando 
aquellas estén mejor estudiadas; pero incesantes investigaciones, solore todo en las formaciones mis recientes, harin descubrir otras nuevas. Nos falta lodavia ma clasificacion natural de los helechos: en los vivientes está basadia principalmente en la disposicion de los soros, en su forma, la presencia ó ansencia parcial ó total del indusio y la estructura de los esporangios; mientras que en los helechos fósiles, la nervacion es la inica que nos sirve de guia. Aunque esta ńltima clasificacion es más imperfecta todavia que la primera, y no es mis que un expediente momentineo, una solucion provisional, tiene la ventaja de reunir juntas las formas que más se parecen en su general aspecto, y permitir la agrupacion mis ó ménos natural de la mayor parte de las especies antiguas, que no tienen antalegas en la Flora viviente. Es claro que ciertos lipos de helechos de la época hullera, y áun de los sistemas rriásico y jurásico han desaparecido por completo, y que su interealacion en 111 sistema exclusivamente fundado en las formas vivientes, debe estar preñada de mayores dificultades. La mayor parte de las impresiones carecen de órganos, en Ios cuales se funda lia clasificacion; y donde han dejado huellas de su existencia, sólo se distingnen el lugar y forma reneral de los soros, sin percibirse, más que en casos muy excepcionales, el tegumento y las cípsulas. El sistema de clasificacion establecido por Brongniart es el que todaria reune las mejores condiciones, y vamos por lo tanto á trasladarle(1).

I.-Nerviós primarios pixados, xertios secuxdarios vo reticulados.

a Fronde simple; nervios secundarios simples o bifurcados.-Teniopleris.

$b$ Pínulas simples ó semi-pinatifidas de lobas

A Nervios sim- innales; nervios secmudarios poco oblicuos al ples, bifurcados nervio central.-Pecopteris.

o pinados. cinulas profundamente lobadas de lobas decrecientes, divergentes; nervios secundarios bifurcados ó bipinados, oblicuos.-Sphenopteris.

(1) Histoire des végéteaux fossiles; v. 1, p. 148. 
a Fronde simple.-Glossopteris.

b Pinulas adherentes por la base al raquis; de este arrancan directamente los nervios secundarios; sin nervio central.-Odontopteris.

$B$ Nervios secun- $c$ darios dicotomos, muy oblicuos al nervio central.

Pinulas no adherentes al raquis:

1 Pinulas enteras simétricas. - Neuropteris.

2 Pinulas enteras ó lobadas, mıy inaquiláteras, nervio principal casi marginal.-Loxopteris.

5 Pinulas flabeliformes ó en abanico, lobadas.-Leptopteris.

4 Pinulas palmeadas de nervios pinarlos en cada loba.-Cheiropteris.

\section{II. - Nervios secundarios flabeliformes ó EN ABANico;} SIN NERVIO PRINCIPAI.

A Nervios secundarios pediarios.-Cyclopteris.

$B$ Nervios secundarios radiantes dicotomos.-Hymenopleris.

$C$ Fronde profundamente lobada; un solo nervio en cada loba.Schizopteris.

\section{III.-Nervios SEcundarios anastomoseados.}

A Todos los nervios secundarios iguales, reticulados y sin nervio libre.-Lonchopteris.

$B$ Nervios principales formando un enrejillado; nervios secundarios reticulados; ninguno libre.-Calthropteris.

$C$ Nervios desiguales, areolados; algunos terminados libremente en las areolas. - Phlebopteris.

Eutinghausen desarrolló esta misma clasificacion del modo siguiente:

1. Hyphopteris.-Fronde nunca pinatifida con regularidad. Nervio único en cada loba.

2. Craspedopteris. - Segmentos, lobas ó dientes recorridos por un solo nervio, que nace directamente, ya del raquis, ya del nervio primario. Nervios y recortes de las hojas regularmente pinados.

5. Camplopteris. - Segmentos, lobas ó dientes ocupados por un nervio que da origen á otro de segundo órden, generalmente arqueado.

4. Cyclopteris. - Las lobas están recorridas por un gran número 136 
de nervios primarios, simples a bifurealos, extendidos en forma do abanico, siendo á veces el del medio mís fuerte que los demas.

万. Yeumpleris. - Un solo nervio primario que se divide en su extremo superior, $\dot{a}$ que desaparece antes de llegar al vértice de la hoja ó loba. Los nervios secumlarios lorman con los primarios ángulos agudos y divergen deseribiendo areos. No hay nervios de tercer órden.

6. Treniopteris.-Nervio primario muy luerte, naciendo de él en íngulo recto ó poco agudo los nervios secundarios muy apretados, arqueado-convergentes ó rectos, simples, dicotomos ó tricotomos. Sin nervios de tercer órden.

7. Sphenopleris.-Nervio primario delgado, con frecuencia bifido en medio del vértice; nervios secundarios destacados bajo ángulos de 5 á $45^{\circ}$, simples, dicotomos ó tricotomos.

8. Alethopteris. Los nervios secundarios, en general simplemente dicotomos desde la base, nacen de un nervio primario prolongado hasta el vértice de las pinulas.

9. Pecopteris. - Nervio primario fuerte y prolongado hasta el vértice de las pinulas; de él nacen, bajo un ángulo de 70 á $90^{\circ} \operatorname{los}$ nerrios secmidarios, que son simples ó divididos. Los nervios de tercer órden se desarrollan por ambos lados.

10. Goniopteris.-Todos los nervios de tercer órden, al ménos los interiores, concluyen por anastomosarse dos á dos, conlundiéndose en uno rue termina en el punto de union del par inmediato, i termina antes de haber llegado á él.

11. Diclyopteris. - Los nervios de segundo ó tercer órden, $\dot{a}$ unos y otros, son muy cortos y se reunen formando una red por ambos lados del nervio de primer irden io de los de segundo: Los nervios de tercer órden forman siempre un tejido de mallas.

El género Sphenopteris corresponde al órden Sphenopteridex, rompuesto de especies que pertenecen, sin duda, á varios géneros, formando tiposmuy parecidos a las Polipodiaceus vivientes; pero hasta que no se conozcan mejor los órganos de fructificacion, el establecimiento de los grineros sólo será provisional. Del Sphenopteris se hacen varias subdivisiones, correspondiendo el $S$. trifoliata, Brong., al grupo Cymorgramides, y las dos especies siguientes que mencionamos al Dicksonia.

El Sphenopteris trifoliata, Brong., es de fronde tripinada; raquis grueso, fuerte, acanalado y liso; hojuelas ensanchadas, algo encor- 
vadas hácia su extremidad; pinulas regularmente espaciadas y conliguas, de superficie lisa ó muy finamente granulada, sin apariencia de nervios y de tejido probablemente coriáceo. Las pinulas superiores $\dot{\sigma}$ extremas son trilobadas, de loba terminal algo mayor, ligeramente oblonga y á veces dividida en tres lobas muy poco marcadas. Las pinulas inferiores son más alargadas, y su loba terminal es mucho mayor y está formada por tres lobas ménos separadas entre si que las dos laterales, las cuales son redondeadas, estrechadas en su base y siempre parecen enteras. Cada una de estas lobas es algo convexa, y su borde se encorva hácia abajo.-Mieres.

* 558. S. tridactylites, Brong. (Ihill; p. 181, 1. 50).-Fronde Iripinada; raquis comun y de las hojuelas ó penas gruesos, y sin hordes membranosos; hojuelas alternas, bipinadas; pimulas muy numerosas y próximas entre si, ovales, obtusas, cuneiformes, profundamente lobadas. Los segmentos superiores son simples; los medios é inferiores formados por dos ó tres lobas muy cortas, truncarlas y ligeramente reilondeadas. Los nervios son bien perceptibles, bipinados, y corresponde uno á cada loba. Nina Morena, Belmez; Villanueva del Rey (Córdoba).

* 559. Schlotheimii, Sternh). (Ibid; p. 195, l. 51).-Fronde ancha, tripinada; raquis principal bastante delgado para una planta tan grande; raquis secundarios muy ténues, casi filiformes y sin bordes membranosos. Ilojuelas inferiores alargadas y lanceoladas; las superiores $\dot{o}$ secundarias disminuyen wradual y lentamente en longitud, y varian mucho en la division y subdivision de sus pinulas, segun la parte de la lıoja que se observe. Eu su parte terminal apenas estín lobadas; un poco más abajo tienen pínulas cortas y divididas tan sólo en tres, cinco ó siete lobas; en la base de las hojas las pinulas estim profundamente divididas, con lobas á su vez de contorno sinuoso. Todas las hojas son lisas, sin señales de escamas ni de pelos. Los nervios signen en sus últimas ramilicaciones todas las divisiones indicadas, mostrándose en el centro de cada una de las lobas ó dentelladuras de la fronde. Ogasa. San Adrian de Juarros.

* 560. S. tenuifolia, Brong. (Ilid,; p. 190, 1. 48, f. 1).-Especie notalole por la delicadeza de las divisiones de las frondes. Ra- 
yuis comm grueso y aplastabo: rapus laterales allermos ron regularidad, muy oblicuos, bastante latros. P'immlas oblicuas, muy próximas entre si, lan largas como los espacios que separan uns hojuelas de otras, lanceoladas y muy agulas; decrecen lentamente desde la base á la extremblad de roda hojuela, y están prolundamente divididas en lohas bastante separadas, oblicuas, y cuyo tamáno disminuye rápidamente deste la hase al vérlice; las inferiores son cuneiformes, divididas en sus extremos en tres ó cuatro dientes profundos; las superiores son bidentadas ó enteras, oblongas, rorrespondiendo un nervio á cada diente.-Canıgas de Tineo.

* 561. S. latifolia, Brong. (Itid; 1. 205, 1. 57, l. 1 a 1). Las hojas o frondes eran probablemente bastante grandes, tripinadas las inferiores, bipinadas las smperiores; rapuis delgalo y flexnoso; pemas it hojuelas alargadas y lanceoladas. Las pímlas, mu proximas pntre si, sólo son trilobadas en la parte superior de la lromte; en la parte media son pinatifidas; las lobas son ovales, obtusas, la terminal no muy alargada, y las más inferiores bilobadas o r ribobaras. Las pinulas de la parte inferior de la fronde son mu grandes, profundamente pinatifidas, de lobas ovales bastante grandes. Los nervios están muy marcados y se hifurcan hácia el medio. El S. acuta, Brong., es de penas más espaciadas, más oblicuas, de raquis más delgado y de pínulas más alargadas, casi lanceoladas, remalando en una pinula terminal muy aguda.-San Juan de las Abadesas.

\section{CYCLOPTERIS (1).}

* 562. C. trichomanoides, Brong. (Ilril; p. 217, 1.61 his, f. 4).-Hoja delgada, redondeada, de márgen algo simuosa é irreqularmente recortada, no muy escotata en la base, de la cual parten numerosos nervios muy léuues, varias veces bifurcados, contándose muchos en el márgen, y siendo cada vez mas cortos hicia los larlos, con lo cual se puede distinguir del $C$. flahellata, Brong., cuyos ner-

1) El cyclopteris peltata, Goepp., citado por algunos autores, no es otra cosa, segun M. Schimper, que el producto de infiltraciones de hierro hidroxidado, formadas al rededor de un palillo ó raicilla que atravesára la roca y que fué reemplazado por la misma sustancia. 
vios laterales son casi tan largos como los del centro y paralelos á los bordes de la hoja.-Barruelo. Ogasa y Surroca.

\section{NEUROPTERIS.}

565. N. cordata, Brong.= Cyclopteris varians, Gutb. (Ibid; p. 229, I. 64, f. 5). - Grande y hermosa especie, de la que sólo se conocen las pinulas, las cuales son de base profundamente escotada y con un nervio central muy fino, del que divergen en arco los secundarios bien señalados, muy espaciados, varias veces bifurcados.-Villanueva del Rio.

* 564. N. acutifolia, Brong. $=N$. angustifolia, Brong. (Ibid; p. 251, 1. 64, f. 5, 4, 6, 7).-Las hojas figuradas por Brongniart no son pinulas, sino penas de primer órden, no divididas, que se distinguen de las penas de la especie anterior por su forma más lanceolada y aguda, y por la extremidad ó base de insercion, que es truncada por' el lado superior y redondeada por el inferior. Villajer (Leon).

565. N. Scheuchzeri, Hoffm. (Ibid; p. 250, 1. 65, f. 5).De base redondeada, nervio principal fuerte, nervios secundarios muy apinados, divergentes, ligeramente arqueados. Villanueva del Rio. Surroca.

* 566. N. fiexuosa, Sternb. $=$ Osmunda gigantea, var. $B$, Sternb. (Ibid; p. 259, 1. 65, f. 2, 5, 1. 68, f. 2).-Frondes grandes cuadripinadas, raquis grueso y estriato, saliendo de él en ángulo recto las hojuelas secundarias. Las pinulas tienen de 15 a $50^{\mathrm{mm}}$ de longitud y de 10 á 18 de anchura; varian mucho en dimensiones y forma; en general son de base ancha, ligeramente cordiforme, y su ángulo inferior se prolonga con frecuencia en una especie de orejeta redondeada; se hallan todas tan apretadas que se cubren unas à otras por sus bordes. Debieron ser muy caducas estas hojas, poryue se las halla generalmente aisladas y dispersas en gran cantidad it través de las pizarras que las envuelven. Valles de Langreo y Mieres. San Adrian de Juarros. Belmez y Espiel. 
* $567 . \quad \mathrm{N}$. gigantea, Sternb.=0smumla gigunten, Sternb. (Brong: Ibid; p. 240, I. 69).-Esperie compuesta de wrandes fromdes bipinadas, distinta de la V. flexuosa, Brong., por la longilud de sus penas y por sus pinulas algo menores y mís apartadas entresi, pmes raras veces son contiguas. La long. de estas es de 90 a $50^{\mathrm{mm}}$; sul lat. 7 á 10. Tambien dehieron haber sido caducas, porque se encuentran aisladas con bastante frecuencia. Por la longitud de las penas se parece al $N$. lenuifolia, Schlot (sp.); pero en esta especie las pinulas son generalmente algo menores, están más juntas, pues en parte se cubren unas á otras; su base es claramente escotada en forma de corazon, y parecen haber silo ménos caducas. Valles de Nieres, Aller, Langreo y Riosa. Orbó. San Adrian de Juarros. Belmez.

* 568. N. Loshii, Brong. (Ibid; p. 242, 1. 75).-Esta especie, la siguiente, las $N$. temifolia y $N$. Soretii, Brong., deberian tal vez, segun M. Schimper, reunirse en una sola diferente de la anterior por sus pinulas algo menores, más inmediatas entre si, claramente escotadas en forma de corazon en su hase y quizas ménos caducas. La N. Loshii, Brong., difiere de la $N$. flexuose, Brong., por sus pinulas ovales, mucho más cortas y anchas, y por la loba terminal muy corta, oval y con frecuencia trilobada. El raquis comun es fuerte y estriado; los nervios secundarios muy finos, apretados, arqueados y varias veces dicotomos. Longitud de las pinulas de 7 a $10^{\mathrm{mm}}$, latitud de 4 á 7 . - Sabero. San Juan de las Abadesas.

* 569. N. heterophylla, Brong.二Gleichenites neuropteroides, Goep. $=$ Cyclopteris otopleroides, Goep. (Ibid; p. 245, 1. 71).-No hay que perder de vista que en esta especie, como en las anteriores, las hojuelas y las pinulas varian mucho, segun el lugar que ocupan en la fronde. En los extremos de las de esta especie y de la $N$. Loshii, Brong., pueden confundirse, porque entonces las hojuelas se hacen muy pequeñas y redondeadas; pero en la especie de que tratamos las penas decrecen mucho más rípidamente, y la pimula terminal, aunque mayor que en las partes inferiores de la fronde, es más alargada y aguda. A pesar de todo, Brongniart tambien sospecha que ambas especies tal vez no sean más que var. de ma sola. Sama; Ciaño; Forcada. Arroyo del Albardado; Belmez.

* 570. N. Grangeri, Brong. (Ibid; 1) 257, 1. 68, f. 1).- 
Frondes muy grandes, á juzgar por la longitud de las penas ù hojuelas y la igualdad en el tamaño de las pínulas. Esta especie es un término medio entre la anterior y $N$. gígantea, Sternb., de la que se distingue por sus pinulas más cortas y anchas, no encorvadas, más acorazonarlas, por sus nervios ó venas ménos numerosos y más gruesos. Se diferencia de la anterior por este viltimo carácter y por sus piunlas más espaciadas. - San Juan de las Abadesas.

571. N. Cistii, Brong. (Ibid; p. 258, 1. 70, f. 5).-Creen IIII. Brongniart y Schimper que esta especie deberia agregarse á la auterior, de la cual sólo difiere por sus pínulas más ovales, más espaciadas, ménos oblongas, y por sus nervios ó venas dos veces bifurcados en vez de tres.-Espiel y Belmez.

\section{ODONTOPTERIS. (1)}

572. O. Schlotheimii, Brong. = Filicites Osmundaformis, Schl. $=F$. vesiculuris, Schl.$=$ Weissites vesicularis, Goepp. (Brony.: Ihid; p. 256, 1. 78, f. 5).-P'inulas casi redondas, tan anchas como largas. Esta especie y la 0 . lingulata, Goepp. $=0$. obtusa, Brong., son de las pocas del género cuyas pinulas no rematan en punta; y la segunda se distingue de la primera por sus pinulas oblongas y hendidas ó separadas hasta la base.-Puerto de Leitariegos.

(1) Recordaremos al lector los caractéres diferenciales entre este género y el anterior. En los Odontopteris, las hojas se insertan á los raquis en toda la longitud de la base; son decurrentes y á veces confluentes; la pínula basilar inferior es de figura muy diferente de las demas; casi todas son puntiagudas y algo encorvadas en forma de hoz, y sus nervios nacen directamente del raquis. En los Neuropteris, las foliolas se estrechan más ó ménos en la base y á veces son brevemente pediciladas; las pínulas son obtusas y redondeadas en su ápice, y sus nervios parten de otro central, que á su vez se deriva del raquis. Los dos géneros forman uno de los rasgos mís característicos de la flora hullera, y aunque Goeppert y otros autores citan el (Idrutopteris en la jurásica, ha sido, en concepto de Ir. Schimper, por falsas interpretaciones de los caractéres genéricos. 


\section{RHACOPTERIS.}

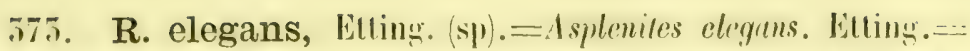
Sphenopleris asplenites, Gein. (Geinitz: Vestein. Steinti.; 1) 17, 1. 24, f. 6).-11. Schimper no cila mís que esta especie del género Rhacopteris, caracterizado por sus pinulas recortadas en el sentido de los nervios, las cuales, por una torsion en su hase en ángulo recto, se insertan horizontalmente y no en el plano del rapuis como sucedr en los demas helechos. Toreno. Con el nombre de Nrrggerathin la cita el Sr. B. A. Gomez en San Pedro da Clova (Portugal).

\section{PECOPTERIS. (1)}

* 574. P. arborescens, Schlot. (sp).=Filicites arhorescens, Schlot $=F$. cyatheus, Schlot $=$ Pecopteris Schlotheimii, Sternb $=P$. aspidioides, Brong. =P. platyrachis, Brong. =P. lepidarrachis, Brong. $=C$ yatheites arborescens, Gein $=C$. Schlotheimii, Gein. $=C$. Iepidorvachis, Gein. (Brongniart: Hist. des vég. foss.; p. 510, 1, 102, 105,101 , f. 1, 5, 112, f. 2 y 4).-Especie frecuente y bastante variable por la anchura y longitud de las pinulas, que unas veces son estrechas ( $P$. cyathea, Brong.) y otras muy cortas ( $P$. arborescens, Brong.). La fronde es tripinada, el raquis principal hasta de $5 \mathrm{~cm}$ de diámetro, lleva granillos y tubérculos, indicando tal vez otras tantas espinas que existieran cuando la planta crecia; raquis secundarios, fuertes y gruesos; penas alargadas y muy próximas entre si. Las pinulas son apretadas: por regla general largas y estrechas, oblongas y determinacion redondeada de 5 a $8 \mathrm{~mm}$ de longitud, por $1^{1 \text {, }}$ á 5 de anchura, y convexas á uno y otro lado del nervio central. Los

11. De este interesante género menciona M. Schimper 109 especies agrupadas en los subgéneros $P$. Cyatheides, $P$. Aspidides, $P$. Asplenides, $P$. Acrostichiles y $P$. incertre affinitatis, cuyas diferencias apreciará el lector por los caractéres específicos. La clasificacion natural de estos fósiles, con frecuencia muy incompletos, presenta dificultades contra las que se han estrellado cuantas tentativas se han hecho hasta el dia para desarrollar una perfecta determinacion. 
nervios secundarios son simples ó una sola vez bifurcados (1). El $P$. nodosa, Goep., es probablemente la fronde fértil del $P$. arborescens, y la forma de sus pinulas se aviene exactamente con las del P. platyrachis, Brong., var. de la especie de que lratamos, de penas apartadas unas de otras y compuestas de piunlas bastante cortas para dejar entre dos penas inmediatas una distancia considerable. Este carácter, unido á lo grueso del rarpuis, que pone mis en relieve 10 delgado de sus penas, contribuye à dar á esta planta un aspecto muy distinto del tipo primilivo del $P$. arborescens. A pesar de reunir á esta el $P$. lepidorachis, arvierte Mr. Schimper que tal vez esta íllima especie deba remirse mejor al $P$. Candolleana, Brong., cuyas pinulas son greneralmente doble más anchas, su insercion nís oblicua y sus nervios siempre bifidos, y alguma que olra vez trifidos. El $P$. pulchra, Ileer., difiere del $P$. arborescens por sus penas más cortas, más estrechas y más espaciadas. - Rengos; Ferrones; Arnao; Sama; Foreada; Ciano; Ballina de Sotrondio; Cerredo; Mieres; Riosa y otros puntos de la provincia de Oviedo. Puerto Manzanal; Sabero (Leon). Guarlo; Vegacervera; Orbó; Barruelo; Otero de Dueñas (Palencia). San Adrian de Juarros (Burgos). Valdesotos (Guadalajara). Eril-Castell (Lérida). San Juan de las Abadesas (Gerona). Puerto Llano (Ciudad-Real). Belmez y Espiel (Córdoba). Villanueva del Rio (Sevilla).

575. P. oropteridia, Schloth. (sp.)=Filicites oroplerideus, Schlot. = Cyatheites oropterilia, Goep. (Ihid; p. 517, I. 104, f. 1 y 2, 1. 105, f. 1 a 5 .-Compuesto de pimulas oblongas, obtusas, más ó ménos alargadas, separadas hasta la base ó hasta cerca de ella, muy poco oblicuas al rayuis que es muy delgado; nervios secundarios, una sola vez hilurearlos hacia su base ó en la milad de su extension, bastante espaciados y casi perpendiculares al nervio central.-Ferrones: San Juan de las Abadesas.

$\because$ 57t. P. Bucklandi, Bront.=Alethopteris Bucklandi, Goep. (Ihid; \%. 519, 1. 99, 1. 2).-Penas oblicuas, oblongas y agudas; piunlas apretadas, oblongas, de 8 a $9^{\mathrm{mm}}$ de longitud y 5 de anchura;

1) Esta especie y las diez siguientes corresponden al grupo $P$. Cyatheides. 
nervios secundarios muy oblicuos, bifureados cerca del nervio central, y á reces, segunda vez bifurcado el ramal superior. Guardo.

* 577. P. pteroides, Brong.=Alethopteris Brongniarli, Goep. (Ithil; 1. 529, 1. 99, f. 1).-Especie muy parecida á la anterior, pero de pinulas no decurrentes, de nervios más arfueados, y siempre dos reces dicotomos por lo ménos. La pínula inferior de cada hojuela se inserta en el ángulo inferior (de 95 á $100^{\circ}$ ), que forma el raquis comun con el de la pena, y áun se adhiere por toda su base a este raruis comun, naciendo su nervio central á cierta distancia por bajo del origen de la pena. El $P$. ovata, Brong., que presenta este mismo carácter, se distingue por sus pinulas cortas, ovales, ensanchadas en sus bases y apartadas hácia el borde. El P. Cistii, Brong., es de pinulas mucho más cortas y sus nervios ménos dicotomos; y por estos tambien se la distingue del $P$. densifolia, Goep. Vergaño.

378. P. pennæformis, Brong. $=P$. wqualis, Brong. (Ibid; p. 545, 1. 118).-Fronde grande, tripinada; penas ú hojuelas inferiores ( $P$. pennefformis, Brong.) muy alargadas y próximas entre sí, con 15 a 50 pinulas de 5 a $4 \mathrm{~mm}$ de longitud cada una; penas superiores ( $P$. aqualis, Brong.) con 5 a 6 pinulas solamente de 1 á $2^{\mathrm{mm}}$ de longitud. Todas las pinulas se adhieren entre si por la base y son muy redondeadas en su extremo. Nervio central muy marcado, saliendo de él á cada lado, 2, 5, 4 y hasta 5 nervios simples ó una sola vez bifurcados. Cuesta de la Torre á Brañuela. Espiel.

579. P. unita, Brong. $=$ Cyatheites unilus, Goepp. $=$ Oligocarpia unita, Goepp. (Ibil; p. 542, 1. 116, f. 1 á 5).-Tal vez una variedad de la anterior, de la ine se distingue por sus pinulas unidas entre si, por lo ménos hasta la mitad de su longitud (var. $\beta .=$ major $=P$. pectinata), y à veces hasta su extremo (var. $\alpha_{0}=$ minor. $=P$. unila). Los nervios secundarios son simples. Olloniego; Mieres. San Juan de las Abadesas.

* 580. P. Miltoni, Artis. (sp).=Filiciles Milloni, Artis.= Cyatheites Miltoni, Goepp. (Itid; p. 555, 1. 114).-Fronde tripinada; raquis comun, grueso y liso; penas secundarias oblongas, obtusas, con una pinnla terminal pequeña. Las pimulas son casi contiguas, lige- 
ramente estrechadas en la base y redondeadas en el ápice; las extremas ó superiores enteras, las del medio sinuosas, las inferiores mís ó ménos profundamente lobadas; en las primeras los nervios se dividen en su base en otros dos, que se bifurcan de nuevo parcial ó totalmente; en las últimas, los nervios se subdividen más. La fruclificacion se indica como en el $P$. arborescens, por grupos de cápsulas puntiformes y salientes, situados en pinulas cuyos nervios se bifurcan simplemente, llevando uno de los ramos el grupo de cápsulas. Long. de las pínulas 8 a $12 \mathrm{~mm}$, lat. 5 à 5 . Rio Oscuro; Ferrones; Mieres. Otero de Dueñas; Orbó; Barruelo. San Adrian de Juarros. Valdesotos. San Juan de las Abadesas. Eril-Castell. Henarejos.

581. P. polymorpha, Brong.=P. abbreviata, Brong. (Ibid; p. 551, 1. 115, y l. 115, f. 1 á 4).-Muy parecida á la anterior, con la cual algunos autores la reunen, y de la que se distingue por sus pinulas ménos redondeadas en sus extremos, algo agudas, y por sus nervios laterales muy finos, muy apretados y más pronunciados. La textura de la hoja parece más coriácea. El $P$. abbreviala, Brong., no es más que una de las numerosas formas de esta especie. Las piunulas del $P$. distans, Lesquer, son mucho más espaciadas, y parecen haber sido de una consistencia ménos coriácea. San Adrian de Juarros. San Juan de las Abadesas. Eril-Castell.

582. P. Defrancii, Brong. (Ibicl; p. 523, 1 110, J. 111, f. 1 y 4).-Tan parecida á un Neuropteris, que solo se diferencia de varias especies de este género por sus pinulas completamente adherentes al raquis por toda su base, y aun soldadas entre si hácia esta parte. El P. Nesileriana, Brong., es una variedad cuyas pínulas son más estrechadas en sus bases; la inferior es más larga que las demás, y los nervios son más finos y más apretados.-Toreno.

** 585. P. Plukeneti, Schlot.=Filicites Plukeneti, Schlot. (Ihid; p. 555, 1. 107, f. 1 a 5).-Penas apretadas, alternas; pínulas muy cortas; las superiores enteras y oval-triangulares; las inferiores, con 5 í 9 lobas y algo más alaryadas; nervios muy finos, aryueados, de dos á tres veces bifurcados.-Orbó.

* 584. P. hemiteloides, Brong. (Ilid; p. 514, 1. 108, f. 1 y 2). -Fronde tripinada; raruis grueso, fuerle y espinoso; pimulas espa146 
ciadas, de 6 a $7^{\mathrm{mm}}$ de longitud por unos 5 de ancho, enteras 0 ligeramente sinuosas y con nervios simples. En varios ejemplares de Saarbruck y de Saint-Etienne, se han olservado los granos de fructificacion (soros), perfectamente esféricos, indicindose en la superficie la presencia de una memhrana envolvente. Ciangas. Surroca.

585. P. nervosa, Brong.=P. Sauveurii, Brong.=Alethopleris nervosa, Goepl. (Ibid; p. 297, I. 94, 95, 1. 1, 2 y 5).-Especie notable por sus nervios fuertes y por la pinula basilar inferior bilobildi. Fronde tripinada; penas oblongo-lanceoladas, anchas y unidas en el tercio inferior; oval lanceoladas en la parte superior; nervios una sola vez bifurcados. El $P$. Sauveurii, Brong., es una variedad (tal vez de la parte superior de la fronde) que se distingue por sus pinulas más obtusas, más cortas; por sus nervios ménos pronunciados y por su pínula terminal muy ancha y alargada. El $P$. subnervosa, Ad. Roem, difiere por sus pinulas más próximas y soldadas entre si hasta la mitad de su longitud, y por la pinula basilar inferior no dividida.-N. E. de Cangas de Tineo.

* 536. P. angustissima, Brong. (Ilbil; p. 545, 1. 120, f. 5). -Fronde bipinada; raquis espinoso; penas secundarias muy estrechas; pinulas dentiformes y de igual tamaño en cada pena. Las penas del $P$. pusilla, Lesquer, tienen la forma y dimensiones de las del P. angustissima, Brong.; pero las lobas de las pinulas, ignalmente soldadas hasta el medio, son oval-redondeadas. El $P$. cerpualis tiene las pinulas más profundamente separadas; y en el $P$. unita el grado de adherencia de estas últimas varia mucho segun las partes de la hoja que se examine.-0rbó.

587. P. heterophylla, Goepp. (sp).=Asplenites heterophyllus, Goepp.-Del grupo P. Asplenides. Toreno (Leon).

588. P. Meriani, Brong. (Ihid; p. 289, 1. 91, f. 5).-Pinulas alargadas, contiguas, recortadas hasta la base; nervios muy finos y bifurcados.-Villanueva del Rio. San Juan de las Abadesas.

\section{GONIOPTERIS.}

589. G. arguta, Brong. $(\mathrm{sp})=$ Pecopteris arguta, Brong. (Ilid; p. 505, I. 108, f. 5 y 1).-L'inulas con nervios simples, y tan 
pronunciados, que forman pliegues transversales en aquellas. Se distingue del G. elegans, Germ. (sp), con el cual algunos antores le han confundido, por sus nervios secundarios más numerosos y separados por un ángulo más abierto, y por las lobas más estrechas y más profundamente divididas. - Surroca. Entre Arlanza y Noceda.

\section{ALETHOPTERIS. (1)}

* 590. A. lonchitica, Brong. (sp).=Pecopteris lonchitica, Brong. $=P$. urophylla, Brong. $=P$. heterophylla, Lind. et Hutl. $=P$. Mantelli, Brong.=P. Davreuxii, Brong. (Ibid; p. 275, 1. 34; 1. 85, f. 5 y 4; 1. 86, I. 38).-Esta especie se parece mucho á diversos helechos vivientes (Pteris caudala, esculenta, tremula), y como ellos varia mucho en la forma y dimensiones de las penas y pínulas. Estas son muy alargadas y casi siempre separadas, solre todo inferiormente, ya simples $\dot{o}$ enteras, ya incompletamente pinatifidas ó de lobas muy cortas. El nervio central está bien marcado hasta el ápice, y los nervios secundarios son muy finos, una vez bifurcados desde su origen, interponiéndose con regularidad otros simples, y todos son perpendiculares al márgen.-El $P$. Davreuxii, Brong. es una variedad diferente por sus pinulas, todas decurrentes y reunidas por la base; casi perpendiculåres al raquis, algo mảs pequeñas y no tan alargadas. El $P$. Mantelli es otra variedad de pinulas más estrechas y proporcionalmente más espaciadas. Sama de Langreo; Mieres; Cangas de Tineo. Sabero.

* 591. A. Serlii, Brong. (sp).$=$ Pecopteris Serlii, Brong. $=P$. oblongata, Sternb. (Ibid; p. 292, 1. 85).--Se distingue de la anterior por las pinulas mís anchas, claramente confluentes en su base, y por sus nervios más numerosos y más finos, bifurcados unos, otros simples intermedios como en el $A$. lonchitica. La fronde es bipinada; las pinulas, oblongo-lanceoladas, miden de 20 à $25^{\mathrm{mm}}$ de longitud y 6 à 8 de ancho. La terminal es más alargada. Cangas de Tineo; Langreo; Mieres; Riosa. Las Bobias; Sabero. Guardo; Barruelo. Sulroca. Arroyo del Albardado, Belmez.

(1) Establecer un límite preciso entre este género y el Pecopteris es una cosa imposible, dice M. Schimper, y nos vemos obligados á contentarnos con una agrupacion aproximada. 
$*$ 592. A. aquilina, Schlot. $(\mathrm{sp}) \cdot=$ Pecopteris aquilina, Brong. (Ibid; p. 284, 1. 90). Fronde bastante grande, por lo ménos una milad más que el P'teris aquilina viviente, al que se parece mucho por la forma general; las pinulas muy convexas, de bordes encorvados por abajo, de nervio central muy marcado, y de tejido al parecer, espeso y coriaceo. Las penas ú hojuelas se extienden en íngulo recto con el raquis; las pinulas, oblongas y decurrentes, se unen hácia la base y están separadas por senos no redondeados; los nervios se bifurcan, y uno de sus ramales se bifurca á su vez. $\Lambda \mathrm{l}$ N. E. de Cangas de Tineo. San Juan de las Abadesas; Surroca. Ilenarejos. Valdesotos. Villanueva del Rio.

* 595. A. Grandini, Brong. $(\mathrm{sp}) .=$ Pecopteris Grandini; Brong. (Ibid; p. 286, I. 9I, f. 1 à 4). - Las pínulas varian mucho en su longitud y anchura; las más anchas tienen $5 \mathrm{~mm}$ en su parte media, por una longitud de 15; las más lanceoladas 5 y 25 respectivamente. Los senos de separacion entre ella son redondeados, y además difiere esta especie de la anterior por sus pínulas del todo oblongas y no ensanchadas en su parte media. AI N. E. de Cangas. Barruelo. El Biar, junto á Cantillana. San Juan de las Abadesas.

594. A. Dournaisii, Brong. (sp).= Pecopteris Dournaisii, Brong. (Ibid; p. 282, 1. 89).-Se distingue de las anteriores por sus pínulas menores, con nervios dos veces bifurcados. Las penas superiores son simples y ligeramente flexuosas; las pinulas son adherentes hácia la base, y suelen tener $10^{\mathrm{mm}}$ de longitud por 5 de latitud. Toreno. San Juan de las Abadesas.

\section{DICTYOPTERIS.}

* 595. D. Brongniarti, Gutb. (Geinitz: Steink. von Sachsen; p. 25, 1. 28, f. 4 y 5).-Fronde bipinada; pinulas acorazonadas en la base, oblongas, encorvadas en forma de hoz, redondeadas en el ápice, de 25 a $50^{\mathrm{mm}}$ de longitud y 10 á 12 de anchura. Ballina de Sotrondio; San Martin del Rey Aurelio; Sama de Langreo; Mieres. Barruelo; Vergaño. San Adrian de Juarros. Espiel.

* 596. D. neuropteroides, Gutb. (Ibid; 1. 28, f. 6).-Di- 
fiere de la anterior por ser más finamente reticuladas sus pinulas. Lago de las Lomas; Orbó (1).

\section{SCHIZOPTERIS.}

597. S. anomala, Brong. (Itist. des vég. foss.; p. 584, I. 155). -Planta extraña, cuya posicion entre los helechos no ha podido fijarse todavía, si bien á ellos se asemeja por la fiuura de su nerviacion. La fronde es plana y de apariencia resistente, sin la tenuidad de las algas membranosas, ni el aspecto carnoso é irregular de las algas de fronde espesa. Sus nervios, muy finos y bien señalados, son paralelos entre sí, bifurcándose únicamente cuando la fronde se ensancha ó se divide.-Arnao; Cangas de Tineo.

\section{SPIROPTERIS.}

* 598. S. Miltoni, Schimper (Traité de Paléont. vég.; t. 1, p. $688,1.49$, f. 4).- La palabra Spiropteris no tiene la significacion de un nombre genérico, pues, naturalmente, hay tantos Spiropteris como helechos fósiles; pero como la mayor parte de las frondes jóvenes en espiral que se hallan en el grupo hullero no podrian referirse á especies determinadas, bueno es designarlas con un nomhre particular, tanto más, cuanto que algunas de ellas han sido confundidas con otros tipos vegetales. El raquis se encorva en figura de cayado, y va disminuyendo su grueso desde la base hácia el vértice; las penas ú hojuelas se encorvan en arco y son pinatifidas en su extremo; con pelos apretados, largos y lanceolados. San Adrian de Juarros.

\section{LYCOPODIUIM.}

599. L. primævum, Goldenb. (Schimper; Traité de Palion. vég.; t. 2, p. 8, 1. 57, f. 1 y 2).-Esta planta herbácea tiene el tallo

(1) Por el modo de division de la fronde y la forma de las pínulas, se parece este género al Neuropteris, del cual puede distinguirse fácilmente por su nervacion reticulada. 
dicotomo y fuerte; sus hojas sou dimorfas, extendidas, de base esIrechal oval-lanceoladi, grandes las caulinas, pequeñas las rameas. Puerto de Leitariegos.

\section{LEPIDODENDRON.}

* 400. L. Sternbergii, Brong. $=L$. obovalum, Sternl. $=L$. dichotomum, Sternb. $=L$. elegans, Brong. $=L$. gracile, Brong. $=L$. ruyosum, Brong.=Sagenaria dicholoma, Geinitz.=S. obovata, Sternb. =S. rugosa, Presl. (Schimper: Ibid; p. 19, 1. 58, 59, f. 2, 1. 60, f. 5 á 5).-El género Lepidodendron es uno de los más importantes. Las cicatrices del tronco sólo se conocen, en general, por sus contraimpresiones. En cada cicatriz foliar hay tres cicatrices vasculares dispuestas horizontalmente hácia la base; la del medio es alargada a través en forma de media luna, las otras dos son puntiformes. Debajo de ellas hay otras dos mayores, implantadas en el coginete foliar, y son alargadas en el sentido de la quilla que las separa, o redondeadas en forma de verruguitas. En los troncos sin corteza las cicatrices grandes desaparecen por completo, y sólo se ve un hoyuelo corto lineal, algo ensanchado en el medio. Sobre la estructura de este género, poco ó nada podemos decir. Generalmente los troncos aparecen muy comprimidos; la corteza con los coginetes y cicatrices foliares se halla transformada en carbon ó falta por completo; el tejido parenquimatoso desapareció por completo y está reemplazado por materia inorgánica, y el cilindro leñoso se halla tan apretado, que queda reducido á una lámina carbonosa tan delgadla como una hoja de papel. Es dificil, si no imposible, reconocer siempre el género á la simple inspeccion de las cicatrices foliares, y más dificil todaria delerminar las especies, principalmente cuando los fragmentos provienen de diferentes partes del árbol. Sobre torlo las cicatrices del tronco difieren notablemente por su tamaño, y muchas veces por su forma, de las que existen en las ramas de primer irlen; estas son distintas de las de segundo, y asi sucesivamente. Las hojas y órganos de fructificacion se hallan casi siempre aisladas, y cuando se les encuentra reunidos á los ramitos, no se ven en estos más que las cicatrices que les son propias y que tienen forma y dimensiones muy diversas de las del tronco. De aqui la gran confusion que todavia existe en la determinacion de las es- 
pecies, y la imposibilidad de remir con certeza bajo el mismo nombre los fragmentos de troncos, ramas, ramitos, hojas y frutos procedentes de una sola especie. Los ramitos, á causa de su parecido con los Lycopodos, han recibido el nombre de Lycopolites; las hojas aisladas se han reunido en un género aparte, Lepidophyllum; y las espigas ó conos fértiles se llaman Lepidostrobus.

El L. Sternbergii, Brong., tiene sus cicatrices romboidales muy agulas en sus extremos, de unos $50^{\mathrm{mm}}$ de long. por 15 de anchura. El L. crenatum, Sternb., solo difiere de éste por sus cicatricillas mayores y proporcionalmente más anchas, carácter que, segun Schimper, es de poca importancia. El L. Haidingeri, Etting., por sus hojas más anchas y más largas y las cicatrices rameales más alargadas, se distingue del $L$. Sternbergii Brong., con el cual tendrán que reunirse, tal vez, el $L$. clypeatum, Lesquer., y otros varios. Valles de Riosa, Quirós, Nieres, Langreo, Aller, Bimenes, San Martin de Rey Aurelio. Barruelo. San Adrian de Juarros. Fuente 0vejuna.

* 401. L. aculeatum, Sternb. =Aspidiaria undulata, Sternb. $=$ Sagenaria confluens, Sternb. $=S$. caudala, Sternb. (Ibid; p. 20, 1. 59, f. 5, 1. 60, f. 1, 2 y 6.)-Se distingue del anterior por sus cicatrices más alargadas por arriba y por abajo. Tal vez debe reunirse á ésta el $L$. ccelatum, Brong. (sp), que sólo difiere por sus cicatrices algo menores.-Sama. San Adrian de Juarros. Surroca. Espiel.

* 402. L. longifolium, Brong. $=L$. dichotomum, Sternb. (pars).=L. Sternbergii, Ettin. (Ibid; p. 22, 1. 59, f. 1).-Las cicatrices de sus ramas y ramitos son parecidas á las del $L$. Sternbergii, Brong.; ramitos gruesos; hojas estrechas, lineales, apretadas, de 60 à $30^{\mathrm{cm}}$ de longitud.-Dlieres.

* 405. I. rimosum, Sterub. = Sagenaria rimosa, Gein. (Ibid: v. 2, p. 55, 1. 60, ศ. 8.)-Cicatrices romboideo-fusiformes, rematadas en punta en las extremidades, de 8 a $11^{\mathrm{mm}}$ de long. y 4 á 5 de anchura; cicatricilla central rombal, algo transversa.-San Adrian de Juarros.

\section{ULODENDRON.}

404. U. punctatum, Lind. et IIntt.=Bolhrodendron mimutum, Lind. et Hut.(Fossil Flora: v. 2, p. 2, 1. 30 y 81).-El tronco del 
Ulodendron debió ser simple ó poco ramificado, cónico, mucho más estrecho hácia el vértice que en la base. Aunque parecidas á las del Lepidodemtron, las cicatrices de las hojas se distinguen por sus dimensiones casi iguales deste la base hasta el vértice; las hojas eran cortas, lanceoladas y rigidas. El coginete foliar es convexo y lleva la cicatricilla en su partesuperior; despues de su caida la cicatriz es cóncava, y en su centro tiene una cicatricilla alargada y cercada de un borde estrecho. Los grandes discos biseriales y alternos que distinguen este género, varian de tamaño y aún de forma, segun el lugar que ocupan en el tronco y en las ramas: hácia la base son ovales, midiendo hasta $15 \mathrm{~cm}$ en el sentido de la longitud y 10 de anchura, y distantes unos de otros, en la misma série, de 4 á $5^{\mathrm{cm}}$; hícia el vértice son redondeados, mucho menores y muy próximos entre si. Su centro está ocupado por una cicatriz pequeña circular ó semi-lunar, umbilicada, de la que parten impresiones en fajas ó séries en tresbolillo de cicatrices foliares semejantes á las del tronco, pero más pequeñas. Algunos autores ven en estas cicatrices los puntos de adherencia de una inflorescencia en estrobilo ó de los conos de fructificacion, que parece debieron ser persistentes.

El $L$. punctatum, Lind. et IInt., se distingue por las cicatrices foliares puntiformes que parecen acusar la existencia de hojas aciculares muy finas, y por la cicatriz de los discos colocada hícia el borde inferior.—Quirós; Mieres.

\section{KNORRIA.}

* 405. K. imbricata, Sternb. (sp). =K. longifolia, Goep.= Sagenaria polyphylla, Gein.=Lepidolepsis imbricata, Sternb.=Lycopodites dilatahus, Gein.=Didymophyllum Schottini, Goep. (Schimper: Traité de Paléonl. végél.; t. 2, p. 46, 1. 65).—El género Knorria difiere del Lepidodendron por la forma de los coginetes y cicatrices foliares que cubren el tronco. Los coginetes son escamiformes ó semicilindricos; están truncados en la extremidad superior, y dejan, despues de su caida, una cicatriz redonda, cóncava, que lleva en el centro una sola cicatricilla vascular. Las hojas, que son largas, lineales y gruesas hácia la base, llevan en el centro un nervio aplastado. Algunas veces son tan largos los coginetes foliares, que algunos autores los han tomado por las hojas mismas. Asturias. San Adrian de Juarros. Puertollano. 


\section{LEPIDOPHLOIOS.}

* 406. L. laricinus, Sternb. = Lepidodendron laricimum, Sternb. = Lepidophyllum majus, Brong.=IIalonia punctata, Gein. (Ibid; p. 51, 1. 60, f. 10 á 12, 1. 61, f. 8).-El género Lepidophloios se distingue del Lepidodendron por sus ramas tetrásticas y por los cogineles foliares muy gruesos, aljiertos ó encorvados hácia atrís, de modo que la cicatriz foliar parece hallarse colocada en la parte inferior. Enchufados en sentido iuverso, probablemente estos coginetes eran suculentos y de epidermis coriácea, que persiste en casi todos los ejemplares bajo la forma de escamas trasversalmente rómbicas, de borde escotado irregularmente, encajadas de arriba abajo, como los coginetes, y llevando en su parte media una cieatricillin vascular redondeada ó triangular.

Del $L$. laricinus, Sternb., sólo hemos observado las hojas que son lanceoladas, estrechas y largas, con una punta muy agruda. Orloó. San Adrian de Juarros.

\section{HALONIA.}

* 407. H. tortuosa, Lind. et IIull.=II. tuberculala, Brong. (Ibid; p. 54, 1. 66, f. 1 y 2).-La manera de ramificarse, la forma y la disposicion de las cicatrices foliares de este vegetil, recuerdan las del Lepidodendron, del que se distingue por un sistema de tubérculos cónicos, obtusos, dispuestos en tresholillo, que cubren el tallo, y cuya signilicacion morfológica no se ha precisado todavia. M. d'Eichwald ve en ellos los puntos de adherencia de las hojas, y en las cicatrices pequeñas romboidales las de las escamas; otros autores creen ver las señales de ramitos al estado latente, que no llegaron al desarrollo normal; y segun II. Schimper, si estas aberturas llevan un forámen vascular en su vértice, es natural suponer que eran puntos de insercion del fruto.-La Florida, San Felices.

\section{SIGILLARIA.}

** 408. S. tessellata, Brong. $=S$. hexagona, Brong. $=S$. elegans, Brong. $=S$. Knorri, Brong. $=S$. alveolaris, Brong. $=S$. mini- 
ma, Brong. =S. ornata, Brong.=-Sypingodendron pachyderma, Brong. (IIistoire des veig. foss.; p. 456, 1. 155, 156, 158, 1. 1, 2, 7, 8, 1. 162, l. 166, f. 1). - Los troncos de sigillaria pueden dividirse en dos grupos: acanalatos y lisos. Los primeros llevan costillas aplastadas, verticales, de lados ya paralelos exactamente, ya estrechados entre las cicatrices. Estas, en las sigilarias sin costillas, son contiguas y cubren toda la superficie del tronco, ó están separadas por espacios lisos más ó ménos anchos. Despues de la caida de la corteza no quedan en el tronco más que las cicatricillas de los haces vasculares ovales, reunidas entre si ó confundidas en una sola, salientes ó hundidas en $u n$ hoyuelo. A reces entre las séries de las cicatrices de las hojas, se ven séries interrumpidas de otras, de las que radian varias arrugas, y que probablemente fueron las cicatricillas de insercion de las espigas fértiles. Como en el Lepidodendron, la estructura microscópica no se ha reconocido todavia más que en algunos fragmentos; pero segun un ejemplar silicificado de $S$. elegans, estudiado por Brongniart, el carácter esencial de estas plantas es el de presentar en el interior de su tallo un cilindro leñoso enteramente compuesto de rasos radiados ó reticulados, dispuestos en séries radiantes, separadas en general por los radios medulares 0 por los haces vasculares que van á las hojas.

En la Sigillaria tessellata, Brong., se han reunido todas arquellas sigilarias que tienen por carácter comun la forma general de las costillas, divididas por surcos trasversales más ó ménos completos en espacios casi cuadrados, cuya extension en longitud es próximamente igual á la anchura de las costillas. Las cicatrices, $\dot{o}$ están contiguas sobre los lados verticales, en cuyo caso la ranura longitudinal es muy estrecha y está plegada en ziģ-zag, ó están separadas, y la ranura se nota bien perceptible y derecha. Las diferencias de sus muchas variedades consisten en modificaciones de la forma de los discos de insercion y de las cicatrices vasculares que presentan: en unas, los discos son redondeados, sin ángulos mareados y ligeramente escotados en su parte superior; en otras (var. $\gamma$ ), los discos son circulares del todo; en la var. o son algo ovales; en la var. $\alpha$ los discos son exagonales, teniendo bien señalados sus ángulos, dos laterales, dos superiores y dos inferiores; en la var. 3 los discos se acercan más á la forma cuadrilátera de ingulos redondeados. Mieres; Santo Firme; Riosa; Sama de Langreo. Matallana; entre Arlanza y Noceda. Barruelo. Sierra de los Palacios, Belmez. 
* 409. S. Dournaisii, Brong. (Ibid; p. 441, 1. 155, f. 5).Muy parecida á la anterior, de la que sólo difiere por el alargamiento de todas sus partes; sus coginetẹs prismáticos son más elevados, y los ángulos laterales de las cicatrices más agudos. Langreo.

* 410. S. mammillaris, Brong. (Ibid; p. 451, 1. 149, f. 1, 1. 165, f. 1).-Discos muy oblicuos con relacion á la superficie del tronco, y casi tan anchos como las costillas, que niden de 6 á $8 \mathrm{~mm}$. Difiere de la $S$. notata, Brong., por sus costillas más estrechas, sus discos más angostos, de ángulos ménos agudos y no dispuestos paralelamente al tronco.-Orzonaga; valles de Langreo y Mieres.

* 411. S. Utscheinederi, Brong. (Ibil; p. 455, 1. 165, f. 2). - La anchura de las costillas no es más que de 4 a a 5 mm; las cicatrices discoides son alargadas, hallándose los ángulos laterales hácia el medio de los lados; los bordes superior é inferior de los discos se encorvan fuertemente.-Sama de Langreo.

* 412. S. elliptica, Brong. (Ibid; p. 447, 1. 152, f. 1 á 5).Costillas de $1^{\mathrm{cm}} \dot{o}$ algo más de anchura; cicatrices discoides de forma exagonal alargada y más ó ménos distantes entre sí, á veces no dejando más que 5 á $5^{\mathrm{mm}}$ de espacio vertical entre unas y otras. La var. $\alpha$ es de discos exagonales, divergiendo de los ángulos inferiores dos líneas salientes. La var. $\beta$ difiere por sus cicatrices muy próximas; y la var. $\gamma$ por sus cicatrices muy espaciadas.-Sabero.

* 415. S. Saullii, Brong. (Ibid; p. 456, 1. 151).-Cicatrices discoides exágono-redondeadas, de ángulos laterales muy poco marcados, y ocupando casi toda la anchura de las costillas, que es de 10 á $12 \mathrm{~mm}$. Su corteza es más gruesa que la de la $S$. scutellata y más delgada que la de la $S$. pachyderma, estando más señalado que en estas un surco transversal, casi recto, colocado encima de las cicatrices.-Valles de Mieres, Langreo y Aller.

* 414. S. Schlotheimiana, Brong. (Ibid; p. 469, 1. 152. f. 4). -Costillas de unos $14^{\mathrm{mm}}$ de anchura; cicatrices discoides exágonoredondeadas, ligeramente escotadas en el lado superior y. de lado inferior muy encorvado. Los ángulos laterales se corresponden con la mitad de la altura de los discos, y de ellos bajan quillas ó salientes 
débilmente marcados, paralelos entre sí, limilando un espacio cuya superficie lleva estrias finas oblicuas. Debajo de los discos (que en general están muy espaciados) se marcan mejor las arrugas de la corteza, que son casi puntiformes.-Ilicres; Riosa; Langreo.

* 415. S. pachyderma, Brong. (Ibid; p. 452, I. 150, f. 1).Como lo indica su nombre, su corteza es muy gruesa, por cuya razon, en el tallo desprendido de ella, no se ven señales de los discos de insercion. Estos tienen la forma de un exágono, cuyos lados superior é inferior son los más cortos, y los laterales superiores los más largos. Las arrugas transversas de la corteza se marcan mejor debajo de las cicatrices que encima de ellas, carácter que distingue esta especie de otras, tales como la $S$. scutellata, en la cual sticede la inversa. Las costillas tienen de 8 a $10^{\mathrm{mm}}$ de anchura, y los discos de 6 a 8 de longitud.-Santofirme.

416. S. orbicularis, Brong. (Ibid; p. 465, 1. 152, f. 5).Notable por sus discos casi redondos, se parece mucho á algunas variedarles de la $S$. tessellata, Brong., de la que difiere por la carencia de surcos transversos, y por hallarse más espaciadas las cicatrices. Las costillas tienen de $10 \mathrm{a} 14^{\mathrm{mm}}$ de anchura, y no presentan, como las otras especies ( $S$. reniformis, $S$. levigata), un espacio central limitado por dos lineas descendentes desde los lados de las cicatrices, y cuya superficie es con frecuencia muy diversa del resto del tallo por sus estrias ó arrugas.-Villanueva del Rio.

* 417. S. Cortei, Brong. (Ibid; p. 467, 1. 147, f. 5 y 5).Costillas de 6 á $9^{\mathrm{mm}}$ de anchura, teniendo su parte central limitada por 2 lineas paralelas, que bajando desde las cicatrices, limitan una superficie rugosa á través; la parte exterior á esta zona está, por el contrario, estriada á lo largo. Cicatrices alargadas y distantes entre si vez y media á dos veces de su longitud, que casi es doble de su anchura.-Mieres.

* 418. S. contracta, Brong. (Ibid; p. 459, 1. 147, f. 2).Difiere de la anterior por sus costillas muy estrechadas ó contraidas en los puntos correspondientes á los de insercion de las hojas, por las cicatrices de estas más alargadas y casi truncadas en sus dos extremos, y por las arrugas dispuestas en angulos agulos, á modo de 
soleras, que surcan las costillas entre los discos. En la Escuela de Minas, conı ya se adelantó á decirlo el Sr. Areitio, hay una var. de esta especie, que difiere del tipo por sus cicatrices colocadas en la parte ancha de las costillas, en vez de hallarse en las angosturas ó estrecheces de ellas. Mieres.

419. S. elongata, Brong. (Ibid; p. 473, 1. 145 y 146, f. 2).Fácilmente distinguible por la forma muy alargada de sus cicatrices de insercion y por la zona central de sus costillas, que es saliente y muy rugosa, mientras que las partes laterales son lisas. La variedad $\alpha$ (major), tiene las costillas de 16 milimetros de anchura; las de la $\beta$ (minor) son de 9, y sus cicatrices más redondeadas. Eutre Arlanza y Noceda. Villanueva del Rio.

* 420. S. intermedia, Brong. (Ibid; p. 474, 1. 165, f. 1).Difiere de la anterior por sus cicatrices ménos alargadas, por las partes laterales de las costillas muy estriadas, y por su parte central casi sin arrugas encima y debajo de las cicatrices de insercion. Mieres y Langreo.

* 421. S. reniformis, Brong. $=S$. monostachya, Lind. el Hut. $=S$. alternans, Lind. et Hut. (Ibid; p. 470, 1. 142).-Costillas hasta de $40^{\mathrm{mm}}$ de anchura, estriadas longitudinalmente; cicatrices redondeadas reniformes, algo transversas, de 6 á $7^{\mathrm{mm}}$ de latitud, y espaceadas unos $15^{\mathrm{mm}}$. - Collada de Llama. Retienda y Valdesotos.

422. S. rhomboidea, Brong. $=S$. obliqua, Brong. (Ibid;p. 425, 1. 157, f. 4).-Los pezones poco salientes y alargados donde se insertaban las hojas dan á este fósil el aspecto de un Lepidodendron; pero el tallo carece de los surcos reticulados de esta planta, las estrias onduladas que cubren á aquel pasan de un disco á otro, y estos últimos no son alargados transversalmente. Entre Arlanza y Noceda.

* 425. S. Brongniarti, Gein $=S$. pes capreoli, Gein. (Verst. der Steink. 1. 7, f. 5 á 5).-Costillas de 8 a $10^{\mathrm{mm}}$ de anchura, estriadas longitudinalmente; cicatrices muy pequeñas, pues sólo tienen $2^{\mathrm{mm}} \mathrm{de}$ longitud, redondeadas, espaciadas á distancias nuy variables, de 20 a $30^{\mathrm{mm}}$ término medio; cicatricillas lineales, simples.-Belmez. 


\section{S T IG M A R I A}

** 424. S. ficoides, Brong. $=$ S. incqualis, (ioep. (Schimper: Paléont. végét.; t. 2, p. 114, 1. 69, f. 7 à 9).-En el género Stigmaria se comprenden los restos vegetales, que por sus caractéres y modo de presentarse deben considerarse como raices ó rizomas de sigilarias, knorrias, etc.; pero quedan todavía dudas sobre su precisa correspondencia con las especies de troncos á que debieron pertenecer. Todas las stigmarias encontradas hasta la fecha muestran próximamente la misma forma exterior. Se componen de un cuerpo central en forma de cúpula, campana ó cono de $20^{\mathrm{cm}}$ á más de un metro de diámetro, del que radian cuatro brazos principales, cada uno de los cuales se divide en dos por dicotomia. Esta division se repite para las raices de segundo órden, hasta alcanzar más de $\mathbf{8}$, de 10 y aun 20 metros. Las raicillas se hallaban dispuestas regularmente en espiral ó en tresbolillo; y al desprenderse dejaron una cicatriz circular ú oval, rodeada de un cerquillo saliente. 0cupa su interior un pezon perforado en el centro por una cicatricilla puntiforme, debida al haz vascular, que atravesaba la corteza formando el nervio axilar. Estas raicillas eran cónico-cilindricas, hinchadas hácia la base, raras veces bifurcadas y cubiertas de una epidermis lisa; su long. seria de 15 á $50 \mathrm{~cm}$, y su espesor en la base le 8 a $15 \mathrm{~mm}$. Concejos de Mieres, Aller, Riosa, Langreo y San Marlin del Rey Aurelio. Barruelo. Surroca. Puerto-Llano. Belmez.

425. S. minuta, Lesণ. (Ihid; p. 117).-Cuesta de la Torre ì Brañucla.

\section{WALCHIA.}

426. W. piniformis, Sternb.=Lycoporiolithes piniformis, Schlot.=Lycopodites piniformis, Brong. (Ibid; p. 256)._Esta especie es caracteristica de la flora permiana; y como se ha encontrado en la hullera de Puerto-Llano, el Sr. Areitio llama la atencion sobre este hecho curioso. 
Como se ve, el sistema carbonifero nos da mayor número de especies que el devoniano; pero todavia su cifra nos parece muy pequeña, atendida su doble importancia paleontológica é industrial. Si esta ha de ir estimulando cada vez más la aplicacion de nuestros compañeros, escaso tiene que ser el interés que despierte el estudio de los fósiles, para que el número de estos no aumente en breves años y vayan cesando los justos lamentos de las personas que consideran muy exiguos los materiales disponibles hasta la fecha.

A las especies anotadas podrán agregarse pronto otras muchas procedentes de todas nuestras cuencas, y por hoy nos limitamos á indicar las siguientes:

Varias del género Phillipsia, sobre todo una parecida á la $P h$. mesotuberculata, Phill. (sp), y como ella con tubérculos en el eje del coccix, que es muy saliente y tiene 18 segmentos; un Nautilus parecido al $N$. tuberculatus, Sow.; varios Orthoceratites que recuerdan los 0. giganteum, Sow., O. laterale, Phill., O. calamum, Kon., etc.; Goniatites y Clymenice tanto hulleros como de la caliza de montaña; un Macrocheilus parecido al M. Michotianus, Kon.; varias Pleurotomarias, Isocardias, Cypricardias, etc., y diversos corolarios. La mayor parte proceden de la provincia de Palencia; pero no ha de ser pequeña la cifra con la que habrán de contribuir los distritos de Leon y Oviedo, tan abundantes en fósiles paleozóicos.

L. II. 



\title{
SILURIANO
}

\author{
LÁM. $1{ }^{a}$
}

Figs.

1 Paradoxides Pradoanus, Vern. et Barr. [Núm. 1]

2 Últimos segmentos del torax y coccix de la misma especie.

3 Arionellus ceticephalus, Barr., algo aumentada. [5]

3 a La misma arrollada en bola, vista de costado.

4 Cabeza de Conocephalites Sulzeri, Schlot, procedente de Sabero. $[6]$

5 Conocephalites Sulzeri, Schlot., deformado. De doble tamaño yue el original procedente de Murero.

6 Cabeza de Conocephalites cononatus, Barr. [7]

7 Conogephalites Ribeiro, Barr. et Vern. [8]

8. Capulus cantabricus, Barr. et Vern. [49]

9 Ontils pRmondialis, Vern. et Barr. [67]

9 a La misma especie vista por la valva ventral.

96 La misma por la region cardinal.

9 c La misma por la comisura frontal.

9 La misma por la valva dorsal.

10 Orthisina vatigina, Salter. [71]

$10 a$ La misma especie vista de costado.

$10 b$ La misma vista por la valva dorsal.

11 Onthisixa Peligo, Vern, et Barr. [72]

11 La misma especie vista por la region cardinal.

12 Trochocystites bohemigus, Barr. Molde. [80] 


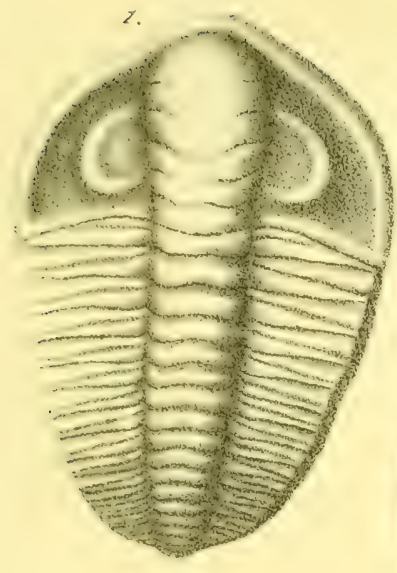

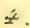
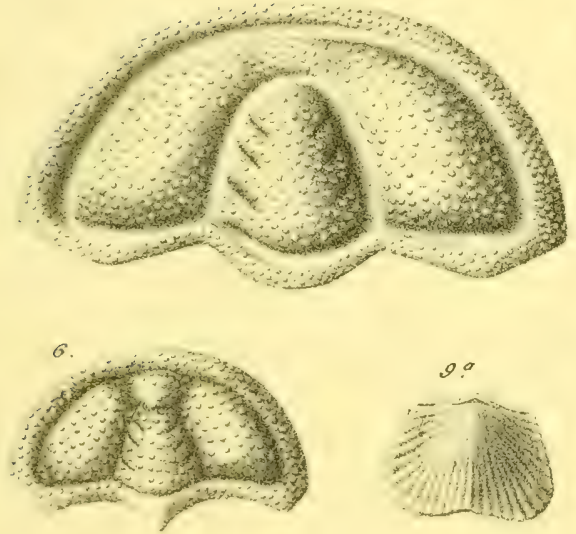

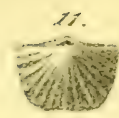

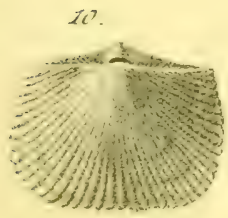

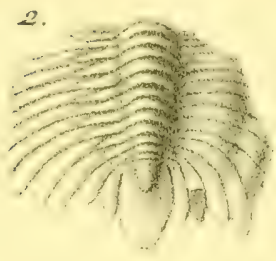

3.
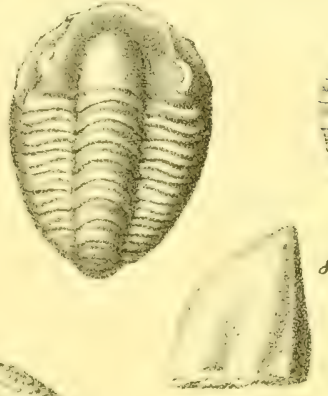

3:
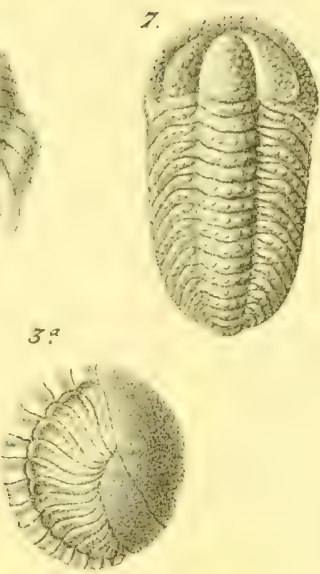

8.

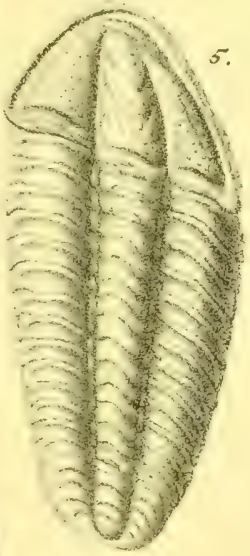

$9 . x^{2}$
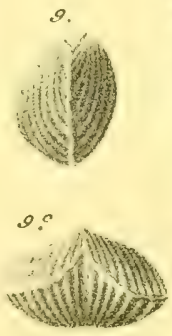

$2 x$

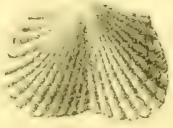

$\rightarrow, 25$

$10^{\circ} \mathrm{C}$
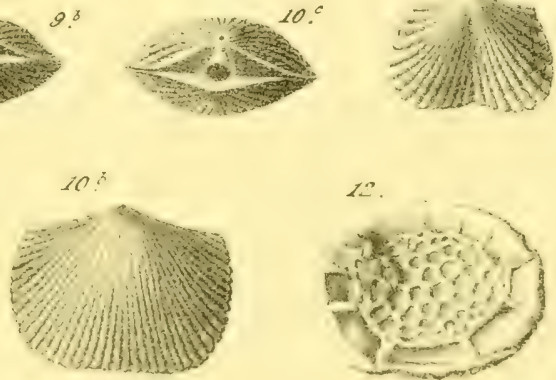




\title{
SILURIANO
}

\author{
Lín. 2,
}

Figs.

1 Dalmanites socialis, Bare. [10]

2 Dalmanites Pilllifi, Bart. [11]

3 Cabeza de Dalmanites Dujardini, Rou. [12]

4 Dalmanites Vetillarti, Rou., arrollado en bola. [13]

5 Dalmanites Tonnubie, Barr. et Vern. [14]

6 Dalmanites Downivgie, Murch., arrollado. [15]

$6 a$ La misma especie vista por la parte inferior.

7 Calymene Tristair, Brong. [17]

8 Calymene Arago, Rou., arrollada. [18]

8 a Coccix aumentado de la misma especie, figura algo imperfecta.

9 Calyuene transiens, Barr. et Veru. [19]

10 Calymene pulgha, Barr. [20]

10 a La misma especie vista de costado

11 Cabeza de Homaloyotus Brovg.yarti, Desl. [22]

12 Coccix de otro individuo de la misma especie.

13 Homalovotus narus, Corda, arrollado en bola. [21 ]

14 Glabela de Chemurus Manianus, Barr. et Vern. [31] 

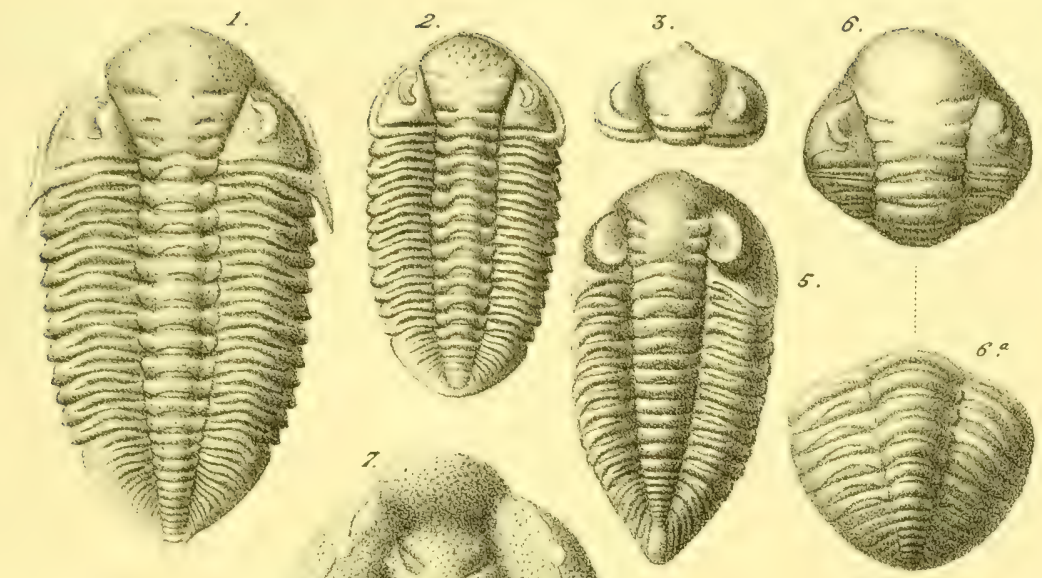

5.
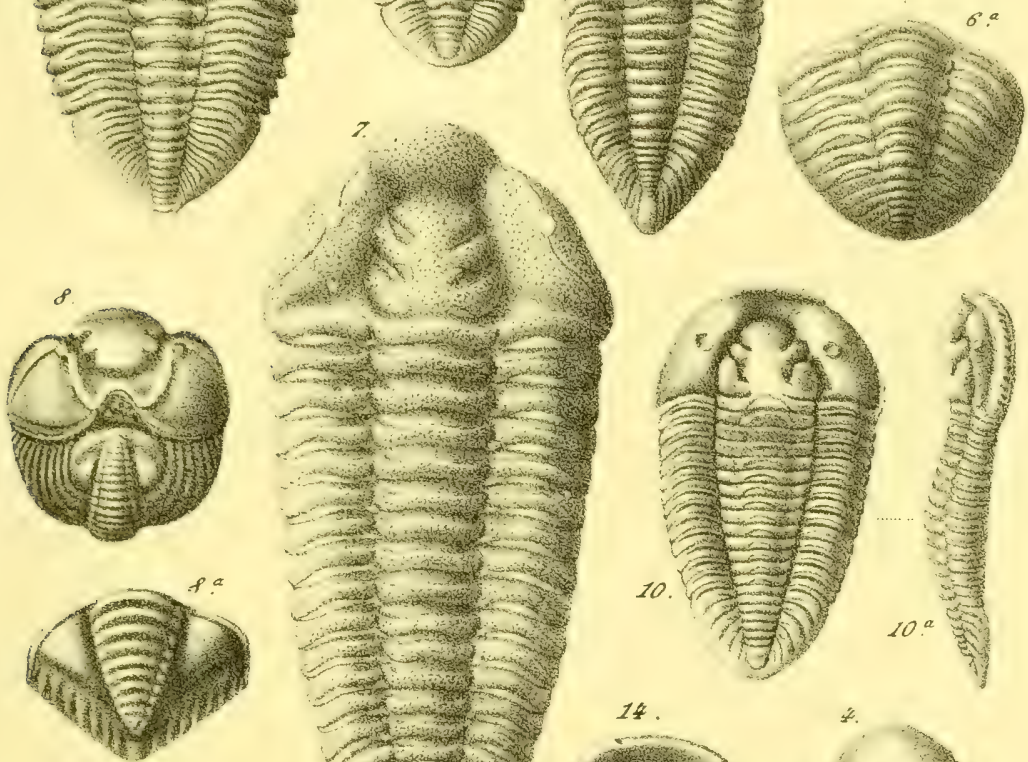

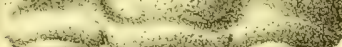

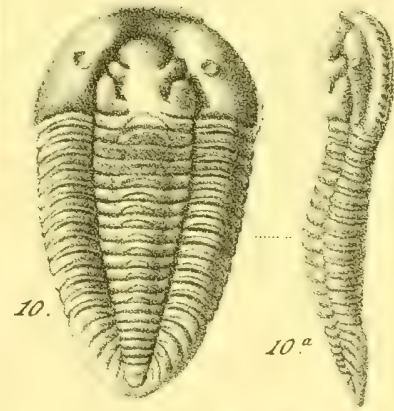

un-

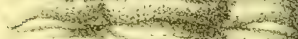

-2 a

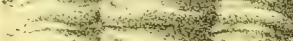

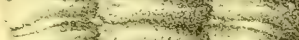

+2 and

K- -4 -

2.

wist

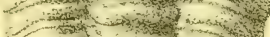

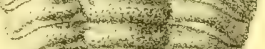

14 .
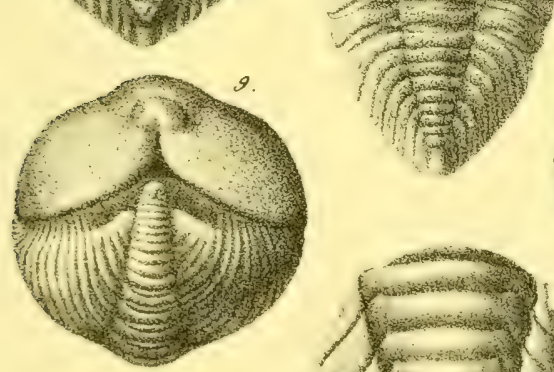

zz.
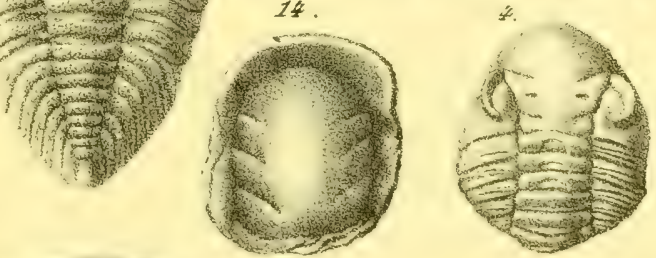

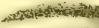
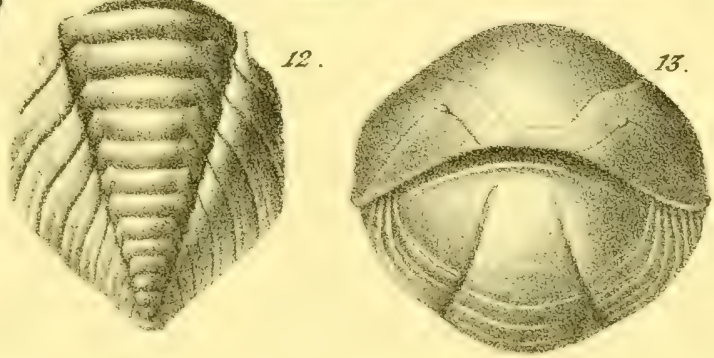




\title{
SILURIANO
}

\author{
LÁm. $3{ }^{2}$
}

Figs.

1 Cabeza de Lichas Hispanica, Barr. et Vern. [23]

2 Glabela de Asaphus contractus, Barr. el Vern. [28]

3 Asaphus nobius, Barr. [25]. Se ha querido representar el molde de un individuo jóven.

4 Asaphus Cranus, Barr. et Vern. [26]

5 Placoparia Tounneminei, Rou. [32]. Ejemplar arrollado en bola visto por la parte anterior.

5 a otro ejemplar extendido de la misma especie, procedente del Puente de las Ovejas. 

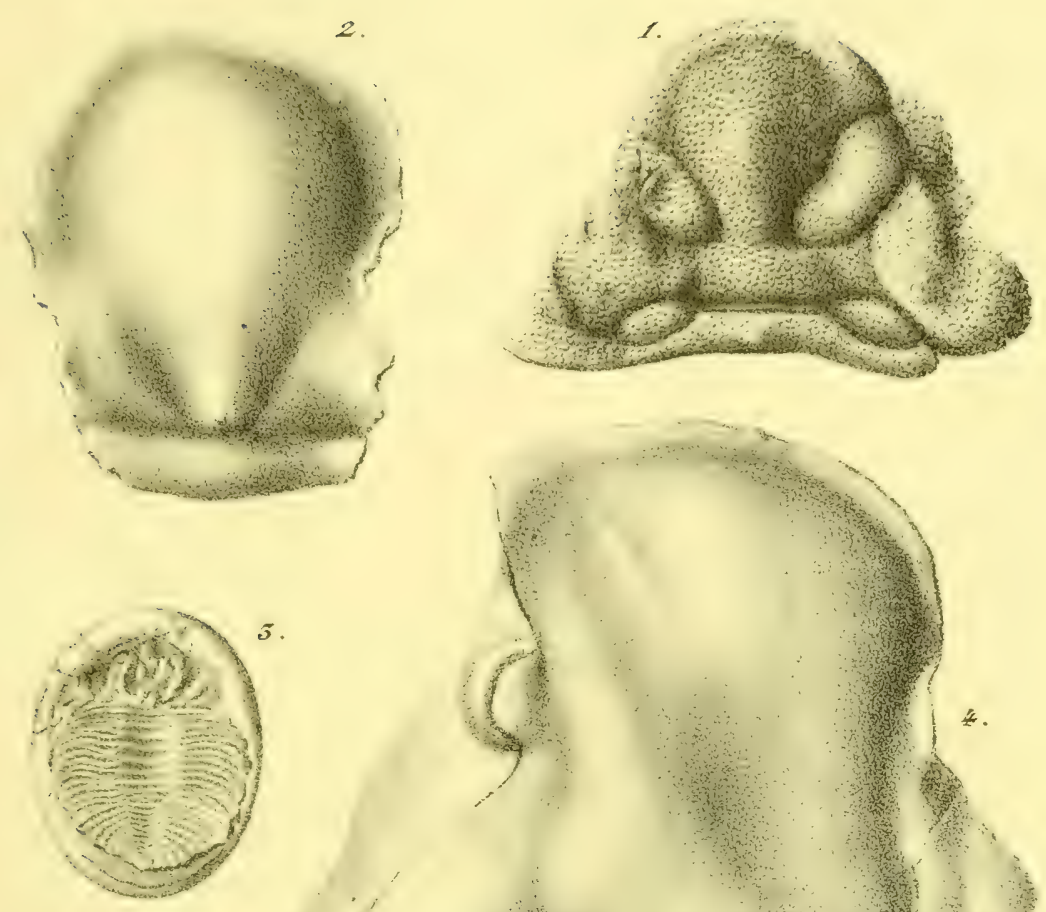

5.
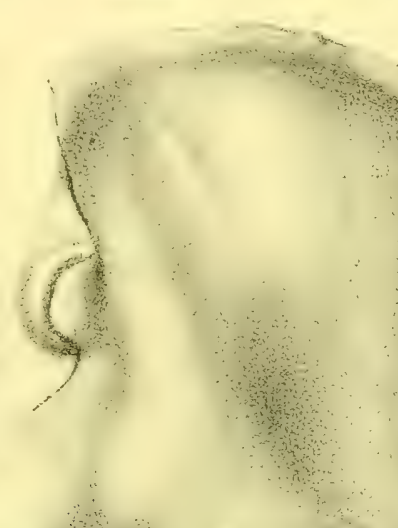




\title{
SILURIANO
}

\author{
LẢM. 4. ${ }^{a}$
}

Figs.

I Asaphus glabratus, Sharpe. Cabeza y torax en parte cubierto por aquella. [27]

1 a Coccix del mismo ejemplar.

2 Asaphus nobilis, Barr. [25]

3 Cabeza de Trinucleus Goldfussi, Barr. [24]

4 Illanus Hispanicus, Barr. et Vern. [29]

$4 a$ Fragmento del carapacho aumentado, para que se distingan las séries de fosetas que le adornan.

5 ILLends Sanchezi, Barr. et Vern. [30] 

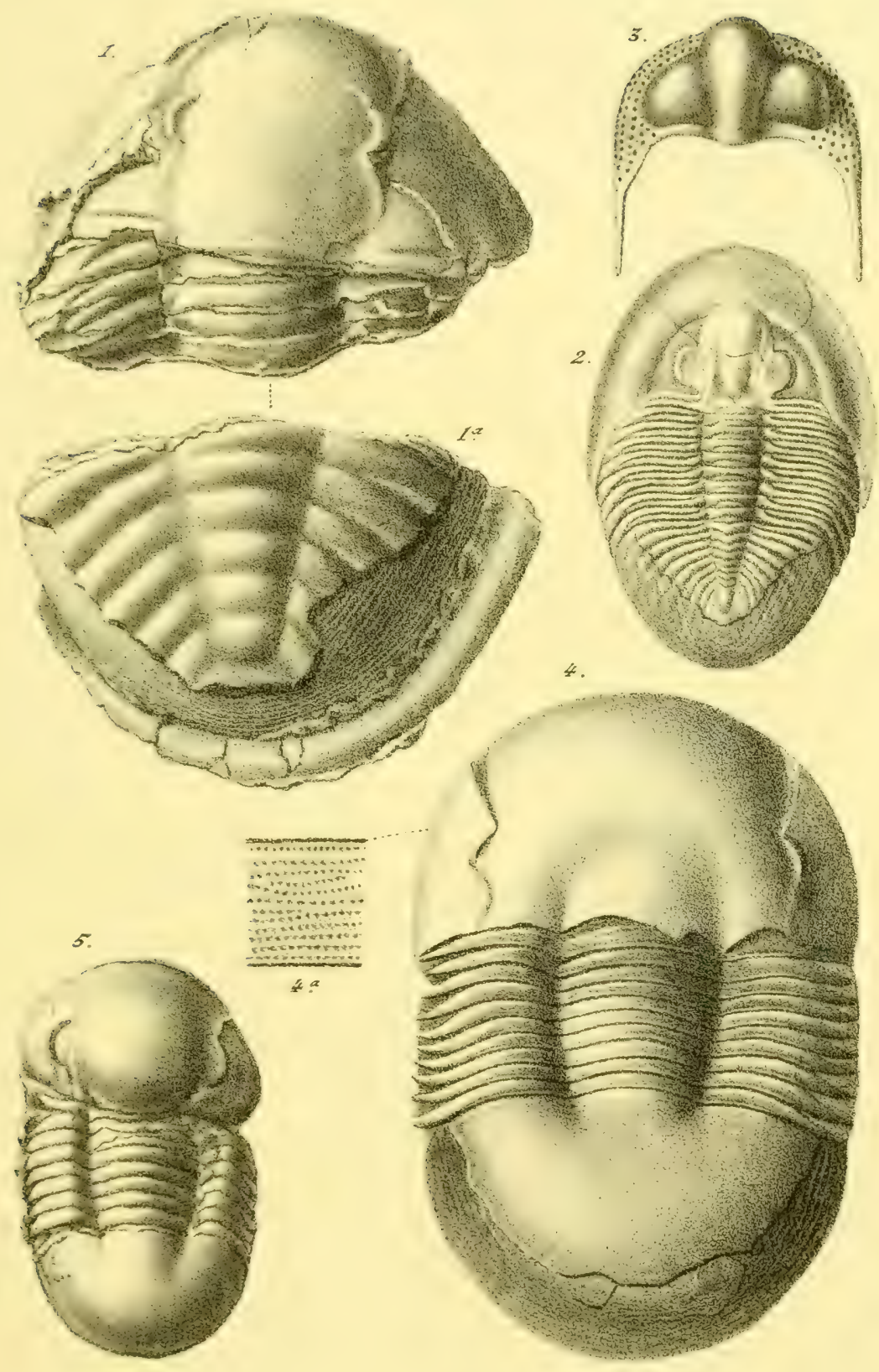




\title{
SILURIANO
}

\author{
LÁM. 5. ${ }^{\mathrm{a}}$
}

Figs.

1 Lituites intenmedius, Veln. et Barr. [45]

la La misma especie vista de costado.

2 Bellenophon agutus, Sow. [52]

3 Bellerophon bilobatus, Sow. [51]

4 Pleunotomania Bussacensis, Sharpe. [47]

5 Thega tringeulanis, Port. (sp). [53]

6 Cardola interrupta, Brod. [57]

$6 a$ La misma especie vista de frente.

7 Arca Naranjoana, Vern. et Barr. [59]

ya El mismo ejemplar visto por la valva derecha.

8 Redonia Deshayesiana, Rou. [65]

8 a Molde de la misma especie visto por el lado de la charnela.

86 Molde de la valva derecha.

9 Redonia Duvaliana; Rou. [66]

9 a Molde de la misma especie visto por la charnela.

9 b Nolde de su valva derecha.

10 Cucullea Caravaxtesi, Vern. et Barr. [60]

10 a Valva derecha de la misma especie.

11 Sanguinolites Pellicol, Vern. et Barr. [55]

11 a Molde del inismo ejemplar visto por la charnela. 


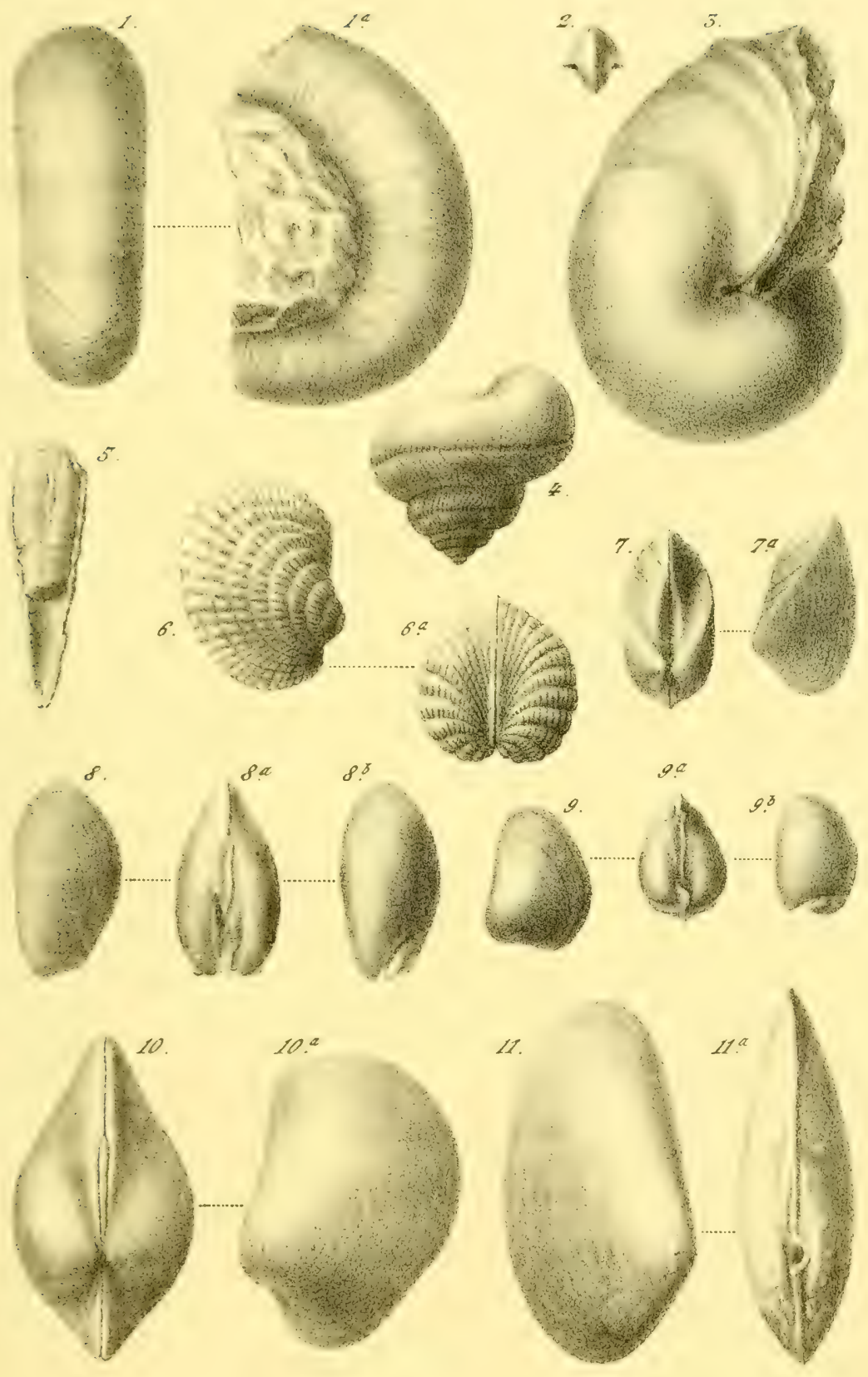






\title{
SILURIANO
}

\author{
LÁM. $6{ }^{\text {a }}$
}

Figs.

1 Ribeima pholadiformis, Sharpe. [48]

2 Nugula Hopensagki, Vern. et Barr. [61]

3 Nugura Ribeiro, Sharpe. [62]

$3 a \quad$ Nolde de la misma especie visto por el lado de la charnela.

4 Nugula Coste, Sharpe. [63]

4 a Molde de la misma especie visto por la valva derecha.

5 Nugula Eschwegir, Sharpe. [64]

$5 a \quad$ La misma especie vista por la valva izquierda.

6 Tentaculites scalaris, Schlot. [54]

7 Orthis Galigigrama, Dalm. [68]

8 Molde de la misma especie visto por la region cardinal.

8 a El mismo molde visto por la valva menor.

9 Orthis testudinaria, Dalm. [70]

9 a El mismo molde aumentado.

96 Molde de la misma visto por la valva ventral.

10 Orthis vespertilio, Sow. [69]

11 Leptorna SERIGA, Sow. [74]

11 a La misma especie vista lateralmente.

12 Onolus rilosus, Hall. (sp) [ [77]

13 Onolus Bowlesi, Vern. et Barr. [78]

$13 a, b$ La misma especie mostrando el interior de la region cardinal.

14 Sryogladi irpmordes, Sharpe. [81]

14 a Rama de la misma especie aumentada.

$14 b$ Impresion interna de la misma rama.

15. Limnospherites Murausoni, Yern. el Barr. [79] 


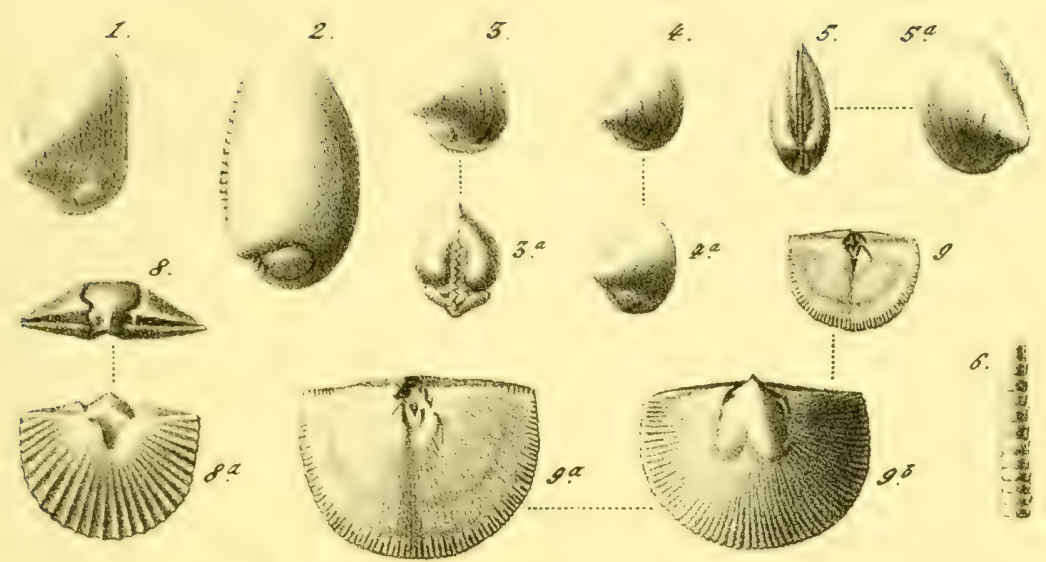

12.
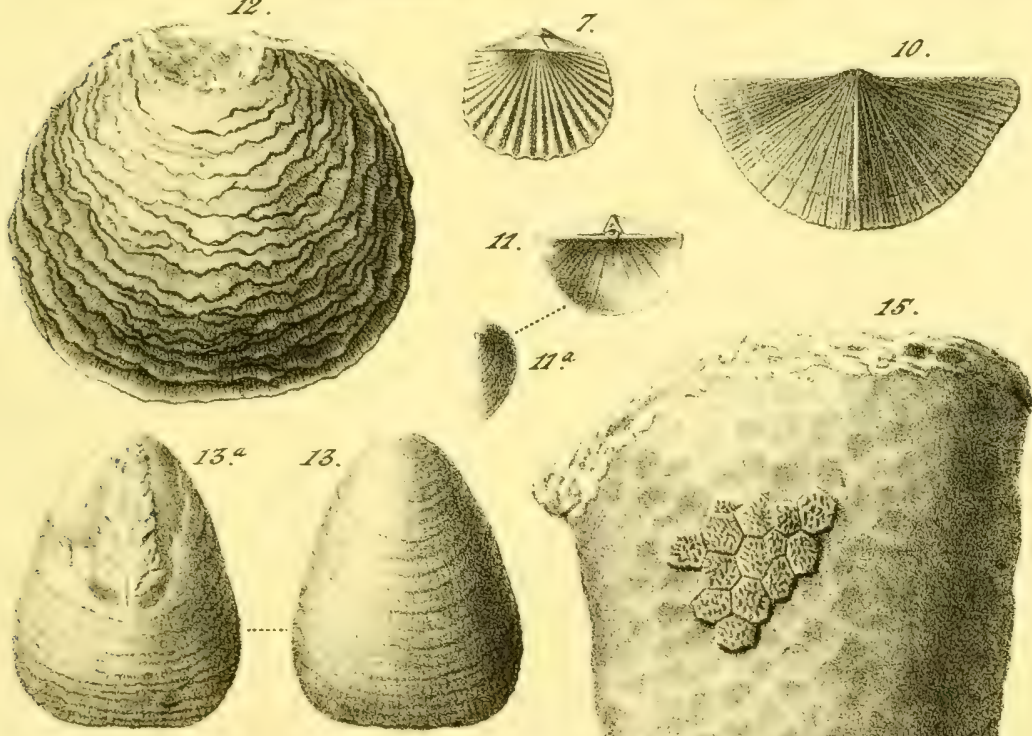

425 isw on
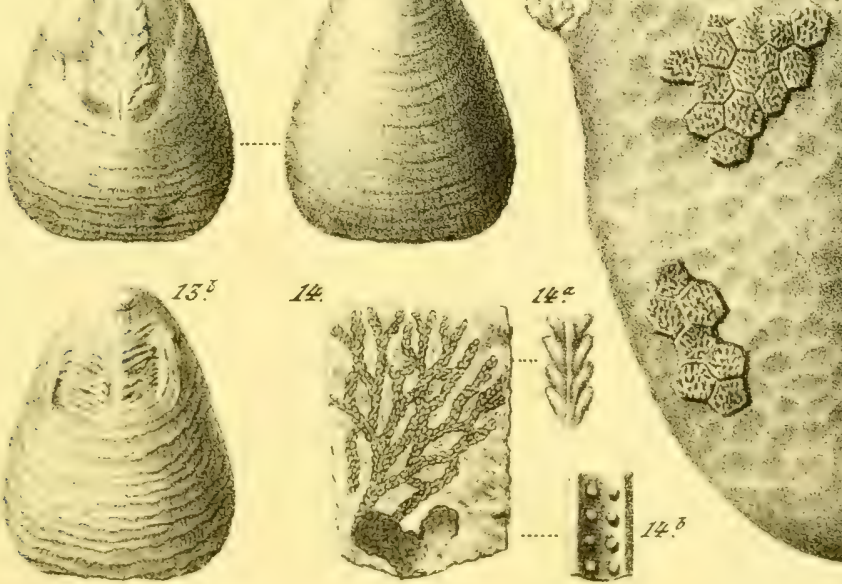

14

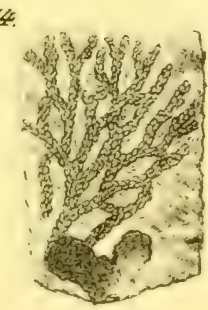

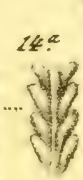

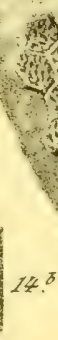

15.

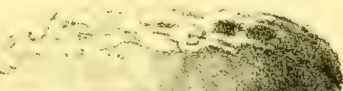






\title{
SILURIANO
}

\author{
LẢ.I. \%.
}

liigs.

1, 2 Monograpsus Nilssoni, Barr. [82]

3 Variedad de la misma especie.

$3 a$ La misma aumentada.

+ Otra variedad.

$4 a$ La misma aumentada.

5, 6 Monognapsus Halli, Barr. [84]

$\tilde{5} a, 6 a$ La misma especie aumentada.

7 Monograpsus latus, Mac. Coy. [83]

7 a La misma aumentada.

8, 9 Monograpsus Becki, Barr. [85]

$8 x, 9 x \quad$ La misma especie aumentada.

11 Monograpsus Priodon, Bronn. [86]

$10,10 a, 11 a$ La misma aumentada.

i2, $12 a, 12 b$ Monograpsus convolutus, Hisinger. [87]

13 Diplograpsus pristis, Hisinger. [89]

$13 a$ La misma especie aumentada.

14, 15 Diplograpsus Palmeus, Barr. [88]

15 a La misma aumentada. 

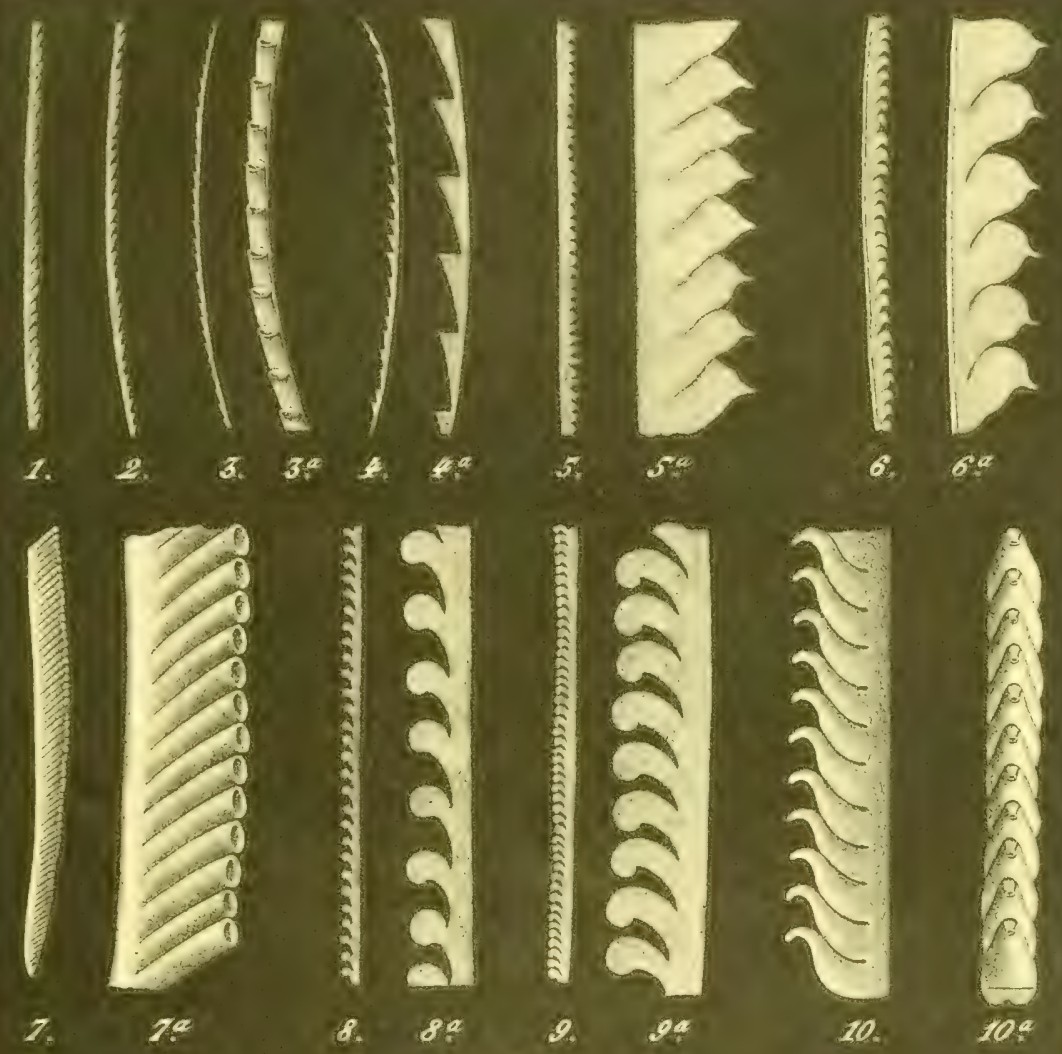

8. $8 a$
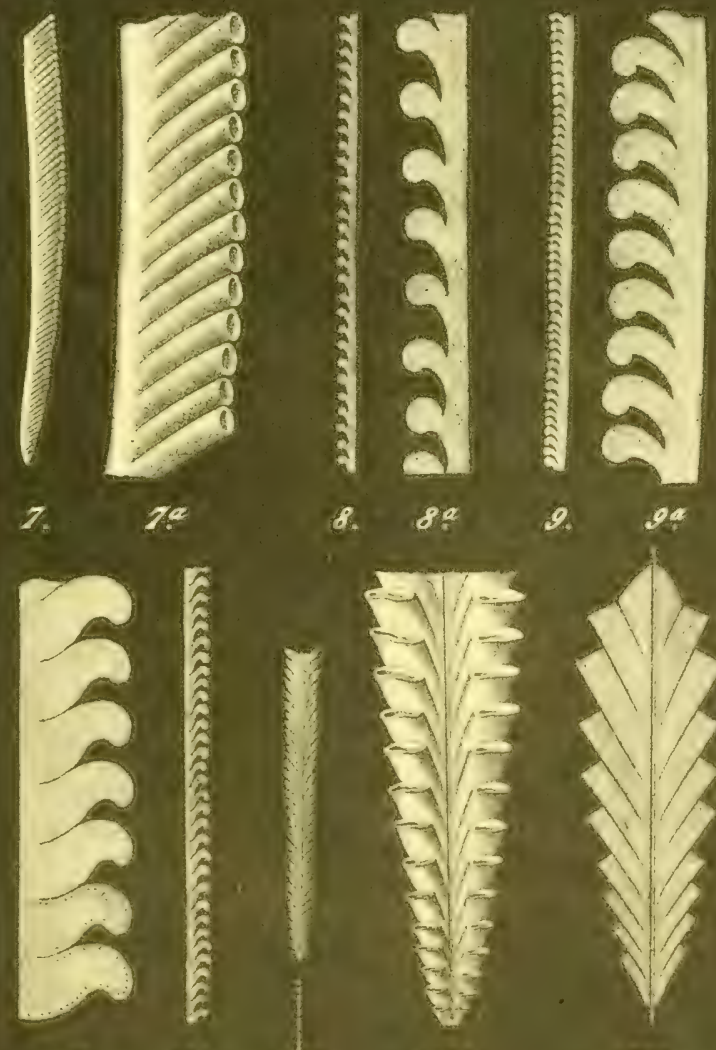

$12 a$

II. 13
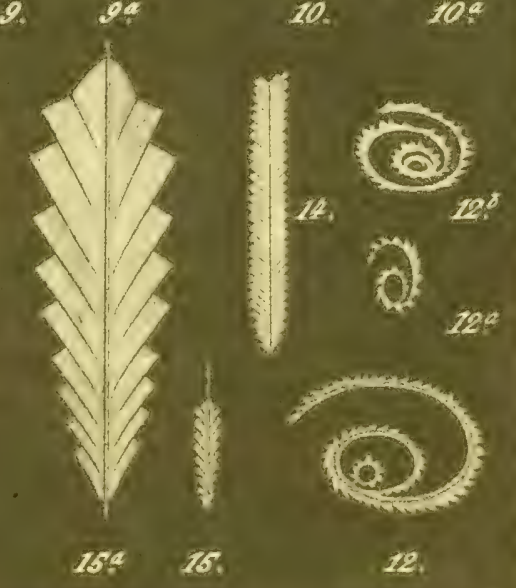




\title{
DEVONIANO
}

\author{
LÁrr. $10^{\mathrm{a}}$
}

Figs.

1 Proetus Cuvient, Steininger. [Núm. 101]

2 Phacops latifnons, Bron. Arrollado en bola, visto por la parte superior. $[102]$

$2 a$ El mismo individuo visto por la parte inferior.

3 Coccix de Homalonotus Pradoanus, Vern. et Barr. [107]

4 Dalmanites calliteles, Green. [103]

5 Coccix de Dalmanites laGiniata, Roem. [105]

6 Cabeza de Dalmanites sublaciniata, Roem. [106]

7 Coccix de otro ejemplar de la misma especie.

8 Coccix de Dalmanites stellifer, Burm. [104]

9 Coccix de Bronteus Castroi, nob. [108]

9 a Parte central de la cabeza de otro ejemplar de la misma especie. 


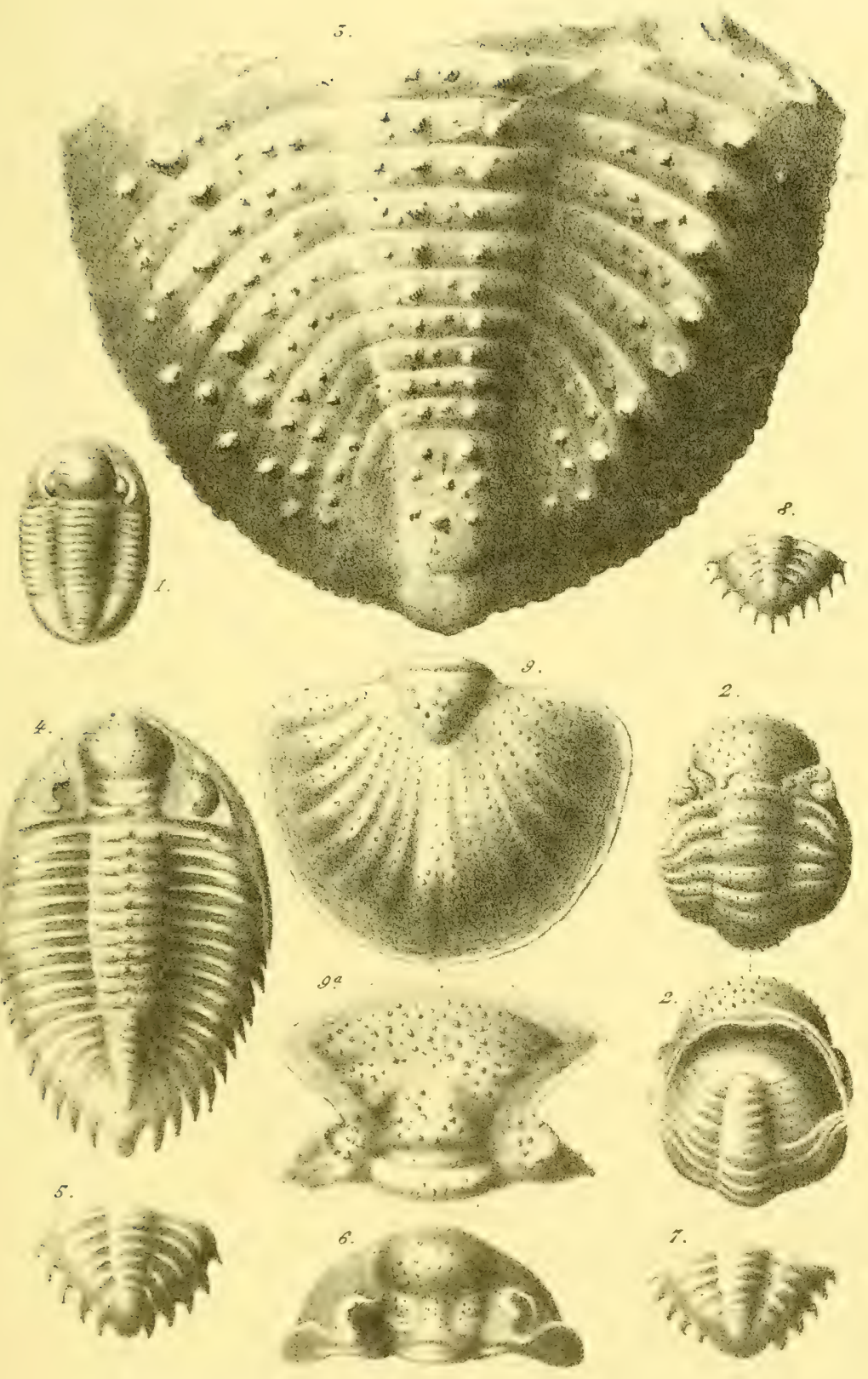






\title{
DEVONIANO
}

\author{
LA่ง. 2. ${ }^{a}$
}

Figs.

1 Orthoceratites Jovellani, Vern. et d'Arch. [110]

2 Seccion longitudinal de un individuo jóven de la misma especie.

3 Cynthocenas Lujaxi, Vern. et Barr. [112]

$3 a$ Parte de la concha aumentada.

4 Tunbo subcostatus, Gold. (sp.) [113]

5 Pleurotomari gatendlata, Vern. et d'Arch. [114]

5 a La misma especie vista posteriormente.

6 Gapulus compressus, Gold. (sp.) [ 115$]$

7 Capulus cissideus, d'Arch. et Vern. [117]

7 a La misma especie aumentada.

8 Conocardum clatiratum, Gold. (sp.) [121]

$8 a$ La misma especie vista por la region bucal.

9 Candium palmatum, Gold. [122]

9 a La misma especie vista con grande aumento. 

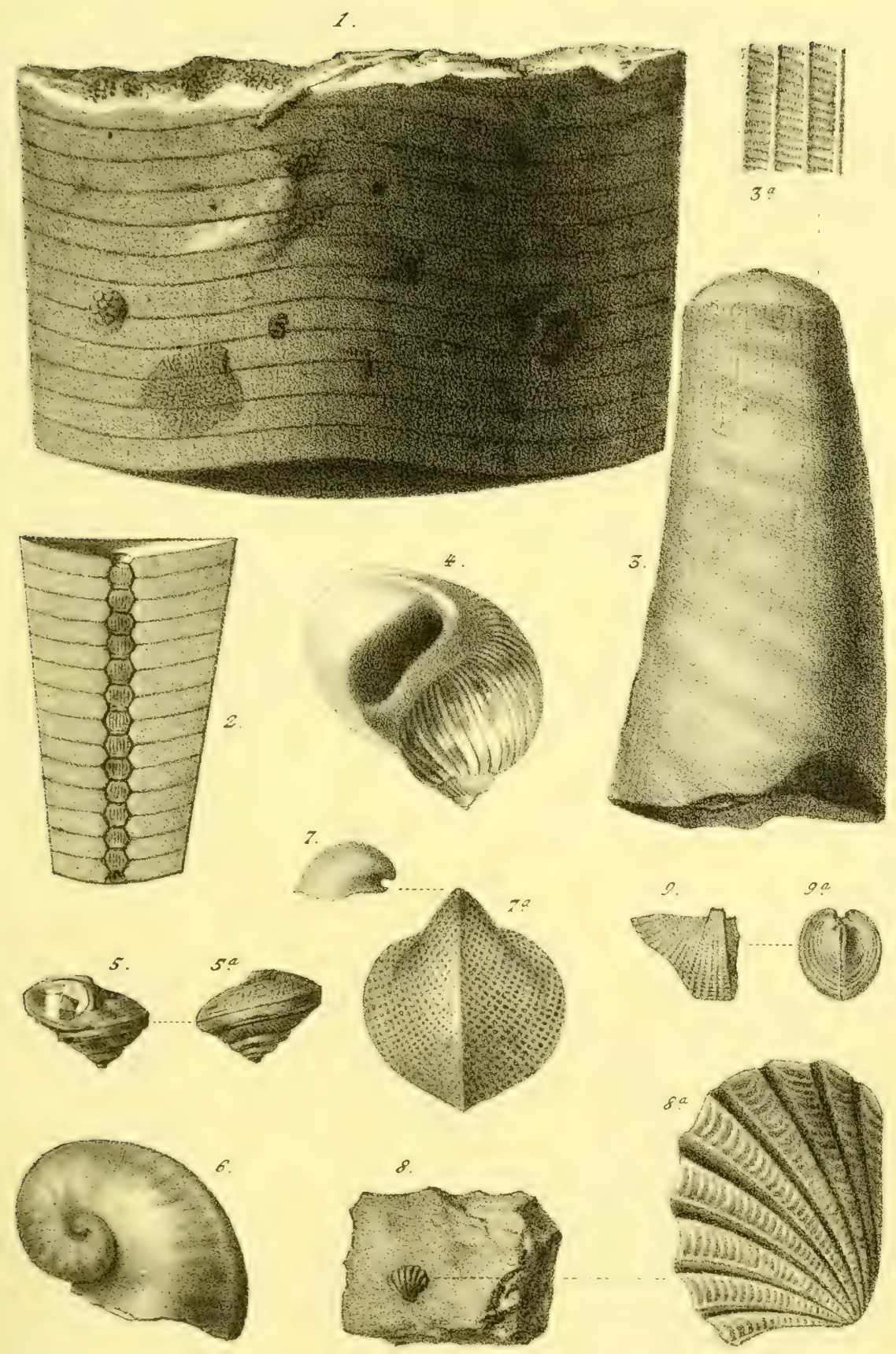




\title{
DEVONIANO
}

\author{
LÁM. $3 .^{a}$
}

Figs.

1 Avicula pailletter, Vern. et Barr. [124]

2 avigula Leplayi, Vern. et Barr. [125]

$2 a$ La misma especie vista lateralmente.

3 Avigula Schulzir, Vern, et Barr. [126]

3 a La misma vista por la valva opuesta.

4 Avigula fascigulata, Gold. (sp). [129]

5. Avigula levis, Gold. [128]

5 a La misma especie vista lateralmente.

6 Avicula subcrinita. Vern. et Barr. [127]

ba Aumento de sus costillas.

7 Avigula Neptuni, Gold. [130] 

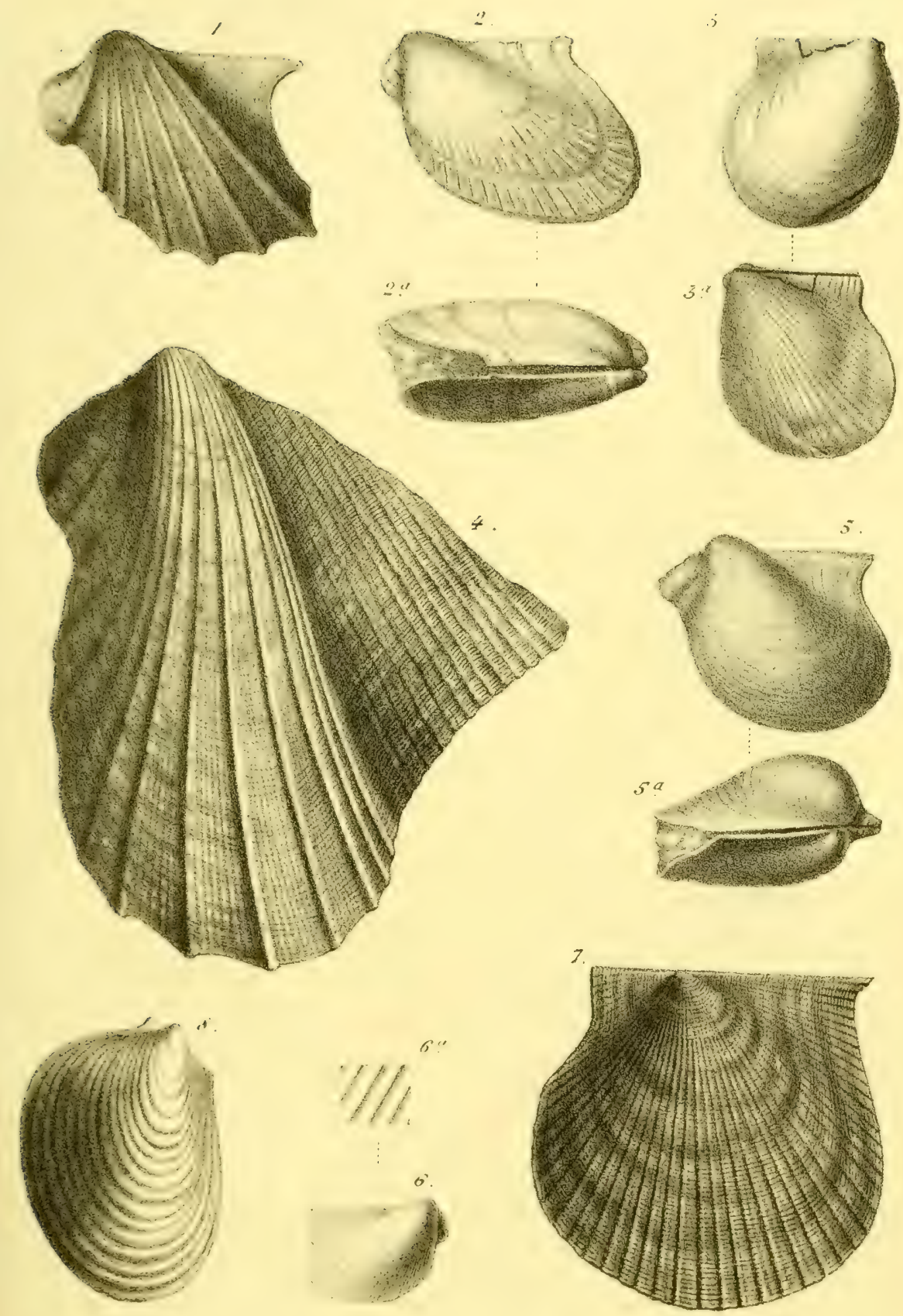




\title{
DEVONIANO
}

\author{
LÁM. $4 .^{2}$
}

Figs.

1 Terebratula Anchiagi, Vern. [133]

1 a El mismo ejemplar visto por la valva dorsal.

1b Parte cardinal del interior de la valva ventral.

$1 c$ Idem de la dorsal.

2 Terebratula Bordu, Vern. [134]

$2 a$ El mismo ejemplar visto lateralmente.

3 Terebratula Samulzir, Vern. [135]

$3 a$ La misma especie vista lateralmente.

4 Spinifer Rojasi, Vern. [145]

$4 a$ El mismo ejemplar visto por el lado opuesto.

$4 b$ Aumento del seno de la misma especie.

5 Sperifer subspegiosus, Vern. [140]

5 a La misma especie vista por el lado opuesto.

6 Spirifer Ezquerra, Vern. [144] 

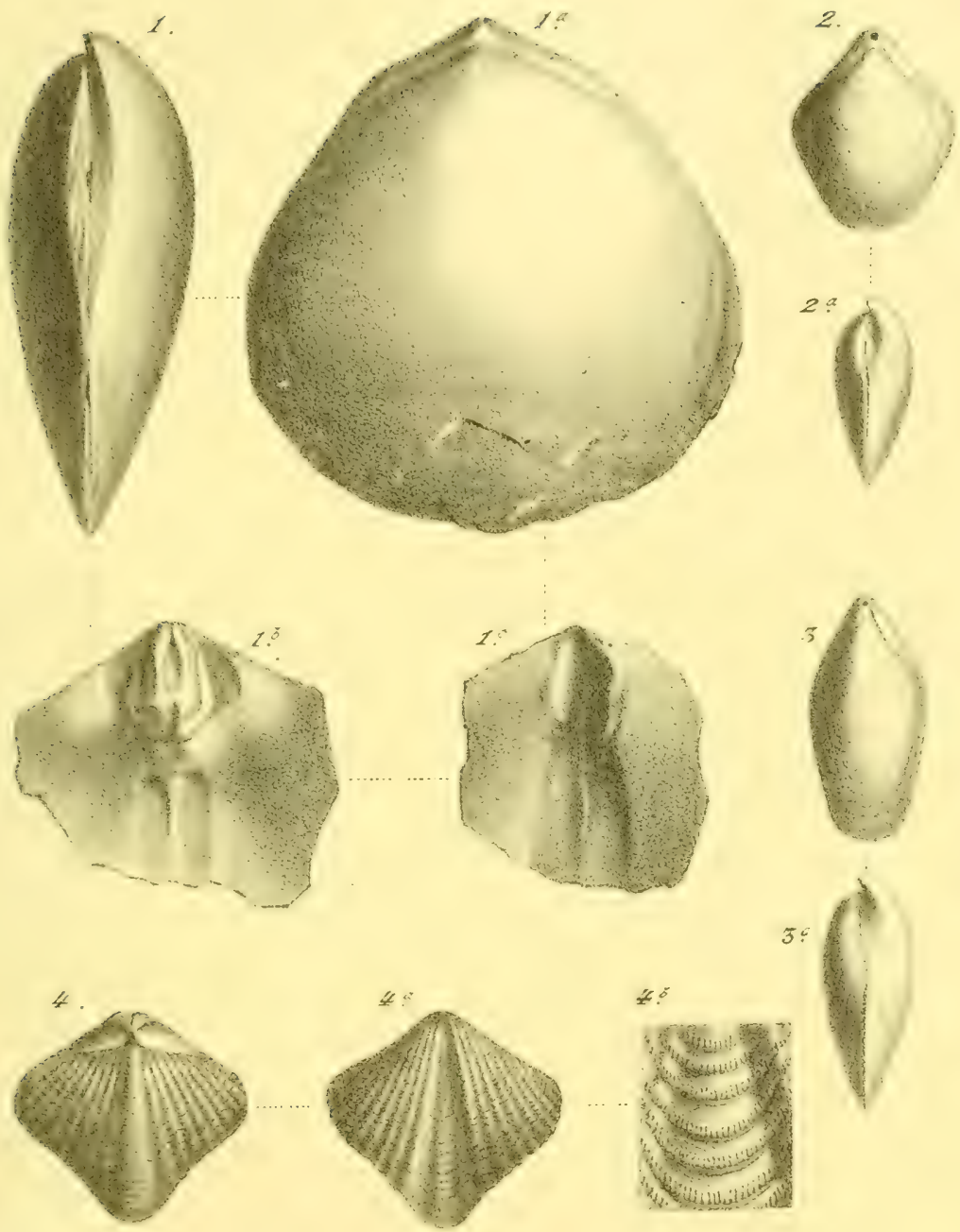

45
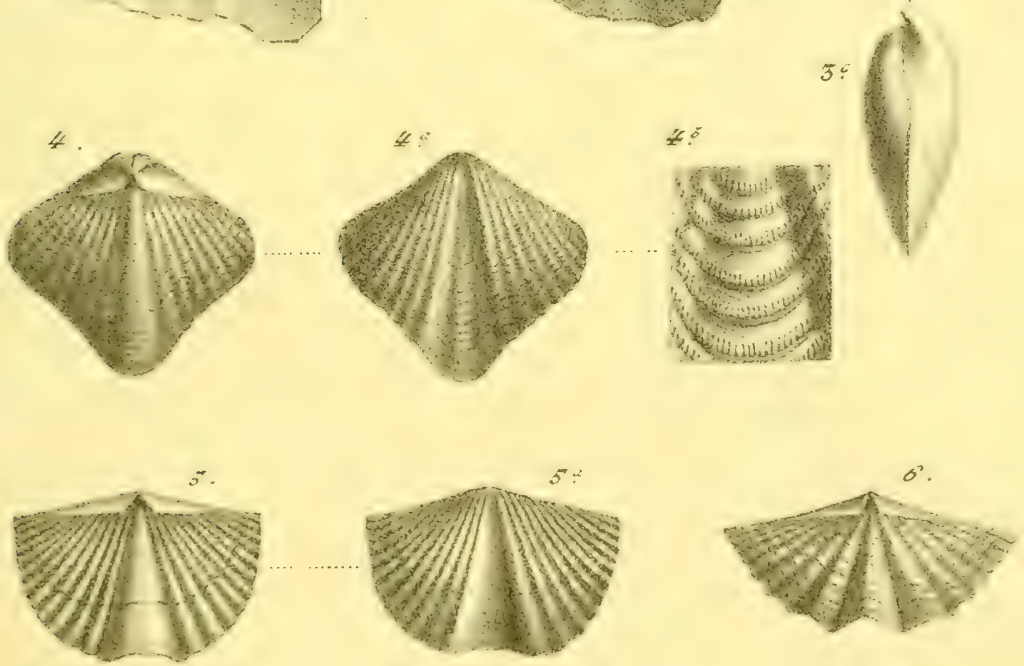




\title{
DEVONIANO
}

\author{
Lìy. วั. ${ }^{a}$
}

Figs.

1 Spirifen Pellico, Vern. et d'Arch. [N. 137]

$1 a \quad$ El mismo ejemplar visto por la region cardinal.

2 Spinifer Pailletii, Vern. [146]

$2 a \quad$ El mismo visto por la valva ventral.

3 Splrifer Cabedanus, Vern. et d'Arch. [142]

$3 a$ La misma especie vista por la region cardinal.

:3 b La misma vista por la valva ventral.

4 Spirifer disjunctus, Sow., var. S. Verneuili, Murch. [147]

$4 a \quad$ El mismo visto por la region cardinal.

5 La misma especie, var. S. Archiaci, Nurch.

6 Spinifer Cabanillas, Vern. et d'Arch. [143]

(6) $a$ La misma especie vista por la valva dorsal.

7 Simifer Rousseau, Rolault. [141]

i a El mismo individuo visto por la valva ventral.

8 Spimifer Bouchamd, Murch. [148]

8 a La misma especie vista por la valva dorsal. 

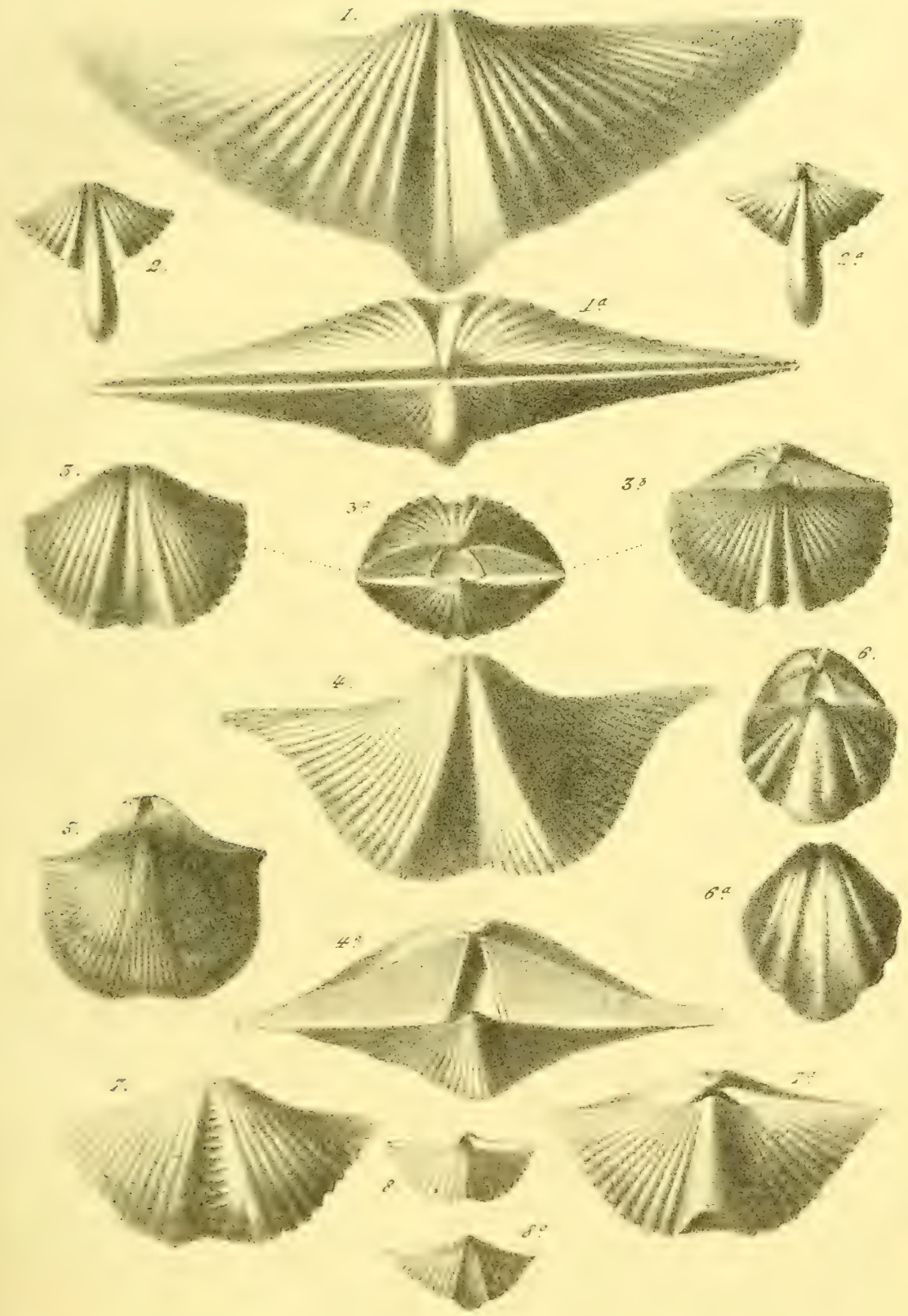




\title{
DEVONIANO
}

\author{
LÁM. $60^{a}$
}

Figs.

l Cyrthia Hispanica, d'Orb. [152]

1 a La misma especie vista por la valva dorsal.

16 La misma, por la region cardinal.

$1 c \quad$ Interior de la region cardinal.

2 Sphigera congentrica, Buch. [153]

$2 a$ La misma especie vista por la valva dorsal.

3 Spirigera undata, Defr. [155]

4 Spirigera Pelapayensis, Vern. et d'Arch, [156]

5 Spirigera subcongentrica, Vern. el d'Arch. [154]

5) El mismo ejemplar visto de costado.

6 Spirigera Ferroxexsis, Vern. et d'Arch. [158]

$6 a$ El mismo ejemplar visto por la valva ventral.

66 El mismo, por la dorsal.

7 Spirigera Cimponanensis, Vern. et d'Arch. [157]

7 a La misma especie vista por la valva ventral.

7b La misma vista por la comisura frontal.

8 Spmigera Tonevo, Vern. et d'Arch. [161]

S a La misma especie vista por la valva ventral.

86 La misma vista por la valva dorsal. 

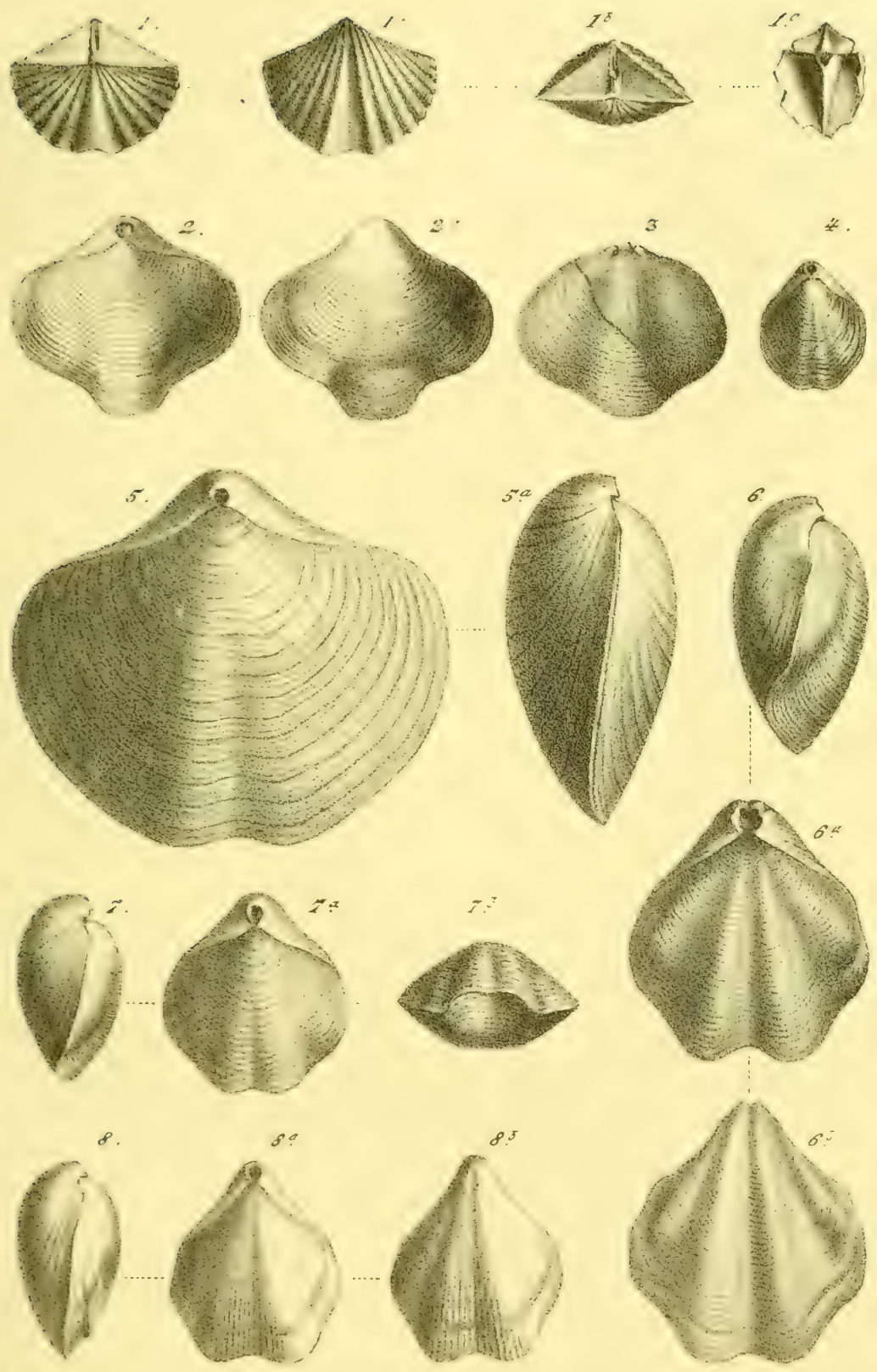




\title{
DEVONIANO
}

\author{
Lím. 7.
}

Figs.

1 Spinigera collettit, Vern. [162]

2 Spirigeri nuckonata, Vern. [163]

$2 a$ La misma especie vista por la valva opuesta.

$2 b$ La misma vista de costado.

3 Spirigera Ezquerra, Vern. et d'Arch. [159]

$3 a \quad$ El mismo ejemplar visto por el lado opuesto.

4 Spirigera phalena, Phill, var. [160]

$4 a$ La misma especie ménos ensanchada.

5 Retzia suberita Vern. [169]

5 a La misma especie vista lateralmente.

5 b La misma por la valva dorsal.

6 Aumento de la region cardinal.

7 Retzia olvidis, Vern. et d'Arch. [166]

i a La misma vista por la valva mayor.

8 Retzin Adriexi, Vern. et d'Arch. Variedad.

9) Retzid Adnient, Vern. et d'Atch. [168]

9 a El mismo cjemplar visto por la valva opuesta.

g) 6 El mismo visto lateralmente.

9c El mismo visto por la region frontal.

10 Sprrigerisa hetigulatis, Linneo (sp). [ 164]

10 a La misma especie vista por la valva mayor.

$10 b$ La misma por la region cardinal.

11 Rynchonelda orbignrana, Vern., de tamaño algo menor que la mayor parte de nuestros ejemplares. [170]

11 t La misma especie vista lateralmente.

11) La misma vista por ia valva menor.

12 Moldes de la misma especie.

13 Spirifieriva Aspera, Schlot. [165] 

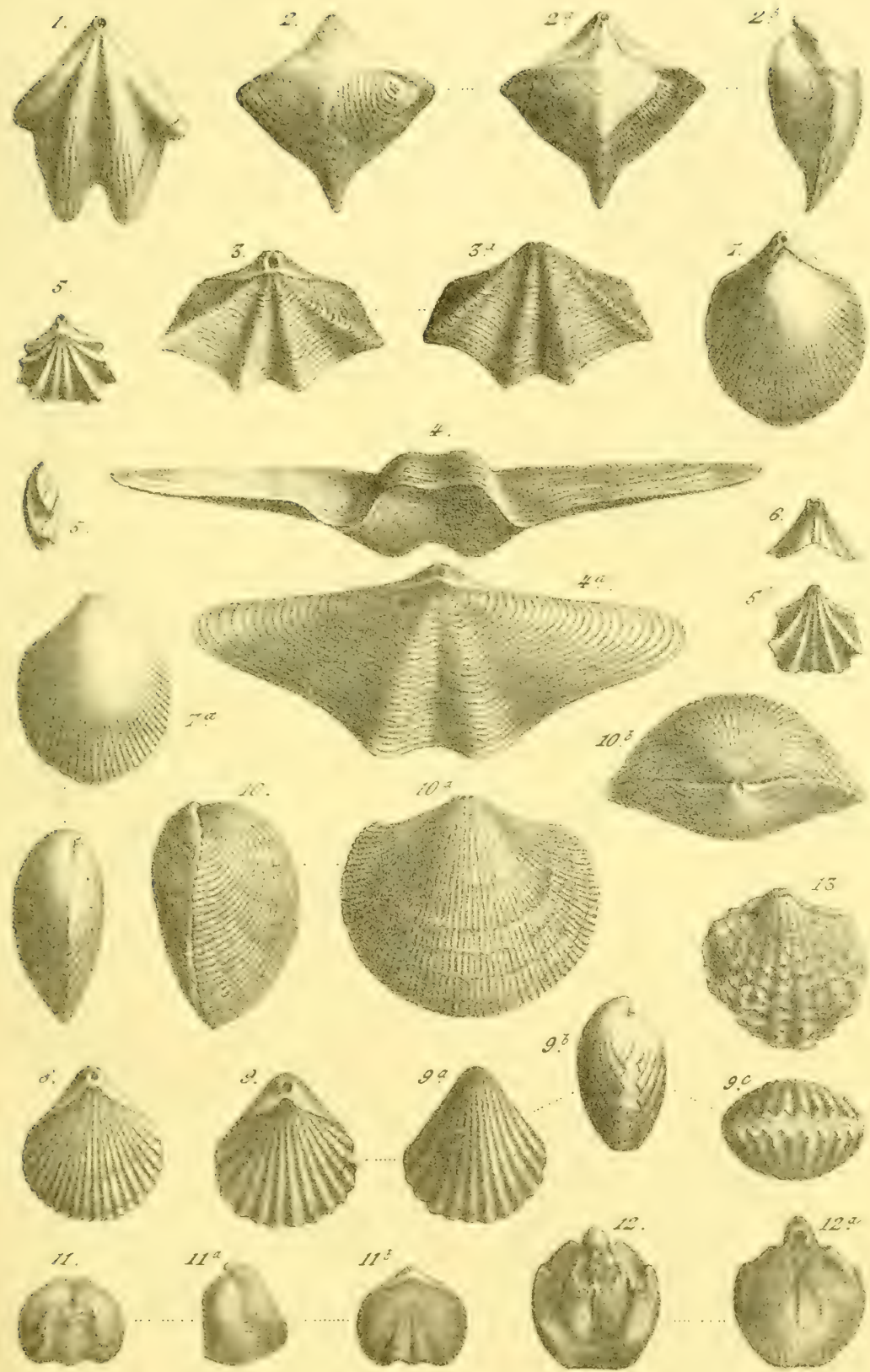




\title{
DEVONIANO
}

\author{
LÁM. 8. ${ }^{a}$
}

Figs.

1 Rhixchonella Paneti, Vern. (sp). [172]

la La misma especie vista lateralmente.

2 Pentamerus brevirostris, Phill. [175]

2 al mismo ejemplar visto por la region frontal.

3 Variedad más alargada de la misma especie.

4 Leprena Phillipsi, Barr. [176]

4 a Aumento de las estrías radiantes.

5 Molde interno de la valva mayor.

5 a Impresion de la valva menor.

6 Leptexa Nananjoana, Vern. [181]

6 a La misma especie vista lateralmente.

7 LEPT ANA LEPIS, Gold. [182]

ia El mismo ejemplar visto por la valva dorsal. 

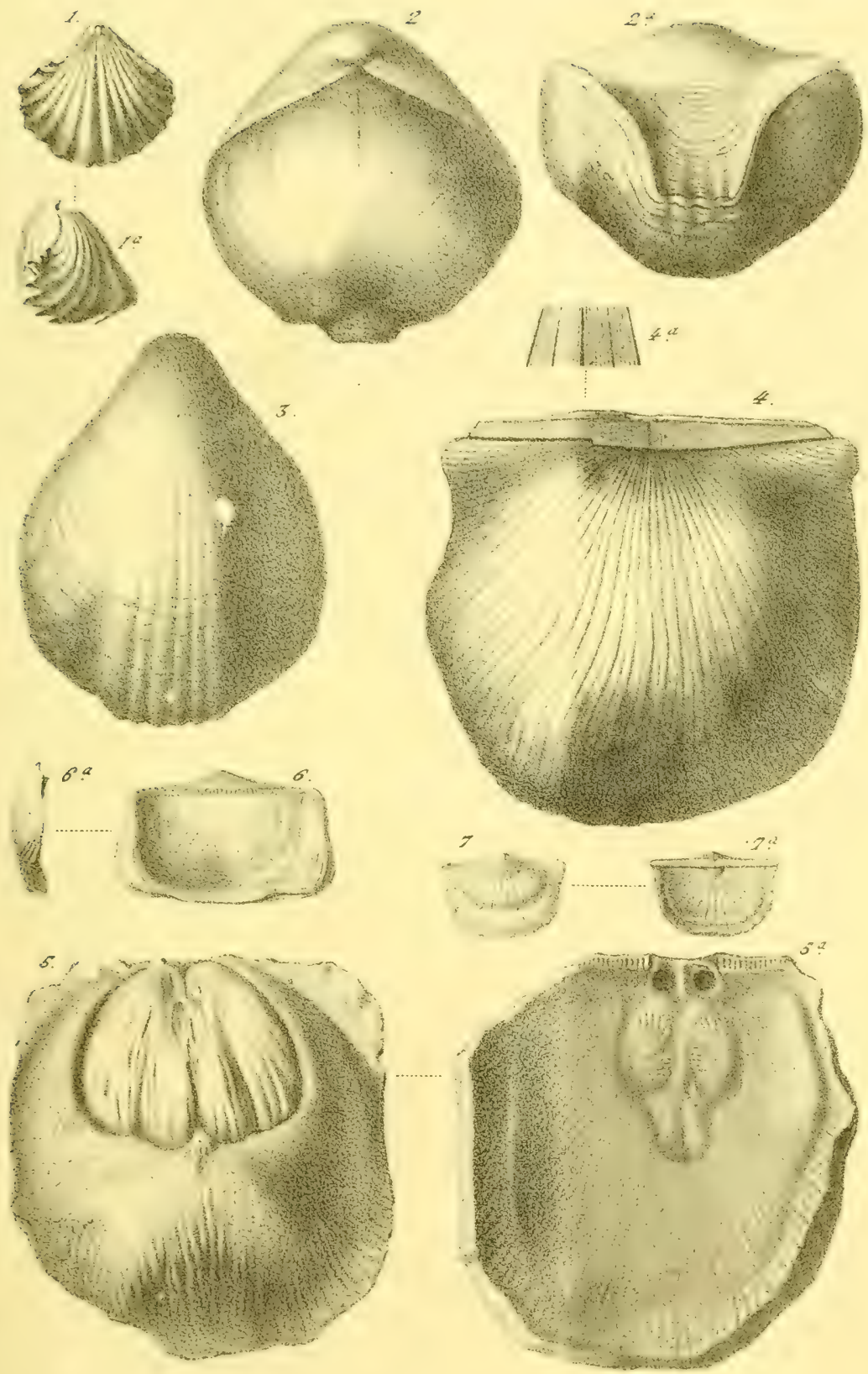




\title{
DEVONIANO
}

\author{
Lín. 9.
}

Figss.

1 Rirychonelia Marian, Vern. et Barr. [173]

1 a La misma especie vista lateralmente.

2 Pentanerus galeatus; Dalm. (sp.) [ 174 ]

3 Variedad de la misma especie.

4 Seccion trasversal de la misma especie.

5 Leptana mastreava, Vern. [180]

5 a La misma vista lateralmente.

6 Leptexi Dutentni, Murch. (sp.) [178]

6 " La misma, vista por la valva ventral.

6i) La misma, vista por la region cardinal.

7 Leptana Sedgwight, Vern. et d'Ar'ch. [179]

8 Leptena Munchisoni, Vern. et d'Arch. [177]

S" La misma especie vista lateralmente.

\&b La misma especie vista por la valva dorsal.

9 Stropmomexa rombordals, Wilckens. (sp.) [183] 

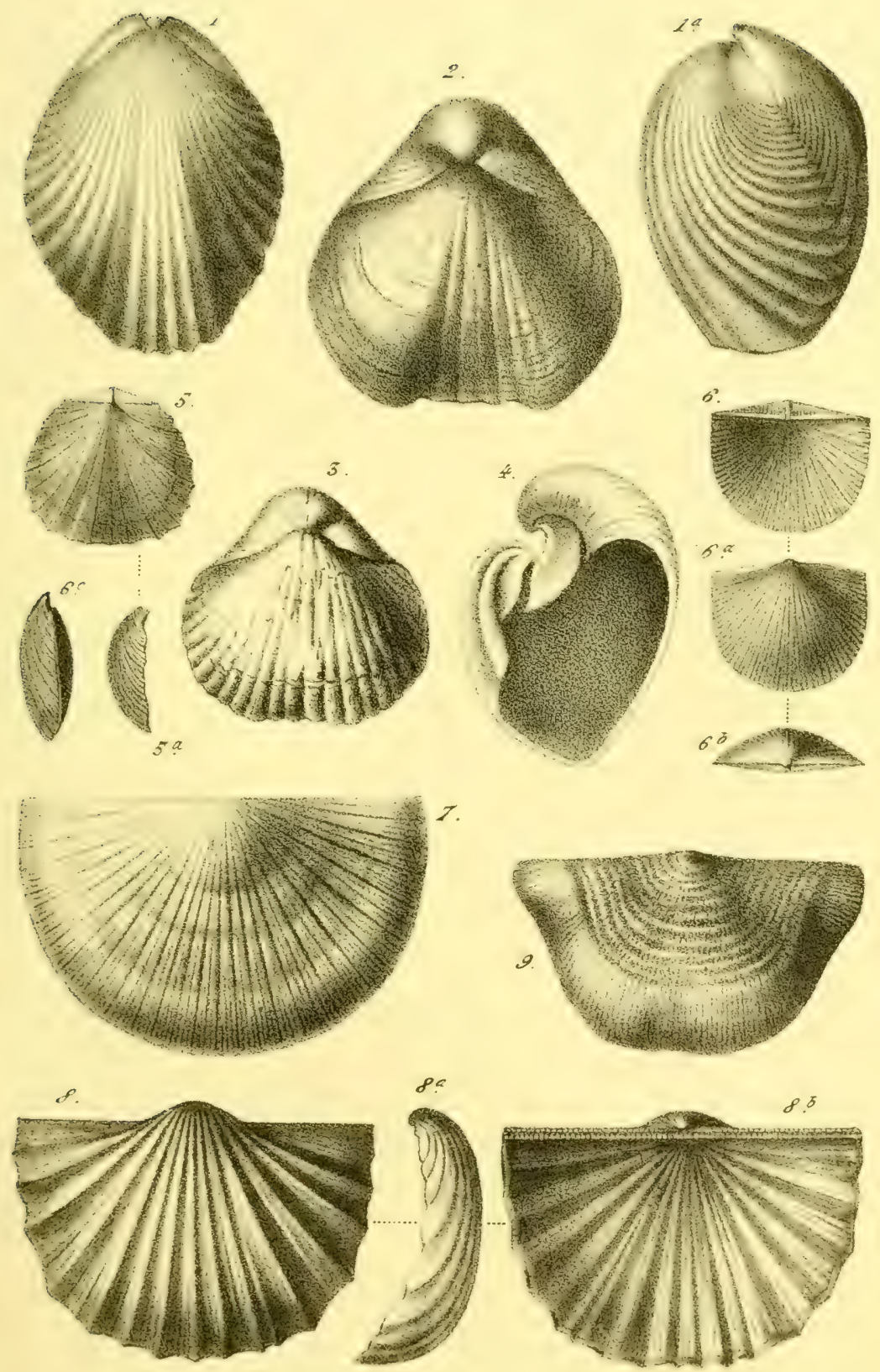




\title{
DEVONIANO
}

\author{
Líxi. 10
}

Figs.

1 Streptorhyngius crevistri, Phill. (sp.) [ 185 ]

2 La misma especie, var. senilis, Phill.

3 Interior de la valva ventral de la misma especie.

4 Interior de la valva dorsal de la misma.

5 Ortiis resupivata, Mart. (sp.) [188]

5 a La misma especie vista por la region cardinal.

6 Interior de la valva ventral de la misma especie.

7 Variedad de la misma especie.

7 a El mismo ejemplar visto por la region cardinal. 

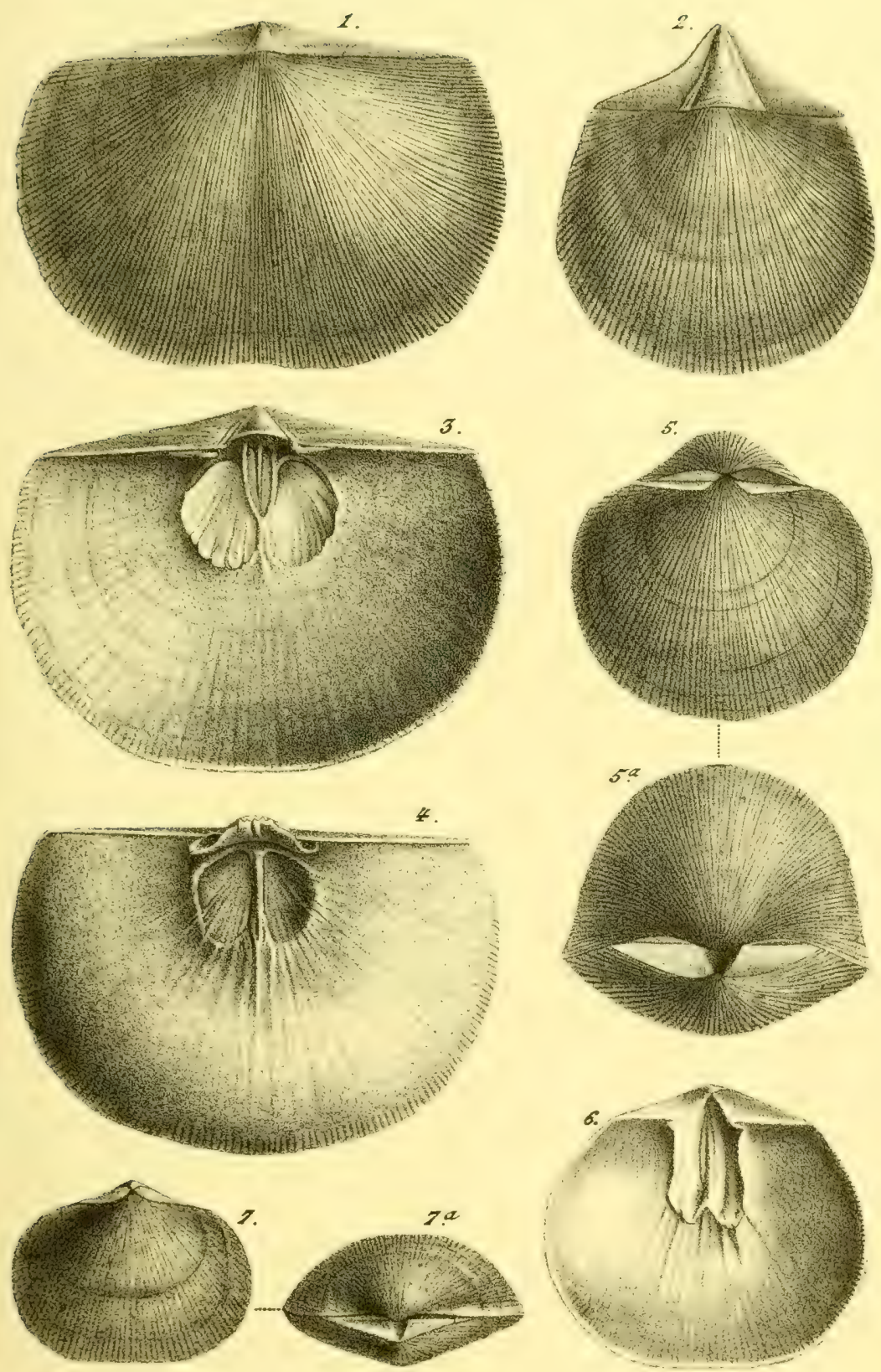




\title{
DEVONIANO
}

\author{
LÁM. 11
}

Figs.

1 Ontuis BeAunontr, Vern. [186]

2 La misma especie vista por la valva menor.

3 Interior de la valva mayor en su region cardinal.

4. Interior de la valva menor de otro individuo.

5 Ortuis Dumontiana, Vern. [187]

6 La misma especie vista lateralmente.

i Orthis operqularis, Vern. et Keys. [191]

$8 \quad$ La misma especie vista lateralmente.

9 Onturs onbigulanis, Vern. [192]

10 Interior de su valva menor.

11 La misma especie vista de costado.

12 Onthis striatula, Schlot, interior de la valva mayor. [190]

13 Interior de valva opuesta de otro ejemplar.

14 Onthis Genvilli, Vern. [193]

15 La misma especie vista lateralmente.

16 La misma especie vista por la valva menor.

17 Produgtus subaguleatus, Murch. [197]

18 La misma especie vista por la valva menor.

19 Produgtus Munchisonianus, Kon. [ 196 ]

20 El mismo visto por la valva menor.

21 Chonetes sarginulata, Schlot. [198]

22 Molde interior de la misma valva mayor. 

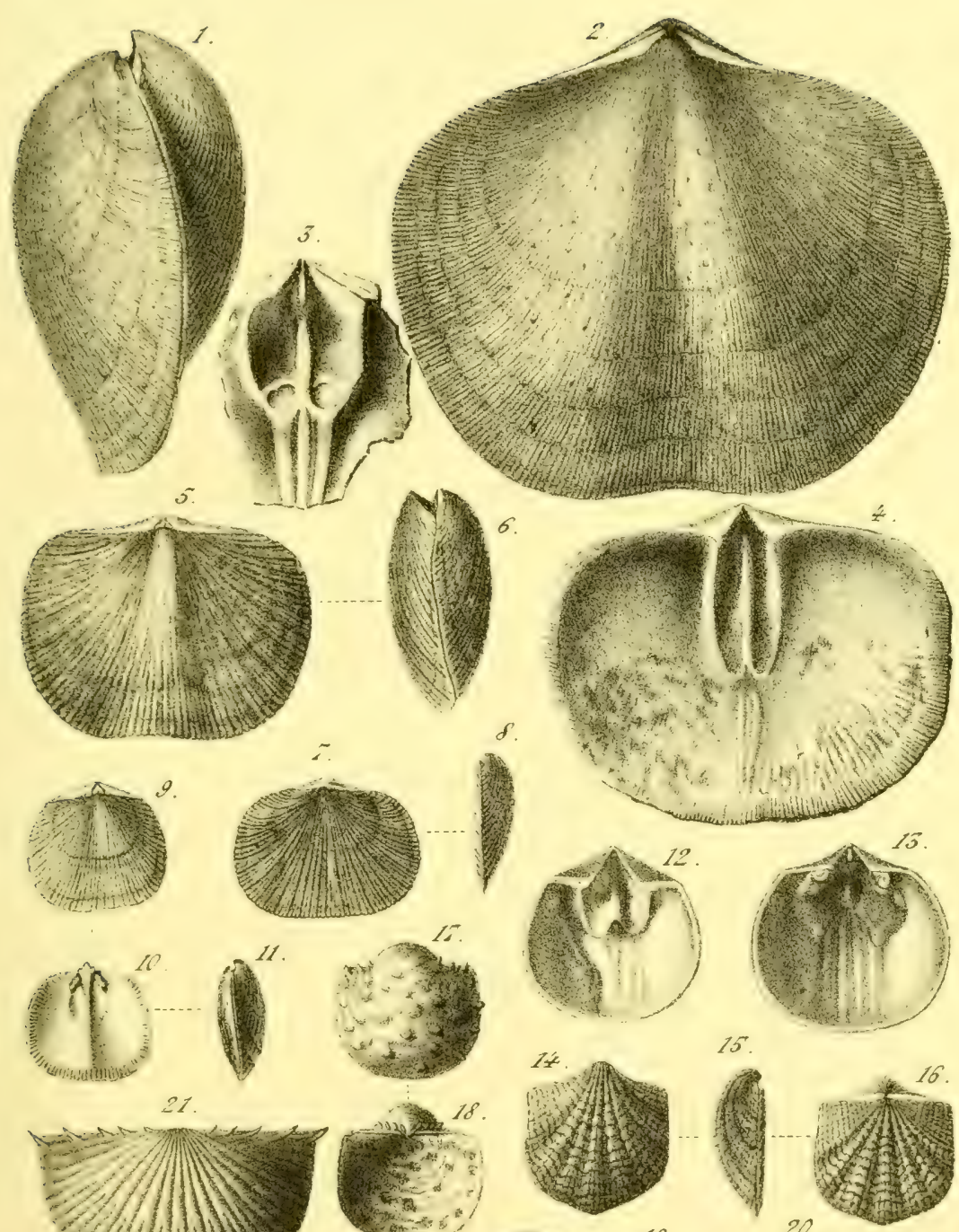

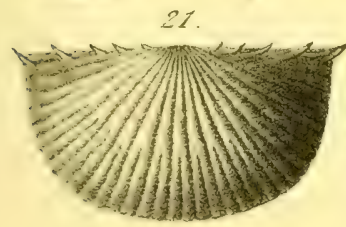

22.
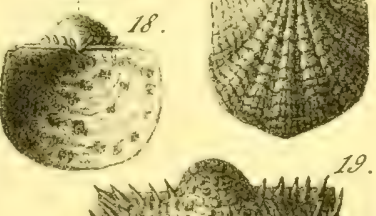

Whis is

Cin

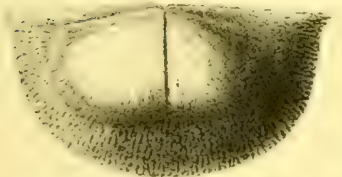

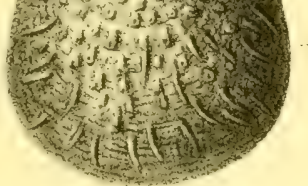

20 .

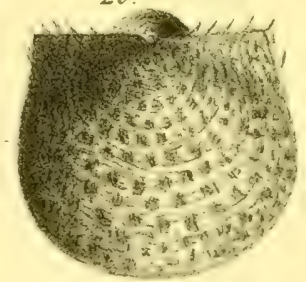






\title{
DEVONIANO
}

\author{
LÁm. 12
}

Figs.

1 Cilceola sandalina, Linco (sp.) [ 199 ]

2 La misma especic vista posteriormente.

3 Fenestrella antiqua, Gold. (sp.) [200]

4 Porcion de la misma aumentada.

5 Pextremites Palleter, Vern. [201]

6 Cáliz aumentado de la misma especie.

7 Pentremite3 Schulzi, Vern. [202]

8 Cáliz aumentado de la misma especie.

9) Pentrenites oblovgus, Gilb. [205]

10 Pentremites Agutus, Gilb. [204]

11 Peutnemites inelatus, Gilb. [203]

12 Piradocninus Baylit, Vern. [207]

13 Otro individuo de la misma especie.

14 El mimo cáliz visto por la parte inferior. 

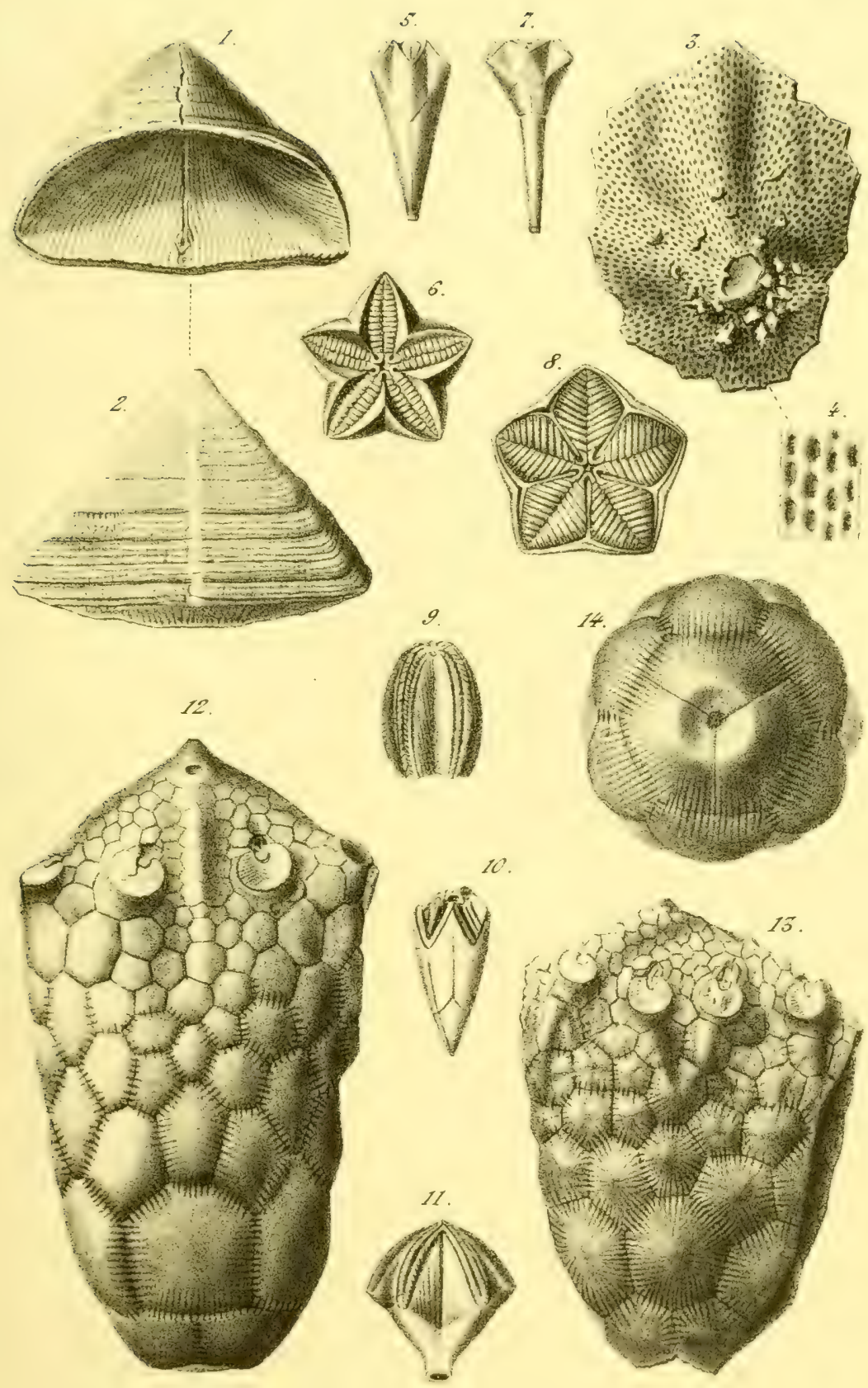




\section{DEVONIANO}

LÁM. 13

Figs.

I Pleurodyctyum problematicum, Gold. [208]

1 a Aumento del mismo.

2 Alveolites subonticulants, Lamarck. [210]

2 a Poliperitos aumentados, en sus diferente secciones. 

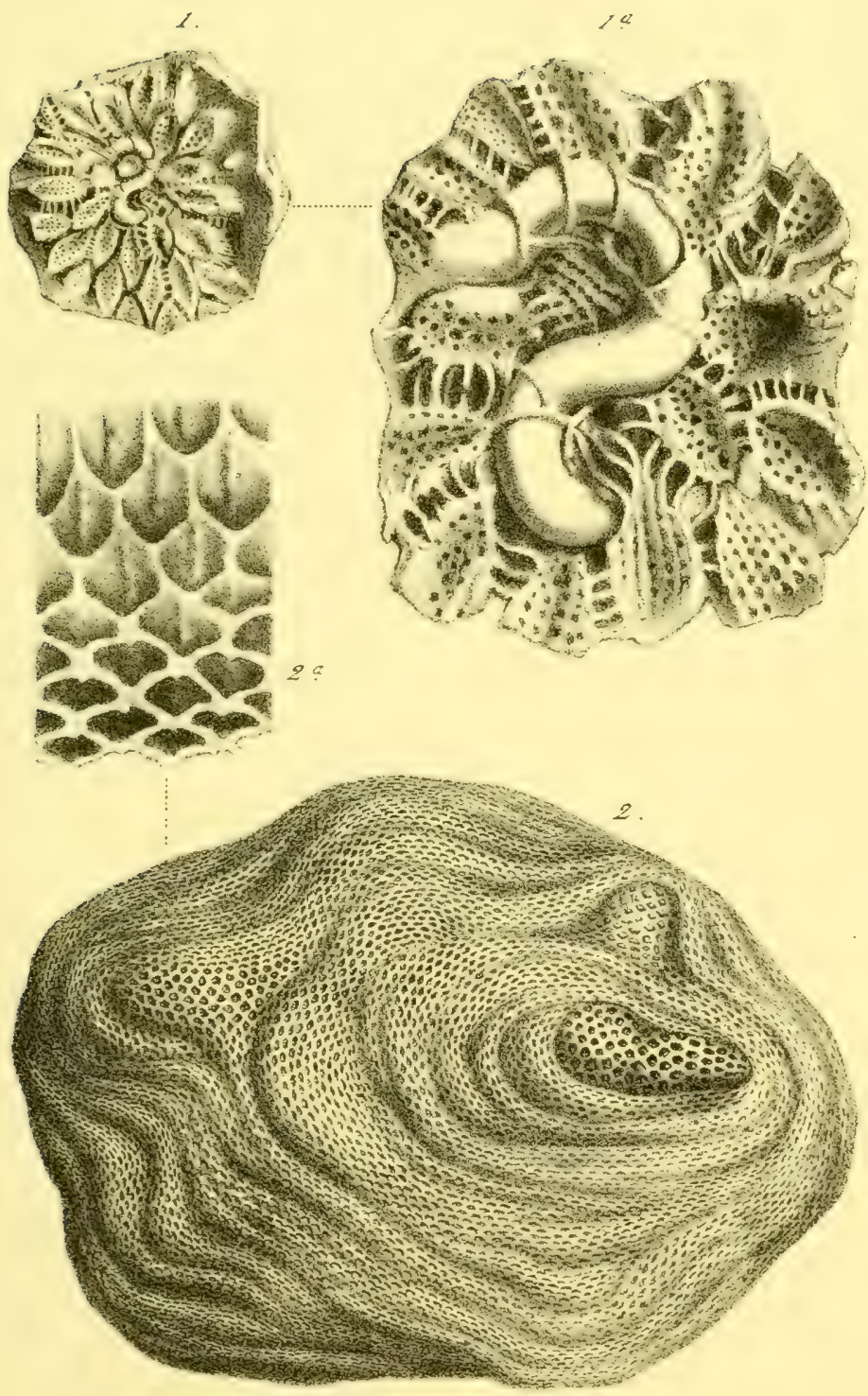




\title{
DEVONIANO
}

\author{
LÁM. 14
}

Figs.

1 SYRingopona cespitosa, Gold. [210]

1 a Poliperito aumentado.

2 Favosites goldpussi, Yern. et d'Arch. [211]

$2 a$ Seccion longitudinal del mismo

3 Favosites polymorpha, Gold. (sp). [212]

$3 a$ Aumento de la misma especie.

4 Otro ejemplar de la misma. 

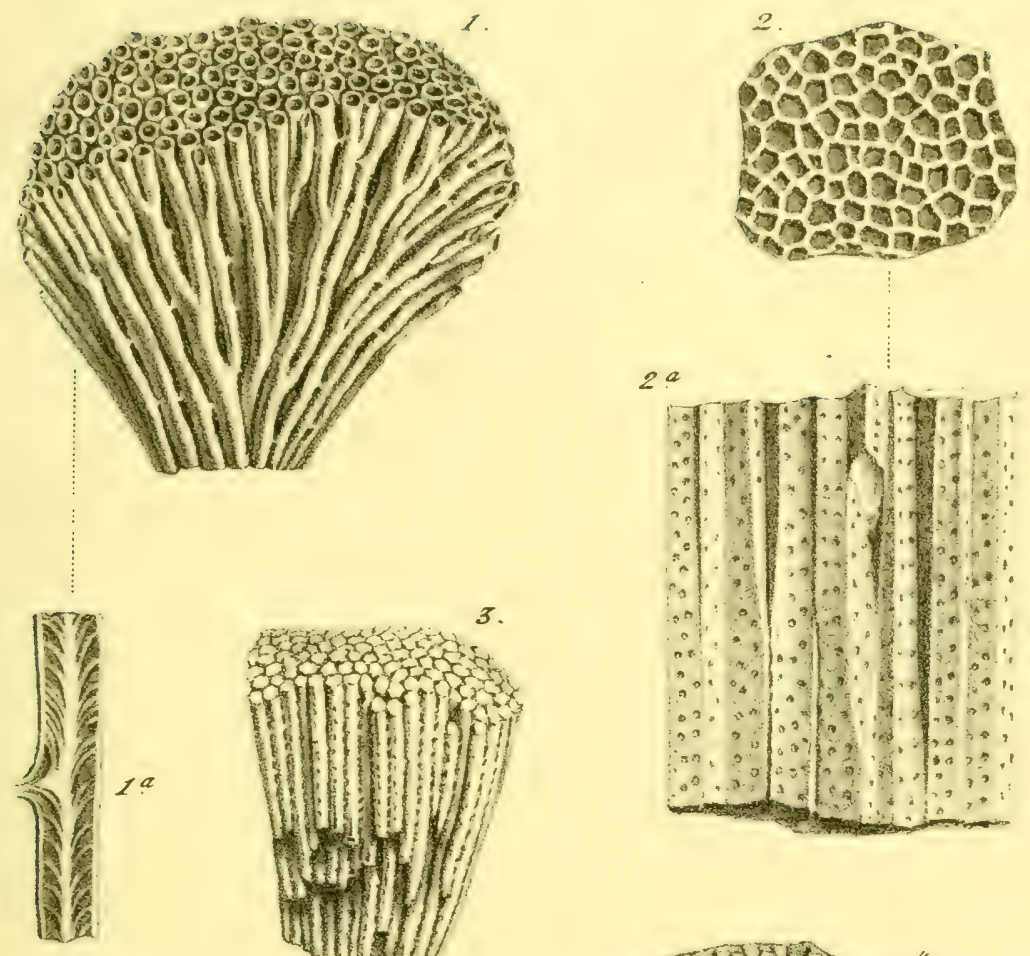

3.
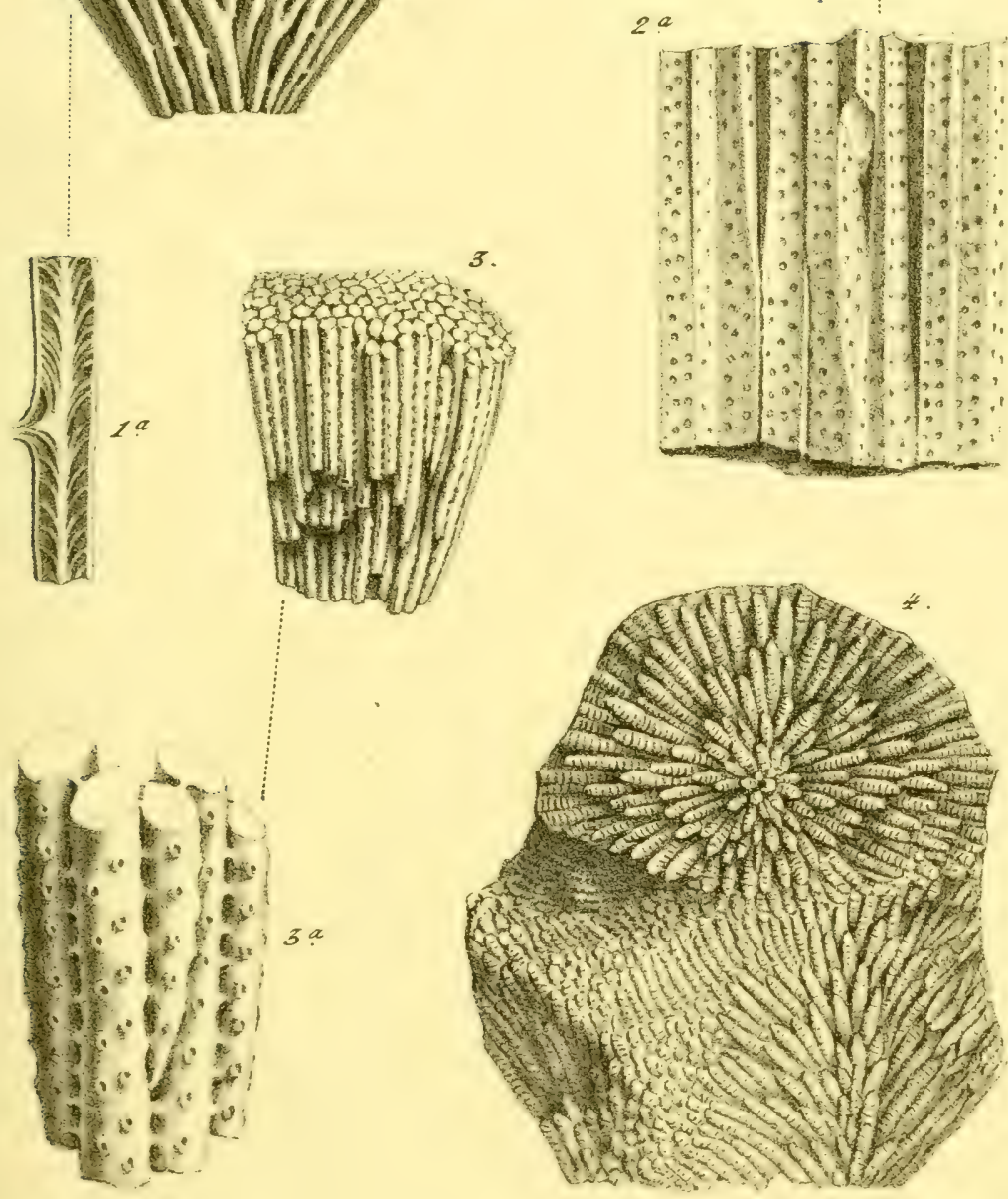




\title{
DEVONIANO
}

\author{
LÁM. 15
}

Figs.

1 Favosites Basiltici, Golf. (sp). [213]

1 a. Aumento de los tabiques de la misma especie.

2 Favosites alveolanis, Gold. (sp). [2]4].

2 a. Tabiques de la misma, aumentados. 


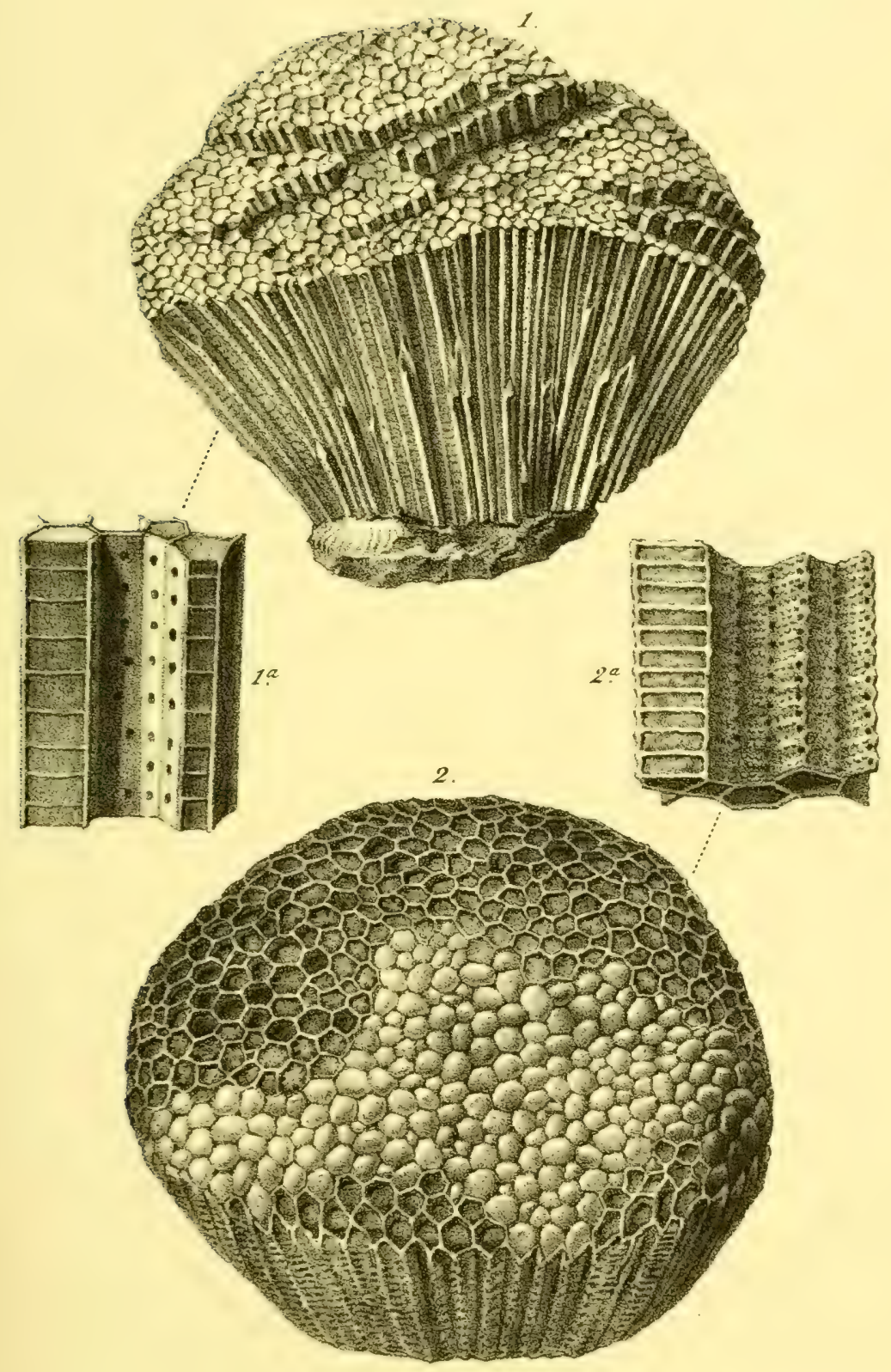






\title{
DEVONIANO
}

\author{
LÁMr. 16
}

Figs.

1 Favosites Cenviconvis, Blain. (sp.) [216]

2 Fivosites reticulata, Blain. (sp.) [ 215]

3) Mignelinia geométrica, Edw. et Haime. [219]

is a Aumento de la misma especie. 


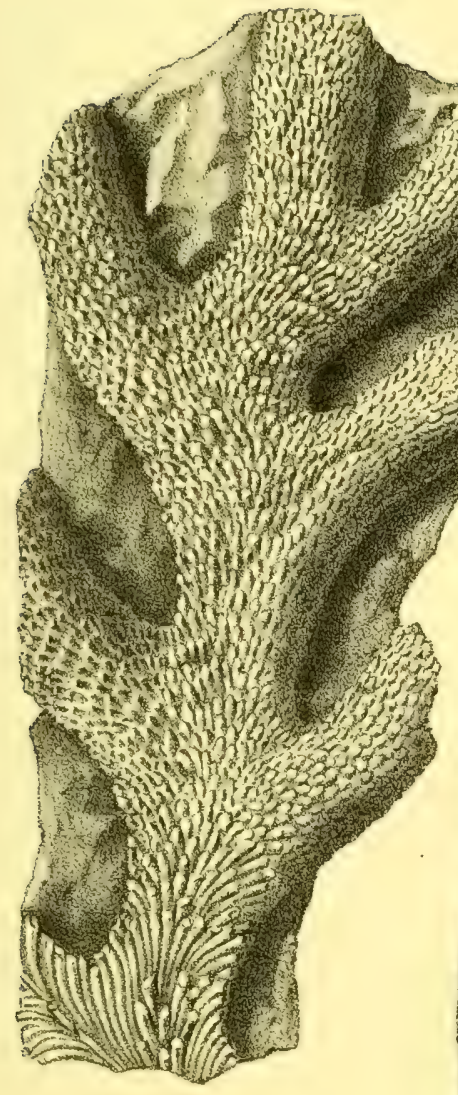

3.

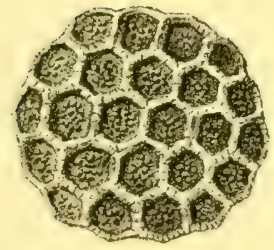

3:

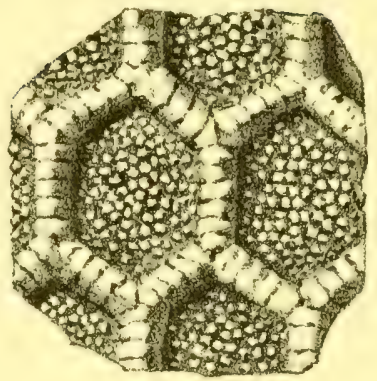

2

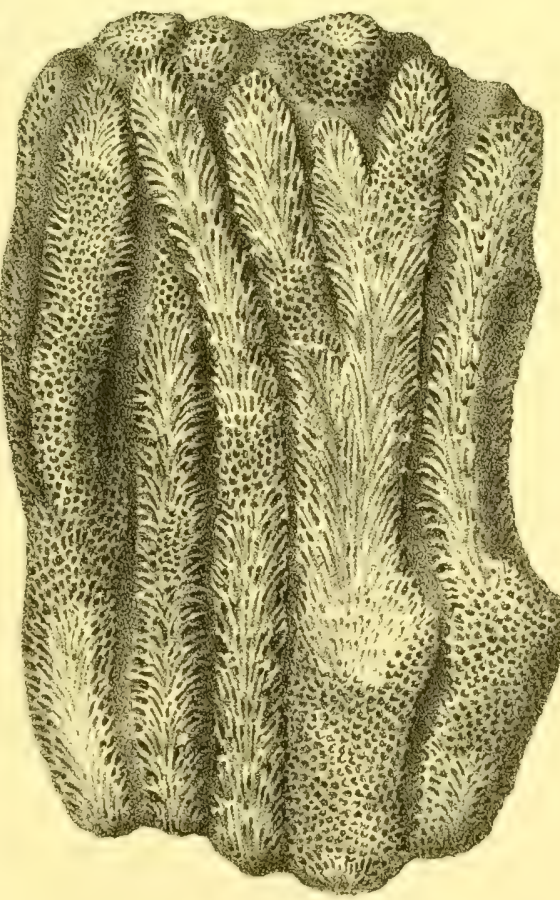






\title{
DEVONIANO
}

\author{
LAMI. 17
}

Figs,

1 Conibophylun LEontanse, Haime. [225]

I « Cáliz aumentado, de la misma especie.

2 Cinetetes Torrubia, Edn. et Haime. [220]

2 ( $)$ Porcion aumentada de su superficie.

3 Cystiphyllua vesigulosum, Gold. (sp.) [224]

3) a Seccion longitudinal de la misma especie.

4. Cinzetes pethopolitanus, Pander. (sp.) [221]

\pm a Seccion longitudinal de la misma especie.

5 Aumento de la misma especie á lo largo.

s a Aumento calicinal de la misma especie.

6 Combopiyllum Maniaum, Haime. [226]

7 Otro ejemplar de la misma especie.

S Bartphyllum Verneuilanuas, Haime. [230]

$8 a$ Cáliz aumentado de la misma especie.

9 Aulopon RePeNs, Kuor. (sp.) [242] 

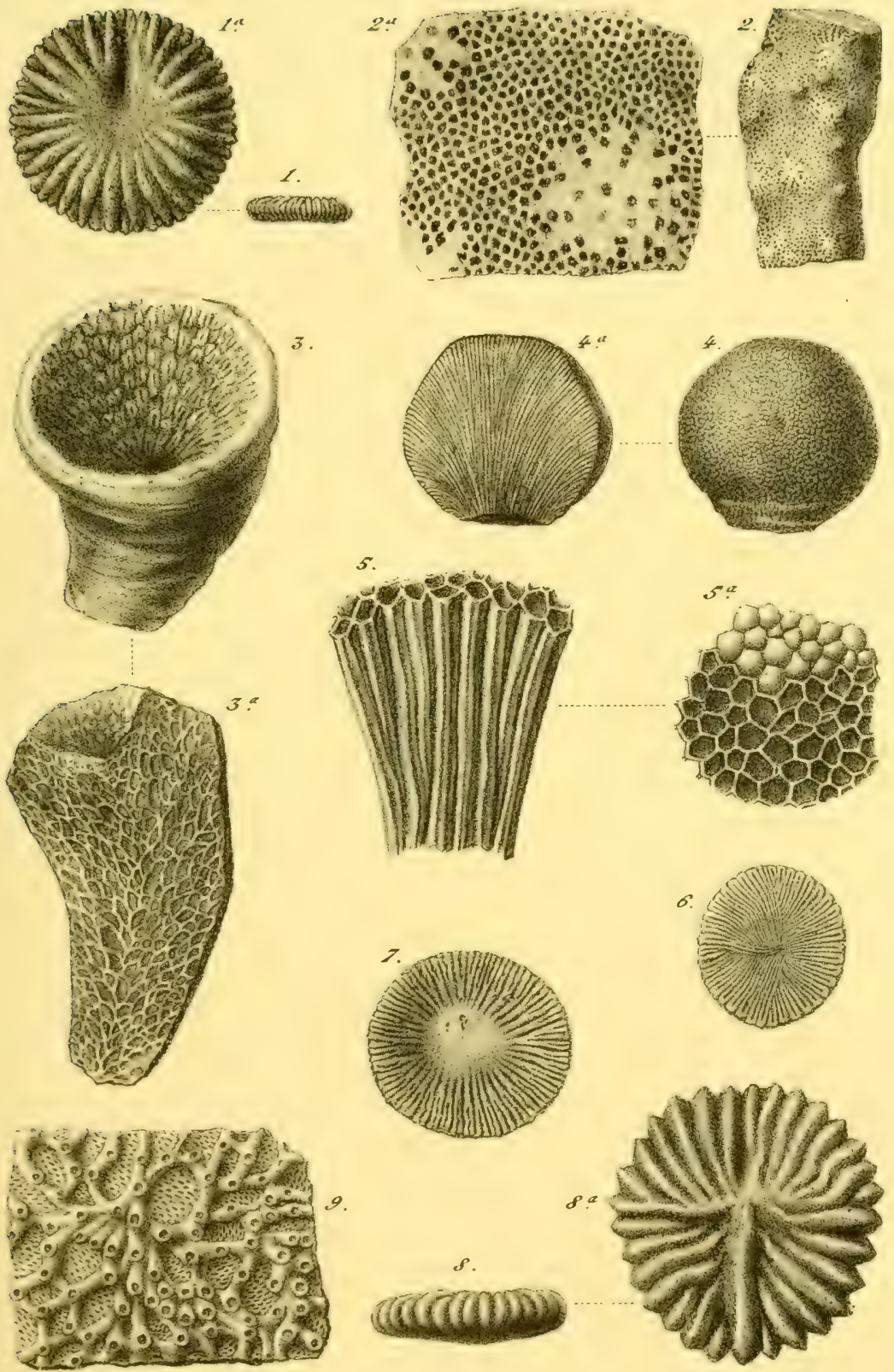




\title{
DEVONIANO
}

\author{
LÁm. 18
}

rigs.

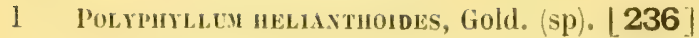

2 Disphyllum cespitosuy, Gold. (sp.) [233] 

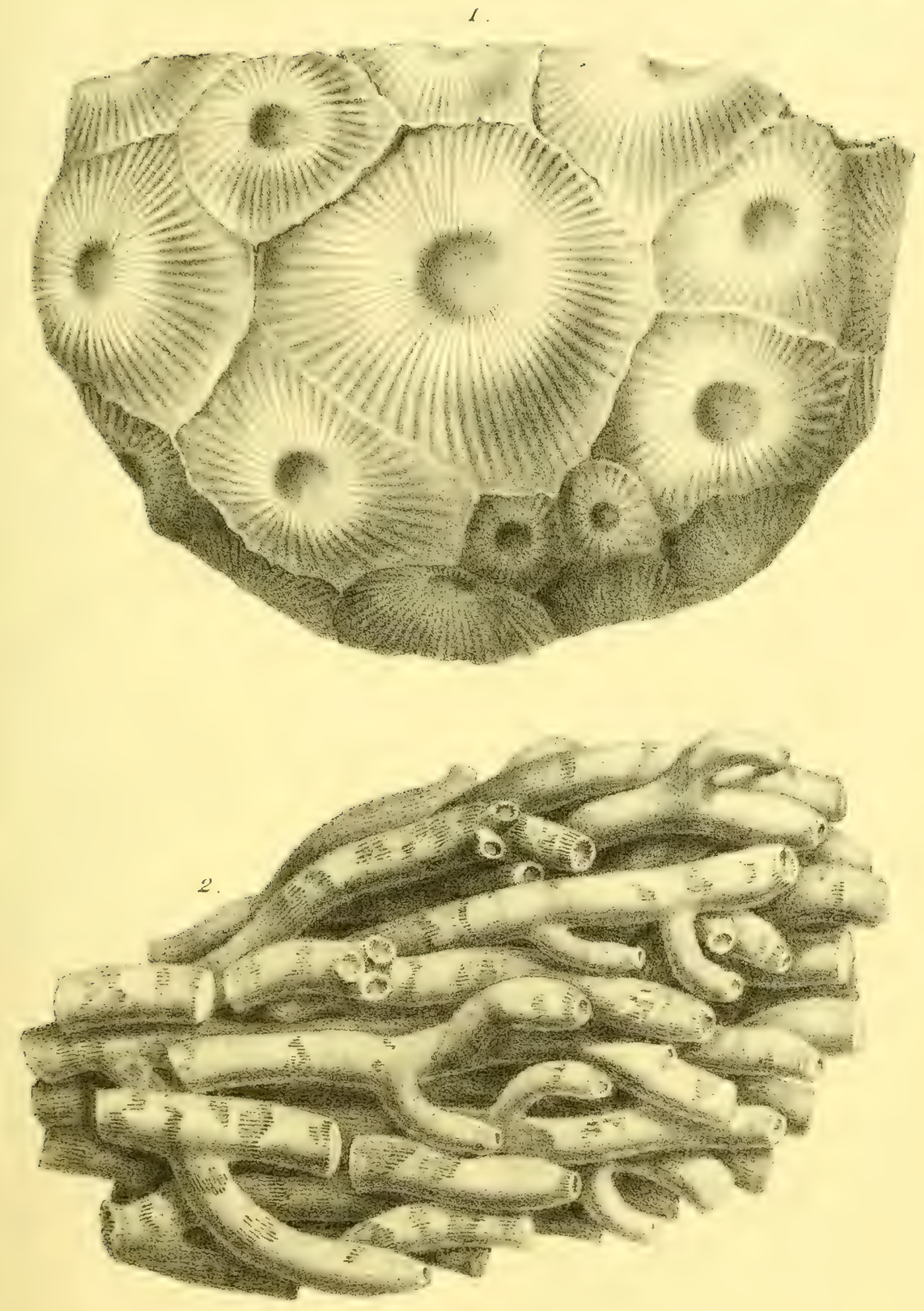



\title{
DEVONIANO
}

\author{
LÁm. 19
}

\section{Figs.}

1 Dispmyllum cÆspitosum, Gold. (sp.) [233]

2 Otro ejemplar de la misma especie.

3 Dispiyllum radicans, Gold. (sp.) [234]

4 agervularia pradoana, Ilaime. [239]

5 Agenvelaria goldfussi, Haime. [237] 

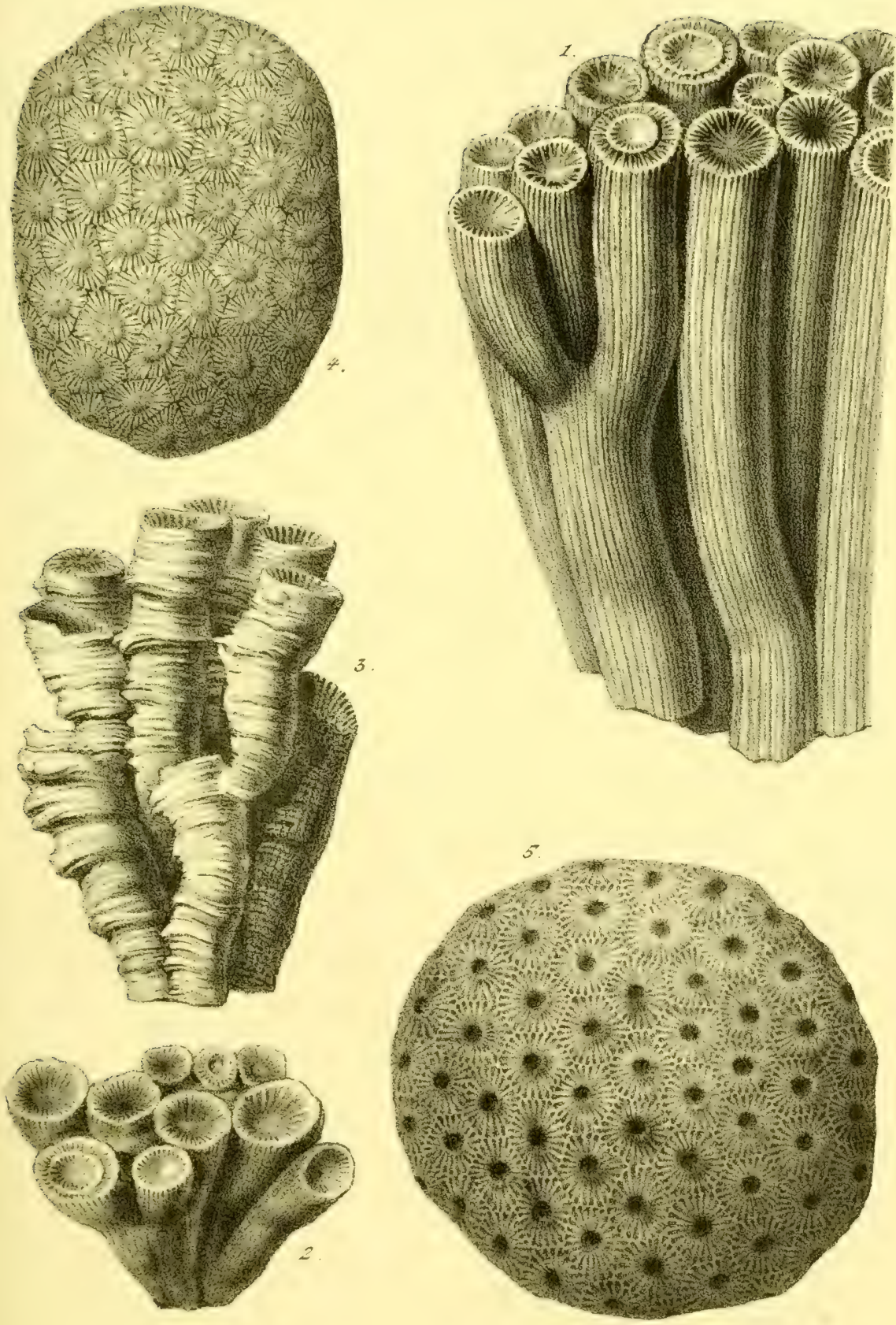




\title{
CARBONÍFERO
}

\author{
LÁM. 1. ${ }^{\mathrm{a}}$
}

Figs.

1 Phillipsia globicers. Phill., aumentada. [244]

2 Philliesia Denbyensis, Mart., aumentada. [243]

3 Coccix de Pulluipsin Eicniwald, Fischer. [245]

4 Onthoceratites cixcitus, Sow. [246]

5 Littonina bisemials, Phill. [248]

$5 a$ La misma especie vista por el lado opuesto.

6 Littorina Giana, Vern. [249]

6 a El mismo ejemplar visto por el lado opuesto.

7 Chemvitzia nugifena, Phill. [250]

8 Chemnitzia scalanioldea, Phill. [251]

8 a La misma especie vista por el lado opuesto.

9 Macrocheilus Agutus, Sow. [252]

9 a La misma especie vista por el lado opuesto.

$9 b$ La misma, vista lateralmente.

10 Eulima Donayneava, nov. sp. [253]

11 Tubo Hoeninghinsianus, Kon. [258]

12 Onthocenatites dactruophonum, Kon. [247] 

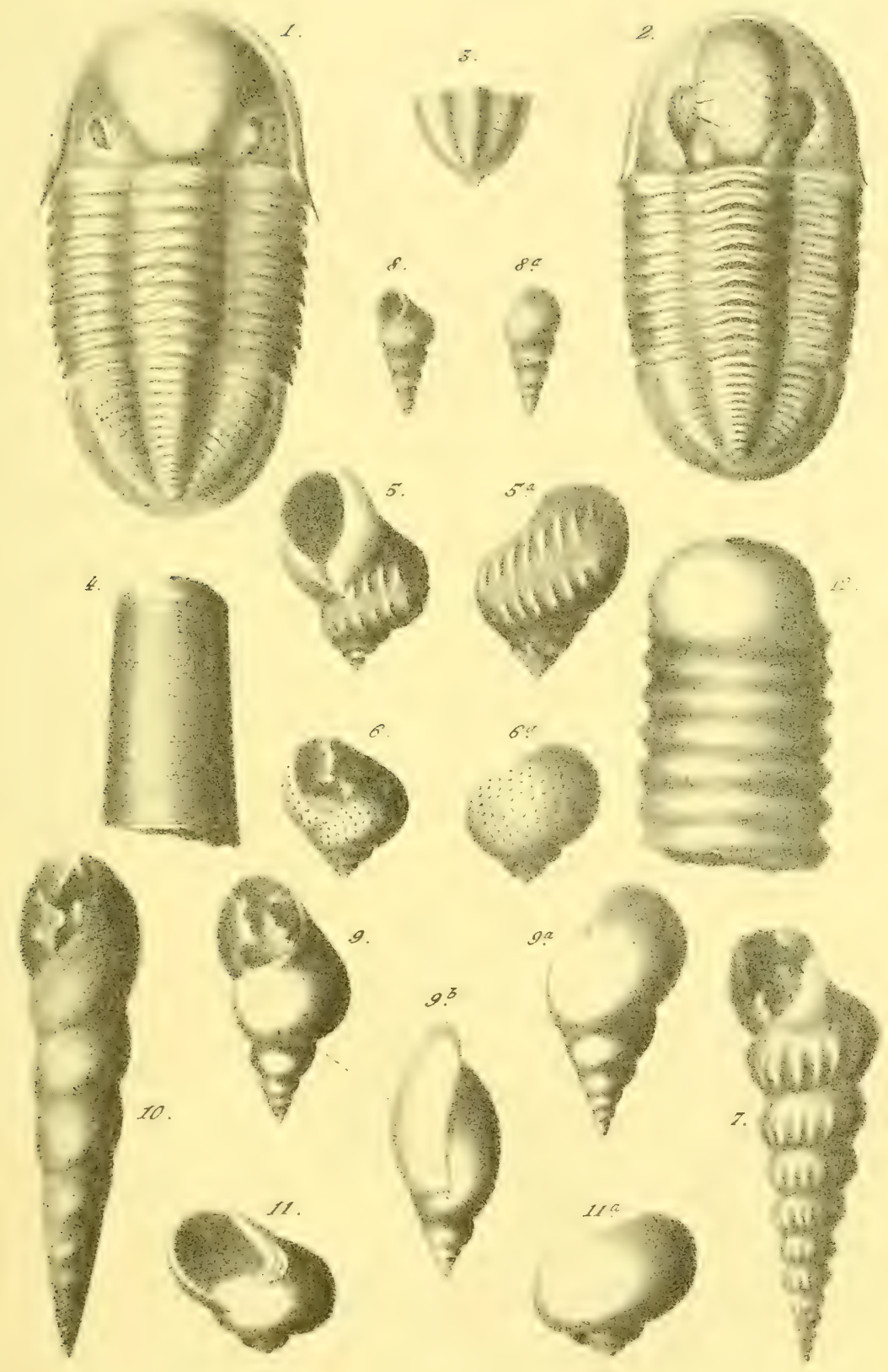




\title{
CARBONÍFERO
}

\author{
LÁm. 2. ${ }^{a}$
}

Figs.

1 Natica variata, Phill. (sp). [254]

I a La misma especie vista por el lado posierior.

2 Natica pligistria, Phill. (sp). [255]

$2 a$ La misma especie vista por el lado de la abertura.

3 Variedad de la misma especie.

4 Natiga spirata, Sow. [256]

5 Natica amplata, Phill. [257]

6 Solarium fallax, Kon. [259]

6 a La misma especie vista por el lado superior.

7 Euomphalus pugilis, Phill. [263]

7 a La misma especie vista por la region umbilical. 
$\triangle A R B O N I F E R O$.
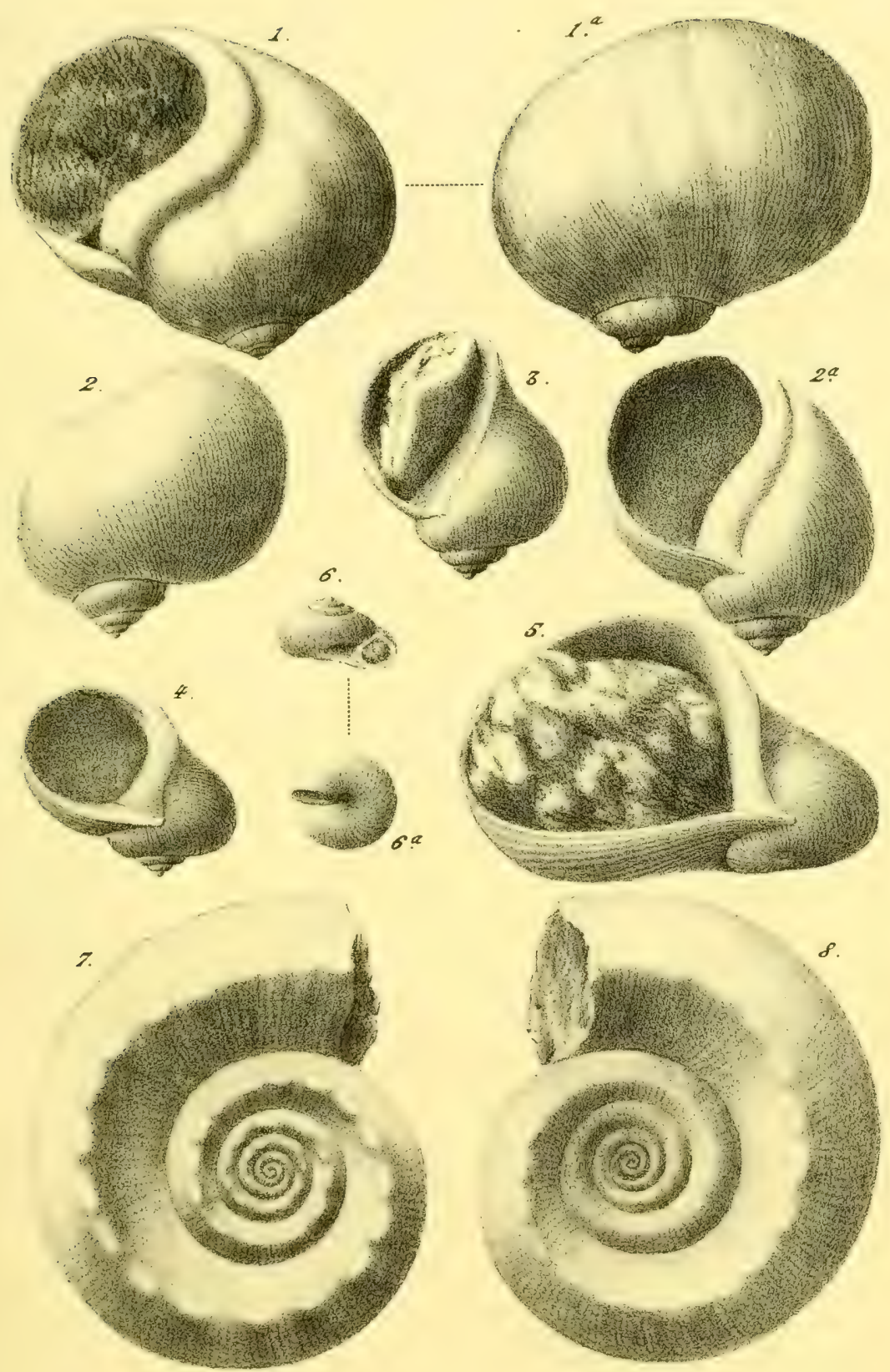




\title{
CARBONIFERO
}

\author{
Lám. $3{ }^{a}$
}

Figs.

I Evonphalus catillus, Lart. (sp). [261]

la La misma especie vista por la parte superior.

2 Eumpilalus, pentangulatus, Sow. [260]

2 a La misma especie vista por la parte superior.

3 Pleurotomaria plegelia, Kion. [265]

4 Pieunotomaria comiga, Phill. [266]

5 Pleurotomama IVani, Leveille, un tercio mayor que nuestros ejemplares. [267]

5 a La misma especie vista por el lado opuesto.

56 Aumento del seno y partes inmediatas.

6 Pleunotomaria Vidalina, nov. sp. [268]

$6 a$ El mismo ejemplar visto por el lado opuesto.

66 El mismo visto por la parte superior.

7 Nurginonia angulat $A$, Phill. [269]

8 Munchisonia abneviata, Sow. [270]

9 Capulus vetustus, Sow. [271]

9 a La misma especie vista por el lado anterior. 

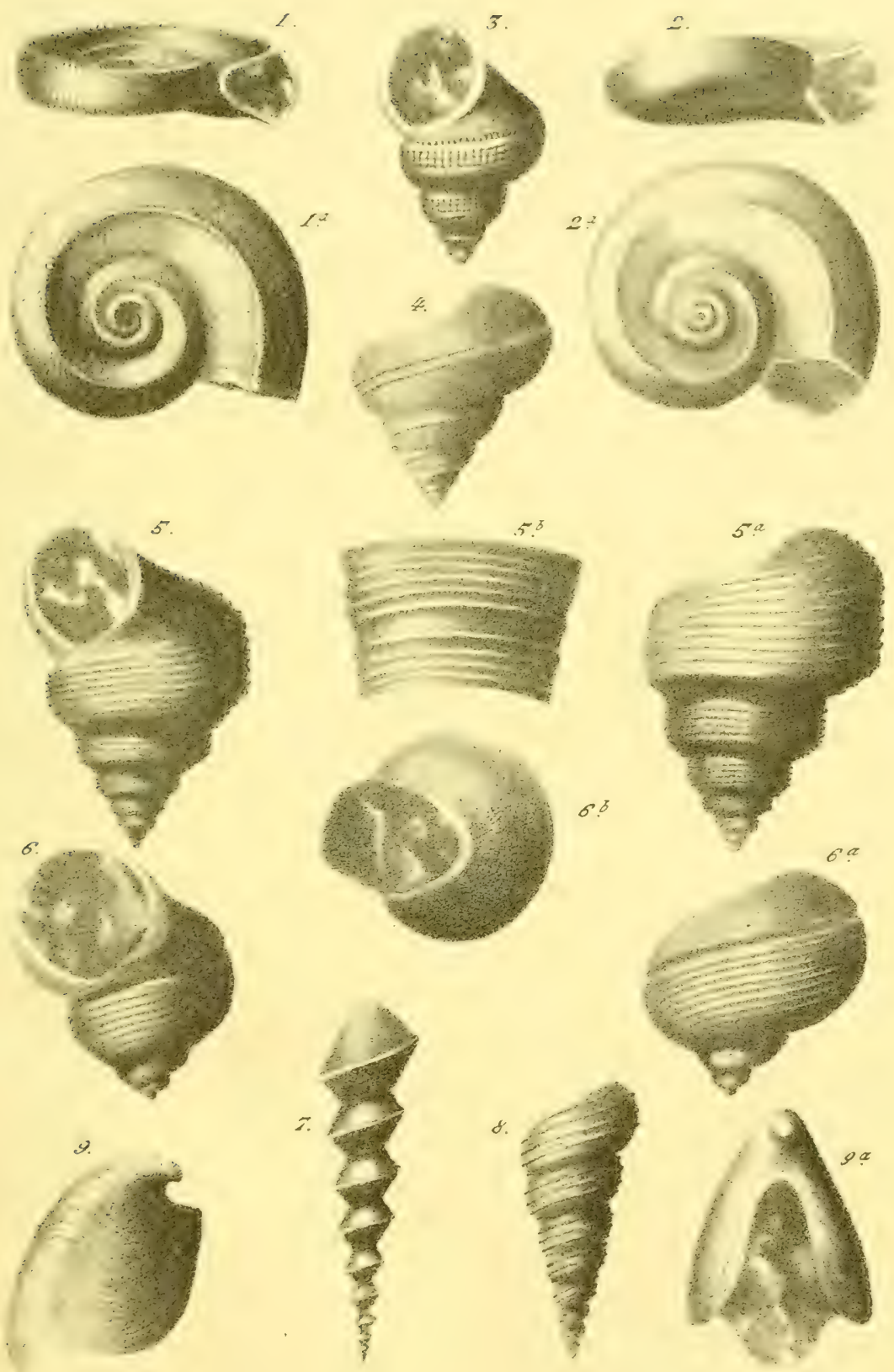




\title{
CARBONÍFERO
}

\author{
Lìn. $4 .^{a}$
}

Figs.

1 Bellenophox miulgus, Mart. (sp.) [273]

1 a El mismo ejemplar visto por la region bucal.

2 Bellemopion vasultites, Montf. (sp.) [274]

3 Bellerophon Dumonti, d'Orb. [275]

$3 a$ La misma especie vista por la region bucal.

4 Bellerophox Utri, Flem. [278]

4 a La misma especie vista lateralmente.

$4 b$ La misma, vista por la region dorsal.

5 Belleropion sub-Urit, nov. sp. [279]

5 a El mismo ejemplar visto por la region dorsal.

6 BeLLenophoN gricilis, nov. sp. [281]

6 a El mismo ejemplar visto por la region dorsal.

7 Dentalium orxatum, Kon. [282]

8 Cardinia subovalis, nov. sp. [289]

8 a El mismo ejemplar visto por la region cardinal.

86 Valva derecha de la misma especie, vista interiormente. 


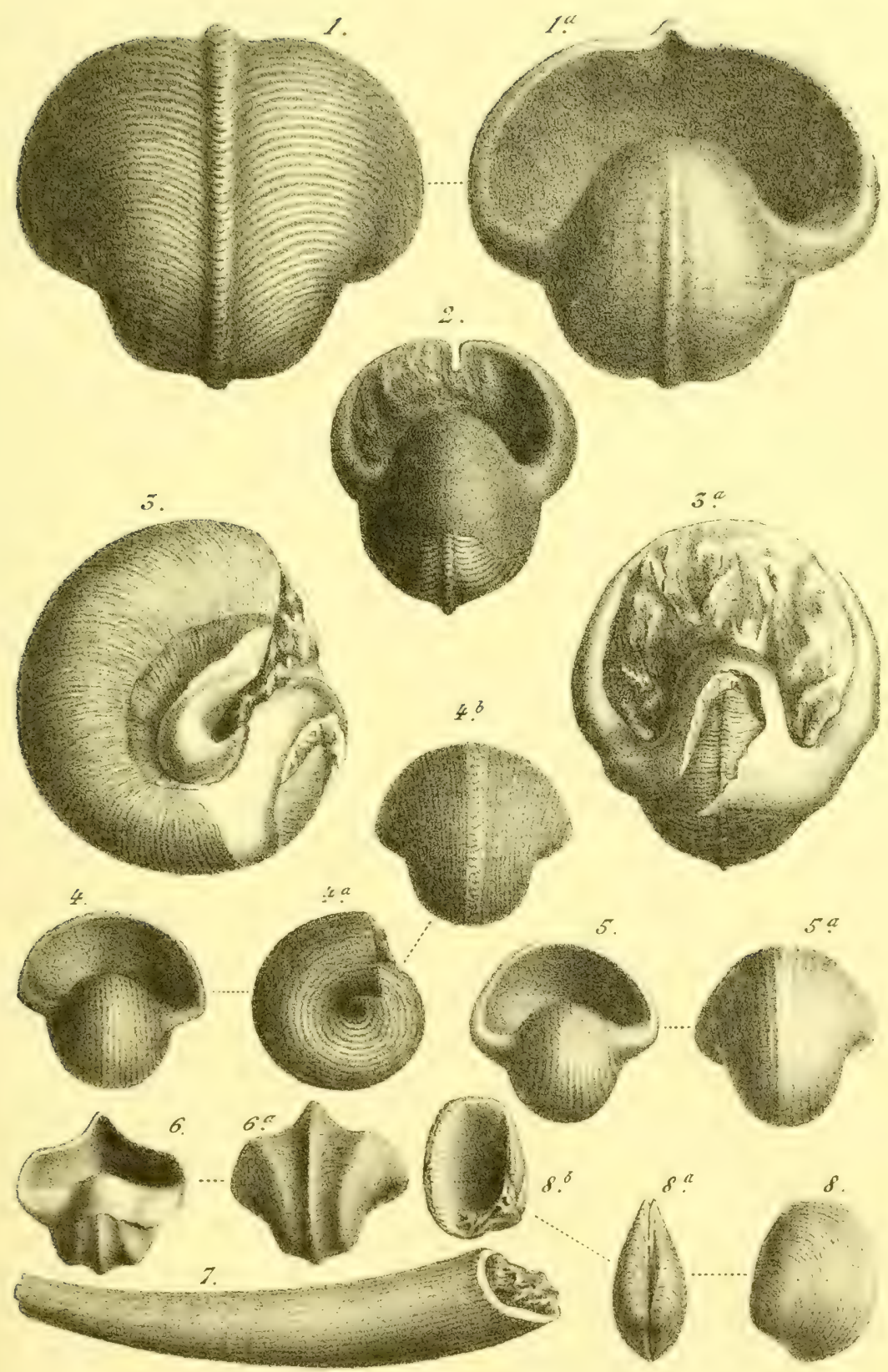






\title{
CARBONÍFERO
}

\author{
Lím. 5.
}

Figs.

1 Pholdgomy negulars, ling. [283]

1 a La misma especie vista por la region cardinal.

2 Conocíndum aleforme, Sow. [286]

3 La misma especie vista exteriormente.

4. Coxocandium Ounalicum, Vern. el Keys. [287]

t a El mismo visto por la valva izquierda.

5 Covogaromem Contázari, nov. sp. [288]

6 El mismo visto por la valva izquierda.

7 Otro ejemplar de la misma especie en que se muestran la epidermis de la concha $a$ y los desgastes sucesivos $b$ y $c$.

$7 a$ Aumento de las costillas desgastadas $c$. 


$$
\text { ubl }
$$






\title{
CARBONÍFERO
}

\author{
LÁM. $6 .^{\text {id }}$
}

ligs.

1 Spirifen striatus, Martin (sp). [293]

2 Otro ejemplar de la misma especie, visto lateralmente.

3 Variedad de la misma especie, de estrias más tinas.

4 Interior de la valva ventral.

5 Spinifer noseuensis, Fischer (sp). [294]

$5 \pi$ La misma especie vista por la region frontal.

6 Spirifer bisulgatus, Sow. [298]

7 Otro ejemplar de la misma especie, visto posteriormente. 

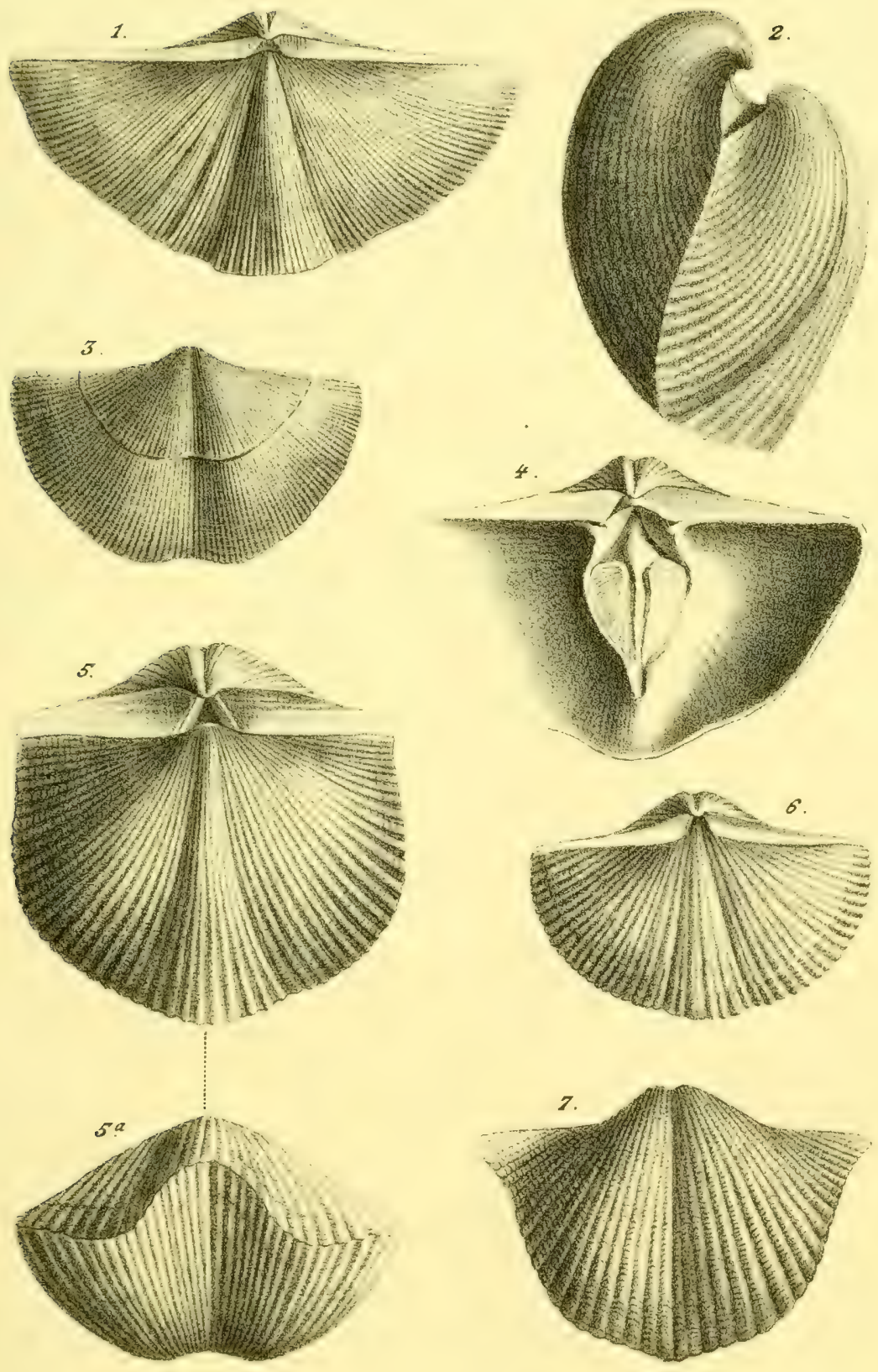



\title{
CARBONÍFERO
}

\author{
LÁM. 7.
}

Figs.

I Spirifer convolutus, Phill. [296]

I a La misma especie vista por la region frontal.

2 Spiriferiva cisstata, Schlot (sp). [305]

2 a El mismo individuo, visto posteriormente.

26 El mismo, visto por la region frontal.

$2 c$ Aumento de una parte de la concha.

3 Spmifer crassus, Kon. [295]

$4 \quad$ Spirifer planatus, Phill. (sp). [297]

4 a la misma especie, vista por la valva menor.

46 La misma, por la region frontal.

5 Spirifer pinguis, Sow. Individuo jóven. [299]

6 Ejemplar adulto de la misma especie, visto lateralmente.

7 Individuo de la misma especie, var. S. rotundatus, Sow. 


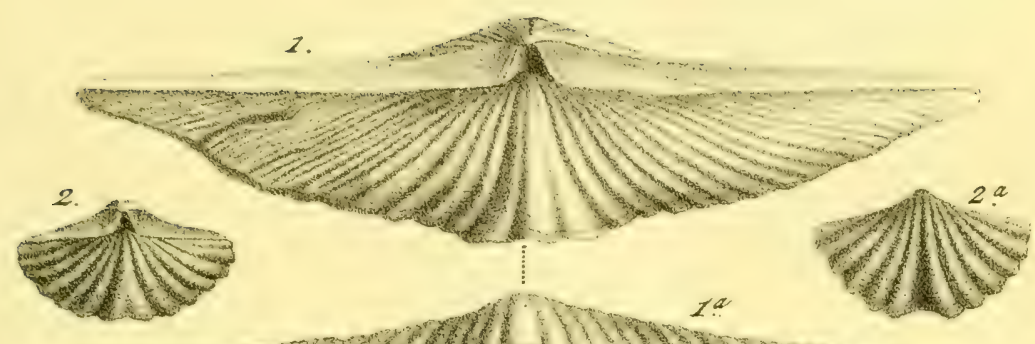

-20 -

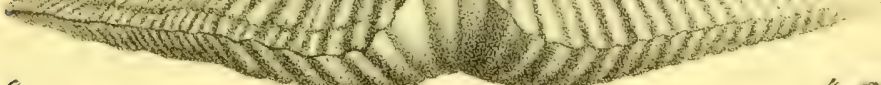
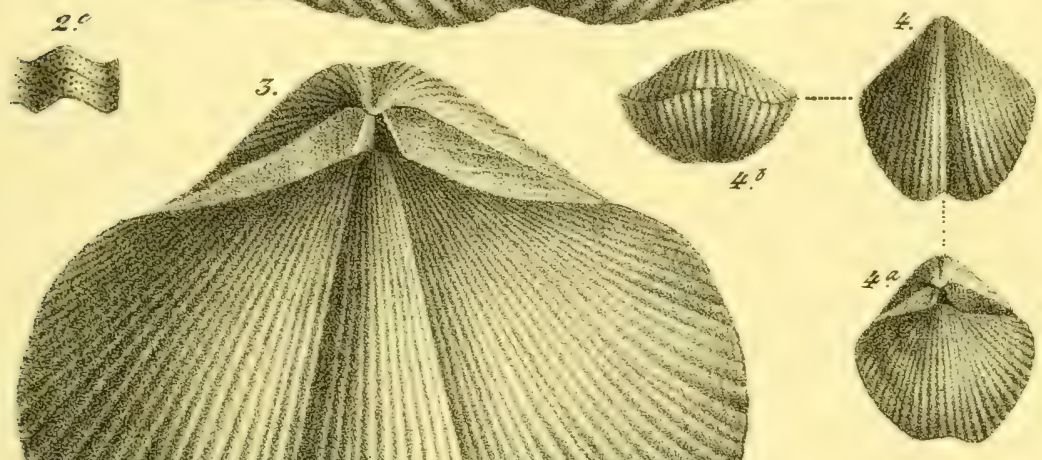

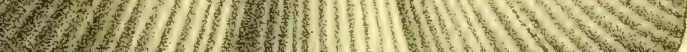

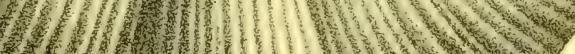
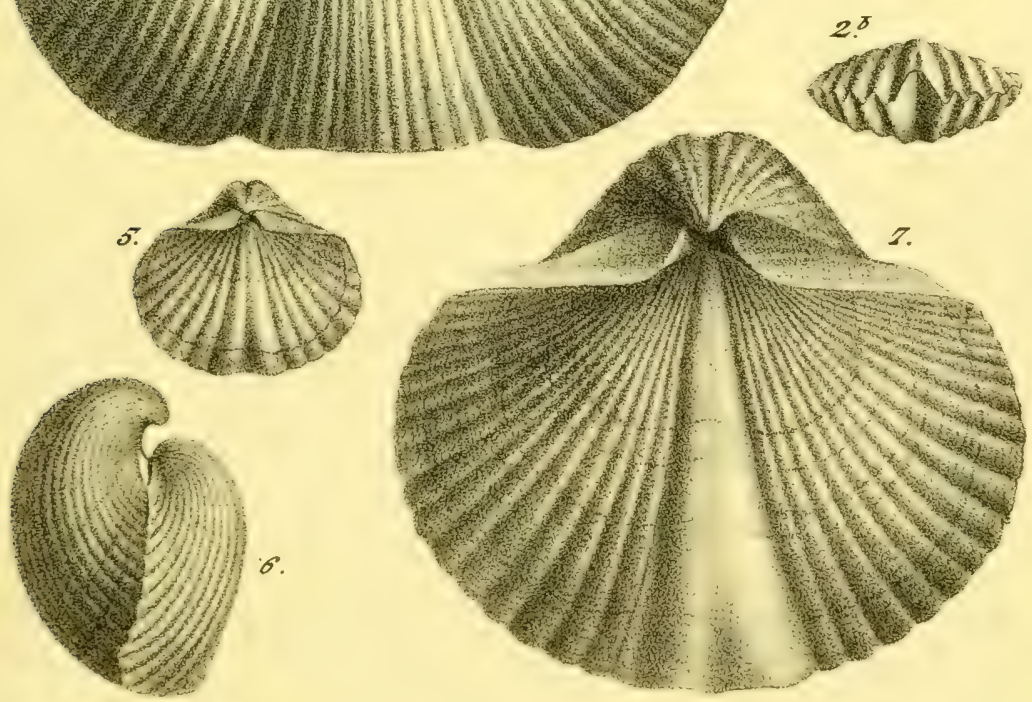




\title{
CARBONÍFERO
}

\author{
LÁ̀. 8. ${ }^{a}$
}

ligen.

I Spinifen integricosta, Phill. [300]

2 Otro indivíduo de la misma especie, visto lateralmente.

:V Variedad más ancha de la misma especie.

1 Spirifen glaber, Martin. [301]

1 E El mismo individuo visto por la region frontal.

-) Otro ejemplar de la misma especie.

Ђ) $a \quad$ El mismo visto lateralmente.

(6) Spirifer lineatus, Martin (sp). [302]

$6 \Omega$ El mismo visto posteriormente.

7 Otro indivíduo de la misma especie, visto por la valva menor.

¿ Otro visto por la mayor. 

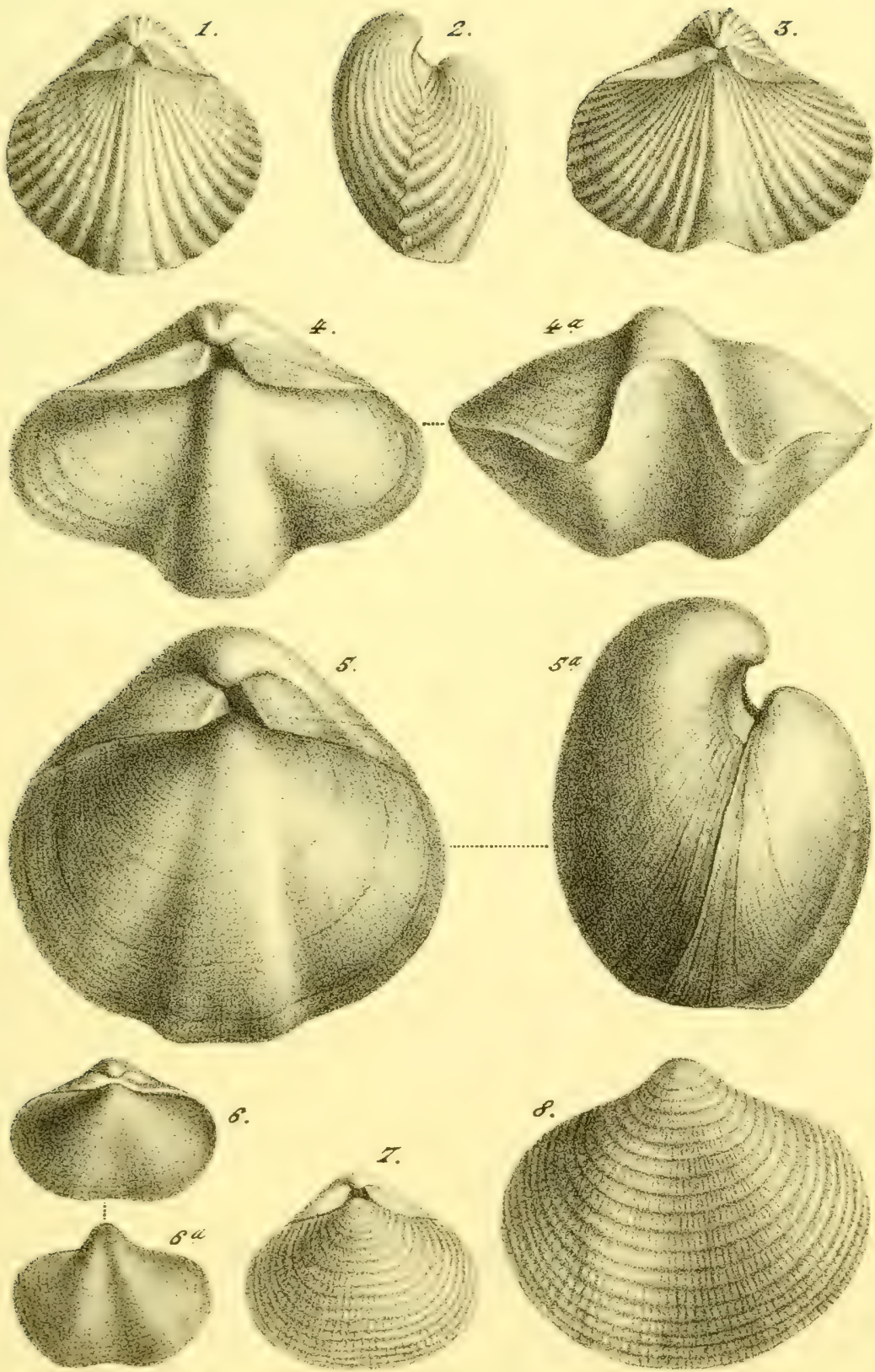




\title{
CARBONÍFERO
}

\author{
LÁM. 9."
}

Figs.

1 Spirigena planosulgata, Phill. [306]

2 Variedad de la misma especie.

3 Otro individuo con las expansiones marginales.

4 Riynchonelda acuminata, Martin (sp). [307]

1 a El mismo ejemplar, visto por la region frontal.

5 Variedad de la misma especie.

5) la misma, vista por la region frontal.

(6) Interior de la valva dorsal.

7 Otro ejemplar de la misma especie.

\& Otra variedad pequeña de la misma.

sin nismo individuo, visto por la region frontal. 

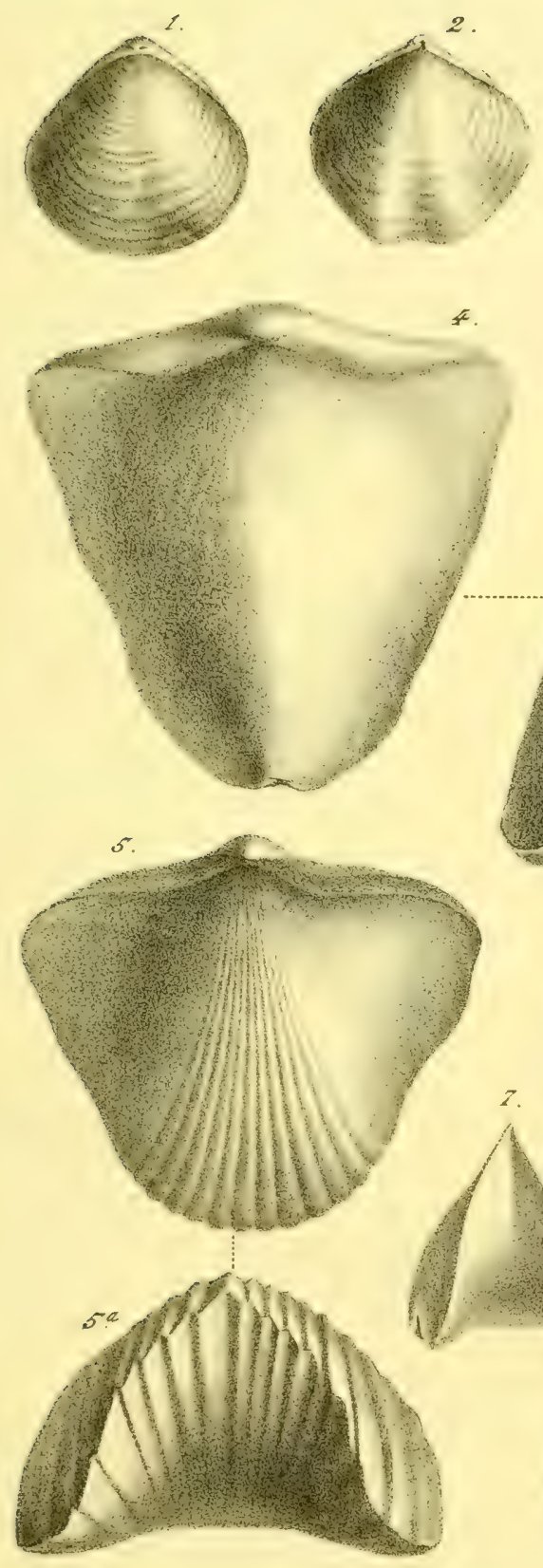

a.
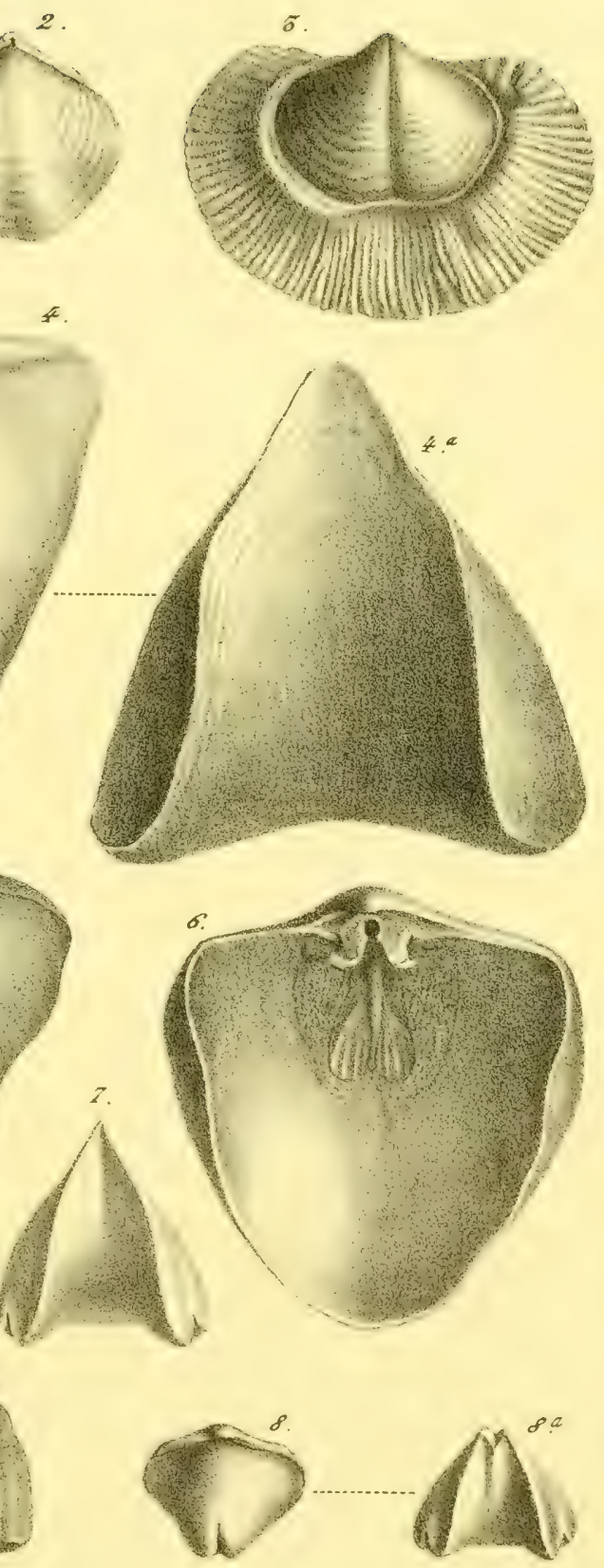




\title{
CARBONIFERO
}

\author{
LÁM. 10
}

Figs.

1 Rirnghonella pugnus, Martin (sp). [308]

la El mismo individuo visto por la region frontal.

2 Interior de la valva dorsal.

3 Variedad de la misma especie.

4 Riynghonella pleurodon, Phill. (sp). [309]

ta El mismo ejemplar, visto por la region frontal.

5 La misma especie, vista posteriormente.

5a La misma, vista lateralmente.

6 Rirnghonella angulata, Linnæus (sp). [311]

$6 a$ El mismo indivíduo, visto lateralmente.

7 Ritynchonella flexistria, Phill. (sp). [310]

ia La misma especie, vista lateralmente.

i. Camanophorta crumeva, Martin (sp). [312]

9 Otro individuo de la misma especie.

9 a El mismo, visto por la region frontal.

$9 b$ El mismo, visto lateralmente. 

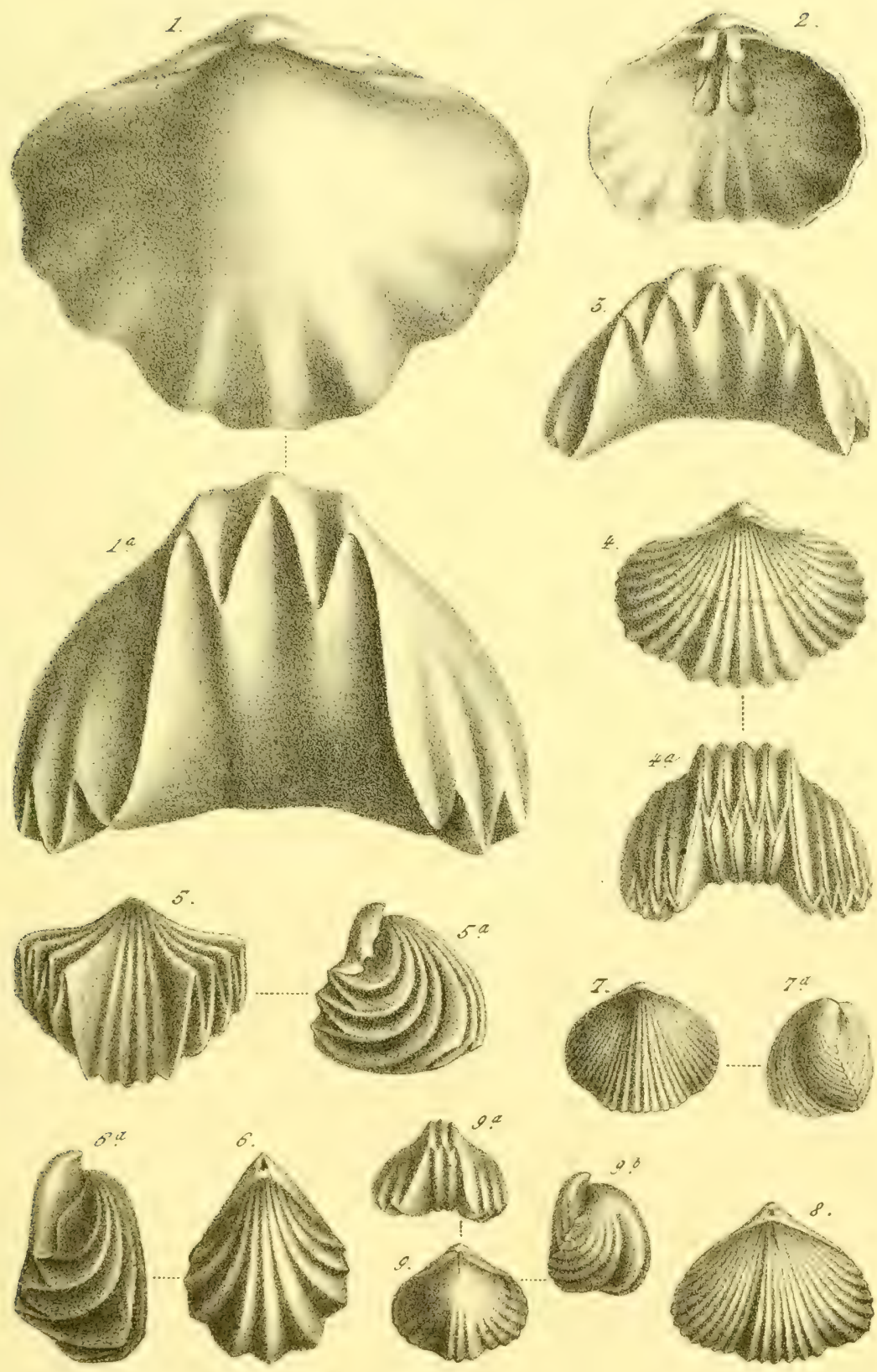




\title{
CARBONIFERO
}

\author{
LÁM. 11
}

Figs.

1 Productus stmatus, Fischer (sp). [314]

la El mismo, incompleto, visto por la valva menor.

2 Productus giganteus, Martin (sp). Indivíduo jóven. [315]

$2 a$ El mismo, visto lateralmente.

$2 b$ El mismo, visto por la valva mayor.

3 Indivíduo de la misma especie de tamaño mediano. 
CARBONÍFERO

LAM. 11.

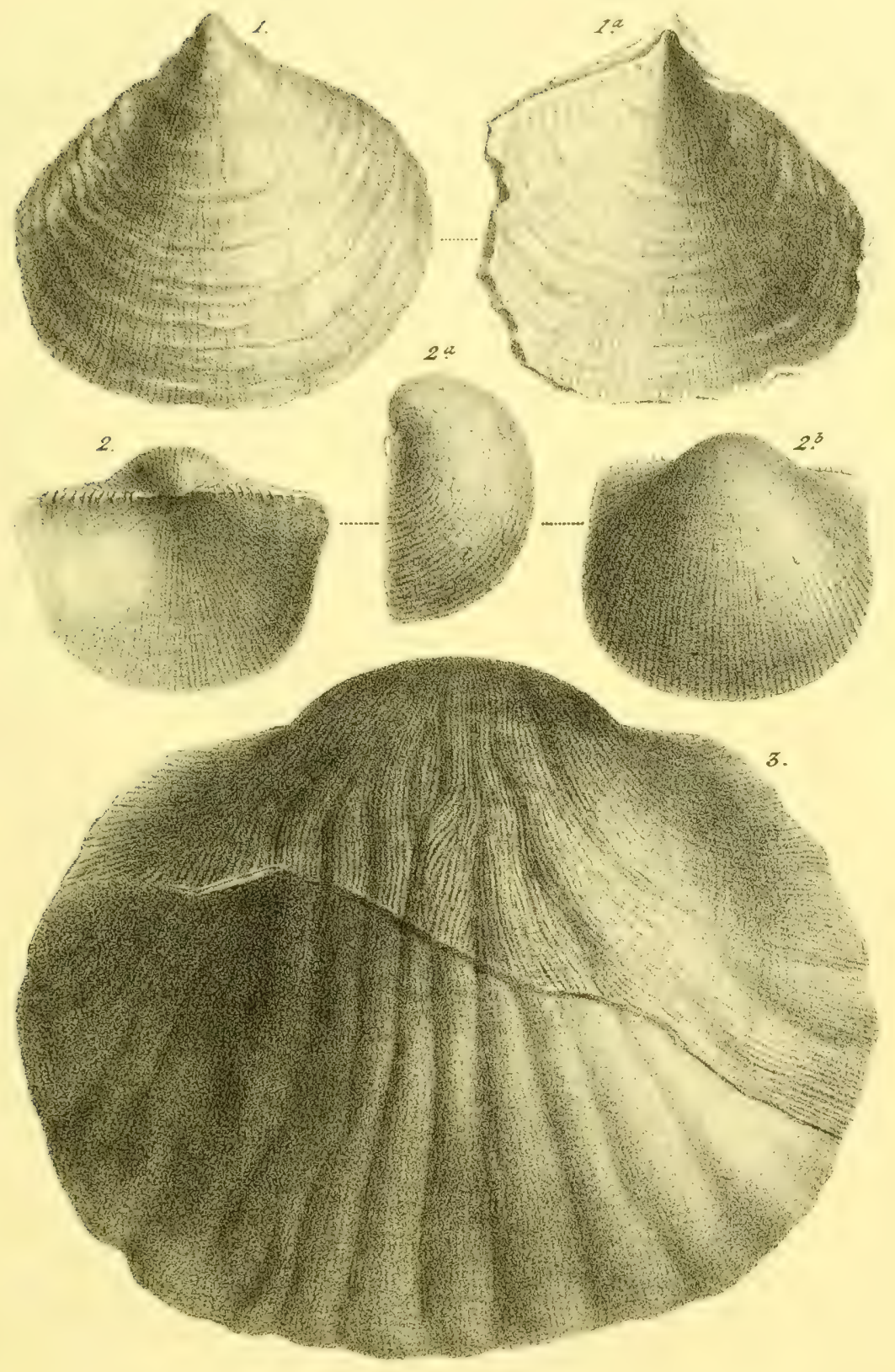






\section{CARBONÍFERO}

LẢM. 12

Figs.

1 Prodectus semineticulatus, Mart. (sp). [317]

I a La misma especic vista lateralmente.

1) La misma vista por la valva mayor.

2 Variedad alargada de la misma especie.

2 a $\mathrm{El}$ mismo individuo visto lateralmente.

:) Ejemplar mostrando la fractura de las valvas.

1 Pronuctus costatus. Sow. [318]

$5 \quad$ Otro individuo de la misma especie.

6 Productus loxgispinus. Sow. [319]

6 El mismo con las espinas.

(5) El mismo por la valva opuesta. 

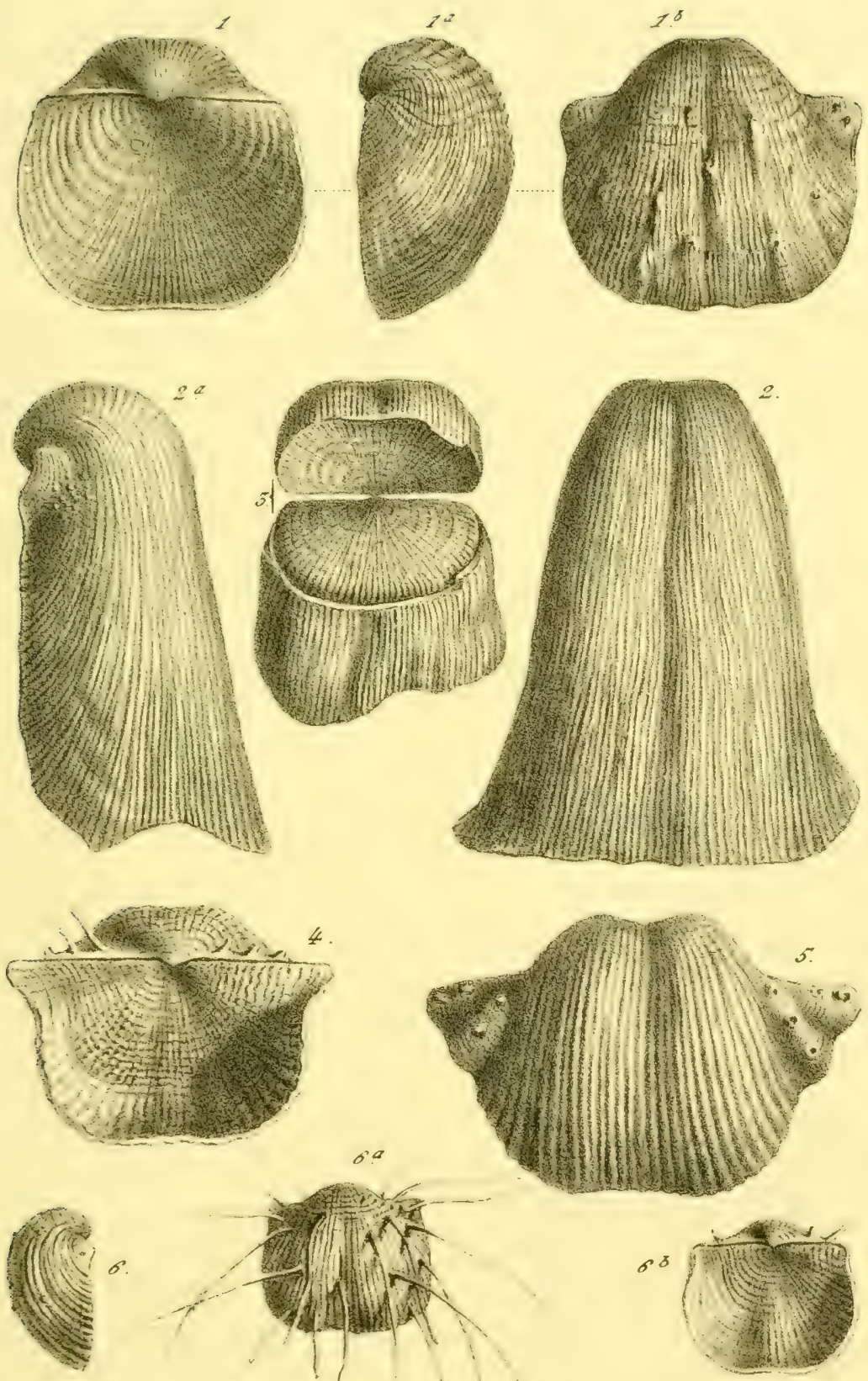

o.
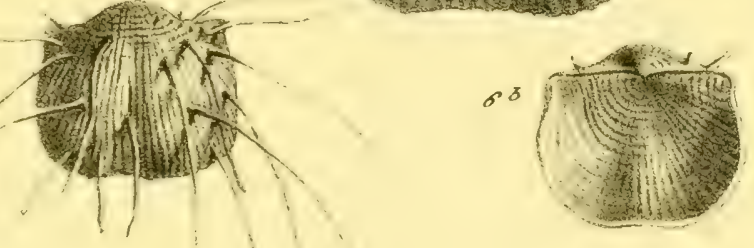




\title{
CARBONÍFERO
}

\author{
LÁм. 13
}

$\mathrm{rin}=\mathrm{n}$

l Proptctes coms, d'Orb. [316]

2 Otro individuo de la misma especie, visto por la valva mayor.

2 "Costillas del mismo, aumentadas.

3 Productus carboxames, Kon. [321 ]

3) El mismo ejemplar visto lateralmente.

:) Costillas del mismo, aumentadas.

4 Productus endatus, defr. [322]

5) Otro ejemplar de la misma especie:

5 “ El mismo visto por la valva opuesta.

5/. El mismo visto lateralmente.

5) C. Costillas del mismo aumentadas. 

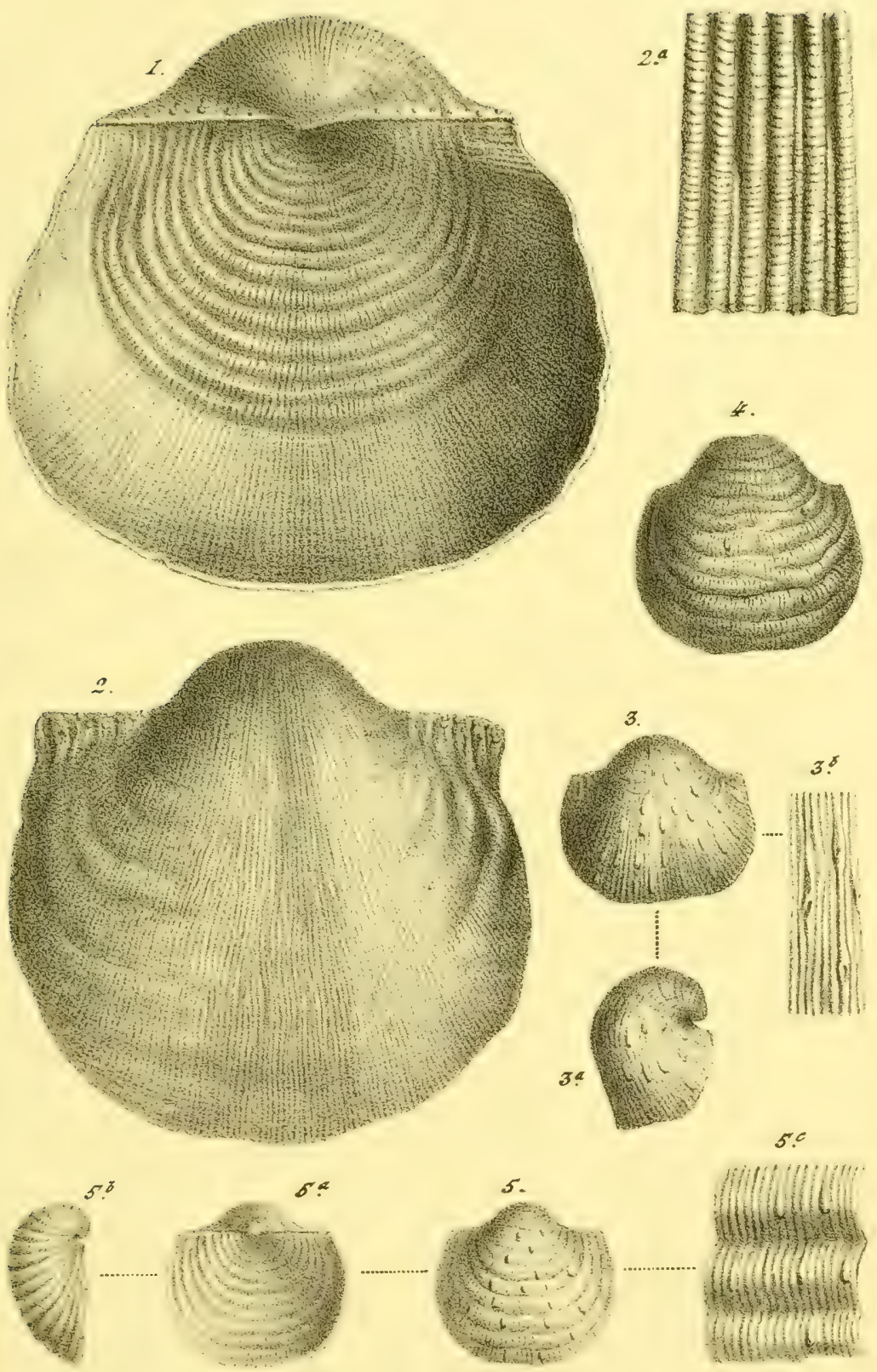




\title{
CARBONÍFERO
}

\author{
Lì. 14
}

Fins

1 Productus sixultus, Kon. [320]

1 a El mismo visto por la valva opuesta.

2 Pronuctus proboscideus, Vern. [323]

2 a El mismo visto lateralmente.

:3 Prodectus enminens, Kon. [324]

1 Productus Aculeitus, Martin. [325]

i) Productes pustulosus, Phill. [326]

(i) Productes sciminculus, Mart. [327]

ff a El mismo visto por la valva opuesta.

- Interior de la valva dorsal de la misma especie.

$\therefore \quad$ Seccion transversal de la misma 

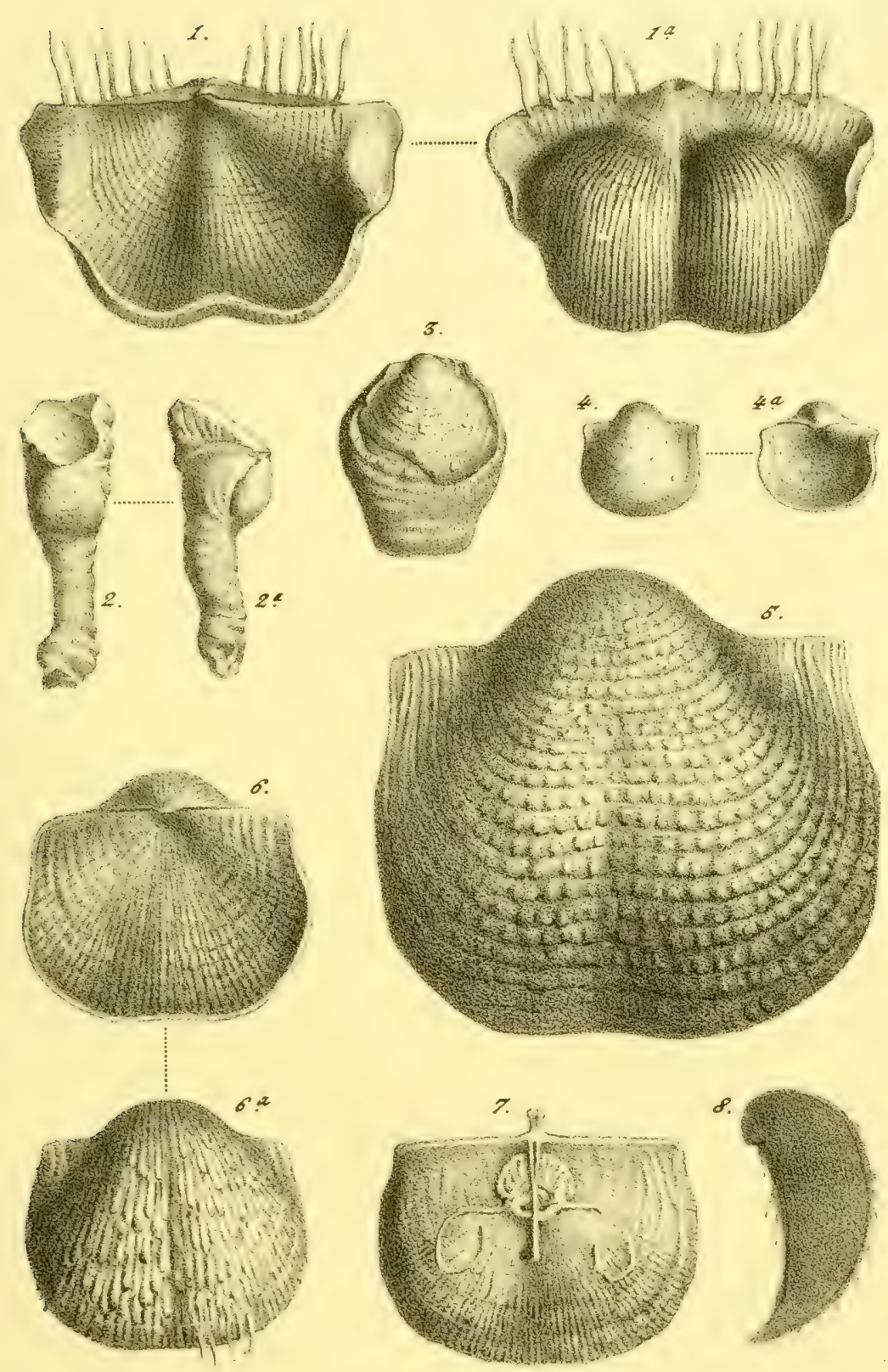




\title{
CARBONÍFERO
}

\author{
L.i.ir. 15
}

liins:

1 Productus Fumiats, Sow. [328]

I" La misma especie vista lateralmente.

11, La misma vista por lá valva mayor.

: Prodectus pugatatus, Martia. (sp). [329]

$\because \because$ El mismo visto lateralmente.

:) Var. de la misma especie.

1 Chonetrs H.tromexsis, Phill. [330]

!" La misma especie vista por la vaiva mayor.

11. Seccion trasversal de la misma.

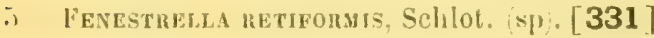

¿il lumento de la misma.

(i) Chetetes raduns, Fischer. [333]

fi" tumento de la misma.

i Fusulina grindica, Fischer. [335]

it Aumento de la misma, dejando ver en su interior las láminas concéntricas.

SINÓPSIS PALEONTOLÓGICA DE ESPAỸ 

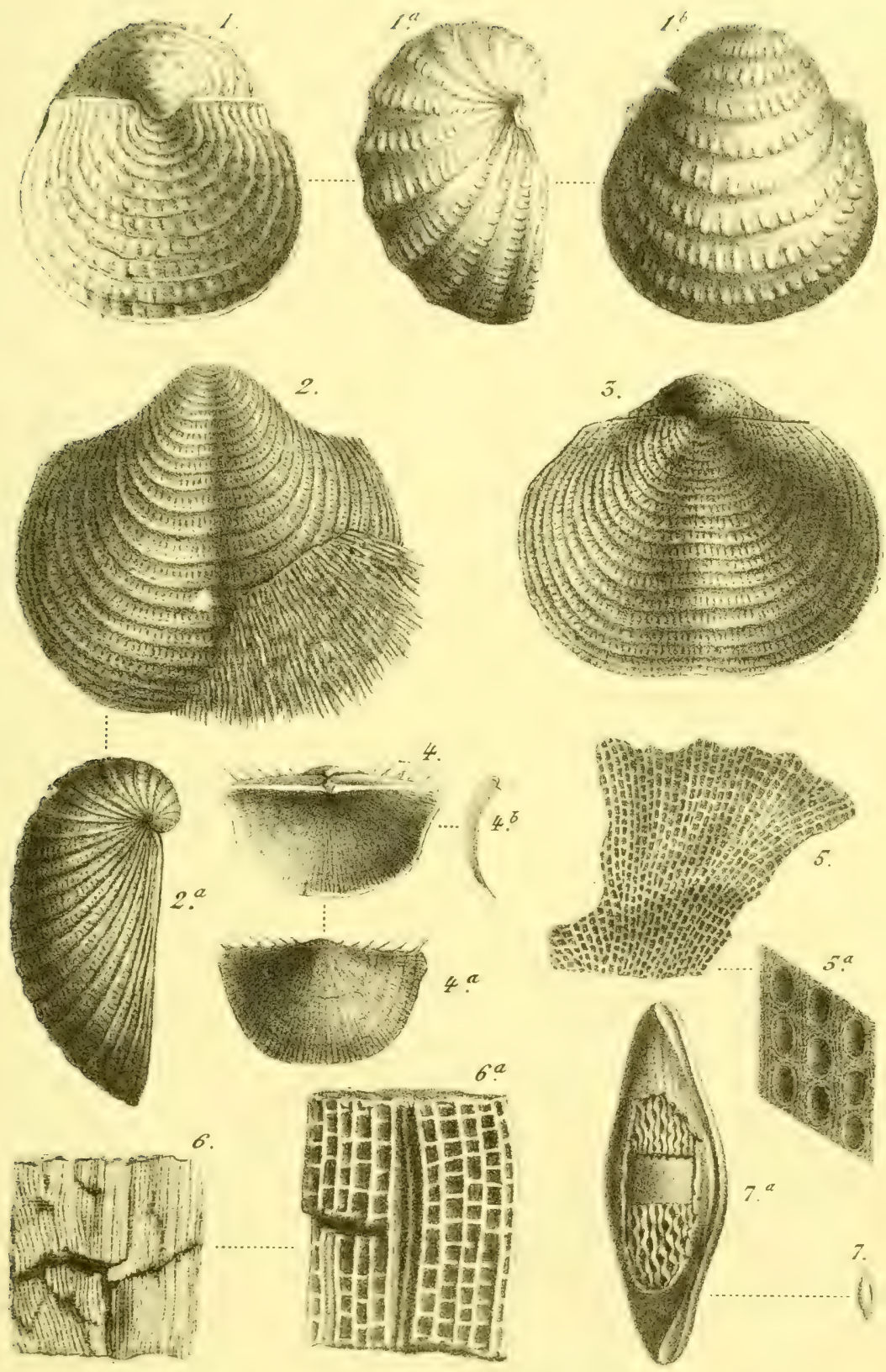

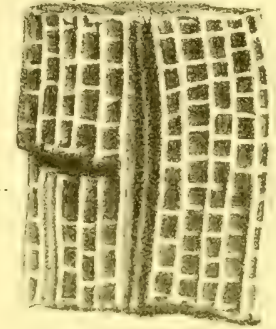






\title{
CARBONIFERO
}

\author{
L.ẢM. 16
}

Fis.

1 CAlintes Sickowi, Brong. [339]

2 Costillas de la misma especie algo aumentadas.

;) Costillas de una variedad de la misma muy aumentadas.

t Costillas de otra variedad muy aumentadas.

SINópsis PALENTOLOGICA DE ESPAÑ 


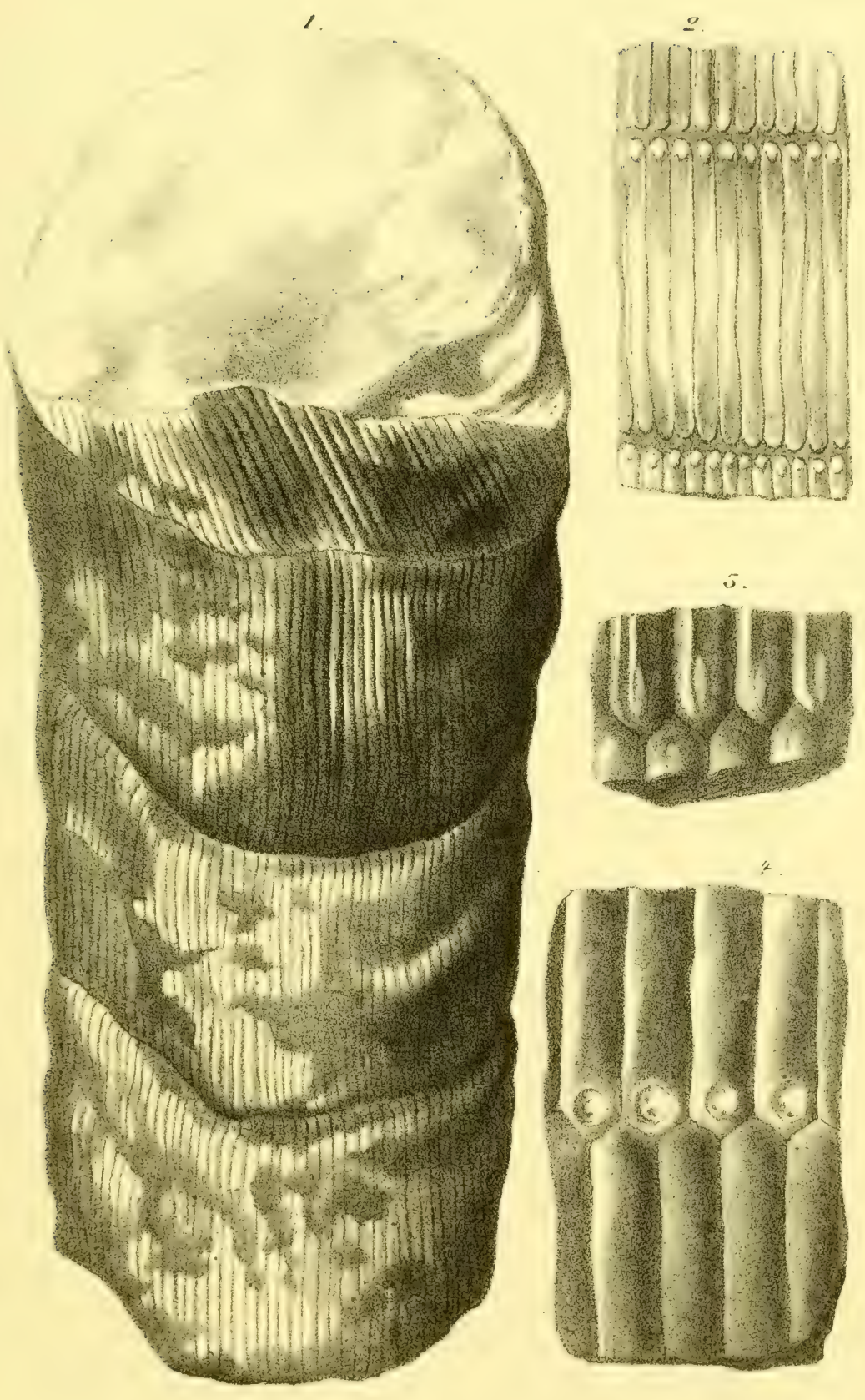






\title{
CARBONÍFERO
}

\author{
LÁM. 17
}

Figs.

1 Cilimites cistif, Brong. [340]

1 a Costillas aumentadas de la misma especie.

2 Cilmates dubius, Artis. [341]

$2 a$ Costillas aumentadas de la misma especie. 

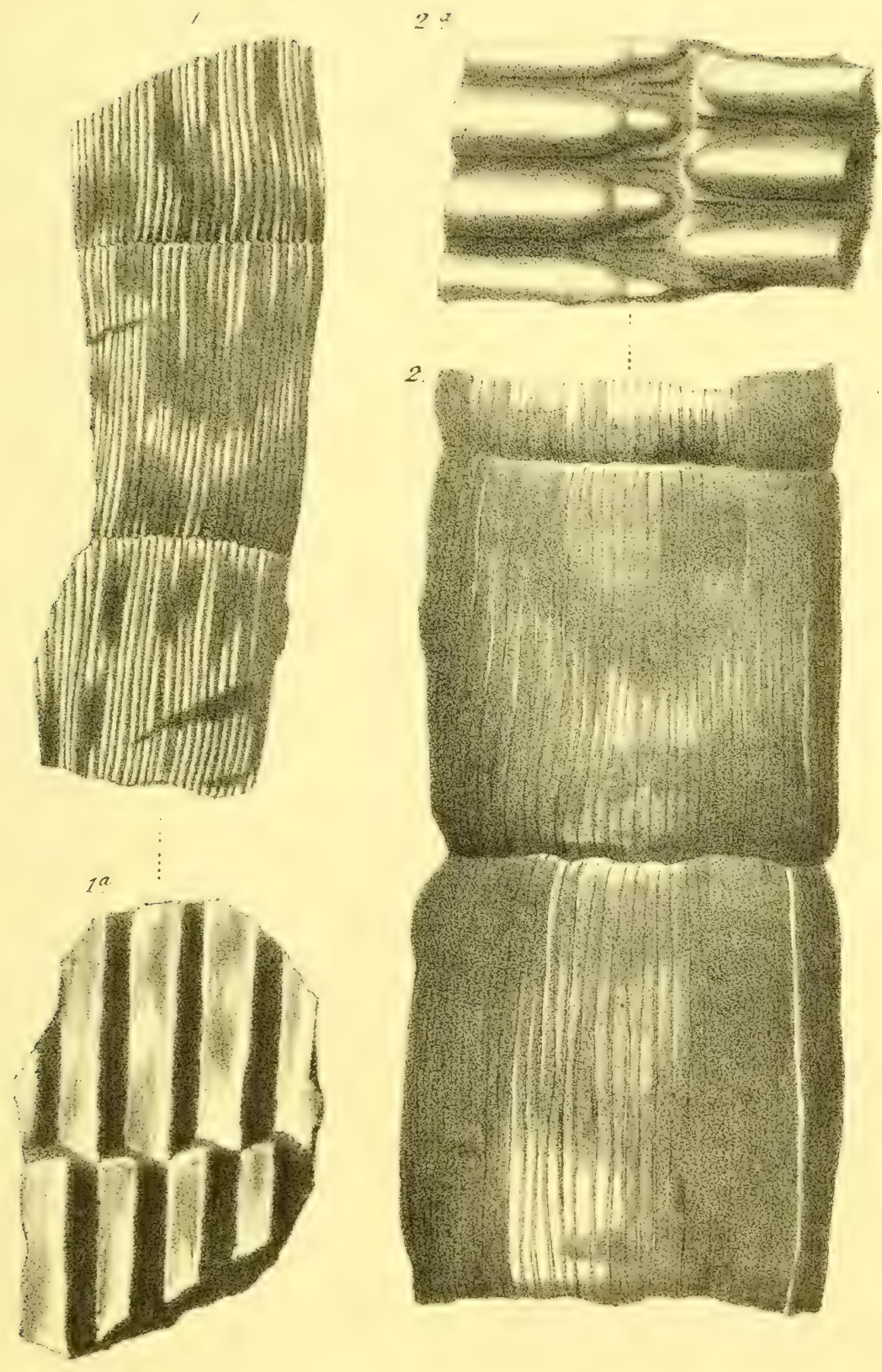




\title{
CARBONIFERO
}

\author{
LẢN. 18
}

Figs.

1 C.MAMITES GMVEFonvis, Schlot. [343]

2 Calamites approximates, Schlot. [342]

3 Calsmites scckow, Brong., variedad C. undulalus, Stern. 


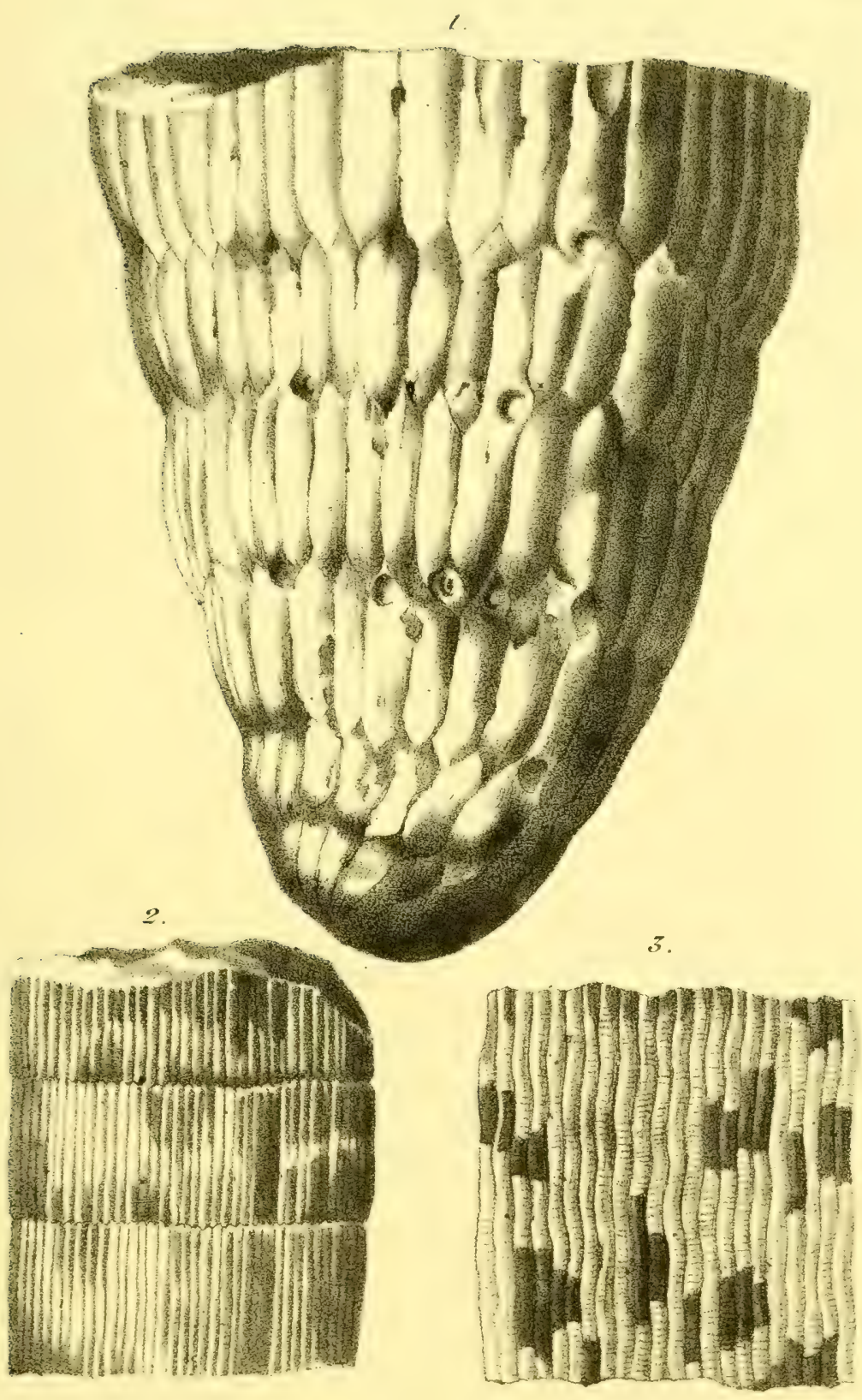






\title{
CARBONIFERO
}

\author{
LÁM. 19
}

Figs.

1 Calamociadus longifolius, Bron. (sp) . [345]

2 Calamochadus equisetifonmis, Schlot. (sp). [346]

3 Calanocuadus gimands, Sternb. (sp.). [347]

4 Microstachy infundibulfanms, Bron. (sp). [349] 


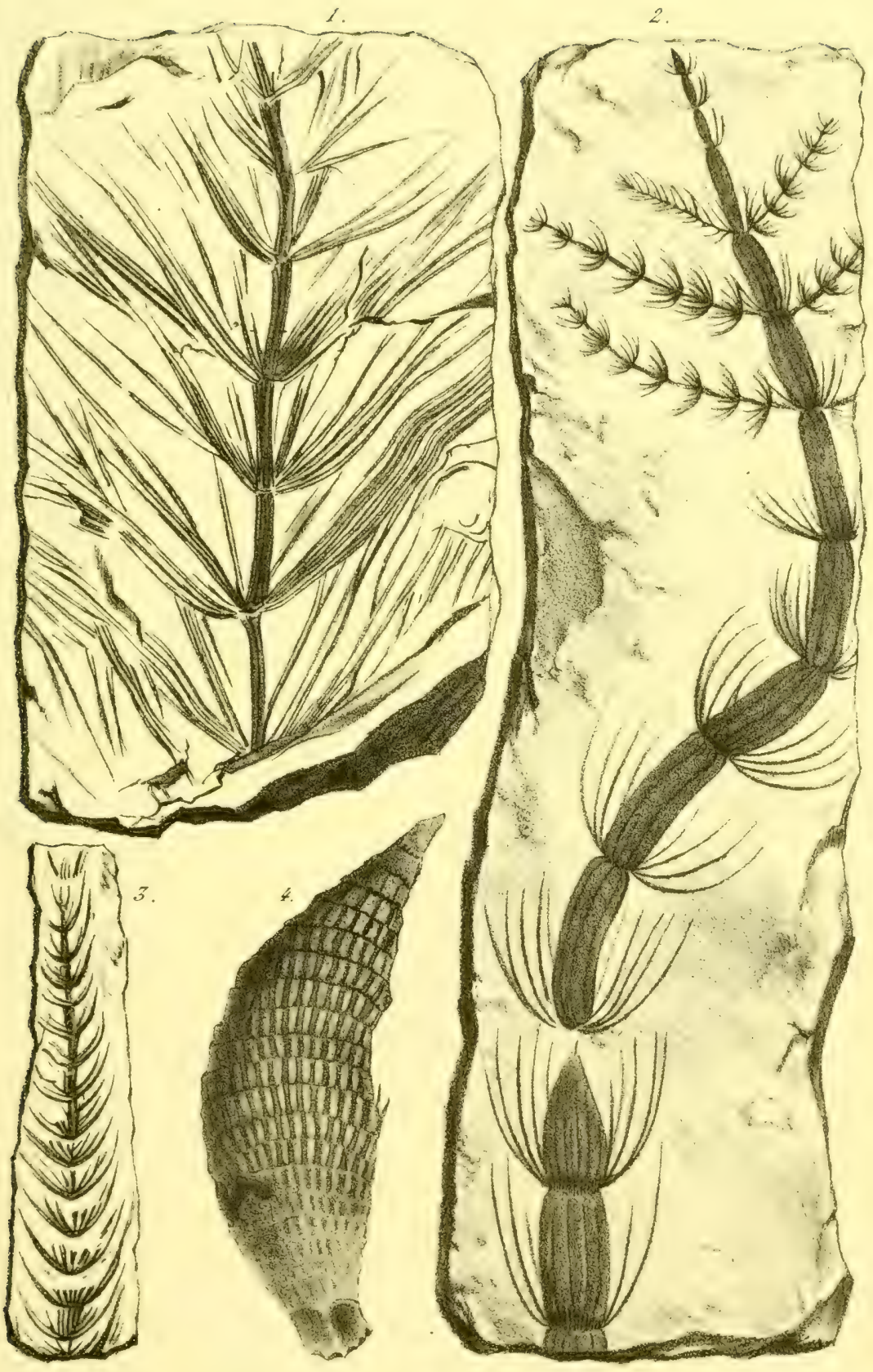






\title{
CARBONÍFERO
}

\author{
Lí.II. 2)
}

Figs.

1 Sphenomiyllum Schlothemim, Brong. [350]

2 Hoja de la misma especie.

3 Annuliria spiexopiylloides, Zenk. (sp.) [354]

4 Sphenophylum emarginatum, Brong. [351]

5 La misma especie, var. Bronginatiayum.

6 Hoja aumentada de esta variedad.

7 Hoja aumentada de Sphenopiyluum erosum, Lind. et IIutt. [352]

8 Hoja de la misma especie tomada á otra altura del tallo.

9) Idem id.

10 Annularia lovgrfolit, Brong. [355]

11 Variedad de la misma especie. 


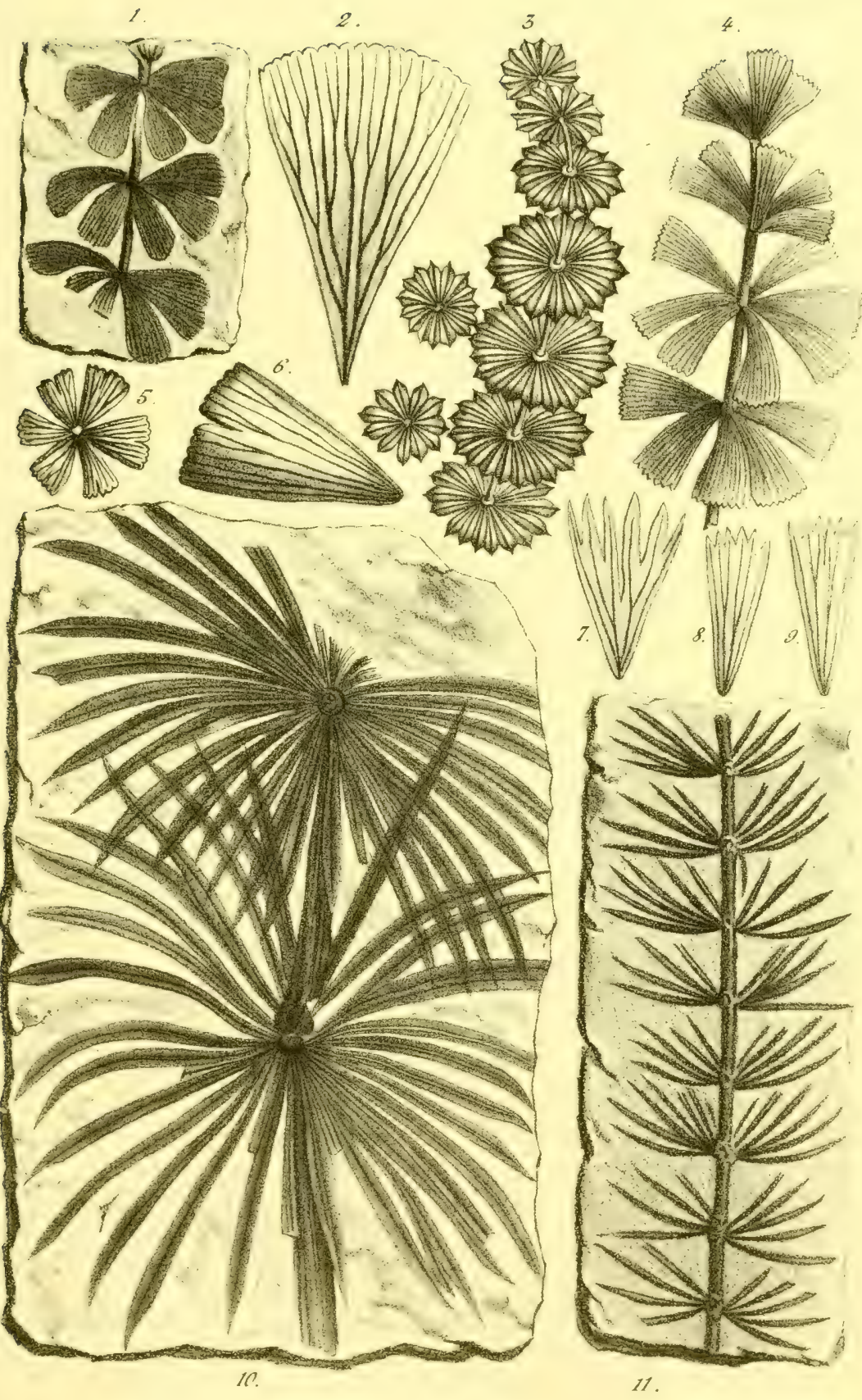






\title{
CARBONÍFERO
}

\author{
LÁNI: 21
}

Figs.

1 Sphenopteris trifoliti, Brong. [357]

2 Sphenopteits tridatilutes, Brong. [358]

$2 a$ Pínula de la misma especie, muy aumentada.

3 Sphexopteris latiolia, Brong. [361]

4 Sphexopteris tenufolis, Brong. [360] 

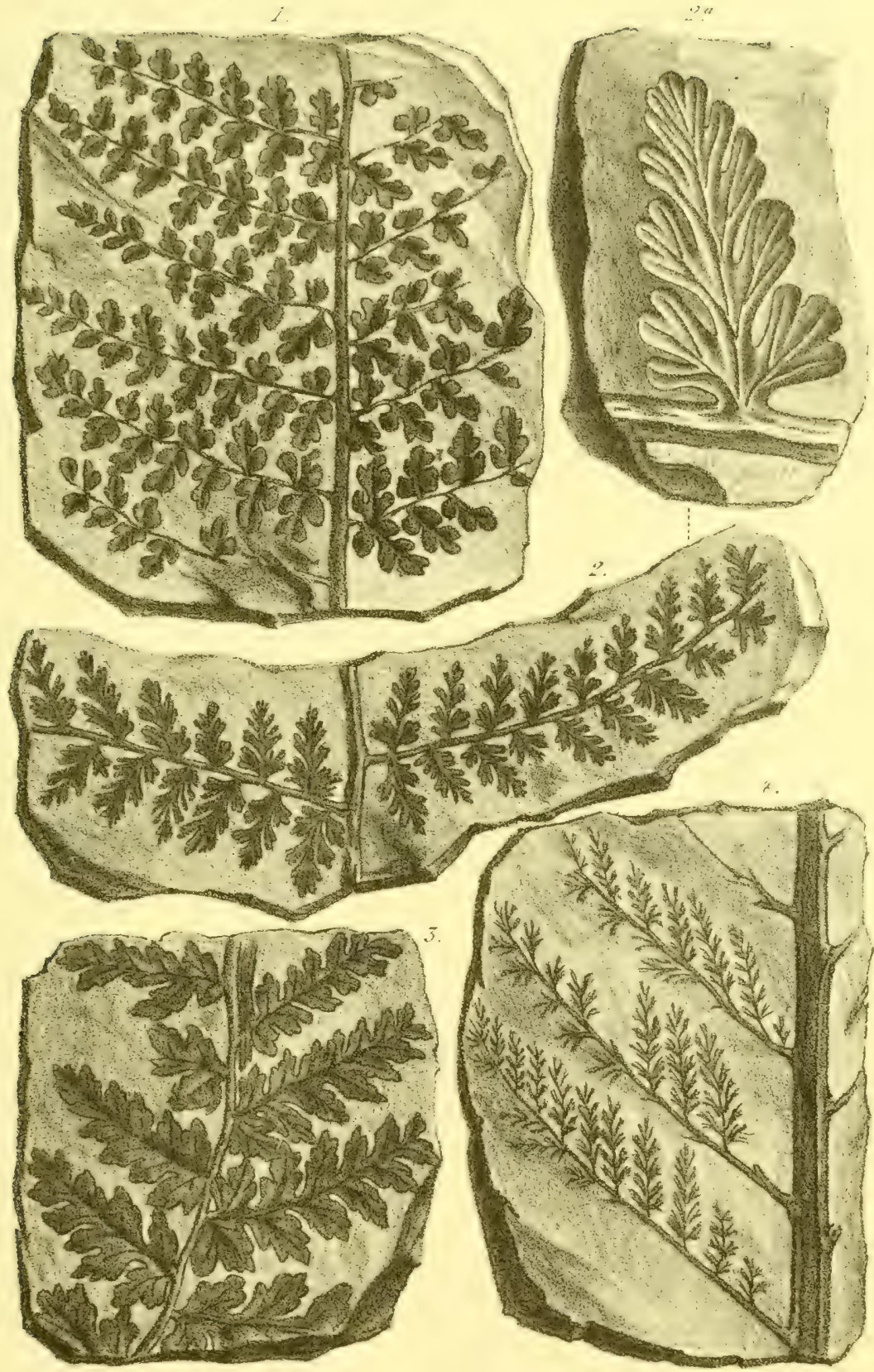




\title{
CARBONIFERO
}

\author{
LẢM. 22
}

Yins.

1 Neunopteris Scineuchzeri, Hoffm. [365]

2 Neunoptenis icutifolia, Brong. [364]

3 Neunopteris flexuosa, Sternb. [366]

4 Píuulas de la misma, aumentadas.

5 Neuropteris gigantea, Sternt. [367] 


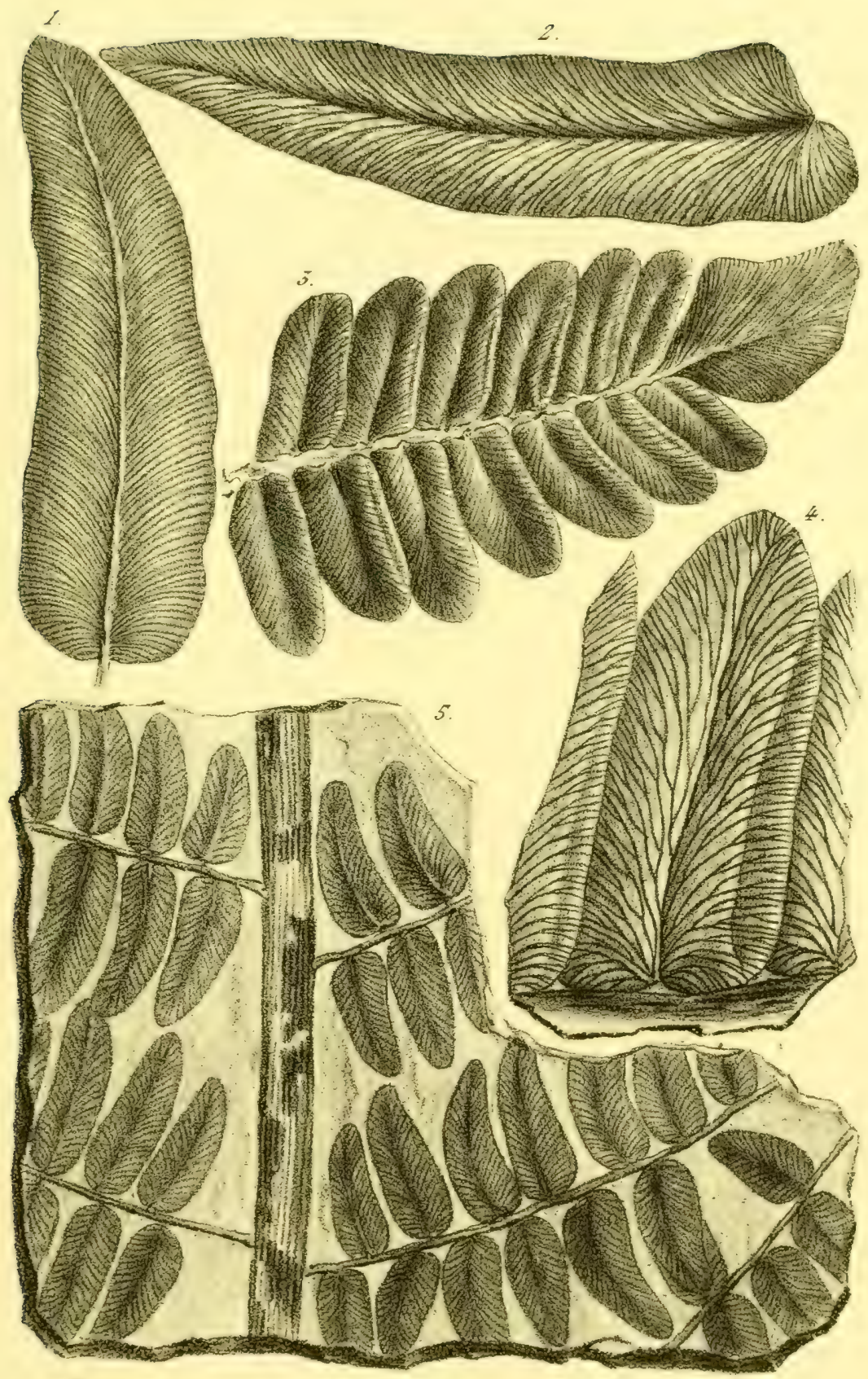






\title{
CARBONIFERO
}

\author{
LÁM. 23
}

Firs.

1 Crclopteris trichomanoides, Brong. [362]

2 Nevropteris heterophyla, Brong. [369]

3 Pena de la misma especie; aumentada.

4 Neunopteris loshit, Brong. [268]

5 Pena de la misma especie, aumentada.

6 Neuropteris grangeri, Brong. [370] 


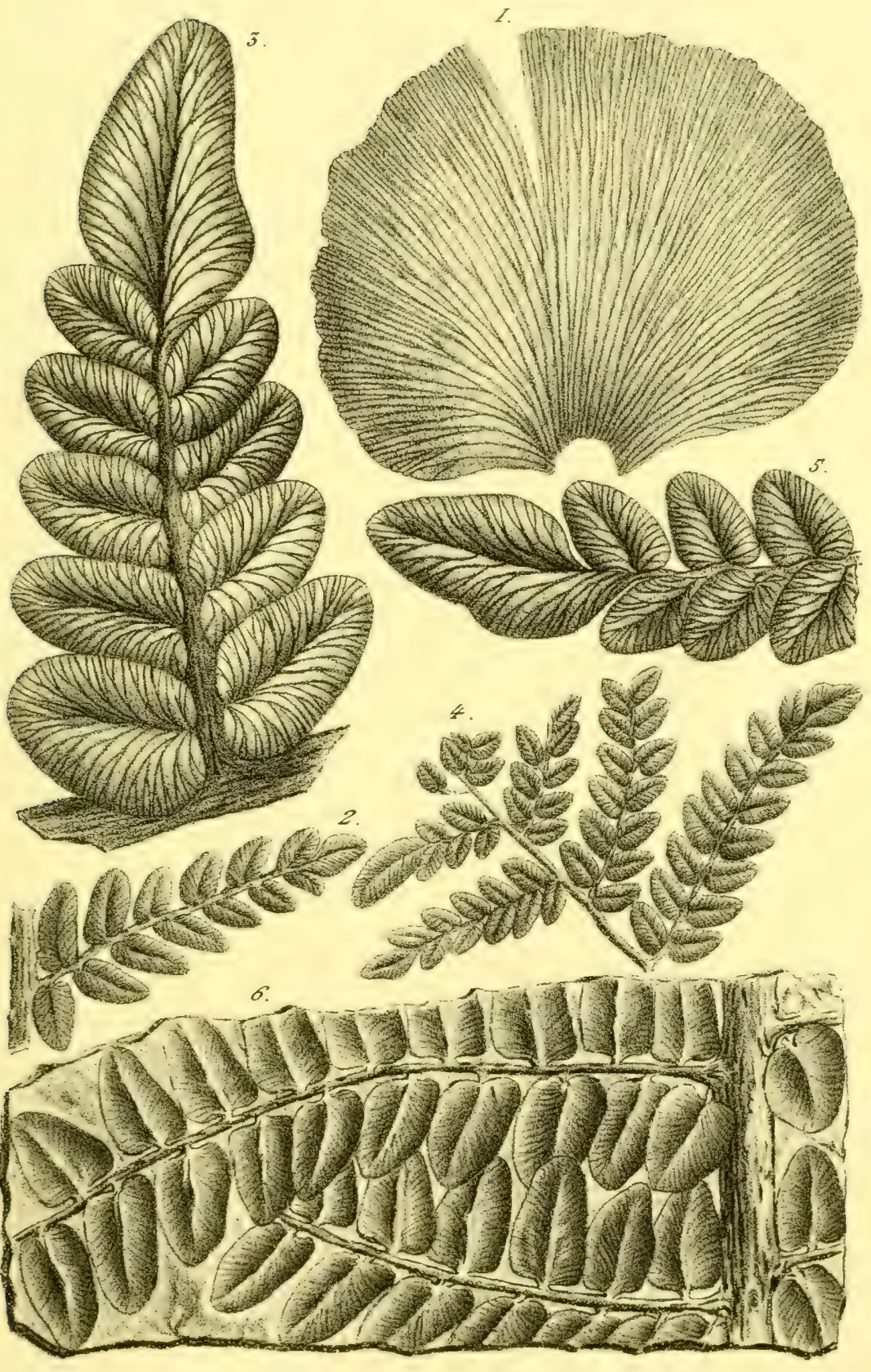






\title{
CARBONÍFERO
}

\author{
I.ÁM. 24
}

Figs.

1 Pecoptenis anbonesgens, Schlot. [374]

2 P'ínulas de la misma especie, aumentadas.

3 Otro aumento de las mismas.

4 Pegopteris oropteridi, Schlot (sp.) [375].

5 Pínula aumentada de la misma.

6 Pegopteris Annorescers, Schlot. (Var. P. cyathea, Brong.) 


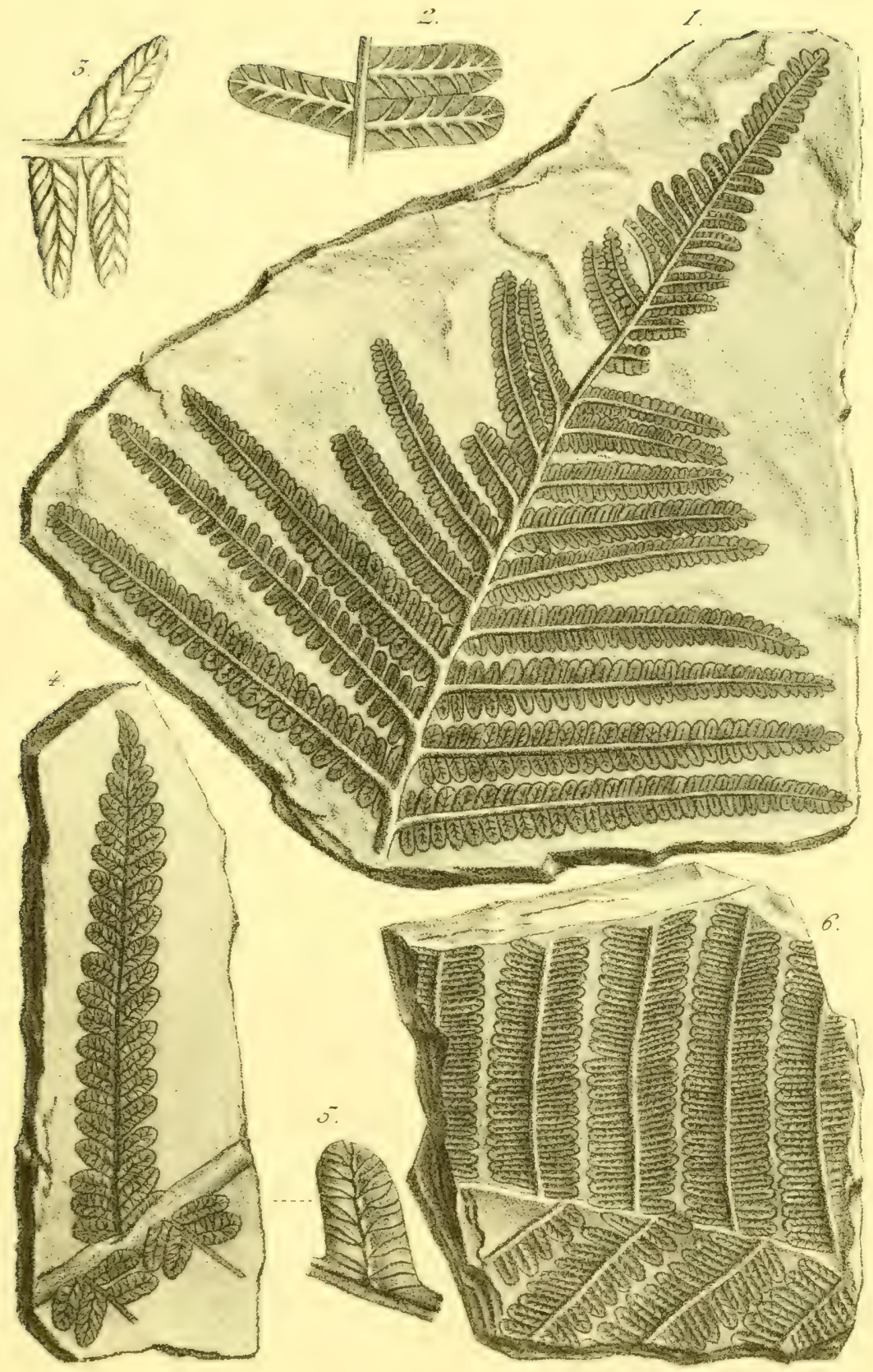






\title{
CARBONÍFERO
}

\author{
LÁM. 25
}

Figs.

1 Pecoptenis nüGklandi, Brong. [376]

2 Pínula de la misma especie, aumentada.

3 Pecopteris ptenoides, Brong. [377]

4 Pínula aumentada de la misma. 


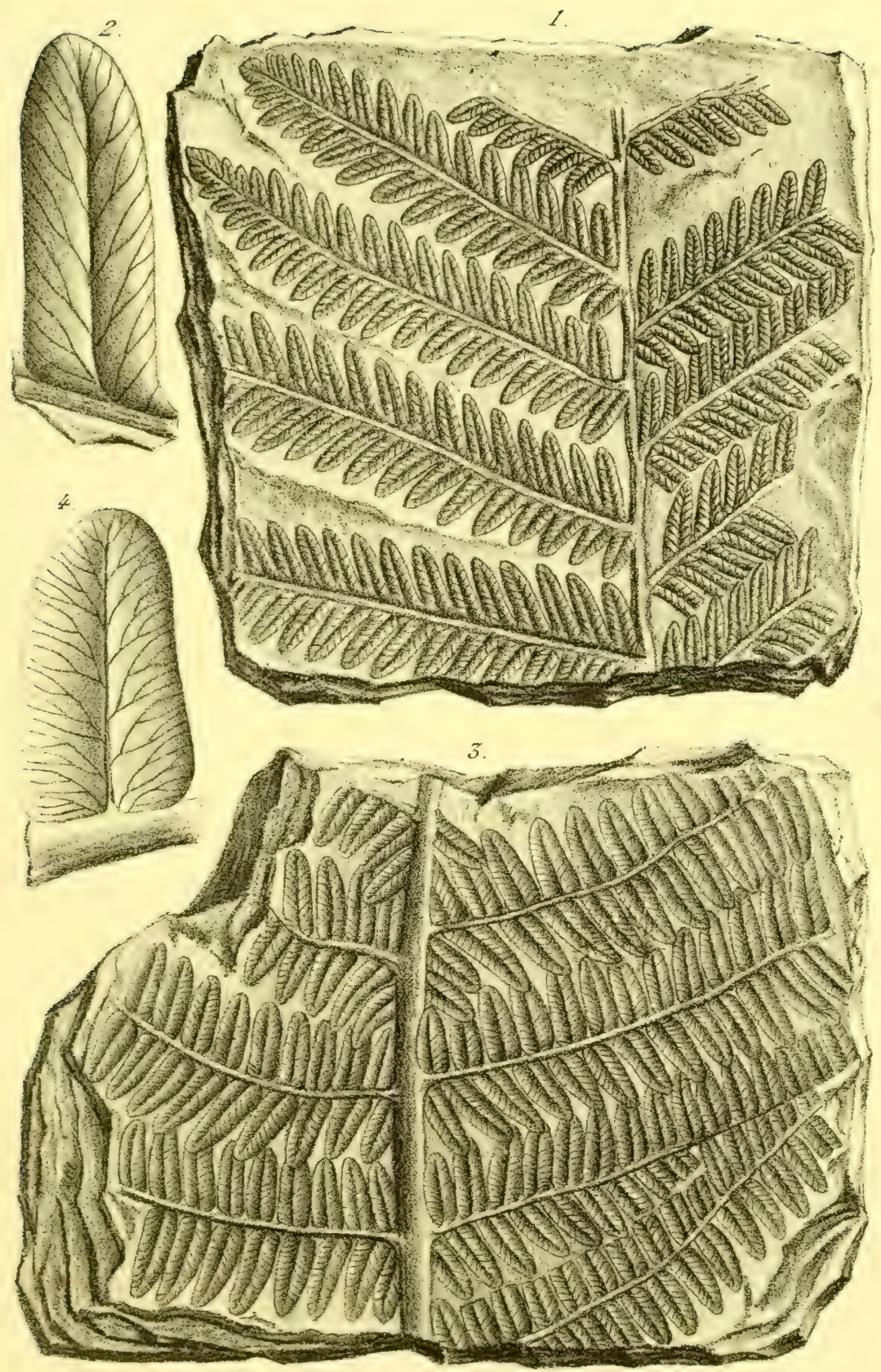






\title{
CARBONÍFERO
}

\author{
LÁM. 26
}

Figs.

1 Pecopteris penxefonmis, Brong. [378]

2 Aumento de sus pínulas.

3 Pecoptenis unita, Brong [379]

4 A umento de sus pínulas.

5 Pecoptenis Miltoxi, Artis. (sp.) [ 380 ]

6 l’íuula aumentada de la misma especie.

7 l'ena superior de la misma especie. 


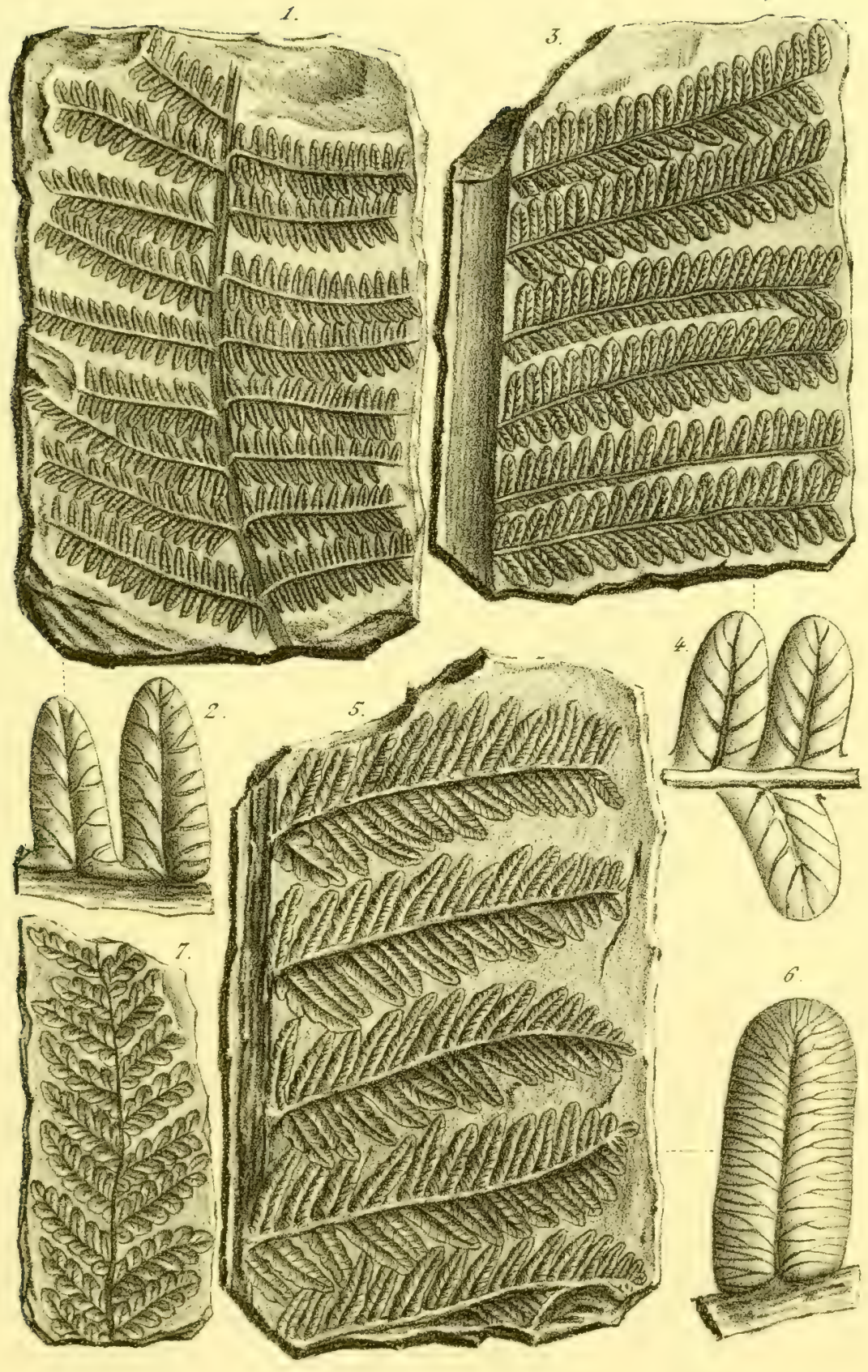






\title{
CARBONIFERO
}

\author{
LÁM. 27
}

\begin{abstract}
Figs.
1 Pegopteris defrangir, Brong. [382]

2 Otro ejemplar de la misma especie.

3 Pínulas aumentadas de la misma.

4 Pegopteris angustissma, Brong. [386]

5 Pegopteris nemiteloides, Brong. [384]

6 Pínula aumentada de la misma especie.

i Goniopteris arguta, Brong. (sp.) [389]

8 Pínula de la misma especie aumentada.
\end{abstract}




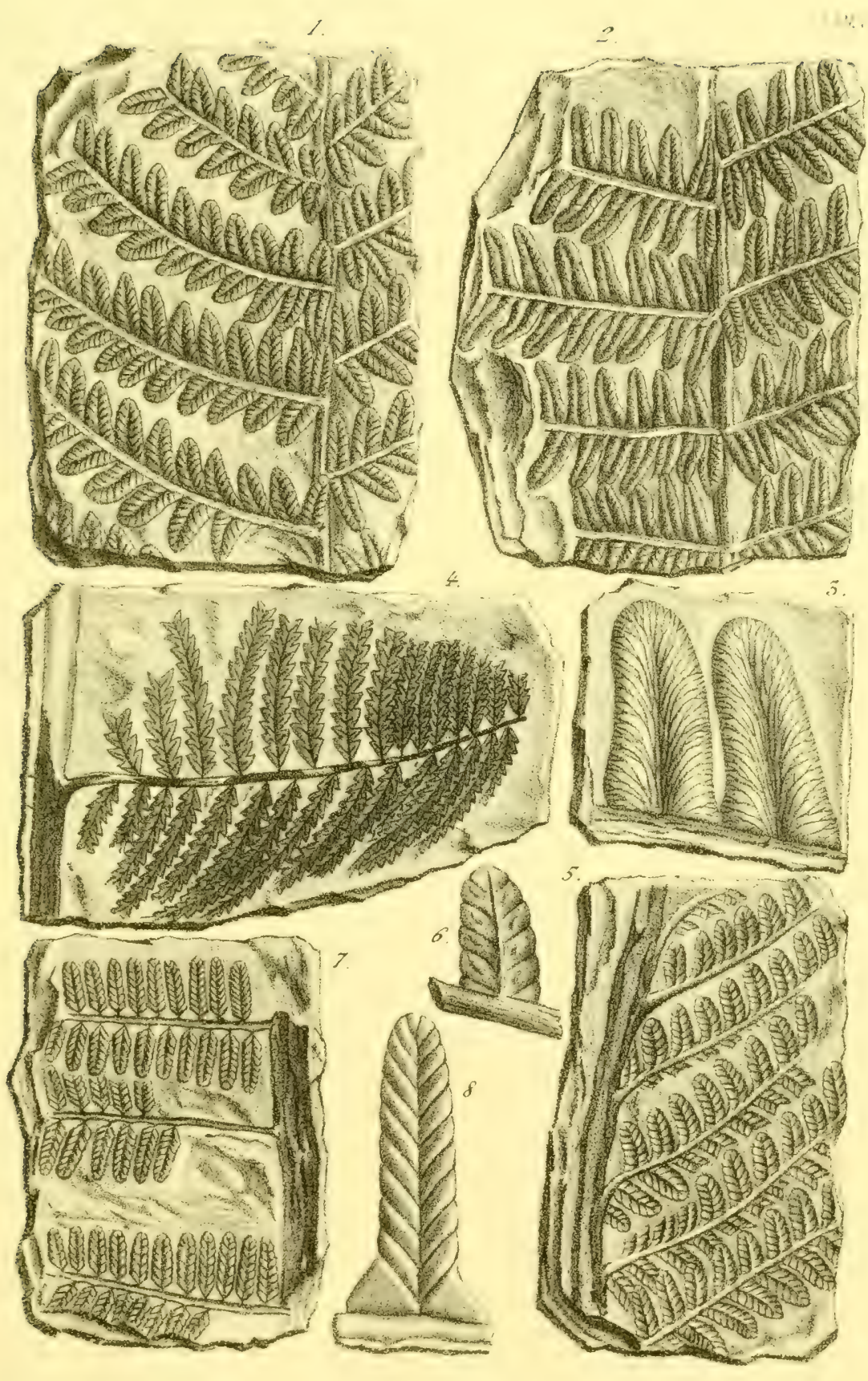






\title{
CARBONÍFERO
}

\author{
LÁM. 28
}

Figs.

1 Pecopteris Pluckeneti, Schlot. [383]

1 a l'ínulas superiores aumentadas.

1b Pínulas inferiores aumentadas.

2 Variedad de la misma especie.

3 Otra variedad de la misma.

4 Pecoptents nenvosa, Brong. [385] 
2
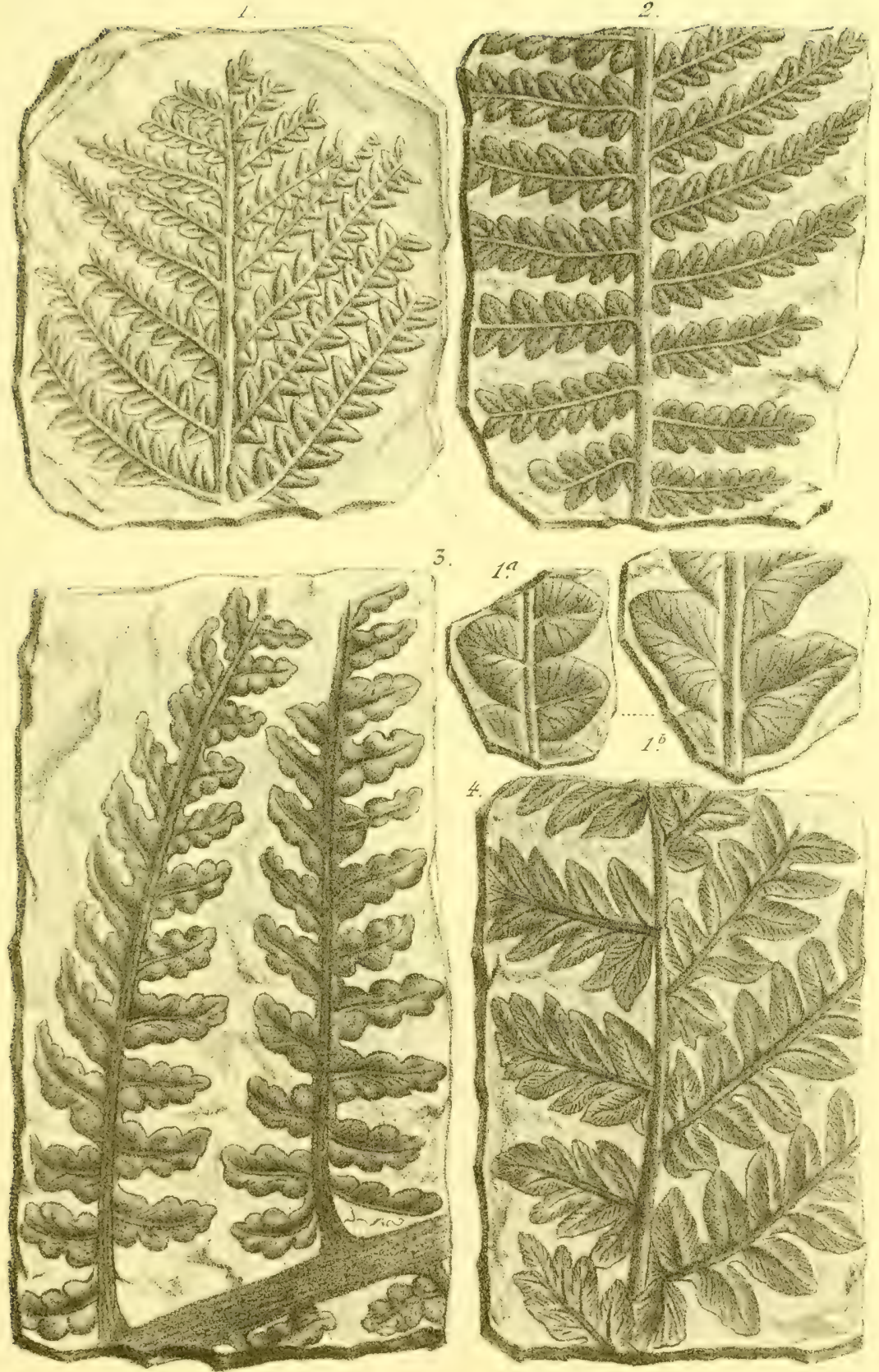




\title{
CARBONÍFERO
}

\author{
LẢM. 29
}

Figs.

I Alethoptenis loxaitica, Brong. (sp.) [390 ]

2 Aumento de sus pínulas.

3 Variedad P. Mantelli, Brong, de la misma especie.

4 Variedad $P$. Davreuxii, Brong de la misma.

5) Alethopteris serli, Brong. [391]

6 Pinula aumentada de la misma especie.

7 Idem más aumentada. 


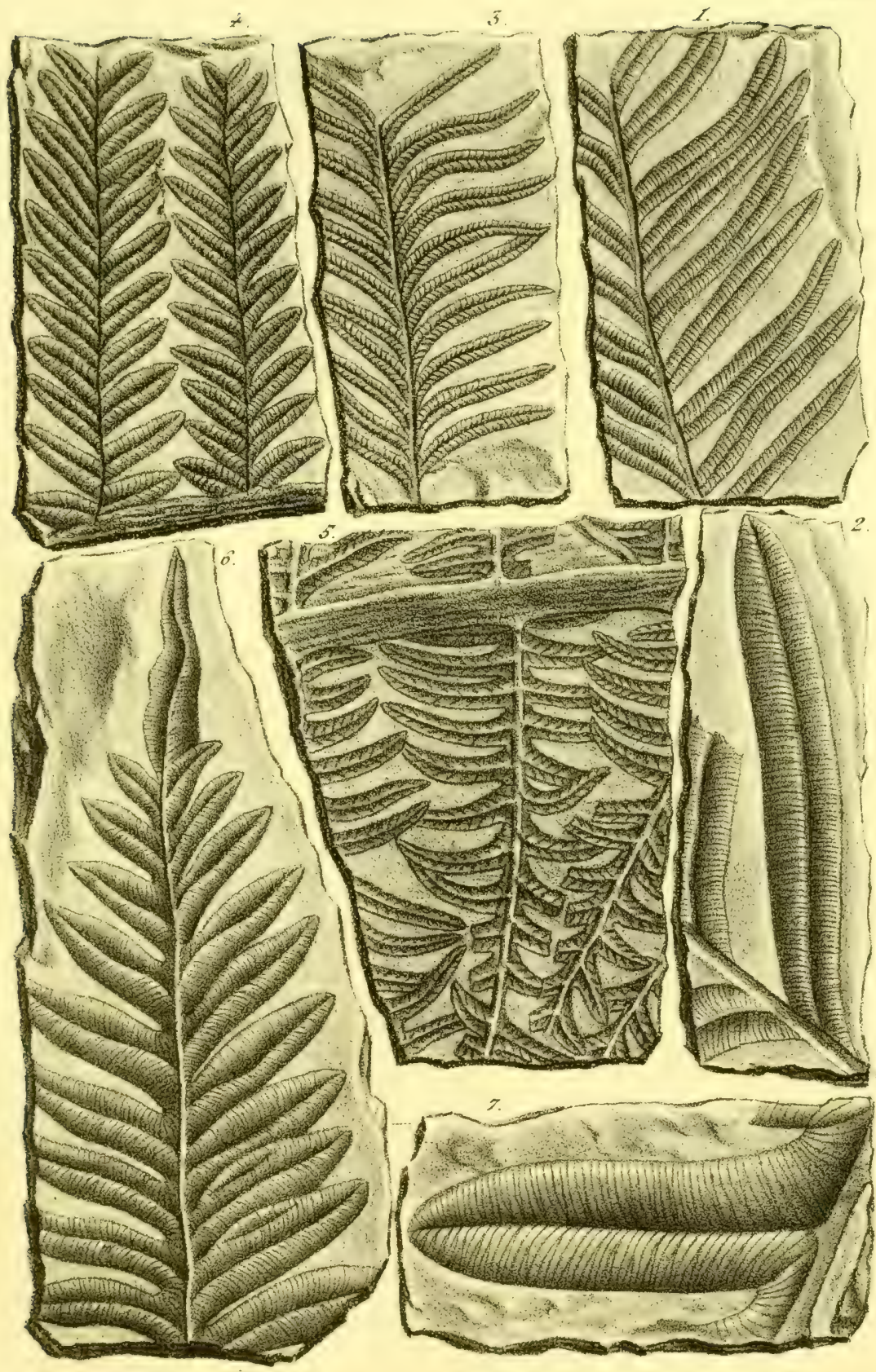






\title{
CARBONIEERO
}

\author{
LÁM. 30
}

\section{Figs.}

1 Alethoptenis aquilina, Schlot. (sp.) [ 392 ]

2 Aumento de sus pínulas.

3 Alethopteris gr.indini, Brong. (sp.) [393] 

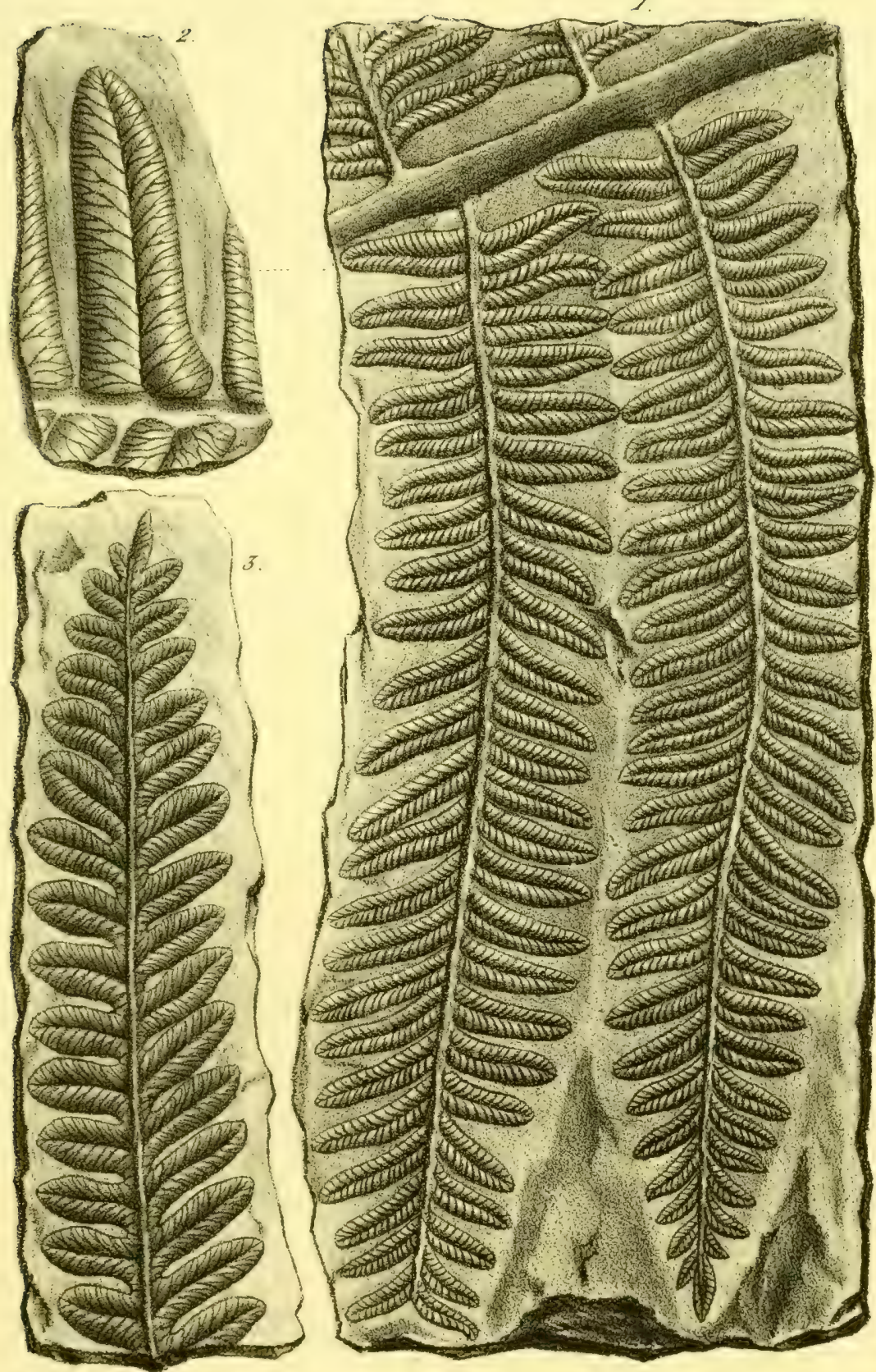




\title{
CARBONÍFERO
}

\author{
LÅM. 31
}

Nigs.

1. Siglliaria Sauldi, Brong. [413]

2 Sigiliami Schlotilemixi, Brong. [414]

3 Sigildari pagitomini, Brong. [415]

4 Sigmedria onbicutamis, Brong. [416] 

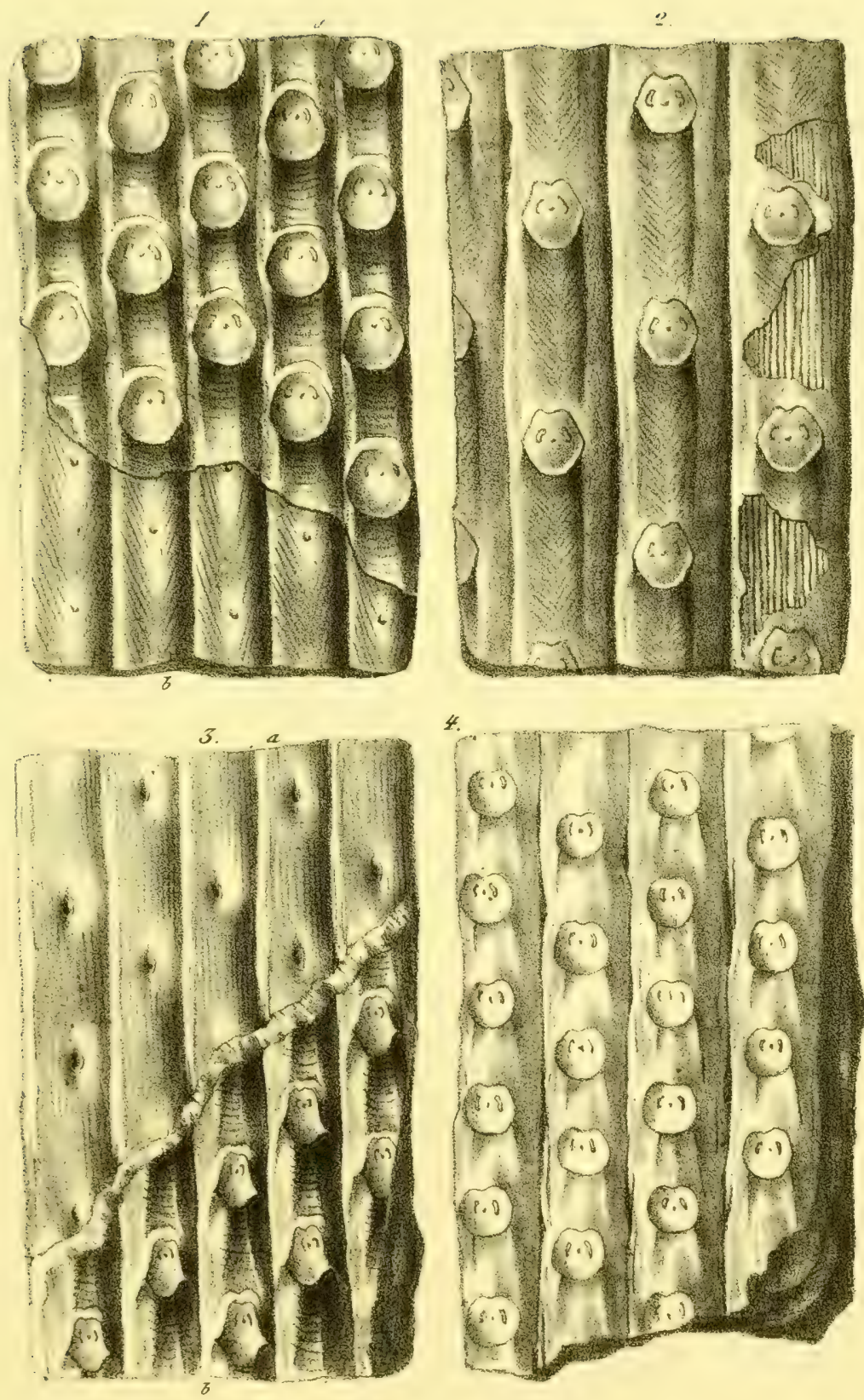




\title{
CARBONIFERO
}

\author{
LÁM. 32
}

Figs.

1 Sigmlaria Contei, Brong. [417]

2 Otro ejemplar de la misma especie.

3 Sigillaria contracta, Brong. [418]

4 Sigildaria elongati, Brong. [419] 

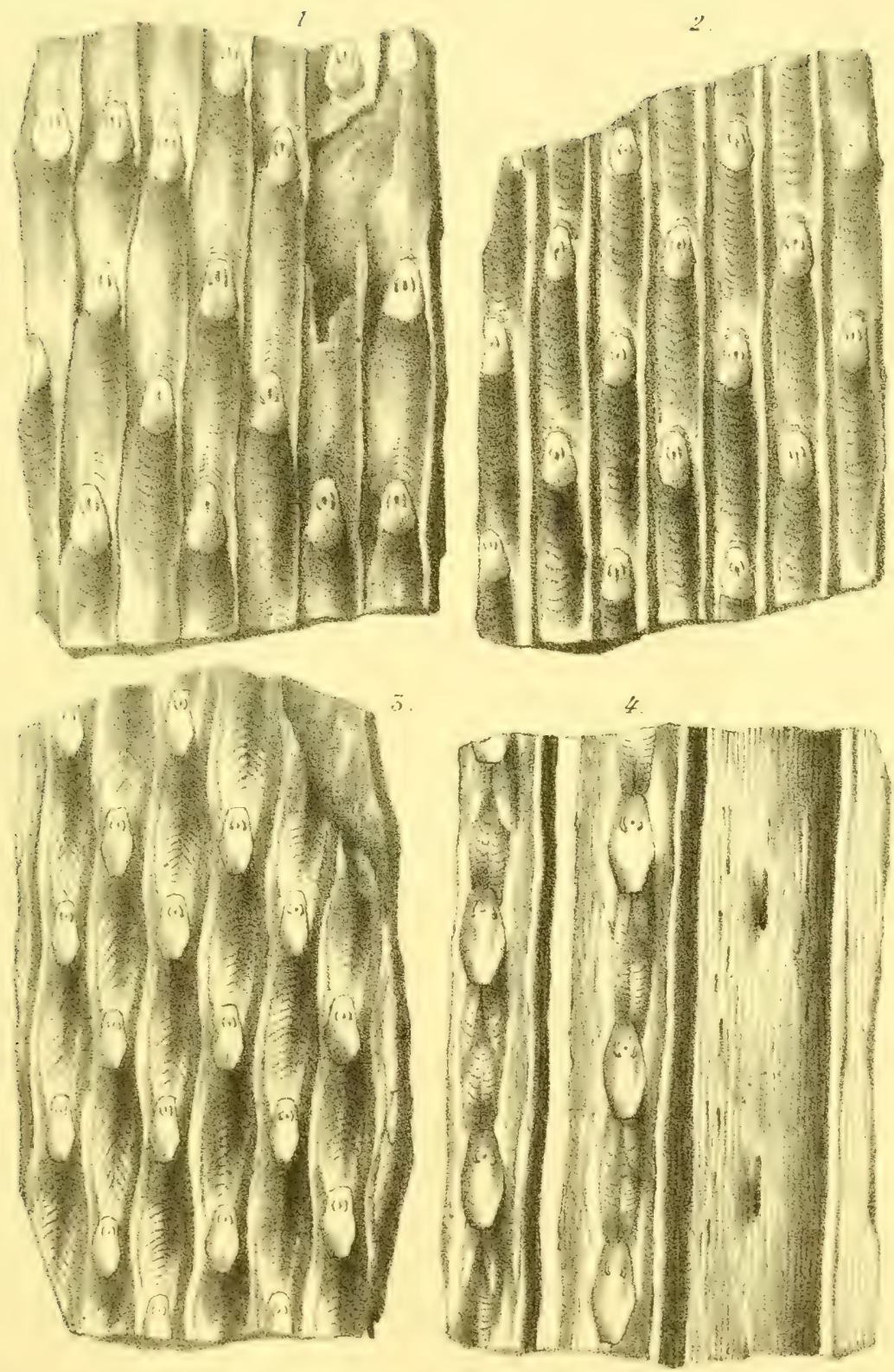




\title{
CARBONÍFERO
}

\author{
LÁM. 33
}

Figs.

1 Sigillaria intermedia, Brong. [420]

2 Sigillarta Broggutarti, Gein. [423]

3 Sighlatili neniformis, Brong. [421] 


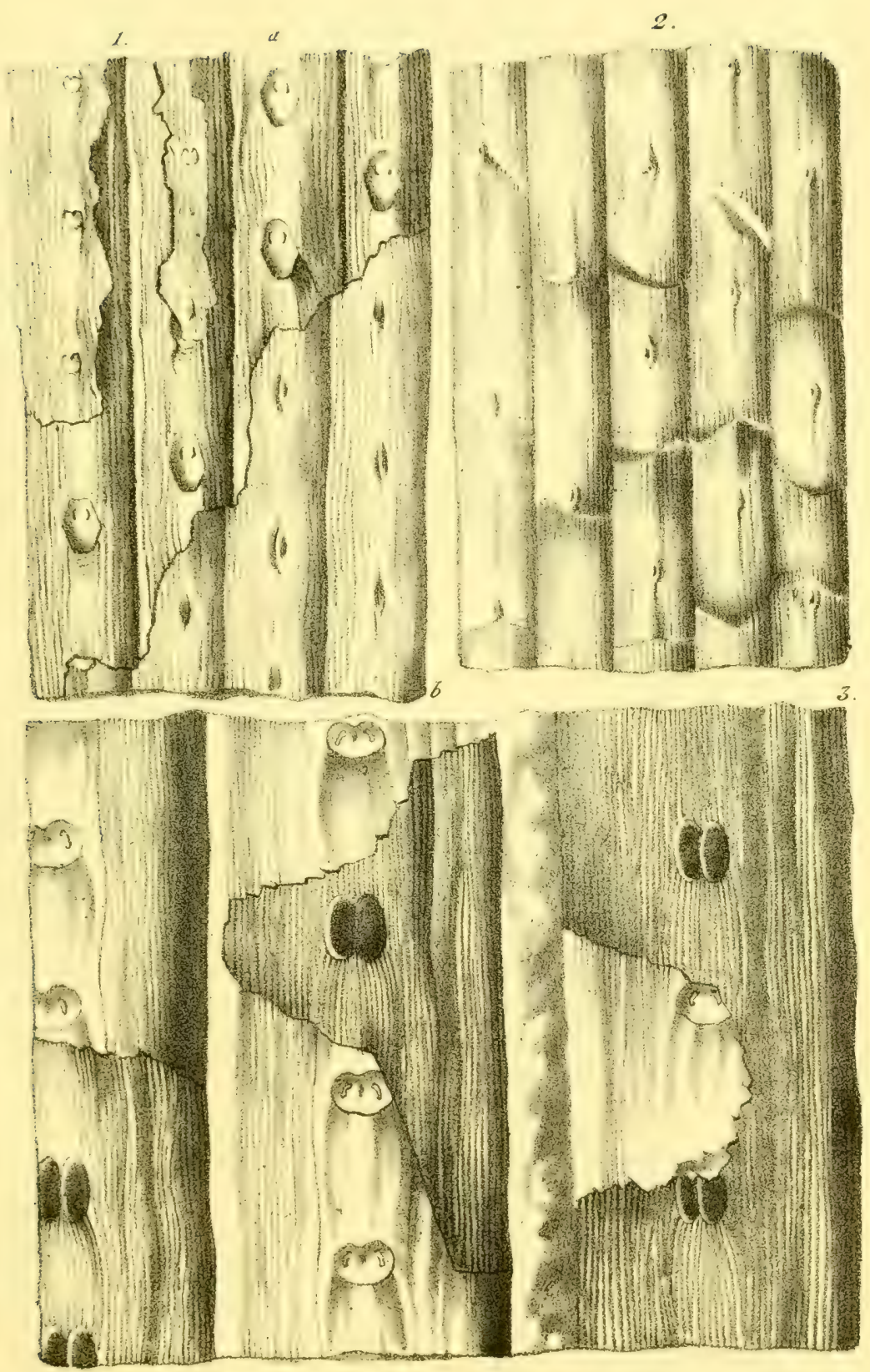






\title{
CARBONIFERO
}

\author{
LÁM. 34
}

Figs.

I Sigillikia tesselitat, Brong. [408] mostrando en $a$ la epidermis con los coginetes y cicatrices foliares, en $b$ la corteza sin epidermis, en $c$ la superficie del tronco, descortezada, sin mostrar más que las cicatrices vasculares.

2 Ejemplar de la misma especie, procedente de Belmez, deformado por presion lateral.

3 Sigiltaria dournaisit, Brong. [409]

4 Sigillakid intermedia, Brong. [420] 

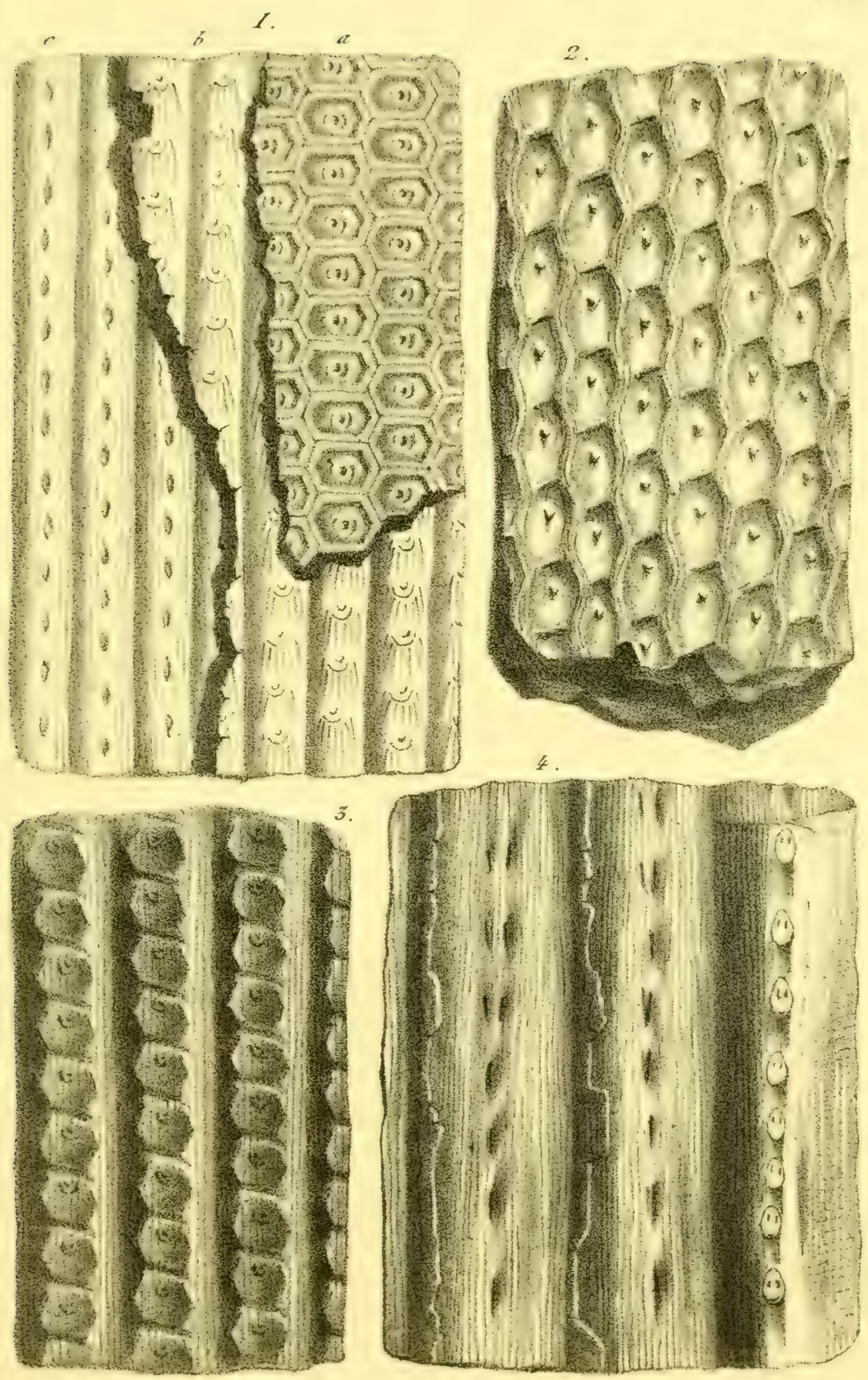




\title{
CARBONÍFERO
}

\author{
LÁM. :35
}

Figs.

1 Sigillania Dounvaisit, Brong. [409]

2 Sigiliaria mamillakis, Brong. [410]

3 Sighlaria Utscheinederi, Brong. [411]

4 Sigillanid eldiptici, Brong. [412] 

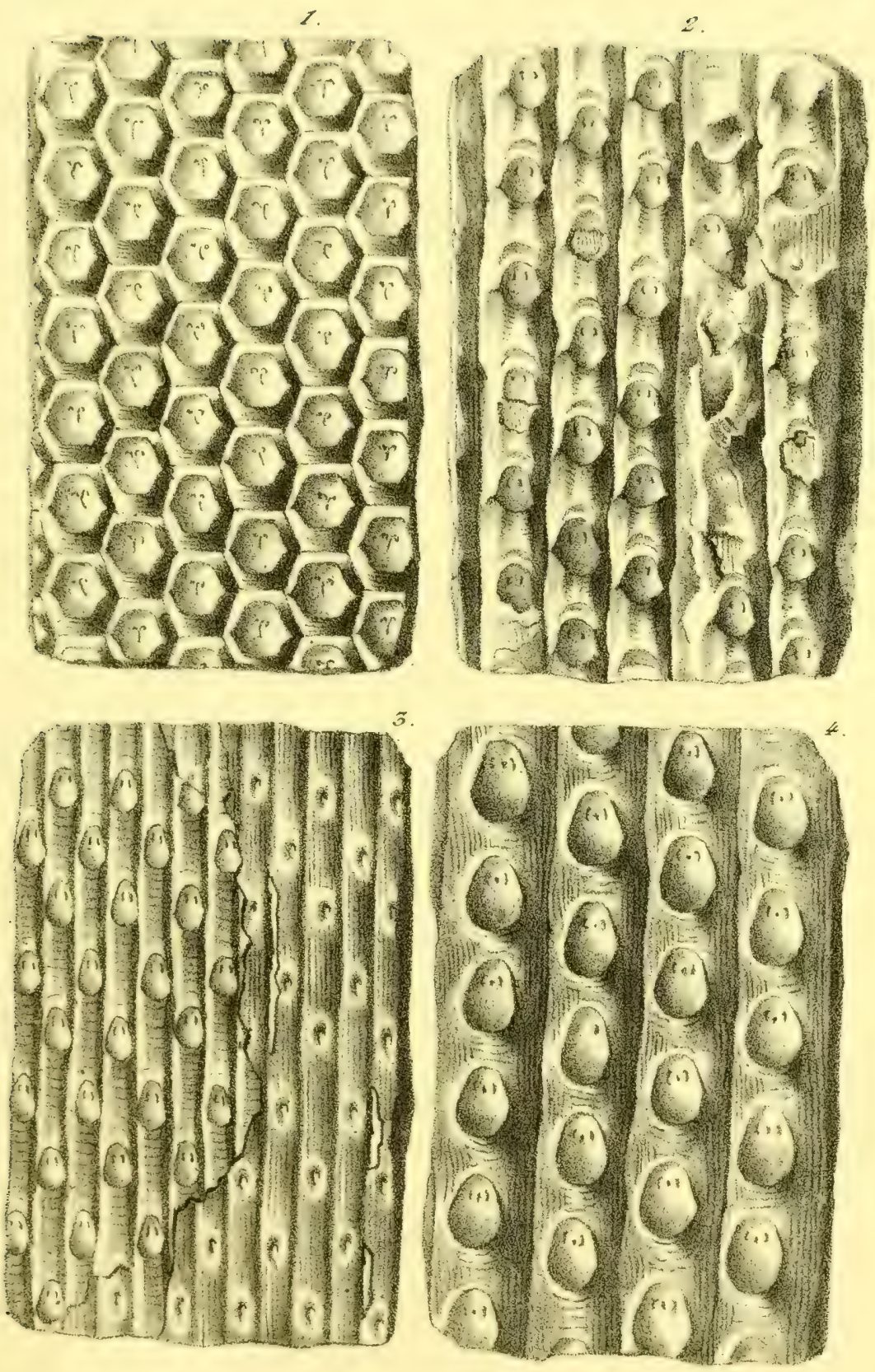




\title{
CARBONÍFERO
}

\author{
LÁM. 36
}

Figs.

1 Lepidodexdrox Sterybergi, Brong. [400]

2 Lepidodeñunon aGuleatum, Stern. [401]

3 Lepinodexdnon loxgifolium, Brong. [402]

4 Lepidodexdron rimosum, Stern. [403] 


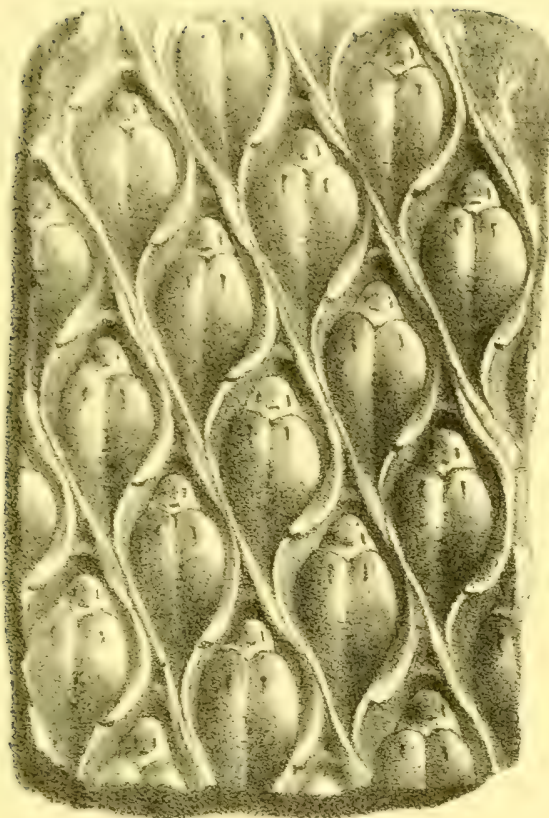

3.
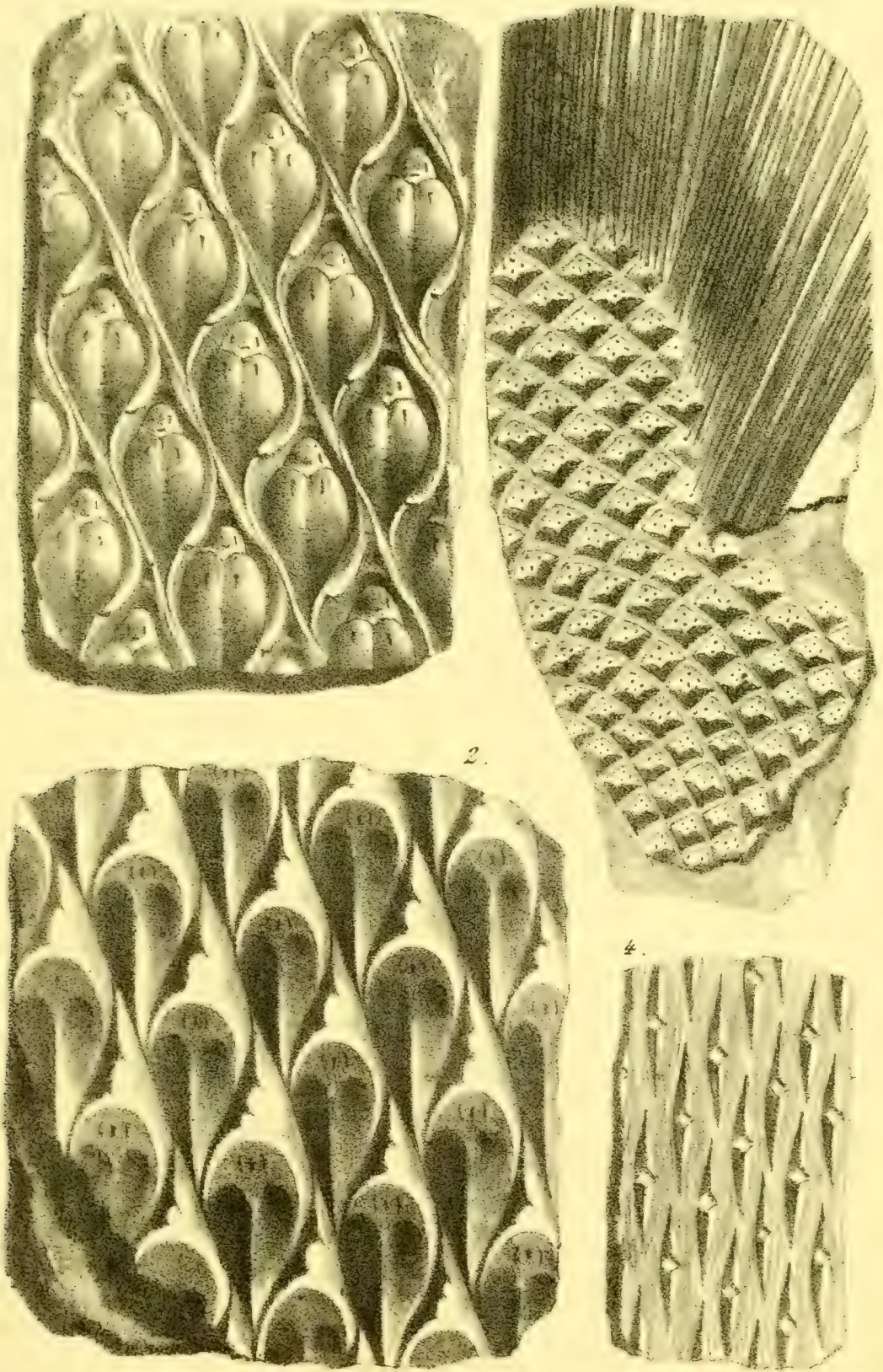




\title{
CARBONÍFERO
}

\author{
LÁง. 37
}

Figs.

1 Kvorria imbricata, Stern. (sp.) [405]

2 Otro ejemplar de la misma especie, con las cicatrices despues de la destruccion parcial de los coginetes foliares.

3 Coginetes foliares de la misma especie.

4 L.epidophloolos lamicinus, Stern. [406] 


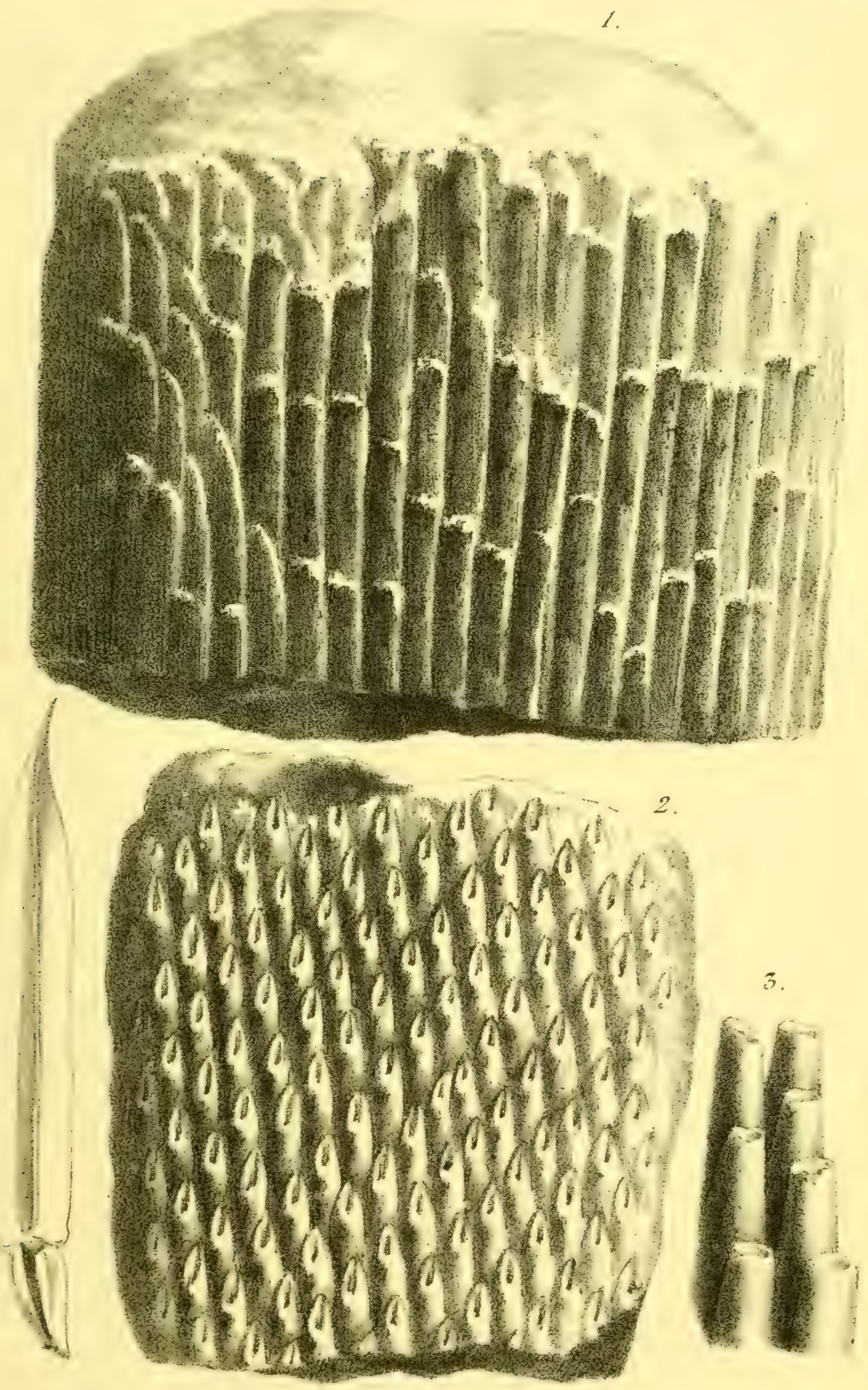






\title{
CARBONIFERO
}

\author{
LÁM. 38
}

Figs.

1 Dictropteris Brovginati, Gutb. [395]

2 Aumento de la misma.

3 Dictropteris neuropteroides, Gutb. [396]

4 Aumento de la misma.

5 Spinoptenis Miltoni, Schimper. [398]

6 Stigmaria ficoides, Brong. [424]

7 Fragmento de otro ejemplar de la misma especie. 

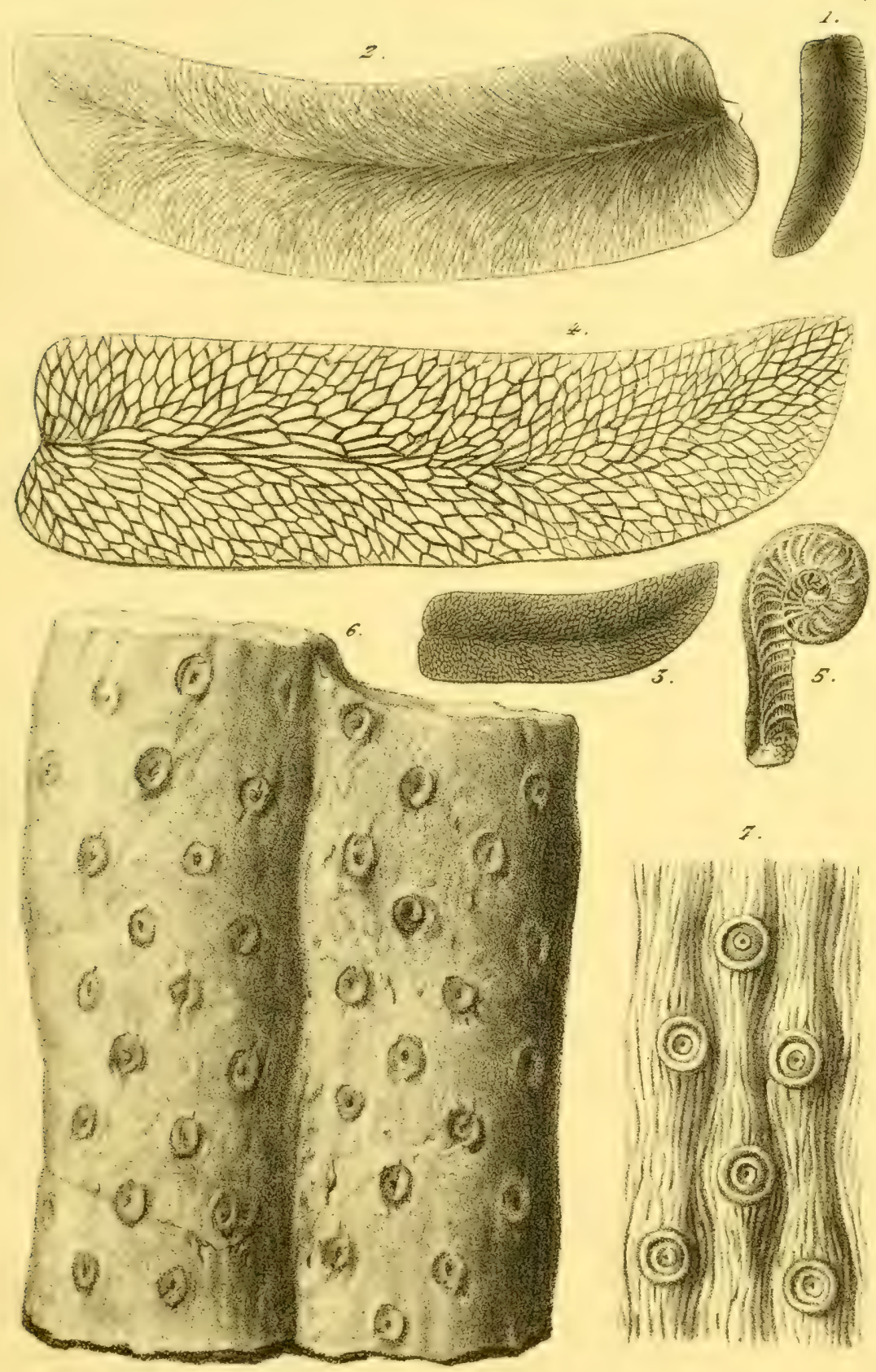



\section{ALVERTENCIA.}

Constará esta obra de cuatro cuadernos próximamente, de igual tamaño.

El cuaderno 1. ${ }^{\circ}$, que comprende el terreno de transicion, se rende á 20 pesetas en la portería de la Comision del Hapa Geológico. 
La Comision del Mapa Geológico de España publica anualmente de 200 á 300 páginas de Memorias y otras tantas de Boletiv; pero como las descripciones geológicas de las provincias difieren mucho en extension unas de otras, no siempre es posible que las Memorias tengan el número de páginas indicado: en todo caso se procura que nunca bajen de 600 las que se dan en ambas publicaciones, compensando las que faltan en la una con las de la otra.

Tanto el Boletin como las Mexorias van acompañados de los mapas geológicos cromolitografiados, láminas de perfiles, vistas y reprodıcciones de fósiles con arreglo á los recursos de la Comision, que invierte en mejorar sus publicaciones todo el producto de la suscricion.

El importe de esta es de 30 pesetas al año, pagadas de una vez ó en tres plazos al recibir las entregas.

Se admiten suscriciones en las Oficinas de la Comision del Mapa Geológico de España, calle de Isabel la Católica, núm. 25, cuarto principal; en las de los Jefes de los Distritos mineros, y en las principales librerías.

En los mismos puntos se encuentran de venta las obras siguientes:

Boletin de la Comision del MIapa Geolúgico. T. I á IV, á... . 15 pesetas. Descripcion geclógica de Cuenca, por D, de Cortázar.. . . . . 15

Descripcion geológico-minera de Cíceres, por D. J. Egozcue y

D. L. Mallada. . . . . . . . . . . . . . . .

Descripcion física, geológica y agrológica de Valladolid, por

D. de Cortázar. . . . . . . . . . . . . 15

Descripcion fisico-geológica de Santander, por D. A. Maestre. . 10

Descripcion geognóstica de Teruel, por D. J. Vilanova. . . . 15 "

Descripcion geológico-minera de Anurcia y Albacete, por D. F. de Botella. . . . . . . . . . . . . . . 50

MFapa geológico de la provincia de IFadrid, por D. C. de Prado. Mata geológico estratigrifico del $N$. de Palencia, por D. C. de Prado..

Obras agotadas:

Descripcion geológica de Astúrias, por D. G. Schulz.

Descripcion fisica y geológica de Madrid, por D. C. de Prado. Bosquejo físico-geológico de Zaragoza, por D. F. M. Donayre. Trabajos geodésicos y topográficos en Astúrias. 




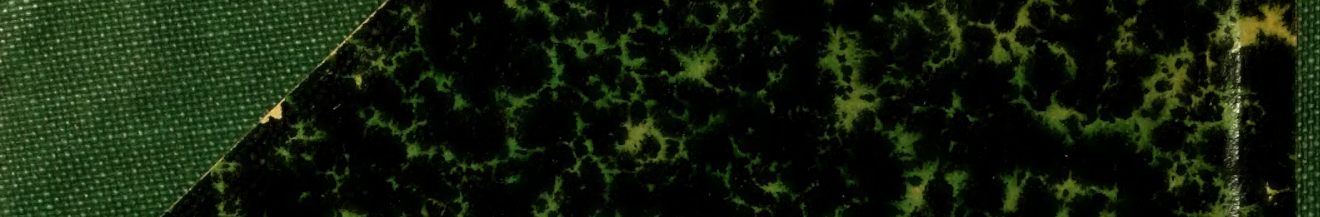

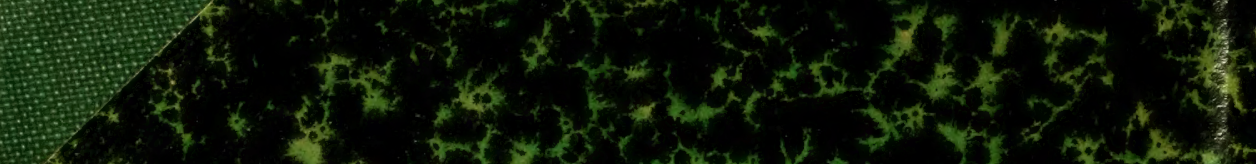

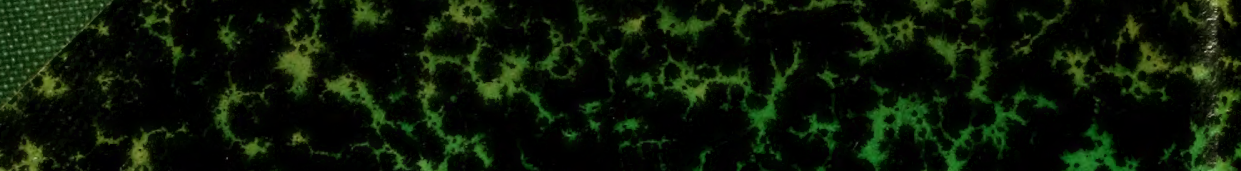

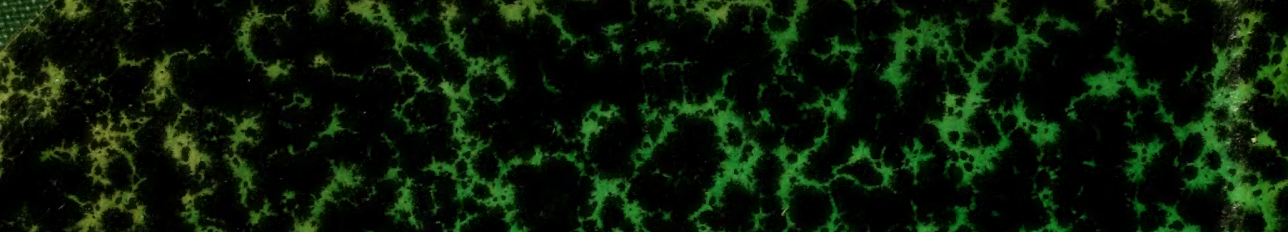

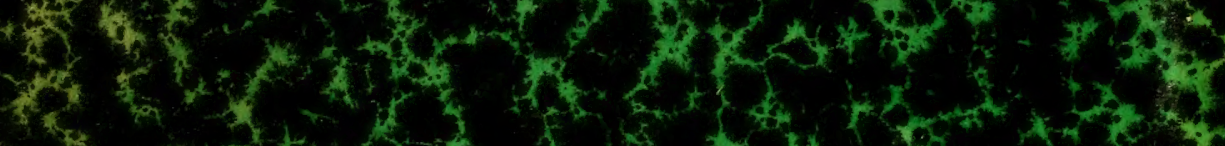

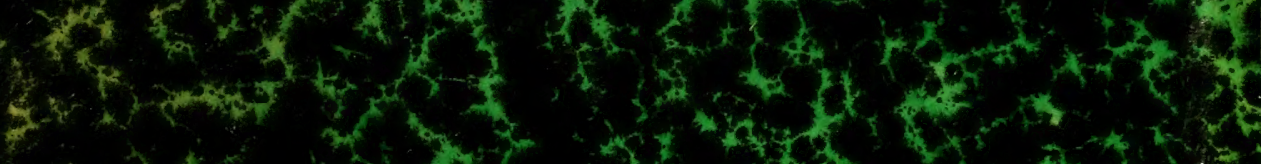

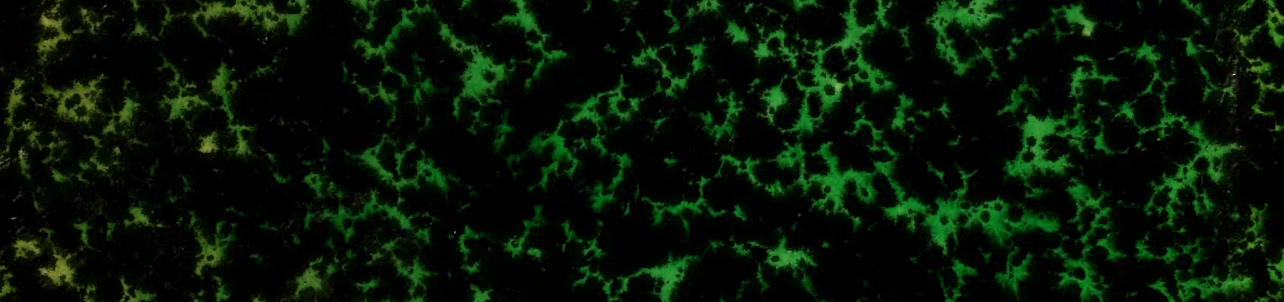

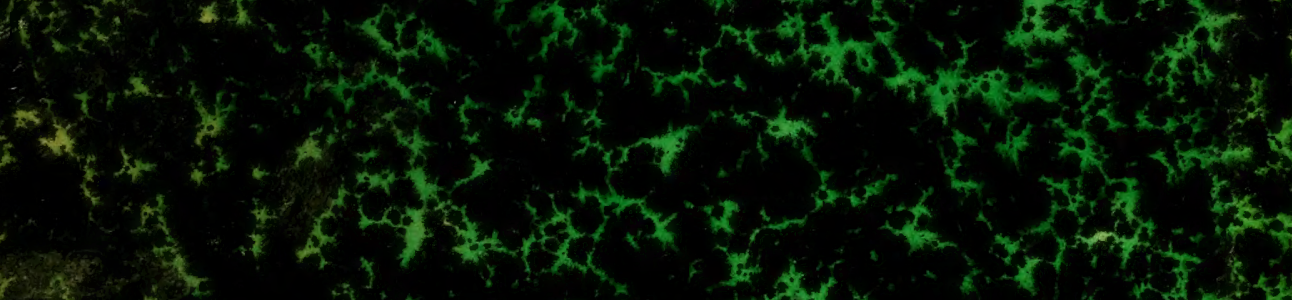

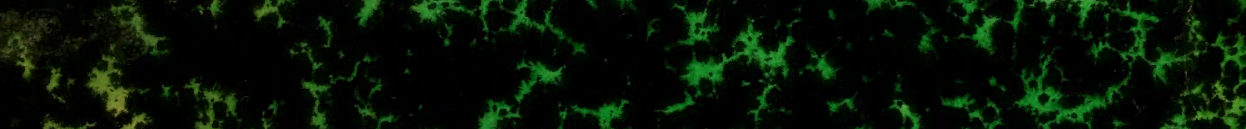

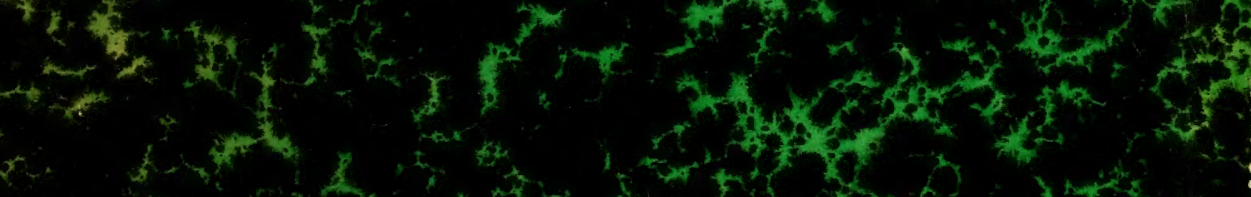

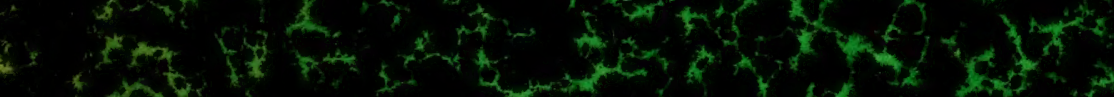

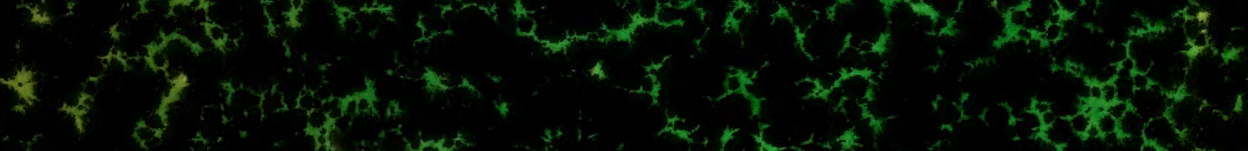
D.t. 1.

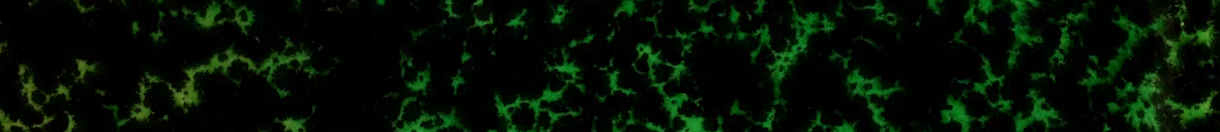

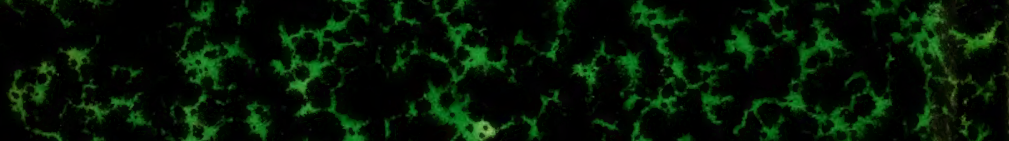

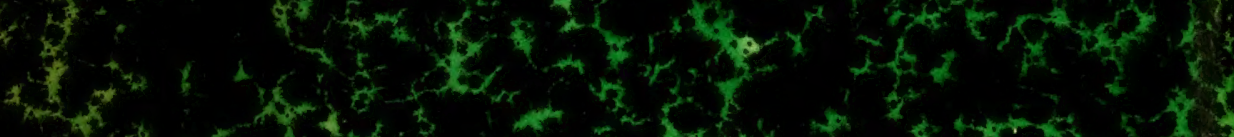

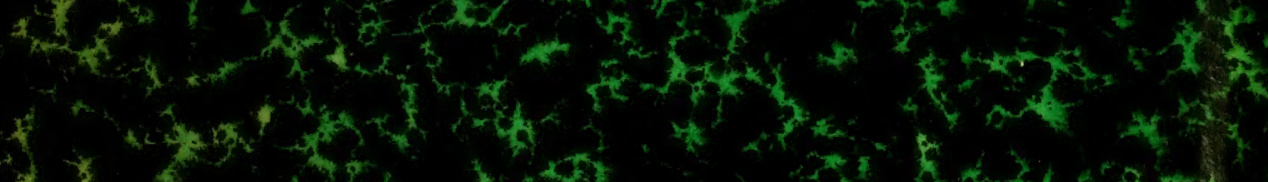

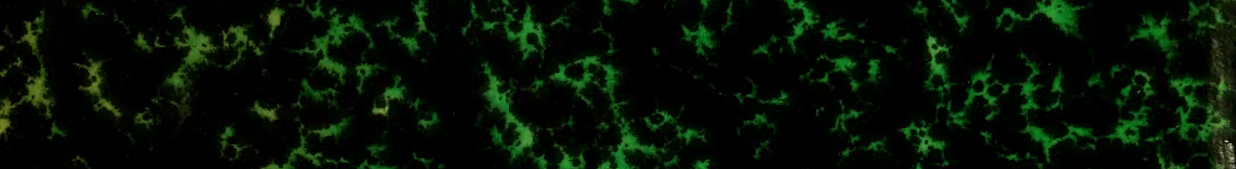

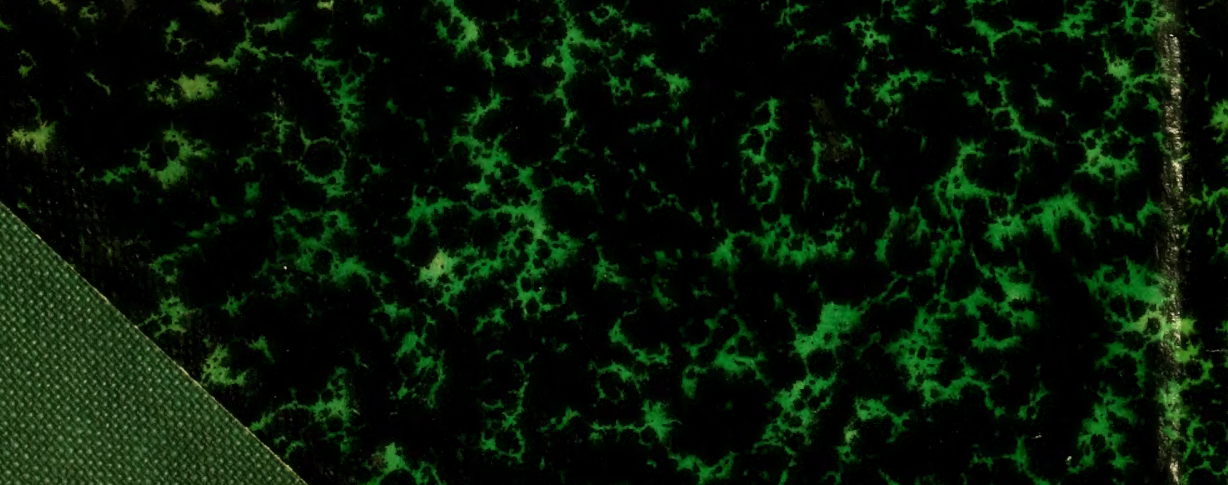

